\title{
SELEÇÃO DE LINHAGENS EXPERIMENTAIS DE SOJA PARA ADAPTABILIDADE E ESTABILIDADE FENOTÍPICA
}

\section{MAURISRAEL DE MOURA ROCHA}

Tese apresentada à Escola Superior de Agricultura

"Luiz de Queiroz", Universidade de São Paulo, para obtenção do título de Doutor em Agronomia, Área de Concentração: Genética e Melhoramento de Plantas.

\author{
P I R A C I C A B A \\ Estado de São Paulo - Brasil
}

Janeiro - 2002 


\title{
SELEÇÃO DE LINHAGENS EXPERIMENATIS DE SOJA PARA ADAPTABILIDDE E ESTABILIDADE FENOTÍPICA
}

\section{MAURISRAEL DE MOURA ROCHA}

Engenheiro Agrônomo

\author{
Orientador: Prof. Dr. NATAL ANTONIO VELLO
}

\begin{abstract}
Tese apresentada à Escola Superior de Agricultura
"Luiz de Queiroz", Universidade de São Paulo, para obtenção do título de Doutor em Agronomia, Área de Concentração: Genética e Melhoramento de Plantas.
\end{abstract}

\author{
P I R A C I C A B A \\ Estado de São Paulo - Brasil \\ Janeiro - 2002
}


Dados Internacionais de Catalogação na Publicação (CIP)

DIVISÃO DE BIBLIOTECA E DOCUMENTAÇÃO - ESALQ/USP

Rocha, Maurisrael de Moura

Seleção de linhagens experimenta is de soja para adaptabilidade e estabilida de fenotípica / Maurisra el de Moura Rocha. - - Piracicaba, 2002.

$173 \mathrm{p}$.

Tese (doutorado) - Escola Superior de Agricultura Luiz de Queiroz, 2002. Bibliografia.

1. Estabilidade fenotípica 2. Interação genótipo - Ambiente 3. Linhagens vegeta is 4 . Soja I. Título

CDD 633.34

"Permitida a cópia total ou parcial deste documento, desde que citada a fonte - $\mathrm{O}$ autor" 
Aos meus pais Manoel e Isabel

Ao meu irmão Everaldo

Aos meus avós Maria da Paz e Cristovão

Aos meus tios e primos

\section{DEDICO}

Aos meus avós Antônio e Adélia (in memorian) 


\section{AGRADECIMENTOS}

Ao Professor Dr. Natal Antonio Vello, pela orientação, amizade e ensinamentos fornecidos no decorrer do curso;

* Aos Drs. Regina Lúcia Ferreira Gomes e Francisco Rodrigues Freire Filho pelos incentivos fornecidos no início de minha vida acadêmica;

* À CAPES pela concessão de bolsas de estudos;

* Ao convênio EMBRAPA-CNPDIA e Gil Equipamentos Especiais pela cessão do aparelho de ressonância nuclear magnética para a realização das análises de teor de óleo;

* Ao CNPq e FAPESP pelo financiamento de várias etapas do programa de pesquisas que originaram o germoplasma utilizado nesta tese;

* Ao Prof. Dr. João Batista Duarte pelas sugestões e auxílio nas análises estatísticas;

* Aos amigos Ademir S. F. Araújo, Adriana C. Alves, Alessandra P. Fávero, Ângela C. A. Lopes, Andréa Mittelmann, Claudio Y. Tsutsumi, Estela Kaminagakura, Edson A. Bastos, Fábio Pandini (in memorian), Fernando T. Miranda, Francisco C. C. Lopes, Gilberto K. Yokomizo, Maria A. J. F. Ferreira, Maria C. A. Lopes, Maria I. Zucchi, Maria T. R. Lopes, René P. Araújo, Rodrigo Brogin, Sandra H. U. Trevisoli, Vanderlei S. Santos, Vanolli Fronza e Wellington L. Araújo, pela amizade e convívio durante o curso;

Aos funcionários do Setor de Genética Aplicada às Espécies Autógamas, Antônio R. Cogo, Claudinei A. Didoné e Marcos C. Nekatschalow, pelos auxílios fornecidos no preparo e instalação dos experimentos;

* Aos professores e funcionários do Departamento de Genética pela atenção e ajuda fornecida no decorrer do curso. 


\section{SUMÁRIO}

Página

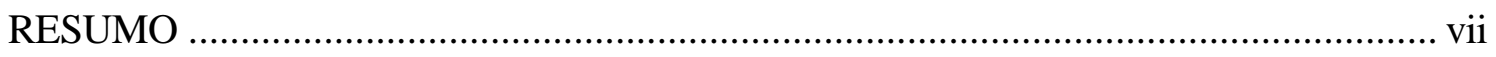

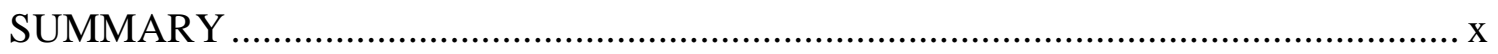

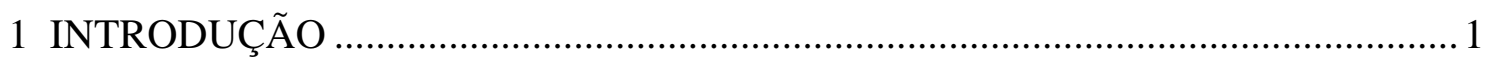

2 REVISÃO DE LITERATURA ..................................................................... 4

2.1 Interação de genótipos com ambientes ................................................................ 4

2.2 Interação de genótipos com ambientes em soja .............................................. 8

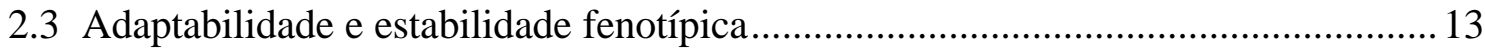

2.4 Metodologias para avaliar a adaptabilidade e estabilidade fenotípica .................... 15

2.5 Adaptabilidade e estabilidade fenotípica em soja ............................................. 25

2.6 Comparação entre metodologias que avaliam a adaptabilidade e estabilidade

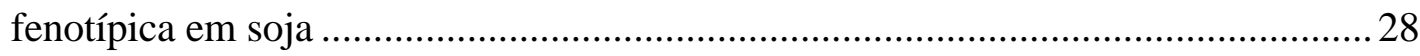

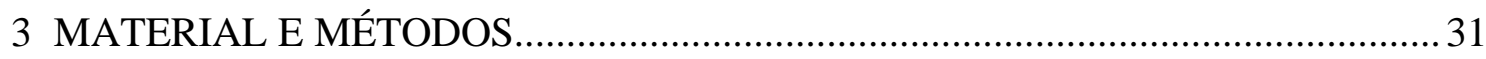

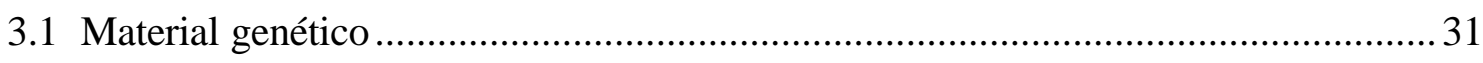

3.2 Ambientes de condução dos experimentos.................................................... 32

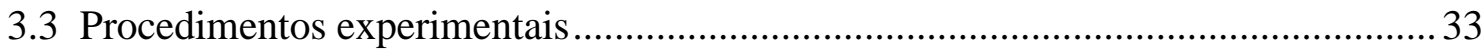

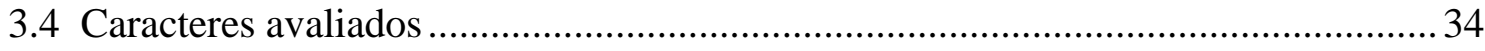

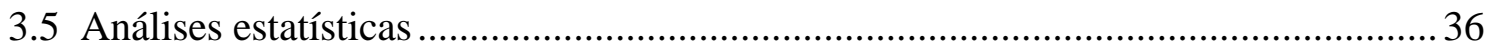

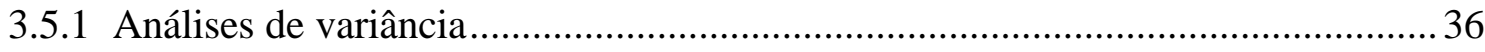

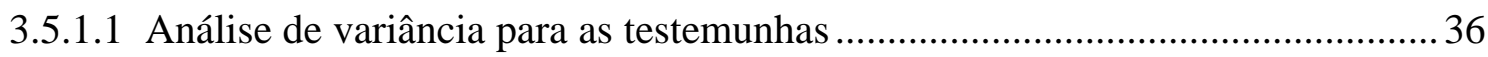

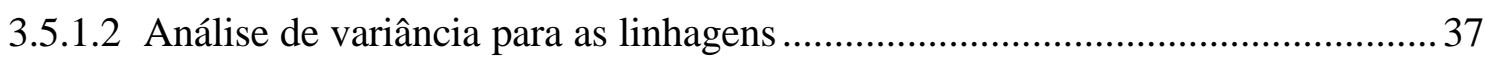

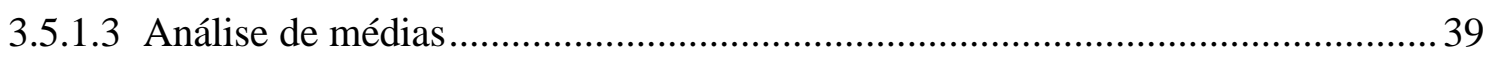

3.5.1.4 Análise de adaptabilidade e de estabilidade fenotípica .................................. 39

3.5.1.5 Análise de correlações ............................................................................. 48

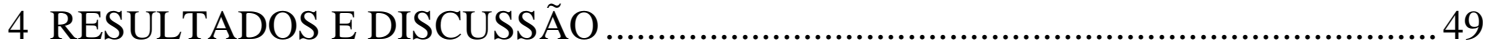

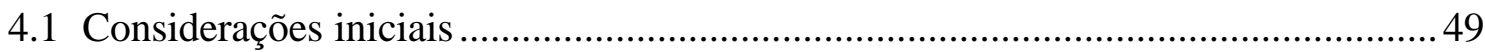

4.2 Análise de variância para as testemunhas ........................................................ 51 


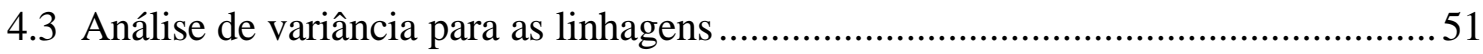

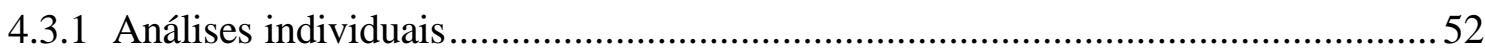

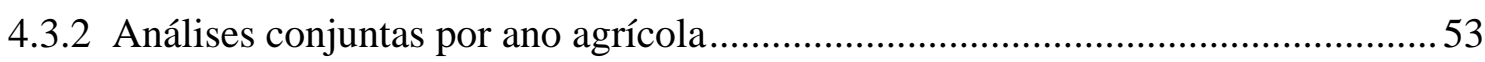

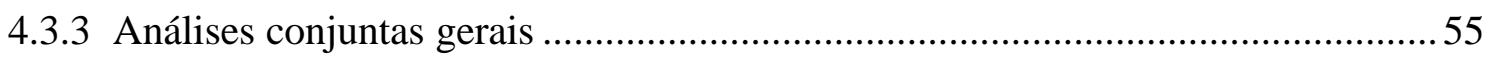

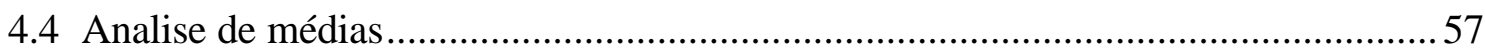

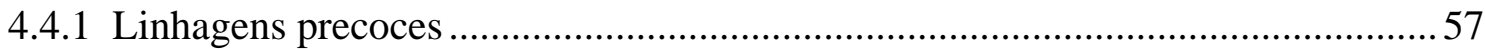

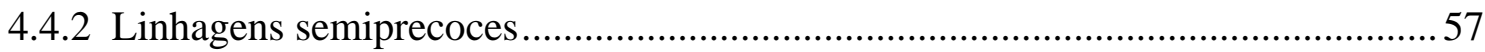

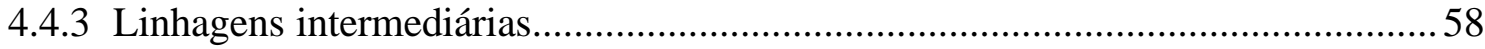

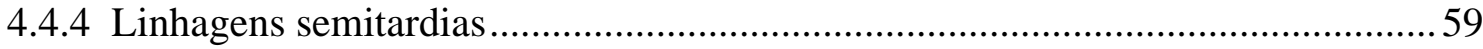

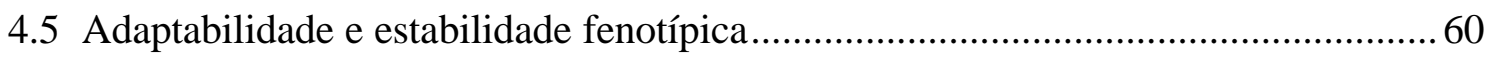

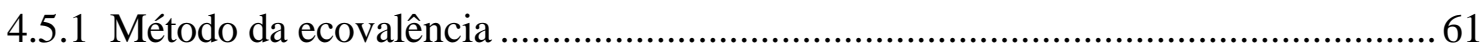

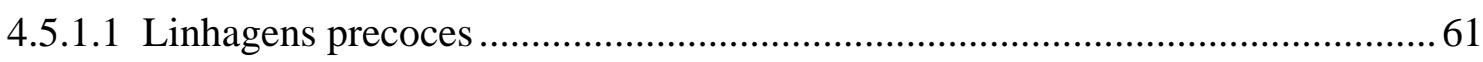

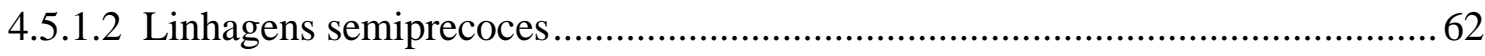

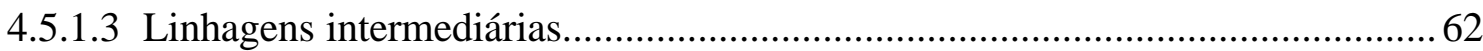

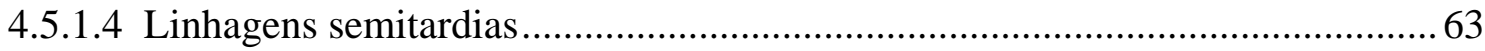

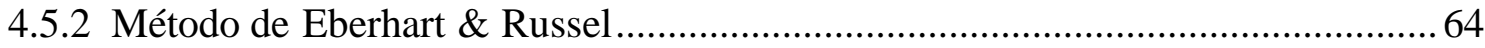

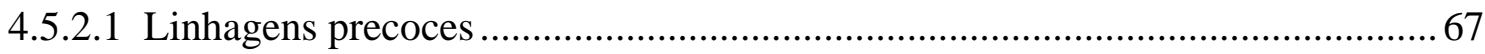

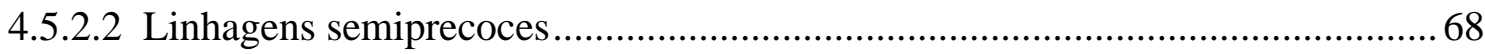

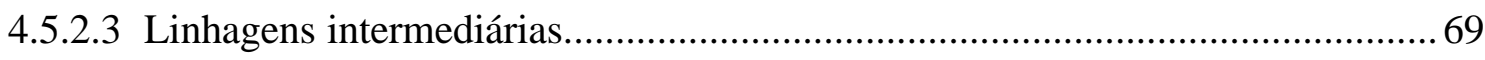

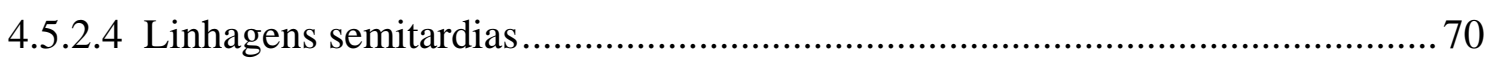

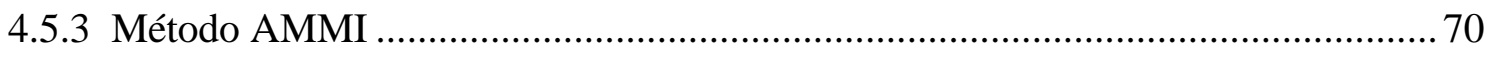

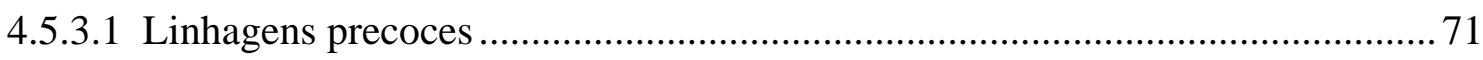

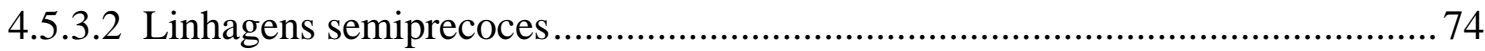

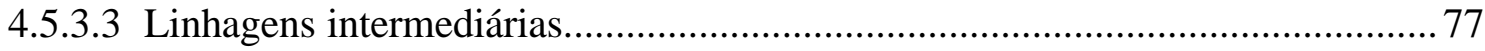

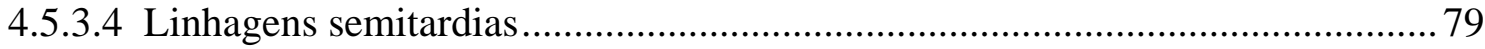

4.5.3.5 Análise AMMI para os quatro ciclos de maturação ...................................... 82

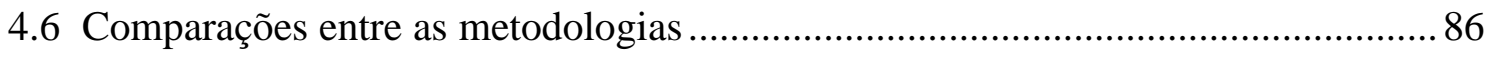

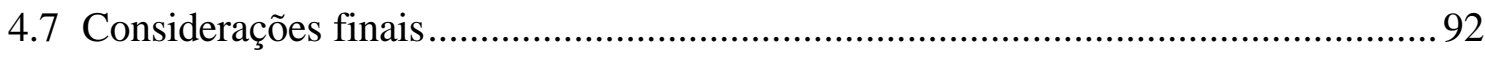

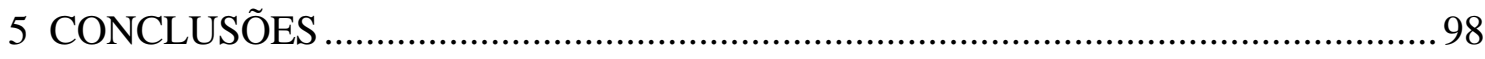

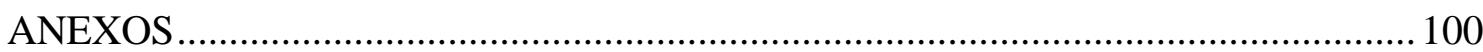

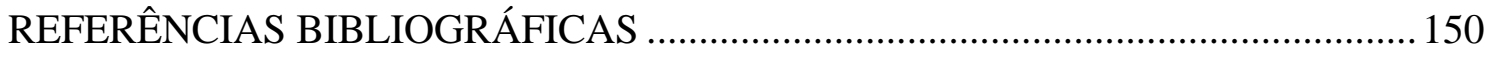

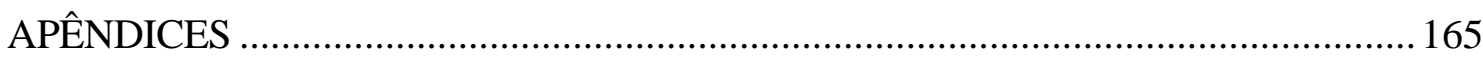




\title{
SELEÇÃO DE LINHAGENS EXPERIMENTAIS DE SOJA PARA ADAPTABILIDADE E ESTABILIDADE FENOTÍPICA
}

\author{
Autor: Maurisrael de Moura Rocha \\ Orientador: Prof. Dr. Natal Antonio Vello
}

\section{RESUMO}

O objetivo desta pesquisa foi avaliar a magnitude da interação genótipos $x$ ambientes ( $\mathrm{G} \times \mathrm{E}$ ) e a sua consequiência na adaptabilidade e na estabilidade fenotípica de 100 linhagens experimentais de soja pertencentes a quatro ciclos de maturação (28 precoces, 38 semiprecoces, 27 intermediárias e sete semitardias), através de três metodologias que quantificam a adaptabilidade e/ou estabilidade fenotípica (ecovalência, regressão linear de Eberhart \& Russel e AMMI ou "Additive Main effects and Multiplicative Interaction"), com ênfase nas produtividades de grãos e óleo. Os experimentos foram conduzidos em três localidades (Anhembi, Areão e ESALQ) do município de Piracicaba, Estado de São Paulo, Brasil (540 m de altitude, $22^{\circ} 42^{\prime}$ de latitude sul e $47^{\circ} 39^{\prime}$ de longitude oeste), em cultivo de verão (semeadura em novembro), nos anos agrícolas de 1996/97, 1997/98, 1998/99 e 1999/00. Em cada local foram avaliados quatro experimentos, correspondentes a quatro ciclos de maturação (CM). O delineamento utilizado foi o de blocos ao acaso com duas repetições estratificadas em conjuntos experimentais e quatro testemunhas comuns por conjunto. A parcela experimental foi representada por quatro fileiras de 5 metros de comprimento, espaçadas de 0,5 metro, sendo utilizadas para a tomada de dados apenas os 4 metros centrais das duas fileiras intermediárias da parcela. Os ambientes corresponderam à combinação de ano e local, totalizando 12 ambientes por CM. Os caracteres avaliados foram: número de dias para a maturidade (NDM), altura de planta na maturidade (APM), acamamento $(\mathrm{Ac})$, valor agronômico (VA), produtividade de grãos (PG), porcentagem de óleo nas sementes (\%OL) e produtividade de óleo (PO). Para a análise de adaptabilidade e estabilidade fenotípica utilizou-se apenas os caracteres PG, \%OL e PO. Os resultados 
mostraram que o efeito de ambientes foi mais importante do que o efeito da interação genótipos $(\mathrm{G}) \mathrm{x}$ ambientes (E), e este, mais importante do que o efeito de genótipos (linhagens). A magnitude da interação $\mathrm{G}$ x E, para a PG e PO, foi maior do que para a \%OL, indicando que este último caráter foi mais estável. As linhagens precoces (LP) e semiprecoces LSP) foram mais adaptadas, mas exibiram interações $\mathrm{G} \times \mathrm{E}$ mais complexas e foram mais instáveis do que as intermediárias (LI) e semitardias (LST). As LI associaram alta adaptabilidade com estabilidade média para PG e PO, ao contrário das LP, LSP e LST, nas quais a alta adaptabilidade esteve sempre associada com baixa estabilidade. Os anos agrícolas associados com os locais Anhembi e ESALQ foram mais favoráveis que os ambientes relacionados com o local Areão, mas estes apresentaram maior previsibilidade. A seleção de linhagens com média e previsibilidade altas foi mais difícil para a \%OL do que para PG e PO, em decorrência das correlações negativas entre as médias e os parâmetros de estabilidade; a utilização desses parâmetros em conjunto mostrou-se mais eficiente na seleção simultânea para adaptabilidade e estabilidade. As metodologias foram similares quanto ao ordenamento das linhagens; no entanto, diferiram quanto à precisão, explicação, informação sobre a interação $G \times \mathrm{E}$ e adaptabilidade das linhagens. $O$ método da ecovalência pode ser utilizado para selecionar para estabilidade e, quando associado com a média, também para adaptabilidade, sempre que o melhorista não esteja interessado em obter informações adicionais sobre recomendações de linhagens para ambientes específicos. A regressão linear de Eberhart \& Russel foi mais influenciada pelos efeitos ambientais do que pelos efeitos da interação $\mathrm{G}$ x E, não explicando satisfatoriamente o comportamento das linhagens. $\mathrm{O}$ padrão adjacente à interação $\mathrm{G}$ x $\mathrm{E}$ foi baixo e a presença de ruídos (efeitos aleatórios causados por fatores micro-ambientais) foi alta, evidenciando que apenas parte da variação total observada para a interação $G$ x E foi importante para explicar o comportamento das linhagens. A interpretação gráfica da análise AMMI pelos biplots AMMI1 e AMMI2, para modelos que incluem mais de dois eixos, foi eficiente em explicar a estabilidade das linhagens e ambientes, mas a adaptabilidade foi melhor compreendida com o auxílio das médias preditas para linhagens e ambientes pelo modelo selecionado. O método AMMI foi mais eficiente do que os métodos da ecovalência e da regressão linear de Eberhart \& Russel, pois permitiu analisar com mais detalhes os efeitos da interação $\mathrm{G}$ x E, ganhando precisão e melhorando o processo de seleção. As linhagens que reuniram maior adaptabilidade com estabilidade para PG e PO dentro de cada CM foram: USP 94-1086 (precoce), USP 93-2316 (semiprecoce), USP 93-5243 (intermediária) e USP 93-5684 (semitardia). 


\section{SELECTION OF SOYBEAN EXPERIMENTAL LINES FOR PHENOTYPIC ADAPTABILITY AND STABILITY}

Author: Maurisrael de Moura Rocha

Adviser: Prof. Dr. Natal Antonio Vello

\section{SUMMARY}

The objective of this research was to evaluate the magnitude of the genotypeenvironment interaction ( $\mathrm{G} \times \mathrm{E}$ ) and its consequence on the phenotypic adaptability and stability of one hundred soybean experimental lines belonging to four maturity cycles (28 early, 38 semi-early, 27 intermediate, and seven semi-late), through three methodologies that quantify the phenotypic adaptability and/or stability (ecovalence, linear regression of Eberhart \& Russel and AMMI or "Additive Main effects and Multiplicative Interaction"), with emphasis in the seed and oil yield. The experiments were carried out at three localities (Anhembi, Areão and ESALQ) of the Piracicaba county, State of São Paulo, Brazil (540 m of altitude, $22^{\circ} 42^{\prime}$ South latitude, and $47^{\circ} 38^{\prime}$ West longitude), during the summer crop season (sowing in november) in the agricultural years of 1996/97, 1997/98, 1998/99, and 1999/00. For each locality and maturity cycle, a randomized complete block experiment was designed, with two replications stratified in experimental sets and four common checks in each set. The experimental plot corresponded to four rows $5.0 \mathrm{~m} \mathrm{x} 0.5 \mathrm{~m}$, where the four central meters of the two intermediate rows were evaluated. Each environment corresponded to a combination of locality and year, totalizing 12 environments by maturity cycle. The traits number of days to maturity (NDM), plant height at maturity (APM), lodging (Ac), agronomic value (VA), seed yield (PG), oil percentage in the seeds (\%OL), and oil yield (PO) were evaluated. For the phenotypic adaptability and stability analysis it was only 
used the characters PG, \%OL, and PO. The results showed that the effect of environment was more important than the effect of $\mathrm{G} \times \mathrm{E}$ interaction, and this one more important than the genotype effect (lines). The magnitude of the $\mathrm{G} \times \mathrm{E}$ interaction for PG and PO showed larger than for \%OL, indicating that this was more stable. The early and semiearly lines were more adapted, but exhibited G x E interactions more complex and were more ustable than the intermediate and semi-late lines. The intermediate lines associated high adaptability with medium stability for PG and PO, unlike the early, semi-early, and semil-ate lines, for which the high adaptability was always associated with low stability. The agricultural year associated with the Anhembi and ESALQ localities were more favorable than the environments related with Areão locality, but those showed larger predictability. The selection of lines with high means and predictability went more difficult for \%OL than for $\mathrm{PG}$ and $\mathrm{PO}$, due to the negative correlations between the means and the stability parameters; the combined use of those parameters was shown more efficient in the selection for adaptability and stability. The methodologies were similar with relationship to the ranking of the lines; however, they differed for the precision, explanation, information on the $\mathrm{G} \times \mathrm{E}$ interaction and on adaptability of the lines. The ecovalence method can be used to select for stability and, when associated with the mean, also for adaptability, whenever the breeder is not interested in obtaining additional information on recommendation lines for specific environments. The linear regression of Eberhart \& Russel was more influenced by the environmental effects than the effect of $\mathrm{G} \times \mathrm{E}$ interaction, and it did not explain satisfactorily the performance of the lines. The pattern adjacent to $\mathrm{G} x \mathrm{E}$ interaction was low and the high presence of noises (random variation caused by microenvironments factors), evidencing that only part of the variation observed for the $G \times E$ interaction was important to explain the line performance. The graphic interpretation of the AMMI analysis by biplots AMMI1 and AMMI2, for model that includes more than two axes, was efficient in explaining the stability of the lines and environments, but the adaptability was better understood with the aid of means predicted by the selected model for lines and environments. The AMMI method was more efficient than the ecovalence and linear regression of Eberhart \& Russel methods, because allowed to analyze with more details the effects of $\mathrm{G} \times \mathrm{E}$ interaction, gaining precision and improving the selection process. The lines that gathered larger adaptability with stability for PG and PO, inside of each maturity cycle, were: USP 94-1086 (early), USP 93-2316 (semi-early), USP 93-5243 (intermediate), and USP 93-5684 (semi-late). 


\section{INTRODUÇÃO}

A soja constitui uma espécie de grande interesse socioeconômico, em função dos teores elevados de proteína (40\%) e óleo (20\%), da produtividade de grãos e da possibilidade de adaptação a ambientes diversos. É uma cultura anual de autopolinização, pertencente à família Fabaceae, gênero Glycine, subgênero Soja e espécie Glycine $\max$ (L.) Merrill. Evidências históricas e geográficas indicam que foi domesticada no século XI d.C, no Nordeste da China, e que seu provável lugar de origem seja o Vale do Rio Amarelo (Xu et al., 1989). Apresenta $2 \mathrm{n}=40$ cromossomos, representando um tetraplóide diploidizado (Van Raamsdonk, 1995), ou seja, um poliplóide que se comporta citologicamente como um diplóide (Hymowitz et al., 1997).

Domesticada no Nordeste da China (região da Manchúria), portanto, em latitudes compreendidas entre 35 e $45^{\circ}$, a soja foi disseminada posteriormente para a Europa, América do Norte e América do Sul. No Brasil, foi introduzida na Bahia em 1882 e depois, na região Sul do país, onde apresentou melhor adaptação, face às condições bioclimáticas mais semelhantes àquelas das regiões tradicionais de cultivo (Vernetti, 1983). Na região Sul, os programas de melhoramento de soja basearam-se, inicialmente, em introduções de genótipos desenvolvidos no sul dos EUA e, posteriormente, no desenvolvimento de cultivares mais bem adaptados, a partir de cruzamentos manuais. Para a expansão do cultivo em regiões de baixas latitudes $\left(<15^{\circ}\right)$, programas de melhoramento buscaram o desenvolvimento de genótipos com característica de período juvenil longo (PJL) ou florescimento tardio em fotoperíodo de dias curtos, por causa das limitações no porte e na produtividade (Spehar, 1994). Para o desenvolvimento de cultivares para baixas latitudes, a característica PJL não é obrigatória, sendo, entretanto, 
conveniente. $\mathrm{O}$ fato de o controle genético ser simples permite fácil seleção em condições de dias curtos (Kiihl, 2001).

O maior produtor mundial de soja é os Estados Unidos, com 78.914.000 toneladas métricas, seguido do Brasil (32.800.000 toneladas métricas) e Argentina (21.500.000 toneladas métricas). O maior produtor brasileiro é o Mato Grosso com 8.254.129 toneladas, seguido pelos Estados do Paraná (7.613.412 toneladas), Rio Grande do Sul (5.207.841 toneladas) e Goiás (4.186.332 toneladas) (FNP CONSULTORIA \& COMÉRCIO, 2001). A migração do tradicional centro de produção da soja do Sul para o Centro-Oeste tornou-se realidade graças ao desenvolvimento de cultivares adaptados a baixas latitudes, fruto do melhoramento genético.

Atualmente, no Brasil, a soja é cultivada em considerável diversidade de ambientes, desde as altas latitudes (Sudeste e Sul) até baixas latitudes (Centro-Oeste, Nordeste e Norte). A seleção de genótipos com alta produtividade de grãos e elevados teores de proteína e óleo é o principal objetivo dos programas de melhoramento genético. Assim, por representarem caracteres cuja variação é contínua (caracteres quantitativos), suas expressões fenotípicas resultam não só dos efeitos genotípicos (G), mas também dos efeitos ambientais (E) e das interações genótipos x ambientes ( $\mathrm{G}$ x E) (Rocha, 1998).

A interação $\mathrm{G} \times \mathrm{E}$ é um componente da variação fenotípica resultante do comportamento diferencial apresentado pelos genótipos, quando submetidos a mais de um ambiente. Sua magnitude na expressão fenotípica do caráter pode reduzir a correlação entre fenótipo e genótipo, inflacionando a variância genética e, por sua vez, parâmetros dependentes desta, como herdabilidade e ganho genético com a seleção (Rocha \& Vello, 1999). Uma particularização da interação $G \times$ x evidenciada por genótipos e ambientes pode ser realizada através de estudos sobre a adaptabilidade e a estabilidade fenotípica. A adaptabilidade é a capacidade que um genótipo tem de aproveitar vantajosamente os efeitos ambientais, de maneira a assegurar alto nível de produtividade; já a estabilidade está relacionada com a manutenção da produtividade ou de sua previsibilidade com os ambientes diversos.

Estudos sobre a adaptabilidade e a estabilidade fenotípica são de suma importância, pois permitem particularizar os efeitos da interação $G$ x E ao nível de 
genótipos e ambientes, identificando a contribuição relativa de cada um para a interação total. Inúmeras técnicas estatístico-genéticas têm sido desenvolvidas com o intuito de melhor quantificar o padrão inerente à interação $G$ x E. Estudos comparativos entre diversas metodologias são conduzidos com o objetivo de selecionar métodos que sejam mais práticos e ao mesmo tempo eficazes para a seleção e recomendação de cultivares.

$\mathrm{O}$ uso de métodos baseados em regressão constitui-se na forma mais usual para estimar a adaptabilidade e a estabilidade de genótipos com os ambientes, sendo o método de Eberhart \& Russel (1966) bastante popular entre os melhoristas. Esse método avalia a adaptabilidade pela média e pelo coeficiente de regressão $\left(b_{i}\right)$ e a estabilidade pela variância dos desvios da regressão $\left(\mathrm{s}^{2} \mathrm{~d}_{\mathrm{i}}\right)$. O método da ecovalência (Wricke \& Weber, 1986), é baseado na variância da interação G x E e na estimativa da contribuição de cada genótipo para a interação geral; ambas as metodologias representam modelos univariados e aditivos. O modelo AMMI (Additive Main effects and Multiplicative Interaction) combina um método univariado (análise de variância) para os efeitos aditivos de genótipos e ambientes, com um método multivariado (análise de componentes principais) para o efeito multiplicativo da interação G x E (Gauch \& Zobel, 1988).

Esta pesquisa envolveu linhagens experimentais de soja desenvolvidas pelo Setor de Genética Aplicada às Espécies Autógamas do Departamento de Genética da Escola Superior de Agricultura "Luiz de Queiroz" da Universidade de São Paulo e teve por objetivos verificar a magnitude da interação genótipos $\mathrm{x}$ ambientes, avaliar a adaptabilidade e a estabilidade fenotípica, esta última avaliada por três métodos, quais sejam: ecovalência (Wricke \& Weber, 1986); Eberhart \& Russel (1966) e AMMI (Zobel et al., 1988). As linhagens foram subdivididas em ciclos de maturação (precoce, semiprecoce, intermediário e semitardio), sendo a análise realizada com ênfase nas produtividades de grão e de óleo. A aplicação das diversas metodologias objetivou conhecer as semelhanças e diferenças entre elas e, a partir dessas, obter informações úteis e de maior aplicabilidade para a seleção de linhagens experimentais visando-se futuras recomendações de cultivares e de parentais para novos ciclos de melhoramento. 


\section{REVISÃO DE LITERATURA}

\subsection{Interação de genótipos com ambientes}

A variação fenotípica resulta da ação conjunta do genótipo, do ambiente e da interação entre o genótipo e o ambiente (Allard, 1971). Esse último componente reflete as diferentes sensibilidades dos genótipos às variações ambientais (Falconer \& Mackay, 1996), resultando em mudanças no desempenho relativo dos genótipos (Fehr, 1987).

As interações de genótipos x ambientes ( $\mathrm{G}$ x E) podem surgir por duas razões: (a) por diferentes respostas de igual conjunto gênico em diferentes ambientes; e (b) pela expressão de diferentes conjuntos gênicos em diferentes ambientes (Cockerham, 1963). Quando um mesmo conjunto de genes se expressa em diferentes ambientes, as diferenças nas respostas podem ser explicadas pela heterogeneidade das variâncias genéticas e experimentais ou por ambas; e, quando diferentes conjuntos de genes se expressam em ambientes distintos, as diferenças nas respostas explicam-se por uma inconsistência das correlações genéticas entre os valores de um mesmo caráter em dois ambientes (Falconer, 1989).

O método mais comum para avaliação da interação $G$ x E é a análise de variância (ANAVA), através da análise conjunta de experimentos. A magnitude das interações $\mathrm{G}$ x E é determinada através do uso de um teste, normalmente o teste $F$. Estatisticamente, interações $\mathrm{G}$ x E são detectadas como um padrão de resposta diferencial e significante dos genótipos, entre ambientes. Biologicamente, isto ocorre quando as contribuições (ou nível de expressão) dos genes regulando o caráter diferem entre ambientes. Essa contribuição dos genes para a expressão de um caráter é considerada ser a base biológica das interações G x E (Basford \& Cooper, 1998). As 
causas da interação $\mathrm{G}$ x $\mathrm{E}$ também têm sido atribuídas a fatores fisiológicos e bioquímicos próprios de cada genótipo cultivado (Cruz \& Regazzi, 1994).

O ambiente é um termo geral que inclui uma série de condições sob as quais as plantas crescem, podendo envolver locais, regiões, épocas, anos, práticas culturais ou de manejo, ou a combinação de todos esses fatores (Romagosa \& Fox, 1993). A combinação de local e ano representando um ambiente é muito comum em estudos de estabilidade fenotípica (Zobel et al., 1988; Ariyo, 1998; Galvão et al., 1998; Miranda, 1999 e Unêda \& Vello ${ }^{1}$ ).

Allard \& Bradshaw (1964) classificaram as variáveis ambientais em dois grupos: previsíveis e imprevisíveis. As variáveis previsíveis seriam as características gerais de clima e solos que ocorrem de maneira sistemática (p. ex. comprimento do dia e grau de insolação) ou estão sob controle humano (p. ex. época de semeadura, espaçamento entre fileiras, densidade de semeadura e taxas de aplicação de nutrientes). Por outro lado, as variáveis imprevisíveis caracterizam-se por flutuar inconsistentemente e incluem precipitações, temperatura, umidade relativa e eventos climáticos como por exemplo geadas e granizo. Segundo Fehr (1987), as variáveis imprevisíveis são as que mais contribuem para as interações genótipos $\mathrm{x}$ anos e genótipos $\mathrm{x}$ locais $\mathrm{x}$ anos.

Os ambientes podem ser classificados em duas categorias: micro e macroambientes. Os micro-ambientes estão relacionados a fatores externos (erros estocásticos ou aleatórios) ou internos (acidentes) de um organismo, geralmente, não controláveis (Wu \& Malley, 1998). Os macro-ambientes podem ser controláveis (p. ex. níveis de fertilidade do solo) e não controláveis (p. ex. locais, anos agrícolas e estações ou épocas do ano), que apresentam como principais componentes a temperatura, pluviosidade, e a luminosidade (Kearsey \& Pooni, 1998).

Johnson et al. (1955) estudaram duas populações de soja (P1 e P2) e estimaram as variâncias genéticas $\left(\sigma_{\mathrm{g}}^{2}\right)$ e da interação $\mathrm{G}$ x E $\left(\sigma_{\mathrm{gxe}}^{2}\right)$ em várias combinações de locais e anos; verificaram que, quando as estimativas eram baseadas em apenas um local

\footnotetext{
${ }^{1}$ UNÊDA, S.H.; VELLO, N.A. Assesment of phenotypic stability using ecovalence in soybean progenies derived from multiple crosses. (Em elaboração)
} 
e um ano, a variância genética era maior do que nos demais casos (mais de um ano e local) e que $\sigma_{\text {gxe }}^{2}$ era sempre maior quando era baseada em apenas um ano. Também verificaram que no caso da $\mathrm{P} 1$, para a qual as estimativas da $\sigma_{\mathrm{g}}^{2}$ eram maiores, os ganhos foram menores, ao passo que para a $\mathrm{P} 2$, com estimativas de $\sigma_{\mathrm{g}}^{2}$ menores, os ganhos foram maiores. Eles concluíram que $\sigma_{\text {gxe }}^{2}$ indica a variabilidade no comportamento relativo dos genótipos em diferentes ambientes e sua magnitude, em comparação com a variância genética, pode determinar a necessidade de testes em mais de um local e ano, para melhorar a acurácia das médias nas quais a seleção será baseada. Posteriormente, Comstock \& Moll (1963) comprovaram que a interação G x E diminui a correlação entre valores genotípicos e fenotípicos e, conseqüentemente, a resposta à seleção.

Quando os testes de avaliação dos genótipos são conduzidos em um só ambiente, a variância genética pode ficar superestimada, ou seja, pode conter componentes da interação G x E. Sua magnitude na expressão fenotípica do caráter pode reduzir a correlação entre fenótipo e genótipo, inflacionando a variância genética e, por sua vez, parâmetros dependentes desta, como herdabilidade e ganho genético esperado com a seleção (Rocha \& Vello, 1999).

Burton (1997), enfatizando os meios para melhorar a eficiência dos métodos de melhoramento, incluiu entre eles, o desenvolvimento de métodos para manejar as interações $\mathrm{G}$ x E de forma que as herdabilidades para produtividade sejam aumentadas. Toledo et al. (2000) também comentam que a baixa herdabilidade do caráter e os consideráveis níveis de interação $\mathrm{G}$ x E exigem que a avaliação da produtividade seja criteriosamente realizada para haver progresso genético por seleção.

Vencovsky \& Barriga (1992) relatam que não basta apenas detectar a presença de interações, deve-se também considerar a sua natureza. Assim, a interação $G \times$ x pode ser simples (não causa mudanças na classificação dos genótipos entre ambientes) e complexa (quando altera a classificação dos genótipos entre ambientes). A interação simples indica a presença de genótipos adaptados a uma ampla faixa de ambientes; assim, a recomendação de cultivares pode ser feita de forma generalizada. A interação complexa indica a presença de materiais adaptados a ambientes particulares; isto traz uma complicação para o melhorista uma vez que a recomendação é restrita a ambientes 
específicos (Ramalho et al., 1993). A interação relacionada à parte simples é proporcionada pela diferença de variabilidade entre genótipos nos ambientes, enquanto que a interação complexa, pela falta de correlação nos desempenhos médios dos genótipos entre ambientes (Cruz \& Castoldi, 1991).

Metodologias têm sido propostas no sentido de atenuar os efeitos da interação G x E. Pode-se proceder ao zoneamento ecológico ou estratificação de ambientes (estratificação da região em sub-regiões onde a interação seja não significativa), identificação de genótipos com adaptação a ambientes específicos e a identificação de genótipos com ampla adaptação ou estáveis (Ramalho et al., 1993).

Horner \& Frey (1957) proporam uma metodologia para estratificar ambientes, e utilizaram como medida da dissimilaridade entre locais, o quadrado médio da interação G x E da análise conjunta de variância dos locais, dois a dois. De acordo com este método, faz-se uma análise de agrupamento, juntando-se por etapas, os locais mais similares, para formar sub-regiões mais homogêneas. Em regiões onde ocorre prevalência de fatores ambientais imprevisíveis, a estratificação não se mostra um método eficaz para obter regionalizações consistentes.

Abou-El-Fittouh et al. (1969) propuseram uma análise de agrupamento baseada na similaridade da interação G x E, utilizando Distância Euclidiana. Gauch \& Zobel (1997) utilizaram o modelo AMMI (Additive Main effects and Multiplicative Interaction) com o auxílio da análise gráfica em biplot para alocar locais em megaambientes. Estes, representam porções amplas, não necessariamente contíguas, de uma espécie de cultura, desenvolvida em uma região que apresenta ambientes bastantes homogêneos e que produzem genótipos similares quanto à produtividade (CENTRO INTERNACIONAL DE MEJORAMIENTO DEL MAIZ Y TRIGO, 1989). Romagosa \& Fox (1993) reportaram que a análise AMMI é mais apropriada do que a análise de componentes principais (ACP) para estudos sobre a interação $\mathrm{G}$ x E, no que diz respeito ao agrupamento de ambientes.

Atlin et al. (2000) propuseram um modelo para estratificação de grandes regiões, baseado na resposta correlacionada com a seleção, com base na eficácia para aumento de ganho genético; assim, a resposta correlacionada na sub-região com seleção 
indireta na região, relativa à resposta direta com a seleção dentro da sub-região, é expressa como uma função da herdabilidade na região e na sub-região, bem como da correlação genotípica entre médias da região e sub-região.

A interação $G \times$ x deve ser encarada, não como um problema ou um fator indesejável, cujos efeitos devem ser minimizados em um programa de melhoramento. Ao contrário, como um fenômeno biológico natural, cumpre conhecê-la bem, para melhor aproveitá-la no processo de seleção (Chaves, 2001). Assim, genótipos que interagem positivamente com ambientes podem fazer a diferença entre um bom e um ótimo cultivar (Duarte \& Vencovsky, 1999). Esse enfoque passa a ter maior importância no caso de espécies onde o investimento é muito alto em insumos e manejo para melhoria do ambiente, como é o caso da soja.

\subsection{Interação de genótipos com ambientes em soja}

O desenvolvimento normal da planta de soja depende de vários fatores; dentre eles destacam-se: intensidade da radiação solar (relacionada com a atividade fotossintética, ao alongamento da haste principal e das ramificações, à expansão foliar, à nodulação, etc.), duração da radiação solar (fotoperíodo), pluviosidade, temperatura, umidade (disponibilidade de água) e tratos culturais (manejo). Esses fatores abióticos podem influir diferentemente entre os locais e anos de cultivo, contribuindo para as interações G x E (Câmara, 1998).

Os fatores bióticos também têm contribuído em maior ou menor escala para as interações G x E. Dentre eles, as doenças e pragas destacam-se como os fatores bióticos que mais têm influído no comportamento diferencial dos genótipos de soja entre ambientes. Como exemplo, pode-se citar o cancro da haste da soja (CHS), causado pelo fungo Diaporthe phaseolorum f.sp. meridionalis Morgan-Jones, o nematóide de cisto da soja (NCS, Heterodera glycines Ichinohe) e a síndrome da morte súbita ou podridão vermelha das raízes (PVR) causadoa por Fusarium solani (Mart.) Sacc. f. sp. glycines Roy. Rocha (1998), em um estudo sobre interação genótipos x locais (G x L) em soja, cita a ocorrência do CHS sob infestação natural em dois locais, como uma das causas 
que contribuíram para a interação G x L. Njiti et al. (1998) também reportaram a existência de correlação significativa entre os efeitos de interações $\mathrm{G}$ x E e os danos causados pela PVR, diminuindo a produtividade de genótipos de soja.

No Brasil, devido ao grande aumento dos prejuízos causados por essas doenças, tornou-se urgente o melhoramento genético para a obtenção de novos cultivares resistentes e com alta produtividade de grãos. Atualmente, a avaliação dos genótipos quanto à reação ao CHS e ou NCS, é condição indispensável em programas de melhoramento genético de soja (Rocha, 1998). O uso de germoplasma resistente é um importante passo para manutenção de genótipos com produtividades altas e consistentes.

A interação $G$ x E em soja tem sido muito estudada pelos melhoristas, envolvendo vários tipos de fatores ambientais, tais como: efeitos envolvendo genótipos x locais (Soldini, 1993; Dashiell et al., 1994 e Rocha \& Vello, 1999), genótipos x locais x regiões (Pfeiffer et al., 1995), genótipos x anos (Billore \& Joshi, 1997; Gieco, 1997; Mauro et al., 2000 e Marega Filho et al., 2001), genótipos x locais x anos (Batitucci, 1990; Toledo et al., 1990; Alliprandini, 1992; Alliprandini et al., 1993; Alliprandini et al., 1994; Sneller et al., 1997; Cober et al., 1997; Unêda-Trevisoli, 1999 e Miranda, 1999), genótipos x épocas de semeadura (Raut et al., 1997 e Miranda et al., 1998), genótipos x locais x épocas de semeadura (Laínez-Mejía, 1996), genótipos x anos x épocas de semeadura (Akhter \& Sneller, 1996a, 1996b, Galvão et al., 1998 e Bhatia et al., 1999) e genótipos x locais x anos x épocas de semeadura (Oliveira, 1990 e Ivory et al., 1991).

Os estudos envolvendo interação genótipos x épocas de semeadura têm sido feitos mais com o objetivo de verificar a sensibilidade dos genótipos de soja ao comprimento do dia ou fotoperíodo. Farias Neto (1987), Nass (1989), Moreira (1992) e Laínez-Mejía (1996), estudando tais efeitos, identificaram genótipos com tolerância ao fotoperíodo para o caráter produtividade de grãos (PG), que podem ser cultivados no período outono-inverno, assim como em regiões de baixas latitudes, como as regiões Norte e Nordeste do Brasil. Bhati et al. (1999) constataram que semeaduras tardias levam a redução na produtividade de grãos devido ao efeito combinado de redução da 
biomassa total, vagens por planta, altura de planta, peso de cem sementes e dias para o florescimento e maturidade.

O efeito da interação genótipos $\mathrm{x}$ épocas de semeadura foi avaliado por LaínezMejía (1996). Este autor observou que o caráter produtividade de óleo (PO) foi mais influenciado pela produtividade de grãos (PG) do que pela porcentagem de óleo (\%OL) e que PG e PO apresentaram comportamentos semelhantes quanto à interação $\mathrm{G}$ x E, enquanto \%OL teve comportamento independente. Tomkins \& Shipe (1997), estudando o comportamento de genótipos com período juvenil longo, identificaram genótipos com superioridade de adaptação fenotípica a diferentes épocas de semeadura. Já Miranda et al. (1998) estudaram o caráter \%OL sob diferentes fotoperíodos em parentais, gerações $\mathrm{F}_{2}, \mathrm{~F}_{3}$ e $\mathrm{F}_{9}$ resultantes de diferentes cruzamentos; encontraram que a interação genótipos $\mathrm{x}$ épocas de semeadura foi importante e concluíram que o teor de óleo foi maior nas semeaduras nos meses de setembro-outubro, sendo menor em outubro-dezembro.

A análise da interação genótipos $\mathrm{x}$ locais $(\mathrm{G} \times \mathrm{L}$ ) objetiva, principalmente, pesquisar o comportamento dos genótipos frente aos fatores previsíveis, micro (dentro de locais) e macroambientais (entre locais), no espaço. Soldini (1993), estudando o efeito da interação $\mathrm{G} \times \mathrm{L}$, para diferentes ciclos de maturação (precoce, intermediário e tardio) em cultivo de verão, encontrou interação significativa em todos os ciclos de maturação para todos os caracteres estudados, exceto para a \%OL, que apresentou baixa ou nula interação. Identificou também que as linhagens tardias se comportaram como as mais produtivas e as intermediárias como as mais estáveis. Baixa variabilidade associada com baixa magnitude da interação G x L para \%OL tem sido um resultado comum em alguns trabalhos (Soldini, 1993 e Laínez-Mejía, 1996).

Rocha (1998) também obteve resultados semelhantes àqueles reportados por Soldini (1993) quanto à interação G x L para os caracteres PG, \%OL e PO, em um estudo sob cultivo de verão; no entanto, as linhagens com ciclos precoce e semiprecoce foram mais produtivas do que aquelas de ciclos intermediário e semitardio. Hamawaki (1998) obteve interação G x E não significativa para PG, \%OL e PO, em um estudo envolvendo progênies de soja resultantes de cruzamentos óctuplos. Tsutsumi (2000) obteve resultados semelhantes aos encontrados por Hamawaki (1998) no que diz 
respeito à interação $\mathrm{G}$ x E, estudando um grupo de genótipos se soja tipo alimento. Pandini et al. (2001), em um estudo realizado em duas localidades envolvendo híbridos $\mathrm{F}_{1}$ de soja, obtiveram estimativas de heterose para $\mathrm{PG}$ influenciadas pelo efeito da interação G x L, sendo necessário considerar as estimativas individuais para cada local específico. A interação G x L também influenciou as estimativas da capacidade de combinação entre parentais com resistência ao NCS (Lopes, 2001).

O efeito de anos é caracterizado como um fator imprevisível. A avaliação das interações genótipos $\mathrm{x}$ anos é de suma importância, pois fornece informações sobre a previsibilidade do comportamento dos genótipos frente aos fatores ambientais, no tempo. De fato, Vencovsky \& Torres (1988) enfatizam que, para o produtor rural, é mais importante que um cultivar seja estável ao longo dos anos.

Gieco (1997), estudando o efeito de anos em três populações de soja, concluiu que a seleção baseada na média de três anos foi mais eficiente que a seleção praticada em um determinado ano; também verificou que a aplicação de altas intensidades de seleção, em um determinado ano, pode representar a perda de muitos genótipos promissores. Triller \& Toledo (1996), estudando a predição de cruzamentos em geração $\mathrm{F}_{3}$, enfatizaram que na presença de interação $\mathrm{G}$ x E, o uso de dados de mais de um ano foi útil para aumentar a precisão das estimativas para o caráter produtividade de grãos. Marega Filho et al. (2001) observaram que a correlação entre peso de cem sementes com teor de óleo e teor de proteína foi bastante influenciada pela interação $\mathrm{G} \times \mathrm{E}$, particularmente pelo efeito de anos, em um estudo com genótipos de soja tipo alimento.

Ivory et al. (1991) reportaram que o agrupamento de genótipos e ambientes com base no comportamento médio dos genótipos é não informativo, porque é ignorado o efeito da interação G x E. Assim, utilizaram a distância Euclidiana como medida de dissimilaridade e a análise de coordenadas principais para agrupar genótipos de soja e ambientes com base na sua interação $\mathrm{G}$ x $\mathrm{E}$, de forma que, dentro de grupos de ambientes, os genótipos apresentassem comportamentos similares.

A contribuição de algumas variáveis ambientais (índice ambiental, pluviosidade, temperaturas máxima e mínima, e umidade relativa) para a interação $\mathrm{G} x$ E, englobando diferentes grupos de maturação em soja, foi pesquisada por Kang et al. 
(1989). Os autores comentaram que cultivares pertencentes a grupos de maturação distintos possuem diferentes estádios de desenvolvimento fisiológico, interagindo com o ambiente em um tempo particular. Portanto, espera-se que os componentes da interação G x E sejam diferentes para cada grupo de maturação. Eles concluíram que os grupos de maturação foram mais afetados por fertilidade diferencial de solos e/ou práticas culturais (fatores previsíveis) do que por fatores ambientais do tempo (fatores imprevisíveis). Rocha \& Vello (1999), testando linhagens de soja em três locais, também comentaram que fatores relacionados a características diferenciais de solos foram aqueles que mais contribuíram para a interação G x L.

No Brasil, alguns estudos da interação G x E envolvendo diferentes ciclos de maturação em soja, podem ser encontrados na literatura, a saber: Toledo et al. (1990), Alliprandini et al. (1993, 1994), Soldini (1993), Laínez-Mejía (1996), Bonato et al. (1998), Rocha \& Vello (1999) e Unêda \& Vello ${ }^{2}$.

Alliprandini et al. (1993) avaliaram genótipos de soja, divididos em três ciclos de maturação (precoce, semiprecoce e médio). Segundo os autores, a interação significativa para ciclos de maturação x locais $\mathrm{x}$ anos indica que, para uma determinada combinação entre ano e local, existe um ciclo de maturação com maior adaptação. Alliprandini et al. (1994), em outro estudo, reportaram a existência de efeitos não significativos para as interações $G \times \mathrm{L}$ e genótipos $\mathrm{x}$ anos e mencionaram que na ausência de interação genótipos x anos, havendo a necessidade de abreviar o período de avaliação para apenas um ano, os testes devem ser conduzidos em diversos locais.

Um grupo de linhagens de soja tipo alimento (natto ou fermentado) foram avaliadas por Cober et al. (1997). A interação G x L foi significativa, mas não apresentou padrão aparente; a interação G x E (inclui todas as interações entre genótipos com locais e anos) também foi significativa; no entanto, sua magnitude foi menor que os efeitos principais de genótipos.

\footnotetext{
${ }^{2}$ UNÊDA, S.H.; VELLO, N.A. Assesment of phenotypic stability using ecovalence in soybean progenies derived from multiple crosses. (Em elaboração)
} 
Bonato et al. (1998) avaliaram um grupo de cultivares separados por ciclo de maturação (precoce, médio e semitardio/tardio) conduzidos em três épocas de semeadura, em vários locais e anos, no Rio Grande do Sul. O desempenho dos cultivares dos três ciclos em uma determinada época foi semelhante. Os cultivares de ciclo precoce obtiveram mesmo comportamento em semeaduras realizadas em outubro e novembro. Esses autores argumentam que os cultivares de ciclo precoce podem ser semeados a partir de meados de outubro e que os três ciclos expressam potencial produtivo semelhante nas semeaduras realizadas em dezembro.

A porcentagem de óleo (\%OL) foi avaliada por Bonato et al. (2000), em cultivares de soja lançadas antes e depois de 1990. Estes concluíram que as estimativas variaram pouco com os anos, dentro de locais, e que os cultivares lançados entre 1991 e 1996 foram mais produtivos em óleo do que os lançados antes deste período. A despeito da baixa variação aparente observada para este caráter, foi possível obter ganhos com a seleção.

\subsection{Adaptabilidade e estabilidade fenotípica}

Estudos a respeito da interação $\mathrm{G}$ x E, apesar de serem de grande importância para o melhoramento, não proporcionam informações pormenorizadas sobre o comportamento de cada genótipo frente às variações ambientais. Para tal objetivo, realizam-se análises de adaptabilidade e estabilidade, pelas quais torna-se possível a identificação de cultivares com comportamento previsível e que sejam responsivos às variações ambientais, em condições específicas ou amplas (Cruz \& Regazzi, 1994).

Segundo Vencovsky \& Barriga (1992), adaptação e estabilidade, embora sejam fenômenos relacionados, não devem ser considerados como um só. Mariotti et al. (1976), designam adaptabilidade como a capacidade potencial dos genótipos de responderam vantajosamente ao estímulo ambiental. A estabilidade, por outro lado, seria a capacidade de um genótipo exibir um desempenho o mais constante possível, em função de variações na qualidade ambiental. Cruz \& Regazzi (1994) conceituam adaptabilidade da mesma forma e comentam que estabilidade refere-se à capacidade de 
os genótipos mostrarem um comportamento altamente previsível em função do estímulo ambiental.

Becker (1981) distinguiu dois tipos de estabilidade: estabilidade biológica ou homeostática e estabilidade agronômica. A estabilidade biológica seria aquela em que o genótipo mantém uma produtividade constante entre ambientes; já na estabilidade no sentido agronômico, o genótipo é considerado estável se este produz bem em relação ao potencial produtivo dos ambientes testes. Segundo Fox et al. (1997), implicitamente, a idéia de estabilidade agronômica está relacionada com ordenamento. O genótipo estável é aquele que é consistentemente bem ordenado.

Vencovsky \& Torres (1988) apontam dois tipos de estabilidade: a estabilidade espacial e a estabilidade temporal, enfatizando que a estabilidade espacial é sinônima de adaptabilidade. Fox et al. (1997) seguem essa mesma linha de conceito e usam os termos adaptabilidade e estabilidade para se referir às dimensões espacial e temporal, respectivamente.

Lin et al. (1986) apresentaram uma proposta de conceituação para a estabilidade fenotípica em função dos diversos parâmetros de avaliação, em três tipos básicos: Tipo 1: o genótipo é considerado estável se a variância entre ambientes é pequena; Tipo 2: o genótipo é considerado estável se sua resposta aos ambientes é paralela à resposta média de todos os genótipos do experimento; Tipo 3: o genótipo é considerado estável se a relação entre o quadrado médio do resíduo da regressão pelo índice ambiental é pequena.

As estatísticas relacionadas ao conceito Tipo 1 estão associadas ao conceito de estabilidade no sentido biológico ou estático e são altamente dependentes do grupo de ambientes escolhidos, sendo análoga ao conceito de homeostase; têm pouca utilidade para conjuntos de muitos ambientes, podendo ser úteis em áreas geográficas mais restritas; este tipo de estabilidade está associada a respostas relativamente pobres em ambientes de baixas produtividades e baixas produtividades em ambientes altamente produtivos. O Tipo 2 está ligado ao conceito de estabilidade agronômica e depende grandemente do grupo de genótipos avaliados. As estatísticas do Tipo 3 mostram o 
quanto os dados se ajustam bem à regressão, mas não estabelecem relação direta com a estabilidade dos genótipos (Lin et al., 1986).

Dentro dos conceitos propostos por Lin et al. (1986), o coeficiente de regressão proposto por Finlay \& Wilkinson (1963) pode corresponder ao conceito do tipo 1, se o genótipo estável for definido como o de $b_{i}=0$, caso contrário, com $b_{i}=1$, corresponderá ao conceito tipo 2. Os métodos de Plaisted \& Peterson (1959), ecovalência (Wricke \& Weber, 1986) e Shukla (1972), estimam parâmetros que medem a estabilidade do tipo 2. A utilização dos desvios da regressão (Eberhart \& Russel, 1966; Perkins \& Jinks, 1968 e Tai, 1971), enquadra-se no conceito tipo 3.

Alliprandini (1992) definiu estabilidade com base no coeficiente de determinação $\left(\mathrm{R}^{2}\right)$ e dos desvios da regressão $\left(\mathrm{s}^{2} \mathrm{~d}_{\mathrm{i}}\right)$, e adaptabilidade como conseqüência do desempenho do genótipo em relação à média dos genótipos avaliados e da responsividade medida pelo coeficiente de regressão $\left(b_{i}\right)$.

\subsection{Metodologias para avaliar a adaptabilidade e estabilidade fenotípica}

Diversos métodos têm sido propostos para investigar a adaptabilidade e estabilidade fenotípica. A diferença entre eles origina-se nos próprios conceitos e procedimentos biométricos para medir a interação G x E. Destacam-se os procedimentos baseados na variância da interação G x E (Plaisted \& Peterson, 1959; Wricke \& Weber, 1986; Shukla, 1972 e Magari \& Kang, 1997); regressão linear simples (Finlay \& Wilkinson, 1963; Eberhart \& Russell, 1966 e Perkins \& Jinks, 1968) e múltipla (Verma et al., 1978; Silva \& Barreto, 1986; Cruz et al., 1989 e Storck \& Vencovsky, 1994); regressão quadrática (Brasil \& Chaves, 1994); modelos não lineares (Chaves et al., 1989; Toler \& Burrows, 1998; Silva, 1998 e Rosse \& Vencovsky, 2000) e não paramétricos, como a ordem de classificação genotípica (Hühn, 1996); métodos multivariados, como a ACP (Crossa, 1990), análise de agrupamento (Hanson, 1994), análise fatorial de correspondências (Hill, 1974) e análise de coordenadas principais (Westcott, 1987); e métodos que integram a análise comum de variância (método 
univariado) com a análise de componentes principais (método multivariado), como é o caso da análise AMMI, sugerido por Gauch \& Zobel (1996).

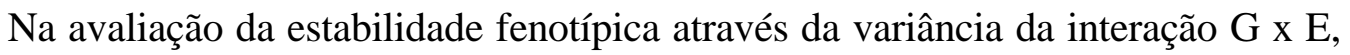
é realizado o desdobramento da interação $\mathrm{G}$ x E total em componentes atribuídos a cada genótipo, como no método tradicional (Oliveira, 1976); neste método, a soma de quadrados da interação $\mathrm{G} \times \mathrm{E}$ mais a soma de quadrados de ambientes é particionada em componentes da variação ambiental dentro de cada genótipo; o genótipo mais estável será aquele com menor quadrado médio para o desdobramento. Plaisted \& Peterson (1959) adotaram como parâmetro de estabilidade a variância da interação G x E estimada para cada par de genótipos. Calculando-se a média das estimativas obtidas com um genótipo em comum, tem-se a sua contribuição para a interação $\mathrm{G} \times \mathrm{E}$; genótipos com baixa contribuição são considerados estáveis. O método da ecovalência (Wricke \& Weber, 1986), segue o mesmo princípio, sendo o parâmetro denominado de ecovalência, que mede a contribuição de cada genótipo para a soma de quadrados da interação total $\mathrm{G}$ x E; assim, o genótipo mais estável é aquele que apresenta ecovalência de mais baixa magnitude em relação aos demais.

Nos últimos 30 anos, o método mais amplamente usado tem sido a análise de regressão linear (Becker \& Léon, 1988). Poucos melhoristas analisam rotineiramente os dados para estabilidade fenotípica, e entre os que o fazem, a grande maioria usa análise de regressão (Romagosa \& Fox, 1993). Yates \& Cochran (1938) foram os primeiros autores a usarem a regressão linear em estudos de estabilidade fenotípica, mas foi a metodologia de Eberhart \& Russel (1966) que popularizou seu uso.

O método proposto por Eberhart \& Russel (1966) baseia-se numa análise de regressão linear simples onde o índice ambiental (efeito do ambiente) é a variável independente, e a produtividade média de cada genótipo em cada ambiente representa a variável dependente. Os parâmetros coeficiente de regressão $\left(b_{i}\right)$ e a produtividade média estimam a adaptabilidade do genótipo; enquanto a variância dos desvios da regressão $\left(s^{2} d_{i}\right)$ mede a sua estabilidade. Esses autores definiram como genótipo ideal aquele com produtividade média alta, $b_{1}$ igual à unidade e $5^{2} d_{i} 0$ menor possível. Uma medida adicional acrescentada por Pinthus (1973) foi o coeficiente de determinação 
$\left(\mathrm{R}^{2}\right)$, que pode substituir $\mathrm{s}^{2} \mathrm{~d}_{\mathrm{i}}$ ou auxiliá-lo, fornecendo uma medida da variação observada explicada pela regressão. Perkins \& Jinks (1968) idealizaram um método baseado em regressão, que permite estimar os efeitos de genótipos, ambientes e a interação G x E, em linhas puras e seus cruzamentos. Tai (1971) propôs um método que usa regressão linear para determinar as respostas linear e não-linear de genótipos com os ambientes.

Verma et al. (1978) propuseram um método baseado na regressão linear bisegmentada, capaz de medir a sensibilidade dos genótipos a duas faixas de ambientes (favoráveis e desfavoráveis). A média dos genótipos é ajustada por dois segmentos de reta, correspondentes às subdivisões dos ambientes, naqueles com produtividade abaixo da média geral e nos com produtividade acima desta média. Portanto, são estimados dois coeficientes de regressão separadamente, que descrevem a resposta de um determinado genótipo aos ambientes favoráveis e desfavoráveis, respectivamente, sendo capaz de identificar genótipos responsivos a ambientes favoráveis e que mantenham produtividades razoáveis em ambientes adversos. Esse método foi modificado por Silva \& Barreto (1986), que adotaram o uso de um modelo de regressão múltipla que permite o ajuste para cada genótipo, de uma curva única constituída por dois segmentos de reta. Posteriormente, Cruz et al. (1989) e Storck \& Vencovsky (1994) propuseram alterações que contribuíram para facilitar a estimação dos parâmetros e melhorar a precisão das estimativas.

Toler \& Burrows (1998) propuseram um método baseado em regressão não linear que permite estimar conjuntamente os parâmetros de adaptação e estabilidade (b1 ${ }_{\mathrm{i}}$, $\mathrm{b} 2{ }_{\mathrm{i}}, \mathrm{R}_{\mathrm{i}}{ }_{\mathrm{i}}$ ), e o "índice” ambiental $\left(\boldsymbol{\mu}_{\mathrm{j}}\right)$. Paralelamente, apresentaram os conceitos de "padrão côncavo" e "padrão convexo" de resposta, para a interpretação adaptativa dos genótipos. Assim, apontam como duplamente favorável, os genótipos que apresentam um padrão convexo, ou seja, de performance consistente em ambientes desfavoráveis e que explorem positivamente condições ambientais favoráveis; por outro lado, duplamente desfavoráveis são aqueles que exibem sensibilidade nos ambientes abaixo da média geral, mas que não respondem às condições ambientais favoráveis. 
Resultados obtidos por Duarte et al. (1994) em soja e Rosse \& Vencovsky (2000) em feijão, mostraram que os melhores genótipos, quase sempre, estiveram entre os de padrão côncavo pouco responsivo preconizado por Toller \& Burrows (1998). Peixoto et al. (1985) argumentam que um genótipo com padrão côncavo de resposta pode, em condições práticas, ser mais desejável do que o chamado "teoricamente ideal", determinado por Eberhart \& Russel (1966). Pois, com tal característica, pode alcançar uma dada produtividade com um menor nível de insumos do que o exigido por genótipos responsivos somente em ambientes favoráveis, os quais necessitariam, portanto, de um maior investimento em tecnologia para atingirem a mesma produtividade.

(Duarte) $)^{3}$ recomenda que os parâmetros $b_{i}, b 1_{i}$ e b2 $2_{i}$ (coeficientes de regressão) não sejam utilizados para fins de seleção de genótipos, mas apenas como indicativos das condições ambientais para as quais eles deveriam ser indicados em termos de adaptação produtiva. Assim, a seleção deveria basear-se na média, como faz a maior parte dos melhoristas e, adicionalmente, numa medida de confiabilidade nas estimativas do(s) coeficiente(s) de regressão. Uma vez selecionados os genótipos de performance média adequada e de padrão de resposta previsível, eles seriam, então, recomendados para as condições apropriadas, em função de suas estimativas de coeficientes de regressão. $\mathrm{Ou}$ seja, quaisquer que sejam os valores destes coeficientes, se a recomendação do genótipo for para as condições em que ele atinge os maiores rendimentos, o produtor terá sucesso.

Lin \& Binns (1988) definiram como medida de estabilidade o parâmetro $\mathrm{P}_{1}$, como sendo a medida de superioridade máxima de um genótipo. Esse parâmetro representa o quadrado médio da distância entre a resposta de um determinado genótipo em relação à resposta do genótipo que apresenta produtividade máxima, entre todos os genótipos, num determinado ambiente. Quanto menor a distância entre a resposta do genótipo e a produtividade máxima, ou seja, quanto menor $\mathrm{P}_{\mathrm{i}}$, mais estável é o genótipo. Uma vantagem dessa metodologia é que ela tenta aliar estabilidade com adaptabilidade.

\footnotetext{
${ }^{3}$ DUARTE, J. B. Questões a cerca da interpretação de padrões de resposta genotípica em estudos de interação genótipos x ambientes. (Em elaboração)
} 
Esse método é similar ao método de Plaisted \& Peterson (1959), exceto que o parâmetro de estabilidade é baseado nos efeitos médios de genótipo e da interação $\mathrm{G}$ x $\mathrm{E}$, e que cada genótipo é comparado somente com a produtividade máxima em cada ambiente.

Os métodos de regressão linear para avaliar estabilidade fenotípica em plantas têm sido amplamente discutidos, sobretudo, com respeito a dois aspectos. O primeiro deles refere-se ao fato de os índices ambientais, tal como são tomados nessas metodologias, não serem independentes das variedades testadas (o índice ambiental é obtido a partir dos próprios dados). Contudo, isso não parece relevante quando o número de genótipos é elevado. O segundo refere-se à pressuposição de uma regressão linear entre o comportamento dos genótipos e o índice de ambiente. Outro aspecto diz respeito ao desdobramento tradicionalmente feito na análise de regressão, onde não é tomada apenas a variação devida à interação $\mathrm{G}$ x $\mathrm{E}$, mas aquela decorrente das fontes de variação: ambientes + interação $\mathrm{G}$ x E (ambientes dentro de genótipos). Esse procedimento usual, sem dúvida, auxilia no processo de recomendação de cultivares, pois fornece uma descrição do padrão médio de resposta de cada genótipo frente à melhoria da qualidade ambiental; entretanto, obscurece a identificação de relações importantes no discernimento das verdadeiras causas da interação G x E em si (Duarte \& Vencovsky, 1999).

Crossa (1990) comenta que, a obtenção de parâmetros via análise de regressão linear, é bastante usada por melhoristas de plantas, por ser uma técnica matematicamente simples e biologicamente interpretável. No entanto, apresenta algumas desvantagens: (a) não é informativa quando a linearidade falha; (b) é altamente dependente do grupo de genótipos e ambientes incluídos na análise; e (c) tende a supersimplificar padrões de resposta diferentes por explicar a variação da interação G x E em apenas uma dimensão (coeficiente de regressão), quando na realidade ela pode ser altamente complexa. $\mathrm{O}$ autor alerta para o perigo em sacrificar informações relevantes para facilitar interpretações estatísticas e biológicas.

A tendência atual é para o uso de métodos multivariados ou aqueles que integram métodos univariados com multivariados. A análise multivariada apresenta três objetivos principais; (a) eliminar os ruídos presentes nos dados; (b) sumarizar os dados; 
e (c) revelar a estrutura nos dados. Ao contrário dos métodos estatísticos clássicos, a função da análise multivariada é elucidar a estrutura interna dos dados a partir de hipóteses que podem ser geradas e depois testadas por métodos estatísticos. A resposta de um dado genótipo $\mathrm{G}$ em $\mathrm{E}$ ambientes pode ser conceituada como um padrão em $\mathrm{N}$ espaço dimensional (Crossa, 1990).

Dois grupos de técnicas multivariadas têm sido usados para elucidar a estrutura interna da interação G x E: (a) técnicas de ordenação, tais como a ACP, análise de coordenadas principais e análise de fatores; e (b) técnicas de classificação, tais com análise de agrupamento e análise discriminante. Dessas, a ACP é a mais freqüentemente usada (Flores et al., 1998). O objetivo principal dessa técnica é transformar os dados a partir de um grupo de eixos de coordenadas em outro grupo, que preserve, o mais possível, a configuração original do grupo de pontos e concentre a maior parte da estrutura dos dados no (s) primeiro (s) eixo (s) da ACP. Esta assume que as variáveis originais definem um espaço Euclidiano na qual a similaridade entre itens é medida como distância Euclidiana (Crossa, 1990).

Uma das metodologias que vem ganhando espaço em uso, tem sido a análise AMMI. Esta representa um modelo linear (efeitos aditivos) e bi-linear (efeito multiplicativo) que integra a ANAVA para efeitos aditivos principais (genótipos e ambientes) com a ACP para o efeito multiplicativo da interação G x E (Gauch \& Zobel, 1996). O número de eixos ou componentes da ACP retidos para a maioria das aplicações é o menor possível (dois ou três no máximo), com o qual se pretende reduzir a dimensão do sistema e fornecer uma descrição mais parcimoniosa à cerca da estrutura da interação (Shafii \& Price, 1998).

A análise AMMI pode auxiliar tanto na identificação de genótipos com alta produtividade e amplamente adaptados, como na realização do zoneamento agronômico, com a finalidade de recomendação regionalizada e seleção de locais de teste (Gauch \& Zobel, 1996). O método ainda permite a obtenção de estimativas mais precisas das respostas genotípicas e possibilita uma fácil interpretação gráfica dos resultados da análise estatística, através do procedimento biplot (Zobel et al., 1988). 
Dados coletados a partir de experimentos que envolvem multilocais são intrinsecamente complexos, apresentando três aspectos fundamentais: (a) padrão estrutural, (b) ruídos não estruturais e (c) relações entre genótipos, ambientes e interação G x E. O padrão implica que um número de genótipos respondem a determinados ambientes de forma sistemática, significante e interpretável, enquanto que ruído sugere que as respostas são imprevisíveis e não interpretáveis, sendo parte integrante da variabilidade estranha contido nos dados (Crossa, 1990). Assim, nesse tipo de abordagem, não se parte da premissa de que os desvios de aditividade decorrentes do ajuste dos efeitos principais sejam inteiramente resultantes da interação G x E. Com efeito, tais desvios podem conter ruídos. O descarte destes ruídos, permitirá caracterizar melhor os fatores genéticos e ambientais realmente envolvidos na interação $\mathrm{G} \times \mathrm{E}$, e melhor estimar as respostas genótipos aos ambientes (Duarte, 2001).

O objetivo principal da análise AMMI é selecionar modelos que expliquem o padrão relacionado à interação ( $\mathrm{SQ}_{\mathrm{GxE}}$ Padrão), descartando os ruídos presentes nos dados e sem interesse agronômico ( $\mathrm{SQ}_{\mathrm{GxE}}$ Ruídos$)($ Crossa, 1990). Ela também é uma ferramenta apropriada para diagnóstico em situações onde a interação significativa é acompanhada por não significância dos efeitos aditivos principais de genótipos e ambientes ou onde a estrutura da interação é influenciada por “outliers" (Shafii \& Price, 1998).

O método AMMI engloba uma família de modelos (AMMI0: não inclui nenhum eixo ou termo da interação; AMMI1: inclui somente o primeiro eixo da interação; AMMI2: inclui somente os dois primeiros eixos da interação; AMMIn: inclui $n$ eixos da interação). O critério mais comum adotado para a definição do número de eixos da análise de componentes principais da interação (ACPI) a serem retidos, ou seja, do modelo mais preditivo e parcimonioso, tem sido o uso de testes estatísticos (Cornelius et al., 1996).

Duarte \& Vencovsky (1999) mencionam que um dos procedimentos usuais adotados para a definição do número de eixos a serem retidos, de maneira a explicar o padrão relacionado à interação, consiste em determinar graus de liberdade associados à parcela da $\mathrm{SQ}_{\mathrm{GxE}}$ relacionada a cada membro da família AMMI. Obtém-se, então, o quadrado médio (QM) correspondente a cada parcela (ou modelo). Em seguida, é obtido 
um teste $F$ avaliando-se a significância de cada componente em relação ao QM $\mathrm{M}_{\text {erro médio }}$. Dessa forma, o ponto de parada que determina a seleção do modelo (AMMI0, AMMI1,..., ou AMMIn) baseia-se na significância do teste $F$ para os sucessivos eixos da interação. O resíduo AMMI, reunindo os eixos descartados da interação, também pode ser testado de maneira a assegurar o seu caráter desprezível. Segundo Gauch \& Zobel (1996), os dois sistemas mais populares para atribuir graus de liberdade a um modelo AMMI são os sistemas de Gollob (1968) e Mandel (1971).

Testes alternativos também têm sido sugeridos, como é o caso dos testes $F_{G H 1}$ e $F_{G H 2}$ (Cornelius, 1993), o teste $F_{R}$ (Cornelius et al. 1992 e Piepho, 1995) e a razão de sinal para o ruído (Gauch, 1992). Pelo teste $F$ (Gollob, 1968), o ponto de parada para seleção do modelo é o $n$-ésimo componente principal da interação (CPI) que for significativo pelo teste $F$; já pelo teste $F_{R}$, o ponto de parada é o $n$-ésimo CPI no qual o seu resíduo seja não significativo.

A atribuição dos graus de liberdade associados à parcela da $S_{\mathrm{GxE}}$ relacionada $\mathrm{a}$ cada membro da família AMMI ainda é um aspecto crucial da análise, e que ainda é motivo de estudo. Destes, o sistema aproximado de Gollob (1968) tem sido o mais usado, por ser de fácil aplicação. Segundo Annicchiarico (1997a), a preferência sobre um ou outro teste deve depender do número de genótipos, locais e anos de testes.

O uso de procedimentos livres de distribuições teóricas, tais como a validação cruzada, têm sido outra alternativa para a seleção de modelos AMMI. Segundo essa abordagem, os dados originais de repetições são divididos em dois grupos: dados de modelagem e dados de validação (ex: 4 repetições, três observações são usadas para modelar e uma é usada para validar); isso permite estimar o que se chama de Diferença Preditiva Média (DPM). A DPM é estimada várias vezes por reamostragem aleatória dos dados, para cada modelo da família AMMI, obtendo-se uma DPM média para cada modelo. Um valor de DPM menor é indicativo de modelo mais preditivo; portanto será o selecionado. Segundo Ortiz et al. (2001), essa abordagem só é possível de ser usada quanto se tem mais de duas repetições por experimento. A validação cruzada representa uma avaliação "preditiva" do modelo, pois o teste é feito a "priori” com os dados 
originais. Já os testes paramétricos baseados no teste $F$ representam um tipo de avaliação "posdictiva", já que o teste é realizado após a análise dos dados (Gauch \& Zobel, 1988).

Comparações entre diferentes testes para a seleção do modelo AMMI têm sido pouco na literatura (Cornelius, 1993; Piepho, 1995 e Annicchiarico, 1997a). Um resultado comum nesses trabalhos é que o teste $F$ de Gollob tendeu ser mais liberal em selecionar mais eixos do que o verdadeiro modelo contempla, enquanto que os testes $F_{G H 1}$ e $F_{G H 2}$ foram mais liberais do que o teste $F_{R}$. O teste $F_{R}$ apresentou resultados semelhantes ao teste da razão de sinal para o ruído. De acordo com Piepho (1995), o teste $F_{R}$ mostrou-se como o mais robusto. Também se observa que o teste $F_{R}$ é o que mais se aproxima dos resultados obtidos pela validação cruzada. Lavoranti et al. (2001) utilizaram o teste $F_{R}$ como critério para a seleção de modelos AMMI, em um estudo envolvendo progênies de eucalipto.

Outras abordagens multivariadas para estudos da interação G x E têm sido observadas na literatura. Yan et al. (2001) propuseram um método para avaliar a adaptabilidade e a estabilidade fenotípica baseado na análise gráfica denominada de biplot GGE (efeitos principais de genótipos e da interação G x E). O biplot GGE é construído plotando os dois primeiros componentes principais de uma ACP, utilizando modelos de regressão de locais (SREG). O objetivo principal é identificar genótipos superiores para recomendação aos agricultores e locais que melhor representem ambientes específicos ou mega-ambientes.

As técnicas multivariadas são estatisticamente muito complexas e a falta de disponibilidade de programas computacionais tem limitado bastante seu uso (Flores et al., 1998). Tais técnicas ganharão maior aceitação a partir do momento que os programas sejam mais informativos e de fácil uso, bem como sejam capazes de manejar experimentos com dados perdidos. A produção de tais programas ainda representa um ponto de entrave para maior utilização dessas técnicas (Romagosa \& Fox, 1993). Alguns sinais se mudanças podem ser evidenciados, como é o caso da análise AMMI detalhada nos trabalhos apresentados por Duarte \& Vencovsky (1999) e Thillainathan \& Fernandez (2001), utilizando o sistema SAS (STATISTICAL ANALYSIS SYSTEM) 
(SAS INSTITUTE, 1997) e o programa "Estabilidade" (Universidade Federal de Lavras, 2000).

$\mathrm{O}$ estudo de fatores ambientais que podem contribuir para a interação $\mathrm{G} \times \mathrm{E}$ também tem sido investigado. Becker \& Léon (1988) comentam que as interações G x E podem ser parcialmente entendidas como um resultado de uma reação diferencial a fatores de estresses ambientais como secas ou doenças e, consequentemente, o melhoramento da resistência é de importância para melhorar a estabilidade de produção. Kang \& Magari (1996) corroboram esse argumento comentando que a estabilidade de produção depende de seus componentes e de outros caracteres, tais como: resistência a pragas, tolerância a fatores de estresses e variáveis ambientais (todas contribuem de forma diferente para a interação G x E). Se a importância relativa desses componentes foi avaliada e um ou mais fatores limitantes é ou são determinados, então, sua manipulação pode aumentar a estabilidade.

Alguns métodos utilizam variáveis ambientais associadas com parâmetros de estabilidade para avaliar com maiores detalhes a interação G x E. Isso é feito com dois objetivos: (a) estudar suas relações com a performance genotípica; e (b) entender as verdadeiras causas da interação $G$ x E. As respostas fisiológicas diferenciais de genótipos a fatores edáficos e climáticos, especialmente aqueles relacionados à eficiência nutricional e tolerância a estresses, são relevantes para a interação $\mathrm{G} \times \mathrm{E}$ (Baker, 1988). Os métodos de regressão multilinear, a ACP e a combinação de ambos, são técnicas bastante usadas com essa finalidade (Crossa, 1990). Nesse sentido, Chaves (2001) comenta que há a necessidade de intensificar os estudos sobre a influência de genes específicos (genes que conferem resistência à fatores de estresse bióticos e abióticos), sobre a manifestação da interação G x E em caracteres complexos como a produtividade.

Vargas et al. (2001) reportaram que, quando informações sobre variáveis ambientais ou genotípicas, tais como dados meteorológicos ou informações de solo são disponíveis, essas variáveis podem ser correlacionadas ou regredidas sobre escores ambientais ou genotípicos estimados pelo modelo AMMI. No entanto, informações ambientais externas não podem ser usadas diretamente no modelo AMMI. Assim, 
quando informações adicionais sobre variáveis externas do cultivar são disponíveis (fisiologia, maturidade, reação a doenças, marcadores moleculares, etc.), outros modelos estatísticos, incluindo modelos bi-lineares como a regressão fatorial e a regressão parcial de mínimos quadrados, são úteis em reduzir variáveis e indicar quais as variáveis relacionadas aos genótipos ou ambientes, influenciam mais a interação G x E.

Um entendimento das bases genéticas e ambientais da interação $\mathrm{G}$ x E é de fundamental importância no melhoramento de plantas. Nesse sentido, alguns autores têm reportado que o mapeamento de locos que controlam caracteres quantitativos (QTLs) e sua interação com o ambiente (interação Q x E), podem ajudam na elucidação das verdadeiras causas e natureza da interação $\mathrm{G}$ x E relacionada a determinado grupo de genótipos e ambientes. Nessa linha de pensamento, Kang (1998), comenta que a identificação de QTLs mais estáveis em diferentes ambientes poderia ser utilizada em um esquema de seleção assistida para estabilidade fenotípica. Por outro lado, Crossa et al. (1999) propõem modelos de regressão fatorial e parcial de mínimos quadrados para análises que envolvem marcadores moleculares e covariáveis ambientais, objetivando estudar a interação Q x E relacionada à Interação G x E.

\subsection{Adaptabilidade e estabilidade fenotípica em soja}

As metodologias mais usadas em soja para acessar a adaptabilidade e estabilidade de genótipos são aquelas baseadas em regressão linear. Entre essas, o método proposto por Eberhart \& Russel (1966) é o mais utilizado em soja (Duarte et al., 1994; Ablett et al., 1994; Scott et al., 1994; Raut et al., 1997; Alliprandini et al., 1998; Galvão et al., 1998; Mohanty et al., 1999; Sood et al., 1999; Lima et al., 2000; Mauro et al., 2000 e Prado et al., 2001). Em todos esses trabalhos, esses autores identificaram genótipos com adaptação ampla (estáveis) e com adaptação específica a ambientes favoráveis (produtividade média alta) e desfavoráveis (produtividade média baixa).

Os métodos baseados em regressão bi-segmentada têm sido muito usados no Brasil, quando se considera todas as espécies de culturas. Os mais usados são os propostos por Silva \& Barreto (1986) e Cruz et al. (1989). No caso da soja, ainda são 
poucos os relatos de uso, como é o caso dos estudos conduzidos por Duarte et al. (1994), Alliprandini et al. (1998) e Prado et al. (2001) que utilizaram o método de Silva \& Barreto (1986), Verma et al. (1978) e Cruz et al. (1989), respectivamente, para avaliar um grupo de genótipos de soja divididos em ciclos de maturação.

O método da ecovalência (Wricke \& Weber, 1986), foi utilizado por Miranda (1999), Unêda \& Vello ${ }^{4}$, Yokomizo (1999) e Prado et al. (2001). De acordo com esses autores, o método se mostrou bastante prático para avaliar a estabilidade fenotípica. No entanto, os três primeiros autores comentam que a seleção foi mais eficiente quando combinou a ecovalência com o desempenho médio dos genótipos avaliados. Unêda \& Vello $^{5}$, avaliaram populações derivadas de cruzamentos óctuplos em genótipos de diversos ciclos de maturação e reportaram que a ecovalência foi mais uniforme com o aumento do número de genótipos testados e aumentou com o ciclo, ou seja, os cultivares tardios foram mais estáveis. Miranda (1999), confirma que a ecovalência é inversamente proporcional ao ciclo, mencionando que quanto mais precoce o material, menor a estabilidade.

Zobel et al. (1988) avaliaram sete genótipos em 35 ambientes (combinação de cinco anos e oito locais). A ANAVA não detectou significância para a interação G x E, enquanto a análise AMMI identificou significância para o primeiro componente principal da interação (CPI1) pelo critério de Gollob (1968). O modelo selecionado (AMMI1) explicou $71 \%$ da soma de quadrados da interação G x E (SQ GxE$)$. Os autores constataram que a relação entre o comprimento do dia (fotoperíodo: latitude) e o grupo de maturação foi responsável pela alta significância da interação $\mathrm{G}$ x E capturada pelo CPI1. Em um estudo posterior, Gauch \& Zobel (1990) encontraram que o CP1 explicou 69,6\% da $\mathrm{SQ}_{\mathrm{GxE}}$, utilizando o algoritmo EM-AMMI para experimentos com parcelas perdidas. Para o estudo de Sneller \& Dombek (1995), CPI1 explicou somente $23 \%$ da SQ ${ }_{\mathrm{GxE}}$. Mais recentemente, Ariyo (1998) utilizou a análise AMMI para avaliar onze genótipos em quatro ambientes (combinação de dois anos com dois locais) na Nigéria.

\footnotetext{
${ }^{4}$ UNÊDA, S.H.; VELLO, N.A. Assesment of phenotypic stability using ecovalence in soybean progenies derived from multiple crosses. 2001. (Em elaboração)
} 
Nesse estudo, o modelo selecionado também foi o AMMI1 e explicou 86,04\% da interação $G$ x E. Os resultados desses trabalhos mostraram que o padrão inerente à interação foi alto e concentrado na sua grande maioria no CPI1, exceto no trabalho de Sneller \& Dombek (1995).

No Brasil, ainda não há relatos na literatura do uso da análise AMMI em soja, sendo encontrados resultados obtidos em milho (Arias, 1996 e Gonçalves, 1997), batata (Pereira \& Costa, 1998) e feijão (Borges et al., 2000). Nesses trabalhos, o CPI1 explicou $28,6 \% ; 34,02 \% ; 44,6 \%$ e $43 \%$; respectivamente, da $\mathrm{SQ}_{\mathrm{GxE}}$. Os resultados desses trabalhos mostraram que o padrão adjacente à interação $G \times E$ foi baixo e em alguns casos distribuídos em mais de dois eixos da ACP.

A repetibilidade de vários parâmetros relacionados à adaptabilidade e estabilidade foi estimada por Sneller et al. (1997). Foram comparadas 9 estatísticas derivadas da análise AMMI, o coeficiente de regressão $\left(b_{i}\right)$, os desvios da regressão $\left(\mathrm{s}^{2} \mathrm{~d}_{\mathrm{i}}\right)$, o parâmetro de Shukla $\left(\sigma_{\mathrm{i}}{ }^{2}\right)$ e a estatística não-paramétrica de Hühn $\left(\mathrm{S}^{(1)}\right)$. As estatísticas derivadas da análise AMMI produziram informações sobre a estabilidade dos cultivares similares àquelas fornecidas pelo $\mathrm{s}^{2} \mathrm{~d}_{\mathrm{i}} \mathrm{e} \sigma_{\mathrm{i}}{ }^{2}$. A repetibilidade da classificação dos genótipos por $\mathrm{s}^{2} \mathrm{~d}_{\mathrm{i}}, \sigma_{\mathrm{i}}^{2}$ e $\mathrm{S}^{(1)}$ e a maioria das estatísticas derivadas de AMMI foram baixas, indicando que essas estatísticas não seriam úteis para melhorar ou desenvolver seleção para estabilidade. A repetibilidade do $b_{i}$ e de uma das estatísticas AMMI foram moderadas, particularmente quando estimadas em ambientes envolvendo dois anos.

Ablett et al. (1989) utilizaram a técnica de agrupamento de genótipos proposta por Francis \& Kannenberg (1978) para discriminar um grupo de genótipos de soja com hábitos de crescimento determinado e indeterminado. Essa técnica baseia-se na produtividade e estabilidade, através de uma análise gráfica, plotando a produtividade de cada genótipo entre ambientes contra seus respectivos coeficientes de variabilidade (CV). Ivory et al. (1991) também adotaram a análise de agrupamento ou classificação numérica, associada com a análise de coordenadas principais, para sumarizar padrões nas performances genotípicas e produtividade ambiental quando ocorre interação $\mathrm{G}$ x E significativa. A representação em gráfico, como um índice de ordenamento relativo de 
genótipos, mostrou ser muito efetiva em separar respostas diferenciais de linhagens de soja em diferentes ambientes da Tailândia.

\subsection{Comparação entre metodologias que avaliam a adaptabilidade e estabilidade fenotípica em soja}

A forma mais comum para comparar as metodologias é através da correlação entre seus parâmetros que medem a adaptabilidade e estabilidade fenotípica. As correlações mais usadas são as de Spearman e Pearson. Essa abordagem tem como principal objetivo verificar similaridades ou divergências quanto ao ordenamento dos genótipos com os ambientes. Um outro tipo de comparação tem sido quanto que a metodologia explica em termos proporcionais da interação $G$ x E. Uma terceira abordagem seria em relação à capacidade de melhor caracterizar ou reunir informações dos genótipos e ambientes quanto à adaptabilidade e estabilidade.

Zobel et al. (1988) comparam a análise de variância (ANAVA), a regressão linear (RL), a ACP e a análise AMMI, utilizando dados de produtividade de grãos (PG) em genótipos de soja avaliados em vários ambientes. Em seus resultados, os autores concluíram que a ANAVA foi ineficiente para detectar significância para a interação, a ACP falhou em identificar e separar os efeitos aditivos principais de genótipos e ambientes, e a RL descreve apenas para uma pequena porção da soma de quadrados da interação (7,9\% apenas). Por outro lado, a análise AMMI exibiu uma alta significância para o componente da interação, que apresenta claro significado agronômico (o CPI1 explicou $71 \%$ da $\left.\mathrm{SQ}_{\mathrm{GxE}}\right)$. Assim, ANAVA, ACP e RL podem ser considerados como sub-casos de um modelo AMMI mais completo, sendo que este oferece uma análise estatística mais apropriada para casos dessa natureza em que ocorre interação G x E. Em um estudo com trigo, Yau (1995), comparou a RL e o modelo AMMI e também evidenciou que o modelo AMMI explica mais a interação G x E do que a RL (37\% contra $11 \%$, respectivamente, da $\left.\mathrm{SQ}_{\mathrm{GxE}}\right)$.

Um estudo comparativo envolvendo metodologias que apresentam parâmetros que combinam simultaneamente PG e estabilidade foi realizado por Dashiell et al. 
(1994). Foram comparados a PG; o coeficiente de regressão (b $b_{i}$ ) e a variância dos desvios da regressão $\left(\mathrm{s}^{2} \mathrm{~d}_{\mathrm{i}}\right)$ de Eberhart \& Russel (1966); variância de "ranking" $\left(\mathrm{S}_{\mathrm{i}}{ }^{3}\right)$ de Hühn (1996); a medida de superioridade máxima $\left(\mathrm{P}_{\mathrm{i}}\right)$ de Lin \& Binns (1988) e a soma de "rank" de Kang (1988). A PG foi correlacionada positivamente com b $(r=0,50)$ e negativamente com $\mathrm{P}_{\mathrm{i}}(\mathrm{r}=-0,84)$ e a soma de "rank" $(\mathrm{r}=0,58) . \mathrm{O} \mathrm{b}_{\mathrm{i}}$ foi negativamente correlacionado com $P_{i}(r=-0,47)$, enquanto a $s^{2} d_{i}$ foi positivamente correlacionada com $\mathrm{S}_{\mathrm{i}}^{3}(\mathrm{r}=0,72)$ e a soma de "rank" $(\mathrm{r}=0,62)$. Os parâmetros $\mathrm{P}_{1}$ e a soma de "rank" apresentaram a mais alta correlação $(r=0,80)$. Os autores concluem que, dada a magnitude de correlação entre $\mathrm{PG}$ e $\mathrm{P}_{\mathrm{i}}, \mathrm{P}_{\mathrm{i}}$ é a melhor técnica que seleciona simultaneamente para produtividade e estabilidade fenotípica.

Sneller \& Dombek (1995) realizaram um estudo comparativo da classificação e seleção para PG realizados a partir de estimativas obtidas pela análise AMMI e pela análise envolvendo dados completos (ANAVA). Todas as correlações entre estimativas obtidas pelo modelo AMMI e dados completos foram significativas dentro de anos e pareceram igualmente preditivas para a classificação dos genótipos. Esses autores mencionam que não há vantagem ou desvantagem para ambos os métodos em estimar a média dos genótipos; aparentemente, para este estudo, o padrão da interação $\mathrm{G}$ x $\mathrm{E}$ incorporado nas estimativas obtidas pelo modelo AMMI, não foram suficientemente repetíveis entre anos para produzir estimativas que fossem mais preditivas, quando comparado às estimativas obtidas a partir de dados completos.

Yue et al. (1997) avaliaram cultivares de soja usando estimativas de estabilidade paramétricas [coeficiente de variância $\left(\mathrm{CV}_{\mathrm{i}}\right)$, ecovalência $\left(\mathrm{W}_{\mathrm{i}}\right)($ Wricke \& Weber, 1986), b e $s^{2} d_{i}$ de Eberhart \& Russel (1966) e a variância de estabilidade de Shukla (1972)] e não paramétricas $\left[S_{i}^{(1)}\right.$ e $S_{i}^{(2)}$ de Hühn (1996)]. Esses autores encontraram que o $\mathrm{b}$ foi significativamente e positivamente correlacionado somente com o $\mathrm{CV}_{\mathrm{i}}$. As medidas não paramétricas $\left(\mathrm{S}_{\mathrm{i}}^{(1)}\right.$ e $\left.\mathrm{S}_{\mathrm{i}}^{(2)}\right)$ foram altamente correlacionadas com os parâmetros $\mathrm{s}^{2} \mathrm{~d}_{\mathrm{i}}$ e $\mathrm{W}_{\mathrm{i}}$.

A estabilidade e adaptabilidade foram analisadas para um grupo de cultivares e linhagens de soja divididas em ciclos de maturação (precoce, semiprecoce e médio) no Estado do Paraná, por Aliprandini et al. (1998). Foram utilizados os métodos de 
regressão única (Eberhart \& Russel, 1966), regressão segmentada (Verma et al., 1978) e as modificações no conceito de adaptabilidade definidas por Alliprandini (1992). Foi constatado que a utilização conjunta das duas metodologias, aliada à definição dos conceitos de Alliprandini (1992), permitiu uma melhor caracterização da adaptabilidade e estabilidade dos genótipos e facilitou a seleção.

Miranda (1999) comparou os métodos da ecovalência (Wricke \& Weber, 1986), e o desvio padrão da ordem de classificação dos genótipos $\left(\mathrm{S}_{\mathrm{i}}\right)$ nos vários ambientes (medida semelhante a $\mathrm{S}_{\mathrm{i}}{ }^{(2)}$ proposta por Hühn (1996) e concluiu que a ecovalência $\left(\mathrm{W}_{\mathrm{i}}\right)$ e $S_{i}$ são altamente correlacionadas para a PG; a ecovalência mostrou-se independente da PG, número de dias para maturidade (NDM) e produtividade diária (PPD), enquanto que o NDM mostrou tendência de associação com alta PG e PPD. Para NDM, os parâmetros $\mathrm{W}_{\mathrm{i}}$ e $\mathrm{S}_{\mathrm{i}}$ não apresentaram correlação tão intensa quanto para $\mathrm{PG}$, sugerindo que esses parâmetros avaliam a estabilidade de maneira diferente para esse caráter.

Um estudo de comparação entre os parâmetros de Eberhart \& Russel (1966) e

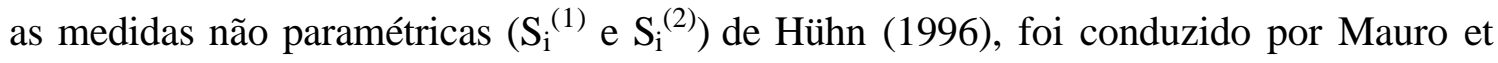
al. (2000), para o caráter PG. Esse autor verificou correlações significativas entre as medidas não-paramétricas e os desvios da regressão, sendo baixas entre aquelas e o coeficiente de regressão. As medidas $\mathrm{S}_{\mathrm{i}}^{(1)}$ e $\mathrm{S}_{\mathrm{i}}^{(2)}$ mostraram-se quase que perfeitamente correlacionadas.

Prado et al. (2001) avaliaram a adaptabilidade e estabilidade fenotípica de cultivares de soja em cinco épocas de plantio no cerrado de Rondônia e utilizou os métodos da ecovalência (Wricke \& Weber, 1986), Eberhart \& Russel (1966) e Cruz et al. (1989). Esses autores concluíram que os métodos utilizados foram coerentes entre si e permitiram identificar, entre os cultivares avaliados, os de maior estabilidade e adaptabilidade. No entanto, a não significância das hipóteses abordadas pelo método de Cruz et al. (1989) indicou que o comportamento dos cultivares com as épocas de cultivo foi melhor representado pelo modelo de regressão linear de Eberhart \& Russel (1966). 


\section{MATERIAL E MÉTODOS}

\subsection{Material genético}

Foram avaliadas 118 linhagens experimentais de soja, divididas em quatro ciclos de maturação (CM): 28 linhagens precoces (LP), 38 semiprecoces (LSP), 27 intermediárias (LI) e 7 semitardias (LST). O material pertence à coleção de germoplasma desenvolvido pelo Setor de Genética Aplicada às Espécies Autógamas, Departamento de Genética, Escola Superior de Agricultura "Luiz de Queiroz" (ESALQ), Universidade de São Paulo (USP). Os quatro CM foram reagrupados após seleção praticada na safra 1995/96, englobando materiais provenientes dos programas produtividade de grãos e óleo. Utilizou-se como critério de reagrupamento os seguintes intervalos de número de dias para maturidade: 112-119 (LP), 120-127 (LSP), 128-135 (LI) e 136-142 (LST).

Estas linhagens receberam a sigla USP e foram desenvolvidas no primeiro ciclo de recombinação dos programas de seleção recorrente para produtividade de grãos e óleo, em andamento no Departamento de Genética da ESALQ/USP. Estes programas têm como objetivo principal, aumentar a base genética da soja cultivada e os níveis de produtividade de grãos e óleo. Informações sobre a identificação, genealogia, geração de endogamia e programa de origem das linhagens avaliadas, são mostradas no Apêndice 1.

As linhagens oriundas do programa produtividade de grãos foram obtidas a partir de cruzamentos biparentais envolvendo quatro dialelos compostos de dez parentais

pertencentes ao mesmo $\mathrm{CM}$, totalizando 40 parentais. Maiores informações sobre a geração $F_{2}$, método de condução das populações segregantes e avanço de gerações, podem ser obtidas nos trabalhos de Freire Filho (1988), Nass (1989), Krieger (1992), 
Moreira (1992), Vello (1992), Carbonell (1995), Gomes (1995), Azevedo Filho (1997) e Rocha (1998).

As linhagens advindas do programa produtividade de óleo foram também obtidas a partir de cruzamentos biparentais envolvendo 40 parentais, sendo $75 \%$ adaptados e $25 \%$ exóticos. Na obtenção dos híbridos, utilizou-se um esquema em cadeia circulante, com a formação de duas cadeias de cruzamentos. A primeira (cadeia mista), com 50\% de parentais adaptados e 50\% exóticos e a segunda (cadeia adaptada), contendo somente parentais adaptados. Detalhes sobre a geração $F_{2}$, método de condução das populações segregantes e avanço de gerações podem ser obtidos nos trabalhos de Vello (1992), Zimback (1992), Montaño-Velasco (1994), Farias Neto (1995) e Laínez-Mejía (1996) e Rocha (1998).

Os parentais envolvidos nos cruzamentos foram selecionados mediante estudos de campo, realizados nas safras 1983/84 e 1984/85, baseando-se em características desejáveis como elevada produtividade de grãos e de óleo nas sementes, tolerância às variações do fotoperíodo, resistência a doenças (cancro da haste, nematóide do cisto e olho-de-rã) e pela sua diversidade genética, sendo esta estimada pelos coeficientes de parentesco baseados nas genealogias (Vello et al., 1988; Vello, 1992 e 1995).

Foram utilizadas quatro testemunhas para cada $\mathrm{CM}$, compreendendo cultivares adaptados, de boa produtividade e com resistência ao cancro da haste da soja (CHS) variando de medianamente a totalmente resistentes. As testemunhas utilizadas por $\mathrm{CM} \mathrm{e}$ ano agrícola, são apresentadas no Apêndice 2.

\subsection{Ambientes de condução dos experimentos}

Os experimentos foram instalados nos anos agrícolas 1996/97, 1997/98, 1998/99 e 1999/00. Em todos os anos agrícolas, os experimentos foram conduzidos em três locais do município de Piracicaba, SP: Anhembi, caracterizado por solo aluvial distrófico, textura médio-arenosa, relevo plano, situado na Estação Experimental Anhembi, distante cerca de $60 \mathrm{Km}$ da sede da ESALQ/USP; Areão, com solo do tipo podzólico vermelho-amarelo distrófico, textura médio-argilosa, relevo ondulado, situado 
na Fazenda Areão e distante cerca de 5Km da sede da ESALQ/USP; e ESALQ, com solo do tipo terra roxa estruturada, textura argilosa, relevo ondulado, situado na área experimental do Departamento de Genética (sede da ESALQ/USP). O solo dos três locais foi uniformizado com cultivo e incorporação de aveia preta (Avena strigosa) no inverno anterior. Todos os campos experimentais pertencem à ESALQ/USP. Uma visão panorâmica dos locais de avaliação dos experimentos é apresentada na Figura 1.

Piracicaba está situada a $22^{\circ} 42^{\prime} 30^{\prime \prime}$ de latitude Sul, $47^{\circ} 39^{\prime} 00^{\prime}$ de longitude Oeste e a uma altitude de 540m acima do nível do mar. No Apêndice 3 são apresentadas as informações referentes às temperaturas, umidades relativas médias, precipitação pluvial e fotoperíodo obtidos durante a fase de condução dos experimentos (dados fornecidos pelo Setor de Física e Meteorologia do Departamento de Ciências Exatas da ESALQ/USP). Nos Apêndices 4 e 5 são mostrados os critérios utilizados para a interpretação de análises de solos para o Estado de São Paulo, segundo Malavolta et al. (1989) e as análises de solo relativas às áreas experimentais utilizadas nos três locais.

O preparo do solo foi similar para todos os experimentos e consistiu de uma aração e duas gradagens. A adubação foi feita no sulco, aplicando-se $25 \mathrm{~g}$ da fórmula 420-20 (N- $\left.\mathrm{P}_{2} \mathrm{O}_{5}-\mathrm{K}_{2} \mathrm{O}\right)$ por metro linear. A inoculação das sementes foi realizada usandose inoculante comercial contendo cepas de Bradyrhizobium japonicum diluído em água (800g/201), através de pulverização costal. Foram realizadas irrigações por aspersão logo após a semeadura e nas fases de maior necessidade da cultura (fase de florescimento e formação dos grãos). Controles de pragas (principalmente percevejos) e de ervas daninhas foram feitos com aplicações de inseticida (Endosulfon a 1,251/ha) e herbicida pré-emergente (Trifluralin a 1,811/ha) incorporado antes da semeadura, complementando-se com capinas manuais quando necessário.

\subsection{Procedimentos experimentais}

As semeaduras ocorreram na época normal de cultivo para o Estado de São Paulo (cultivo de verão), nas seguintes datas: 20/11/96, 16/11/97, 17/11/98 e 23/11/99 (local Anhembi); 12/11/96, 13/11/97, 05/11/98 e 30/11/99 (local Areão); e 06/11/96, 
12/11/97, 05/11/98 e 08/11/99 (local ESALQ). Em cada local foram conduzidos quatro experimentos, cada um correspondendo a um dos CM. Utilizou-se o delineamento em blocos casualizados com duas repetições. Em cada repetição, os tratamentos foram estratificados em conjuntos experimentais com testemunhas comuns de mesmo CM. Para as LST, foi realizada a estratificação em conjuntos experimentais na safra 1996/97, sendo que nos demais anos não houve a necessidade de estratificação devido ao baixo número de linhagens. A estratificação das repetições em conjuntos objetivou detectar possíveis diferenças que possam ocorrer dentro de cada repetição, principalmente para os casos em que há um grande número de tratamentos.

Informações sobre o número de linhagens por $\mathrm{CM}$ e o número de conjuntos experimentais por repetição em cada ano agrícola, são mostrados no Apêndice 2. Observa-se que houve seleção para os quatro CM entre as safras 1996/97 e 1997/98, e 1997/98 e 1998/99, não ocorrendo entre as safras 1998/99 e 1999/00. Essa seleção representou um descarte de linhagens que apresentavam alta suscetibilidade ao cancro da haste da soja e baixa produtividade de grãos, com base nos resultados obtidos em condições de campo por Rocha (1998).

A parcela experimental foi similar em todos os experimentos, sendo representada por quatro fileiras de 5 metros de comprimento, espaçadas de 0,5 metro $\left(10 \mathrm{~m}^{2}\right)$. A área útil para a tomada de dados compreendeu as duas fileiras centrais da parcela, eliminando-se 0,5 metro de cada extremidade $\left(4,0 \mathrm{~m}^{2}\right)$.

\subsection{Caracteres avaliados}

Em todos os experimentos, foram avaliados os seguintes caracteres agronômicos:

- Número de dias para a maturidade (NDM): avaliado no estádio R8 (escala de Fehr \& Caviness, 1977), compreendendo o período entre a data da semeadura e a data em que $50 \%$ das plantas da área útil se encontravam com 95\% das vagens maduras, expresso em dias; 
- Altura de planta na maturidade (APM): avaliado no estádio $\mathrm{R}_{8}$, compreendeu a distância na haste principal entre o colo e a inserção da vagem mais distal, expressa em $\mathrm{cm}$

- Acamamento (Ac): Avaliado no estádio R através de uma escala de notas visuais, variando de 1 (todas as plantas eretas) a 5 (todas as plantas prostradas), com dados transformados em $\sqrt{\mathrm{x}+0,5}$ antes da realização das análises estatísticas;

- Valor agronômico (VA): avaliado no estádio $R_{8}$ através de uma escala de notas visuais, variando de 1 (plantas ruins) a 5 (plantas ótimas), representativa de um conjunto de caracteres visuais adaptativos: arquitetura da planta, quantidade de vagens cheias, vigor e sanidade da planta, debulha prematura de vagens, acamamento e retenção foliar na maturidade; com dados transformados em $\sqrt{\mathrm{x}+0,5}$ antes da realização das análises estatísticas;

- Produtividade de grãos (PG): efetuada através do peso dos grãos, após a colheita, trilhagem das plantas da parcela e secagem dos grãos, expressa em quilogramas por hectare $(\mathrm{kg} / \mathrm{ha})$;

- Porcentagem de óleo (\%OL): avaliado pela metodologia de ressonância nuclear magnética (NMR), utilizando-se o espectrômetro de NMR desenvolvido pela EMBRAPA/CNPDIA - São Carlos, em convênio com a FINEP e o Departamento de Genética da ESALQ/USP. Foi usada uma amostra de 12 sementes em média, com um peso médio de 2,80 gramas, retiradas ao acaso do total de sementes produzidas em uma parcela.

- Produtividade de óleo (PO): caráter obtido pelo produto entre a produtividade de grãos por parcela e a porcentagem de óleo nas sementes, expresso em quilogramas por hectare $(\mathrm{kg} / \mathrm{ha})$; 


\section{5 Análises estatísticas}

Antes de proceder à análise de variância dos dados, realizou-se uma análise exploratória através da análise gráfica dos resíduos, conforme metodologia adotada por Carbonell (1995), Rocha (1998) e Soldini (1998). Essa análise detecta a existência ou não de valores discrepantes ou "outliers", que interferem na normalidade dos resíduos, afetando por suas vez, uma das pressuposições importantes da análise de variância. A análise detectou normalidade para os resíduos associados aos dados em todos os caracteres, exceto para Ac e VA. Para esses caracteres, optou-se pela transformação dos dados para $\sqrt{\mathrm{x}+0,5}$.

\subsubsection{Análises de variância}

\subsubsection{Análise de variância para as testemunhas}

Com a finalidade de verificar a existência de diferenças entre conjuntos experimentais, inicialmente, realizaram-se análises individuais de variância, seguidas de análise conjunta para os três locais (conjunta por ano) e conjunta geral (incluindo as avaliações nos três locais e quatro anos), somente com as testemunhas comuns. Efeitos significativos para conjuntos experimentais e interação conjuntos $\mathrm{x}$ testemunhas indicam a necessidade de se fazer ajustes das médias das linhagens em função das médias das testemunhas, dentro de cada conjunto experimental. Caso contrário (efeitos de conjuntos e interação conjuntos $\mathrm{x}$ testemunhas não significativos), não há necessidade de ajustes e

a análise pode ser feita em blocos ao acaso. Será discutida nesse trabalho apenas a análise conjunta geral; para isso, utilizou-se o esquema de análise de variância mostrado no Apêndice 6.

O modelo matemático adotado é apresentado conforme a equação 1 a seguir:

$$
\mathrm{Yiklm}_{\mathrm{i}}=\mu+\mathrm{t}_{\mathrm{i}}+\mathrm{a}_{\mathrm{m}}+\mathrm{l}_{1}+\mathrm{tl}_{\mathrm{il}}+\mathrm{ta}_{\mathrm{ia}}+\mathrm{la}_{\mathrm{lm}}+\mathrm{c} / 1 / \mathrm{a}_{\mathrm{k}} / \mathrm{l} / \mathrm{m}+\mathrm{ct}_{\mathrm{ki}}+\mathrm{tla}_{\mathrm{ilm}}+\mathrm{e}_{\mathrm{iklm}}
$$


sendo:

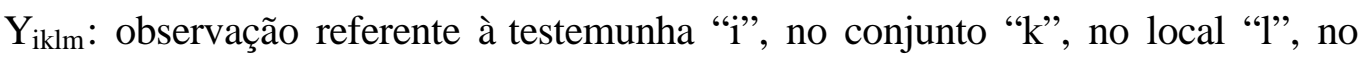
ano "m";

$\mu$ : média geral do caráter;

$\mathrm{t}_{\mathrm{i}}$ : efeito fixo da testemunha " $\mathrm{i}$ ";

$\mathrm{a}_{\mathrm{m}}$ : efeito aleatório do ano "m"

1!: efeito fixo do local "l";

$(\mathrm{tl})_{\mathrm{il}}$ : efeito fixo da interação entre a testemunha "i" e o local "l";

(la) $)_{\operatorname{lm}}$ : efeito aleatório da interação entre o local "l" e o ano "m";

$\mathrm{c}_{\mathrm{k} / \mathrm{a} / \mathrm{l}}$ : efeito aleatório do conjunto "k", dentro do ano "m", dentro do local "l";

(ct) $)_{\mathrm{ki}}$ : efeito aleatório da interação entre o conjunto "k" e a testemunha "i";

(tla) tlm: efeito aleatório da interação tripla entre a testemunha “ï ”, o local "l” e o ano "m";

$\mathrm{e}_{\mathrm{iklm}}$ : efeito aleatório do erro experimental médio associado à parcela “iklm”, admitido ser independente e com distribuição normal de média zero e variância $\sigma^{2}$.

\subsubsection{Análise de variância para as linhagens}

Empregou-se os esquemas de análises de variância dos Apêndices 7, 8 e 9, respectivamente, para as análises individuais, conjunta/ano e conjunta geral.

O modelo adotado para a análise individual de variância foi de acordo com a equação 2 a seguir:

sendo:

$$
Y_{i j}=\mu+g_{i}+r_{j}+e_{i j}
$$

$Y_{\mathrm{ij}}$ : observação do genótipo “i”, na repetição “j”;

$\mu$ : média geral do caráter;

$t_{i}$ : efeito fixo da linhagem " $i$ ”; $i=1, \ldots, T$;

$r_{j}$ : efeito aleatório da repetição “j”; $j=1, \ldots, \mathrm{J}$; 
$\mathrm{e}_{\mathrm{ij}}$ : erro experimental associado à parcela “ij”, admitido ser independente e com distribuição normal de média zero e variância $\sigma^{2}$.

Antes de proceder às análises conjuntas por ano, foi realizado o teste de homogeneidade de variâncias, obedecendo ao critério de relação máxima igual a 7 para o quociente entre o maior e menor quadrados médios do erro (Cruz \& Regazzi, 1994). Em seguida, realizou-se uma análise conjunta de variância para cada CM reunindo os três locais, dentro de cada ano, tendo como principal objetivo determinar possíveis interações de linhagens com locais. O modelo matemático utilizado foi de acordo com a equação 3 a seguir:

$$
\mathrm{Y}_{\mathrm{ijl}}=\mu+\mathrm{g}_{\mathrm{i}}+\mathrm{l}_{1}+\mathrm{r} / \mathrm{l}_{\mathrm{j} / 1}+\mathrm{gl}_{\mathrm{il}}+\mathrm{e}_{\mathrm{ijl}}
$$

sendo:

$Y_{\mathrm{ijl}}$ : observação do genótipo “i”, na repetição “j”, no local "l”;

$\mu$ : média geral do caráter;

$\mathrm{g}_{\mathrm{i}}$ : efeito fixo da linhagem "i";

$\mathrm{l}_{1}$ : efeito fixo do local "l";

$\mathrm{r} / \mathrm{l}_{\mathrm{j} / 1}$ : efeito aleatório da repetição “j”, dentro do local "l”";

$(\mathrm{gl})_{\mathrm{il}}$ : efeito fixo da interação entre a linhagem "i" e o local "l";

$\mathrm{e}_{\mathrm{ij} 1}$ : erro aleatório experimental médio associado à parcela "ijl”, admitido ser independente e com distribuição normal de média zero e variância $\sigma^{2}$.

Por último, foi realizada uma análise de variância conjunta envolvendo o efeito de anos, tendo como principal objetivo determinar possíveis interações de linhagens com locais e anos. O esquema da análise de variância é apresentado no Apêndice 10 e o modelo matemático utilizado foi de acordo com a equação 4 a seguir:

$$
\mathrm{Y}_{\mathrm{ijlm}}=\mu+\mathrm{g}_{\mathrm{i}}+\mathrm{a}_{\mathrm{m}}+\mathrm{l}_{1}+(\mathrm{b} / \mathrm{a}) / \mathrm{l}_{(\mathrm{j} / \mathrm{m}) / 1}+\mathrm{ga}_{\mathrm{im}}+\mathrm{gl}_{\mathrm{il}}+\mathrm{la}_{\mathrm{lm}}+\mathrm{gla}_{\mathrm{ilm}}+\mathrm{e}_{\mathrm{ijlm}}
$$

em que: 
$Y_{\mathrm{ijlm}}$ : observação do genótipo “i”, na repetição “j”, no local "l”, no ano “m”;

$\mu$ : média geral do caráter;

$\mathrm{g}_{\mathrm{i}}$ : efeito fixo da linhagem "i";

$\mathrm{l}_{1}$ : efeito fixo do local "l";

$\mathrm{a}_{\mathrm{m}}$ : efeito aleatório do ano "m";

$(\mathrm{b} / \mathrm{a}) / \mathrm{l}_{\mathrm{j} / \mathrm{m}) / \mathrm{l}}$ : efeito aleatório do bloco "j" dentro do ano "m" dentro do local "l";

ga $_{\text {im }}$ : efeito aleatório da interação entre a linhagem "i”" e o ano "m";

$\mathrm{gl}_{\mathrm{il}}$ : efeito fixo da interação entre a linhagem "i" e o local "l";

$\mathrm{la}_{\mathrm{lm}}$ : efeito aleatório da interação entre o local "l" e o ano "m";

gla $_{\text {ilm: }}$ : efeito aleatório da interação entre a linhagem "i”", o local "l” e o ano "m";

$\mathrm{e}_{\mathrm{ijlm}}$ : erro aleatório experimental médio associado à parcela "ijlm”, admitido ser independente e com distribuição normal de média zero e variância $\sigma^{2}$.

Todas as análises de variância foram realizadas utilizando-se o procedimento GLM do programa SAS (STATISTICAL ANALYSIS SYSTEM) (SAS INSTITUTE, 1997).

\subsubsection{Análise de médias}

Foi utilizado o teste de Dunnet a $5 \%$ de probabilidade para comparação das médias de cada linhagem com a média geral das testemunhas. Para a estimativa da média geral das testemunhas tomou-se apenas aquelas que eram comuns a todos os anos agrícolas. Também foi calculada a porcentagem da média individual de cada linhagem em relação à média geral das linhagens e das testemunhas, dentro de cada CM.

\subsubsection{Análise de adaptabilidade e de estabilidade fenotípica}

Para a análise da adaptabilidade e de estabilidade fenotípica das linhagens, considerou-se como ambiente, a combinação de ano e local. Assim, pela combinação 
dos três locais (Anhembi, Areão e ESALQ) com os quatro anos agrícolas (1996/97, 1997/98, 1998/99 e 1999/00), obteve-se 12 ambientes por CM, quais sejam: Anhembi1996/97 (AN96), Anhembi-1997/98 (AN97), Anhembi-1998/99 (AN98), Anhembi1999/00 (AN99), Areão-1996/97 (AR96), Areão-1997/98 (AR97), Areão-1998/99 (AR98), Areão-1999/00 (AR99), ESALQ-1996/97 (ES96), ESALQ-1997/98 (ES97), ESALQ-1998/99 (ES98) e ESALQ-1999/00 (ES99). A análise foi realizada com as médias de cada ambiente.

Utilizou-se três metodologias para avaliar a adaptabilidade e estabilidade das linhagens: ecovalência (Wricke \& Weber, 1986), regressão linear simples (Eberhart \& Russel (1966) e AMMI (Additive Main effects and Multiplicative Interaction)(Zobel et al., 1988)

A ecovalência é estimada através da partição da soma de quadrados da interação G x E. Assim, para cada genótipo é estimada sua contribuição para a interação total, através da soma de quadrados da interação envolvendo todos os ambientes onde ele foi avaliado. A partição da soma de quadrados da interação $G \times \mathrm{E}$ é estimada de acordo com a equação 5 a seguir:

$$
\omega_{\mathrm{i}}=\sum_{\mathrm{j}=1}^{\mathrm{n}}(\mathrm{ge})_{\mathrm{ij}}^{2}
$$

sendo ge estimado de acordo com a equação 6 a seguir:

$$
(\text { ge })_{i j}=Y_{i j}-\bar{Y}_{i .}-\bar{Y}_{. j}-\bar{Y}_{.}
$$

em que:

$$
\begin{aligned}
& \mathrm{Y}_{\mathrm{i} j} \text { : é a média do genótipo "ij" no ambiente “j”; } \\
& \overline{\mathrm{Y}}_{\mathrm{i} .} \text { : é a média do genótipo “i”" em todos os ambientes; } \\
& \overline{\mathrm{Y}}_{\mathrm{j}} \text { : é a média do ambiente “j” para todos os genótipos; } \\
& \overline{\mathrm{Y}}_{\text {.. }} \text { : é a média geral. }
\end{aligned}
$$

O somatório dos $\omega_{\mathrm{i}}$ corresponde ao valor da soma de quadrados da interação $\mathrm{G}$ x E. Dessa forma, é possível calcular a porcentagem da interação $\mathrm{G}$ x E devida a cada genótipo $\left(\omega_{\mathrm{i}} \%\right)$, dada pela equação 7 a seguir: 


$$
\varpi_{i} \%=\left(\varpi_{i} / \sum_{i} \varpi_{i}\right) \times 100
$$

Quanto menores os valores de $\omega_{\mathrm{i}}$ e $\omega_{\mathrm{i}} \%$, mais estáveis serão os genótipos.

O método de Eberhart \& Russel (1966) baseia-se na análise de regressão linear simples. O coeficiente de regressão linear $\left(\beta_{\mathrm{i}}\right.$ ou $\left.\mathrm{b}_{\mathrm{i}}\right)$ é utilizado como padrão de resposta do comportamento do genótipo aos diferentes ambientes, juntamente com a média (adaptabilidade), e a estabilidade de cada genótipo é avaliada através da variância dos desvios de regressão $\left(\delta_{\mathrm{ij}}\right.$ ou $\left.\mathrm{s}_{\mathrm{di}}^{2}\right)$. O esquema da análise de variância é apresentado no Apêndice 11. O modelo matemático é de acordo com a equação 8 a seguir:

$$
Y_{i j}=\mu_{i}+\beta_{i} I_{j}+\delta_{i j}+\varepsilon_{i j}
$$

sendo:

$Y_{\mathrm{ij}}$ : a média do genótipo "i”" no ambiente “j”;

$\mu_{\mathrm{i}}$ : a média do genótipo "i" em todos os ambientes;

$\beta_{\mathrm{i}}$ : o coeficiente de regressão linear, que descreve a resposta do genótipo "i" a todos os ambientes;

$\mathrm{I}_{\mathrm{j}}$ : o índice ambiental;

$\delta_{\mathrm{ij}}$ : o desvio da regressão do genótipo “i” no ambiente “j”;

$\varepsilon_{\mathrm{ij}}$ : o erro associado à média.

O parâmetro de adaptabilidade $\left(b_{\mathrm{i}}\right)$ é estimado de acordo com a equação 9 a seguir:

$$
\mathrm{b}_{\mathrm{i}}=\sum_{\mathrm{j}=1}^{\mathrm{n}} \mathrm{Y}_{\mathrm{ij}} \mathrm{I}_{\mathrm{j}} / \sum_{\mathrm{j}=1}^{\mathrm{n}} \mathrm{I}_{\mathrm{j}}^{2}
$$

sendo:

$Y_{\mathrm{ij}}$ : a média do genótipo "i”" no ambiente “j”;

$\mathrm{I}_{\mathrm{j}}$ : o índice ambiental, e é estimado de acordo com a equação 10 a seguir: 


$$
I_{j}=\left[\left(Y_{. j} / p\right)-\left(Y_{. .} / p n\right)\right]
$$

tal que, de acordo com a equação 11 a seguir:

$$
\sum_{j=1}^{n} I j=0
$$

sendo:

$Y_{. j}$ : a média de todos os genótipos no ambiente "j";

Y..: a média geral;

n: o número de genótipos;

p: o número de ambientes.

As estimativas para $b_{1}$ foram testadas segundo a hipótese $H_{b}: b_{1}=1$, sendo $a$ hipótese alternativa $\mathrm{H}_{\mathrm{a}}: \mathrm{b}_{\mathrm{i}} \neq 1$, utilizando a estatística $\mathrm{t}$, dada pela equação 12 a seguir:

$$
\mathrm{t}=\left[\left(\mathrm{b}_{\mathrm{i}}-1\right) /\left(\sqrt{\mathrm{QMD}_{\mathrm{i}} / \mathrm{SQI}_{\mathrm{j}}}\right)\right.
$$

O parâmetro de estabilidade $\left(\mathrm{s}^{2} \mathrm{~d}_{\mathrm{i}}\right)$ foi estimado de acordo com a equação 13 a seguir:

$$
\mathrm{s}^{2} \mathrm{~d}_{\mathrm{i}}=\left[\left(\mathrm{QMD}_{\mathrm{i}}\right)(\mathrm{QMR} / \mathrm{r})\right]
$$

em que:

$\mathrm{QMD}_{\mathrm{i}}$ : é o quadrado médio dos desvios da regressão do genótipo "i”;

QMR: é o quadrado médio do resíduo;

r: é o número de repetições.

As estimativas para $\mathrm{s}_{\mathrm{di}}^{2}$ foram testadas segundo a hipótese $\mathrm{H}_{\mathrm{b}}: \mathrm{s}^{2} \mathrm{~d}_{\mathrm{i}}=0$ versus $H_{a}: s^{2} d_{i} \neq 0$, utilizando o teste $F$, dado pela equação 14 a seguir:

$$
\mathrm{F}=\left(\mathrm{QMD}_{\mathrm{i}} / \mathrm{QMR}\right)
$$


Segundo Cruz \& Regazzi (1994), algumas vezes pode ocorrer que muitos genótipos com produtividades médias superiores apresentem $\mathrm{s}^{2} \mathrm{~d}_{\mathrm{i}}$ estatisticamente diferente de zero. Porém, pode ser necessária a seleção de alguns genótipos do grupo em que a estabilidade é baixa. Nesses casos, uma medida auxiliar de comparação entre genótipos é o coeficiente de determinação $\mathrm{R}_{\mathrm{i}}{ }^{2}$, dado pela equação 15 a seguir:

$$
\mathrm{R}_{\mathrm{i}}^{2}=\left[(\mathrm{SQR} . \text { Linear })_{\mathrm{i}} / \mathrm{SQ}\left(\mathrm{A} / \mathrm{G}_{\mathrm{i}}\right)\right] \times 100
$$

sendo:

(SQR.linear) $)_{\mathrm{i}}$ : a soma de quadrados da regressão linear do genótipo "i”;

$\mathrm{SQ}\left(\mathrm{A} / \mathrm{G}_{\mathrm{i}}\right)$ : a soma de quadrados de ambientes dentro do genótipo 'i'.

A análise AMMI foi realizada em duas etapas sequienciais: 1) os efeitos principais, na parte aditiva (média geral, efeitos de genótipos e ambientes), foram ajustados por análise de variância (ANAVA), resultando em um resíduo de não aditividade (interação $G$ x E) e 2) a interação (parte multiplicativa do modelo) foi analisada pela Análise de Componentes Principais (ACP). O esquema da análise de variância é apresentado no Apêndice 12. O modelo geral foi de acordo com aquele apresentado por Duarte \& Vencovsky (1999), segundo a equação 16 a seguir:

$$
\mathrm{Y}_{\mathrm{ij}}=\mu+\mathrm{g}_{\mathrm{i}}+\mathrm{e}_{\mathrm{j}}+\sum_{\mathrm{k}=1}^{\mathrm{n}} \lambda_{\mathrm{k}} \gamma_{\mathrm{ik}} \alpha_{\mathrm{jk}}+\rho_{\mathrm{ij}}+\varepsilon_{\mathrm{ij}}
$$

sendo:

$\mu$ : a média geral;

$\mathrm{g}_{\mathrm{i}}$ : o efeito principal do genótipo “i”;

$\mathrm{e}_{\mathrm{j}}$ : o efeito principal do ambiente " $\mathrm{j}$ ";

$\varepsilon_{\mathrm{ij}}$ : erro experimental médio.

A interação $G$ x E foi modelada de acordo com a equação 17 : 


$$
\sum_{\mathrm{k}=1}^{\mathrm{n}} \lambda_{\mathrm{k}} \gamma_{\mathrm{ik}} \alpha_{\mathrm{jk}}+\rho_{\mathrm{ij}}
$$

em que:

$\lambda_{\mathrm{n}}$ : é o autovalor do n-ésimo componente principal da interação (CPI) retido no modelo AMMI;

$\gamma_{\text {in }}$ : é o autovetor do i-ésimo genótipo no n-ésimo CPI;

$\alpha_{\mathrm{jk}}$ : é o autovetor do j-ésimo ambiente no n-ésimo CPI;

$\rho_{\mathrm{ij}}$ : o resíduo da interação G x E ou resíduo AMMI;

n: o número de CPI's retidos no modelo;

O objetivo da análise é resumir grande parte da interação G x E em apenas uns poucos eixos ( $\mathrm{SQ}_{\mathrm{GxE}}$ Padrão), consumindo assim, poucos graus de liberdade, resultando num modelo reduzido, que descarta um resíduo adicional ( $\mathrm{SQ}_{\mathrm{GxE}}$ Ruídos). Um dos procedimentos mais usuais para a definição do número de eixos a serem retidos, consiste em determinar os graus de liberdade associados à parcela da $\mathrm{SQ}_{\mathrm{GxE}}$ relacionada a cada membro da família de modelos AMMI (AMMI0, AMMI1, ...,AMMIn). Obtém-se, então, o quadrado médio (QM) correspondente a cada modelo. Em seguida, é obtido um teste $F$ avaliando a significância de cada componente em relação ao QM Erro Médio. Dessa forma, o ponto de parada que determina a seleção do modelo, baseia-se na significância do teste $F$ para os sucessivos termos da interação. O resíduo AMMI, reunindo os demais termos da $\mathrm{SQ}_{\mathrm{GxE}}$ (não retidos no modelo selecionado), também pode ser testado de maneira a assegurar o seu caráter desprezível, como é o caso do teste $F_{R}$ (Cornelius et al., 1992; Piepho, 1995) utilizado no presente trabalho e descrito pela equação 18 a seguir: sendc.

$$
\mathrm{F}_{\mathrm{R}, \mathrm{n}}=\left(\mathrm{SQ}_{\mathrm{GxE}}-\sum_{\mathrm{k}=1}^{\mathrm{n}} \lambda_{\mathrm{k}}^{2}\right) /\left(\mathrm{f}_{2} \cdot \mathrm{QM}_{\text {ErroMédio }}\right) ; \quad \text { com: } \mathrm{f}_{2}=(\mathrm{g}-1-\mathrm{n})(\mathrm{a}-1-\mathrm{n})
$$

$\mathrm{f}_{2}$ : o número de graus de liberdade associados a cada parcela da interação $\mathrm{G}$ x E, definidos por Gollob (1968). 
Os resultados da análise são apresentados graficamente em biplot (Gabriel, 1971). Para os casos em que o modelo engloba apenas o primeiro eixo da análise de componentes principais da interação ACPI (CPI1), foi construído o biplot AMMI1, que utiliza o eixo das abscissas para representar os efeitos principais (médias de genótipos e de ambientes) e o das ordenadas para expressar os escores de genótipos e ambientes referentes ao CPI 1. Para os demais casos (modelos que englobam mais de um eixo da ACPI), foi utilizado o biplot AMMI2, que representa somente efeitos de interação referentes aos dois primeiros eixos da ACPI: CPI 1 vs. CPI 2.

A interpretação de um biplot quanto à interação G x E é feita observando-se a magnitude e o sinal dos escores de genótipos e ambientes para o(s) eixo(s) que representam a interação. Assim, os escores baixos (próximos de zero) são próprios de genótipos e ambientes que contribuem pouco para a interação, caracterizando-os como estáveis. Num biplot AMMI1, a estabilidade é avaliada inspecionando-se as ordenadas (CPI 1). Logo, os pontos situados na faixa horizontal em torno de zero em relação ao CPI 1 correspondem aos genótipos e ambientes mais estáveis. Num biplot AMMI2, genótipos e ambientes estáveis são aqueles cujos pontos situam-se próximo à origem, ou seja, com escores praticamente nulos para os dois eixos da interação (CPI1 e CPI2) (Duarte \& Vencosky, 1999).

As relações adaptativas podem ser facilmente percebidas num biplot AMMI observando-se os sinais dos escores para cada par de genótipos e ambientes. Assim, genótipos e ambientes com escores de mesmo sinal $(-,-$ ou,++$)$ devem interagir positivamente. Já aqueles com sinais opostos $(+,-)$ devem interagir negativamente (Duarte \& Vencovsky, 1999). Tem-se observado em alguns trabalhos que nem sempre essa relação se mostra perfeitamente interpretável graficamente. Assim, para maior segurança, confirmou-se tal relação adaptativa pelo uso de tabelas auxiliares (Tabelas 29 a 38) mostrando as médias preditas pelo modelo AMMI selecionado, para cada combinação de genótipo e ambiente.

No presente estudo, como os ambientes representam um mesmo local em diferentes anos, valores baixos para o(s) eixo(s) de interação indicam que a classificação de genótipos de um ano para outro, neste local, é pouco variável, resultando numa 
classificação mais consistente. Uma maior repetibilidade da classificação, ao longo dos anos, está associada a uma maior confiabilidade na seleção de genótipos (Duarte \& Vencovsky, 1999).

Com o propósito de complementar as interpretações da análise AMMI, foi feito o cálculo do parâmetro $\mathrm{A}_{\mathrm{i}}$, segundo a equação 19 a seguir:

$$
\mathrm{A}_{\mathrm{i}}=\sum_{\mathrm{j}=1}^{\mathrm{n}}\left(\mathrm{GxE}_{\mathrm{AMMIn}}\right)_{\mathrm{ij}}^{2}
$$

sendo:

$\mathrm{A}_{\mathrm{i}}$ : a interação predita para a linhagem "i”" pelo modelo AMMIn selecionado;

A interação $\mathrm{GxE}_{\mathrm{AMMIn}}$ foi estimada de acordo com a equação 20 a seguir:

$\left(\mathrm{GxE}_{\mathrm{AMMIn}}\right)_{\mathrm{ij}}=\mathrm{Y}_{\mathrm{ij}}-\overline{\mathrm{Y}}_{\mathrm{i} .}-\overline{\mathrm{Y}}_{\mathrm{j}}-\overline{\mathrm{Y}}_{.}$

sendo:

$\mathrm{Y}_{\mathrm{ij}}$ : a média do genótipo "i”" no ambiente "j" predita pelo modelo AMMIn selecionado;

$\overline{\mathrm{Y}}_{\mathrm{i}}$ : a média do genótipo “i” predita pelo modelo AMMIn selecionado;

$\bar{Y}_{. j}$ : a média do ambiente "j" predita pelo modelo AMMIn selecionado;

$\overline{\mathrm{Y}}_{\mathrm{Y}}$ : a média geral predita pelo modelo AMMIn selecionado.

O somatório dos $A_{\mathrm{i}}$ corresponde à soma de quadrados da interação $\mathrm{GxE}$ predita pelo modelo AMMIn selecionado. Dessa forma, é possível calcular, para cada linhagem, a porcentagem da interação GxE predita pelo modelo AMMIn ( $\left.\mathrm{A}_{\mathrm{i}} \%\right)$, pela equação 21 a seguir:

$$
\mathrm{A}_{\mathrm{i}} \%=\left(\mathrm{A}_{\mathrm{i}} / \sum_{\mathrm{i}} \mathrm{A}_{\mathrm{i}}\right) \times 100
$$


Também foram calculados coeficientes de determinação para computar a influência relativa das fontes de variação (linhagens (G), ambientes (E) e interação $G$ x E) sobre a variação total entre tratamentos (equação 22); a proporção da interação $\mathrm{G}$ x E explicada pela regressão linear de Eberhart \& Russel (equação 23); e a proporção determinada pelos CPIs da análise AMMI em relação à interação G x E (equação 24), como se segue:

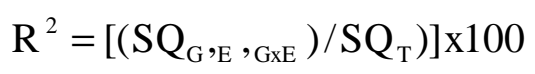

sendo:

$\mathrm{SQ}_{\mathrm{G}}$ : a soma de quadrados de linhagens;

$\mathrm{SQ}_{\mathrm{E}}$ : a soma de quadrados de ambientes;

$\mathrm{SQ}_{\mathrm{GxE}}$ : a soma de quadrados da interação $\mathrm{G}$ x E;

$\mathrm{SQ}_{\mathrm{T}}$ : a soma de quadrados de tratamentos.

$$
\mathrm{R}^{2}=\left[\left(\mathrm{SQ}_{\mathrm{G}_{\mathrm{BE} \text { linear }}}\right) / \mathrm{SQ}_{(\mathrm{A} / \mathrm{G})}\right] \mathrm{x} 100
$$

sendo:

SQGxElinear: a soma de quadrados da interação Gx E linear;

$\mathrm{SQ}_{(\mathrm{A} / \mathrm{G})}$ : soma de quadrados de ambientes dentro de genótipo;

$$
\mathrm{R}^{2}=\left[\mathrm{SQ}_{\mathrm{CPIn}} / \mathrm{SQ}_{\mathrm{GXE}}\right] \mathrm{x} 100
$$

sendo:

$\mathrm{SQ}_{\mathrm{CPIn}}$ : soma de quadrados do componente principal da interação n;

$\mathrm{SQ}_{\mathrm{GxE}}$ : soma de quadrados da interação $\mathrm{G}$ x E.

A análise AMMI foi realizada utilizando os procedimentos GLM e IML do programa computacional SAS (SAS INSTITUTE, 1997), de acordo com o programa sugerido por Duarte \& Vencovsky (1999). Para as metodologias da ecovalência (Wricke 
\& Webber, 1986) e Eberhart \& Russel (1966), utilizou-se os programas computacionais GENES (Cruz, 1997) e ESTABILIDADE (Universidade Federal de Lavras, 2000).

\subsubsection{Análise de correlação}

A comparação entre parâmetros fornecidos pelas três metodologias foi realizada através de um estudo de correlações de Spearman entre as classificações das linhagens, de acordo com cada uma das metodologias. Para efeito de classificação quanto à adaptabilidade e estabilidade, adotou-se os seguintes parâmetros: média $\left(\mathrm{m}_{\mathrm{i}}\right)$, coeficiente de regressão $\left(b_{i}\right)$, ecovalência $\left(\omega_{i}\right)$, variância dos desvios da regressão $\left(s^{2} d_{i}\right)$, coeficiente de determinação $\left(\mathrm{R}^{2}\right)$ e a interação predita pelo modelo $A M M I n$ selecionado $\left(\mathrm{A}_{\mathrm{i}}\right)$.

O coeficiente de correlação de Spearman é baseada na correlação entre o número de ordem de cada linhagem na classificação de acordo com os parâmetros de adaptabilidade e estabilidade, estimado conforme a equação 25 apresentada por Miranda (1999), descrita a seguir:

$$
\mathrm{r}_{\mathrm{S}}=1-\left[6 \sum\left(\mathrm{r}_{\mathrm{ij}}-\mathrm{r}_{\mathrm{ij}}\right)^{2} / \mathrm{g}\left(\mathrm{g}^{2}-1\right)\right]
$$

sendo:

$\mathrm{r}_{\mathrm{S}}$ : o coeficiente de correlação de Spearman:

$\mathrm{r}_{\mathrm{ij}}$ : a ordem de classificação do genótipo i pelo parâmetro j;

$\mathrm{r}_{\mathrm{ij}}$ : a ordem de classificação do genótipo i pelo parâmetro j’;

g: o número de pares $\left(\mathrm{r}_{\mathrm{ij}}, \mathrm{r}_{\mathrm{ij}}{ }^{\prime}\right)$, que é igual ao número de genótipos.

A análise de correlação de Spearman foi realizada através do procedimento COR do programa computacional SAS (SAS INSTITUTE, 1997). 


\section{RESULTADOS E DISCUSSÃO}

\subsection{Considerações iniciais}

O manejo dos experimentos transcorreu normalmente nos três locais e quatro anos agrícolas para os quatros ciclos de maturação (CM). Com relação aos fatores abióticos, as propriedades físicas e químicas dos solos dos três locais são mostradas no Apêndice 2; já os fatores climáticos, tais como, fotoperíodo, temperatura, umidade relativa e pluviosidade, ocorridos nos quatro anos agrícolas, são apresentados no Apêndice 3.

De acordo com o critério utilizado para a interpretação de análises de solos para o Estado de São Paulo (Apêndice 4), os locais Anhembi e ESALQ exibiram pH baixo e médio (6,0 e 5,4; respectivamente), o que favorece ao bom desenvolvimento das plantas. Já o local Areão mostrou pH alto $(4,3)$, condição essa estressante para o desenvolvimento das plantas; o relevo acidentado deste último local favoreceu o movimento de terra durante as chuvas, fato este que provocou diminuição do estande de plantas em algumas parcelas.

No que diz respeito às condições climáticas, no geral, o fotoperíodo não apresentou variações significativas, dentro e entre anos agrícolas, sendo maior o número de horas de luz nos meses de novembro, dezembro, março e abril, e menor nos meses de janeiro e fevereiro. A semeadura realizada em diferentes dias, para os três locais, não deve ter levado a influências significativas do fotoperíodo sobre o número de dias para o florescimento, uma vez que os três locais pertencem a uma mesma latitude e que as semeaduras ocorreram sempre no mês de novembro, época considerada normal para o cultivo da soja no Estado de São Paulo. Segundo Bonato et al. (1998), independente do 
$\mathrm{CM}$, o fotoperíodo influi mais na produtividade quando a semeadura ocorre fora da época normal de cultivo, como é o caso das semeaduras realizadas no mês de dezembro, já que ocorre redução do tempo para o florescimento, em razão do encurtamento dos dias que se verifica a partir de 22 de dezembro.

Quanto à pluviosidade, observou-se uma maior quantidade de chuvas no período de condução dos experimentos (novembro-abril) nos anos agrícolas 1997/98 (1.128mm) e 1998/99 (1.203mm), sendo menor nos anos agrícolas de 1996/97 (935 mm) e 1999/00 (981 mm). Vale ressaltar que o ano agrícola de 1998/99 coincidiu com a presença do fenômeno "El Niño", caracterizado para as condições brasileiras por ventos fortes, chuvas freqüentes, intensas e associadas a elevadas temperaturas durante os meses de dezembro a março nas regiões Sul e Sudeste. Na latitude de Piracicaba - SP, os meses de dezembro de 1998, janeiro, fevereiro e março de 1999, caracterizaram-se pela ocorrência de chuvas torrenciais, freqüentes e por temperaturas elevadas. Estas condições favoreceram o crescimento das plantas de soja, mas contribuíram para aumentar o acamamento, principalmente nas LI e LST, que também apresentaram em média valores maiores para APM, relativamente às LP e LSP (Tabelas 9 e 10).

Entre os fatores bióticos importantes que ocorreram no período de condução dos experimentos, pode-se citar o alto índice de infestação do cancro-da-haste da soja (CHS) nos locais Areão e ESALQ no agrícola de 1996/97 (Rocha, 1998) e presença do complexo de percevejos (Nezara viridula, Piezodorus guildini e Euchistos heros) em todos os locais, com maior nível de população no local Areão, no ano agrícola de 1997/98.

De modo a facilitar a denominação dos ambientes (combinação de ano e local), optou-se pelo uso de abreviações, sendo daqui em diante utilizadas as seguintes siglas: Anhembi 1996/97 (AN96), Anhembi 1997/98 (AN97), Anhembi 1998/99 (AN98), Anhembi 1999/00 (AN99), Areão 1996/97 (AR96), Areão 1997/98 (AR97), Areão 1998/99 (AR98), Areão 1999/00 (AR99), ESALQ 1996/97 (ES96), ESALQ 1997/98 (ES97), ESALQ 1998/99 (ES98) e ESALQ 1999/00 (ES99). 


\subsection{Análise de variância para as testemunhas}

Os resultados obtidos nas análises de variâncias realizadas para as testemunhas comuns, são apresentados nas Tabelas 1, 2, 3 e 4. Serão discutidas somente as análises conjuntas/ano e conjunta geral. Para as linhagens precoces (LP), semiprecoces (LSP) e semitardias (LST), as análises conjuntas foram realizadas considerando os três primeiros anos agrícolas (1996/97, 1997/98 e 1998/99), já que as testemunhas não eram comuns a todos os anos, visto que no ano agrícola 1999/00 algumas testemunhas foram substituídas (testemunhas que mostraram suscetibilidade ao CHS); assim, para esse ano, fez-se uma análise conjunta envolvendo somente o efeito de locais. Para as linhagens intermediárias (LI), a análise conjunta foi realizada envolvendo os quatro anos agrícolas, já que as testemunhas eram comuns a todos os anos.

Os efeitos de conjuntos experimentais e da interação conjuntos $\mathrm{x}$ testemunhas foram não significativos pelo teste $F$ para todos os caracteres e CM. As interações entre conjuntos experimentais com locais e anos também foram testadas, como não exibiram significância, estas foram reunidas com o resíduo. Isto indica que a estratificação dos tratamentos em conjuntos experimentais mostrou-se ineficiente, evidenciando a existência de efeitos pouco pronunciados de conjuntos experimentais dentro das repetições. Assim, a exemplo de Soldini (1993), Rocha (1998) e Unêda-Trevisoli (1999), optou-se por ignorar a estratificação em conjuntos, realizando-se as análises com base no modelo de blocos completos casualizados. Resultado diferente foi obtido no trabalho de Miranda (1999), no qual a análise de testemunhas foi eficiente em detectar diferenças entre conjuntos dentro das repetições, sendo necessário fazer a correção das médias das linhagens em função da média das testemunhas dentro de cada conjunto.

\subsection{Análise de variância para as linhagens}

Ignorando-se o efeito de conjuntos experimentais, procedeu-se às análises de variância para as linhagens experimentais, considerando somente os efeitos de repetições, locais e anos como fontes de variação ambiental. 


\subsubsection{Análises individuais}

As análises de variância individuais são apresentadas nas Tabelas 5, 6, 7 e 8. Em relação as LP, foi detectada diferença entre linhagens em um maior número de ambientes (local e ano) para os caracteres NDM, APM, Ac, PG e \%OL, sendo em menor número para os caracteres VA e PO. As LP exibiram variabilidade para todos os caracteres em todos os ambientes, exceto para PG (ES97 e ES98) e PO (ES98). No que diz respeito às LI, foram detectadas diferenças entre linhagens para a maioria dos caracteres, sendo menores para os caracteres PG e PO. As LST apresentaram maior número de casos com detecção de diferenças entre linhagens, principalmente para os caracteres Ac, VA e \%OL nos três últimos anos agrícolas. No caso das LST, isto se deve, provavelmente, ao fato destas terem passado por uma maior intensidade de seleção, relativamente aos demais CM, no período de avaliação, como mostra o Apêndice 1. A alta suscetibilidade ao cancro da haste da soja (CHS) foi um dos principais motivos para o descarte de muitas linhagens, relativamente aos demais CM, que apresentaram ausência ou baixo nível de danos ao CHS, segundo uma avaliação realizada ao nível de campo, sob infestação natural, nos locais Areão e ESALQ na safra 1996/97 por Rocha (1998).

Quanto à precisão experimental verificada nos ambientes avaliados, os caracteres apresentaram os seguintes intervalos para o coeficiente de variação experimental (C.V.):

LP: NDM (0,76-2,34\%), APM (5,84-13,22\%), Ac (6,30-12,30\%), VA (4,03$13,42 \%)$, PG (11,32-25,92\%), \%OL $(2,74-7,56 \%)$ e PO (13,01-27,41\%);

LSP: NDM (0,88-2,54\%), APM (5,66-13,28\%), Ac (5,47-9,09\%), VA (3,90$8,66 \%)$, PG (11,40-24,29\%), \%OL (2,18-5,44\%) e PO (12,56-24,30\%);

LI: NDM (0,74-2,26\%), APM (7,02-15,25\%), Ac (5,84-10,55\%), VA $(3,98-$ 8,09\%), PG (13,20-30,21\%), \%OL (2,34-6,15\%) e PO (13,52-31,07\%);

LST: NDM (0,42-1,74\%), APM (2,65-16,43\%), Ac (5,08-12,38\%), VA $(2,41-$ $11,75 \%)$, PG $(9,68-30,13 \%), \%$ OL $(2,13-6,60 \%)$ e PO $(9,41-29,49 \%)$. 
A precisão experimental variou entre locais e anos, sendo maior nos locais Anhembi e ESALQ e nos anos agrícolas 1998/99 e 1999/00. Observa-se que os caracteres NDM, APM, Ac, VA e \%OL mostraram maior precisão experimental, sendo esta menor para PG e PO. Isto sugere que a influência de causas não aleatórias foi maior nesses caracteres, comparativamente aos demais, talvez em funções desses caracteres apresentarem herança mais simples, sendo, portanto, pouco influenciados pelo ambiente. Esses valores estão coerentes com os encontrados na literatura em experimentos dessa natureza, como os conduzidos por Soldini (1993), Laínez-Mejía (1996), Rocha (1998) e Unêda-Trevisoli (1999).

Com relação às médias, os locais Anhembi e ESALQ foram mais favoráveis para a expressão de todos os caracteres agronômicos avaliados, exceto para Ac. Se por um lado o local Areão foi desfavorável para APM, por outro, foi favorável para baixa incidência de acamamento das plantas. Essa tendência ocorrida nos anos agrícolas de 1997/98, 1998/99 e 1999/00, concorda com aquela obtida por Rocha \& Vello (1999) em uma avaliação conduzida nos mesmos locais no ano agrícola 1996/97.

\subsubsection{Análises conjuntas por ano agrícola}

As análises de variância conjuntas/ano são apresentadas nas Tabelas 9 e 10. Foram observadas diferenças entre linhagens pelo teste $\mathrm{F}$ para a maioria dos caracteres em todos os CM e anos agrícolas, exceto para as LP, no caráter VA (1998/99) e LST, nos caracteres Ac, VA (1997/98, 1998/99, 1999/00), PG, \%OL e PO (1998/99 e 1999/00). Assim, as LSP e LI apresentam maior variabilidade que as LP e LST; portanto, aquelas apresentam maiores probabilidades de ganhos genéticos em ciclos adicionais de seleção. Os locais também variaram para a maior parte dos caracteres e CM e foi responsável pela maior parte da variação de tratamentos.

A interação genótipos $\mathrm{x}$ locais $(\mathrm{G} \times \mathrm{L})$ foi significativa pelo teste $\mathrm{F}$, dentro de anos, para a maior parte dos caracteres e CM, exceto nas LP: Ac (1996/97), \%OL (1997/98), APM, Ac e \%OL (1998/99), VA, PG, \%OL e PO (1999/00); LSP: NDM e 
PG (1998/99), Ac, VA e \%OL (1999/00); LI: Ac e \%OL (1996/97), APM, PG e PO (1997/98), \%OL (1998/99), APM e VA (1999/00); LST: APM (1996/97), APM, Ac, VA e \%OL (1997/98), APM, Ac, VA, PG, \%OL e PO (1998/99 e 1999/00). Os resultados indicam que as LP, LSP e LI apresentaram interação G x L de maior magnitude, portanto mais complexa. As LST interagiram menos com os locais para a maior parte dos caracteres, principalmente nos anos agrícolas 1998/99 e 1999/90. O caráter \%OL tende a ser mais estável com os locais, concordando com os resultados reportados por Soldini (1993), Laínez-Mejía (1996) e Rocha (1998). No geral, as linhagens apresentaram comportamento diferencial com os locais, indicando a necessidade de se considerar o local específico para efeito de seleção e recomendação.

Maiores médias para PG e PO foram obtidas pelas LP, LSP, LI, enquanto que as LST apresentaram as menores médias em todos os anos agrícolas. Para as LP, LSP e LI, o ano agrícola 1997/98 foi o mais favorável, já para LST foi 1998/99. O ano agrícola de 1996/97 tendeu a não favorecer esses caracteres em todos os CM. Uma explicação provável para este último fato diz respeito à alta incidência de CHS neste ano e à presença de um grande número de linhagens altamente suscetíveis, que contribuíram negativamente para a produtividade média. Um outro aspecto foi a seleção praticada após os anos agrícolas 1996/97 e 1997/98, que contribuiu para aumentar a média das linhagens para esses caracteres nos anos posteriores.

Os valores de CV's para cada caráter e CM ficaram dentro daqueles normalmente obtidos em experimentos dessa natureza em todos os anos agrícolas, sendo menores para os caracteres NDM, APM, Ac, VA e \%OL, e maiores para PG e PO, concordando com as análises individuais. Resultados semelhantes também foram obtidos por Rocha (1998) e Unêda-Trevisolli (1999). A precisão experimental foi mantida num mesmo nível em todos os anos agrícolas, o que contribuiu para a obtenção de boas estimativas de médias de genótipos, locais e da interação G x L. 


\subsubsection{Análises conjuntas gerais}

Os resultados da análise de variância conjunta geral para todos os caracteres e CM são mostrados na Tabela 11. De forma geral, os valores dos coeficientes de variação mostraram maior precisão experimental para os caracteres NDM, \%OL, VA, APM e Ac (1,00- 9,79\%), sendo esta precisão menor para PG e PO (17,95-26,04\%). Menor precisão experimental para esses dois últimos caracteres, comparados aos demais, mostra que os mesmos foram mais influenciados por fatores ambientais, confirmando relatos da literatura de que caracteres controlados por muitos genes são mais afetados pelo ambiente. A magnitude dos CVs está de acordo com os obtidos em estudos dessa natureza e em condições similares (Soldini, 1993; Laínez-Mejía, 1996; Rocha, 1998; Unêda-Trevisoli, 1999).

As estimativas dos CVs para os caracteres PG e PO aumentaram com o aumento dos CM, sendo menores para as LP e LSP e maiores para as LI e LST; isto sugere que a precisão diminui com o aumento do CM; provavelmente, as plantas com ciclos mais longos sofram mais influência do ambiente, já que permanecem no campo por maior período de tempo, confirmando os relatos de Rocha \& Vello (1999).

Os efeitos isolados de anos e locais foram pouco variáveis para todos os caracteres e CM. As linhagens diferiram entre si para a maior parte dos caracteres e CM, exceto para VA, PG e PO nas LST. A interação linhagens $x$ anos ( $\left.\begin{array}{lll}G & \text { A }\end{array}\right)$ foi significativa para os caracteres NDM [LP, LSP, LI $(\mathrm{P}<0,01)$ e LST $(\mathrm{P}<0,05)]$, APM [LSP $(\mathrm{P}<0,01)$ e LI $(\mathrm{P}<0,05)]$, VA [LSP e LI $(\mathrm{P}<0,01)]$, PG [LSP $(\mathrm{P}<0,01)]$, \%OL [LP, LSP $(\mathrm{P}<0,01)$ e LST $(\mathrm{P}<0,05)]$ e PO [LSP $(\mathrm{P}<0,01)]$. A interação genótipos $\mathrm{x}$ locais (G x L) foi não significativa para todos os caracteres nas LP e LST; significativa para NDM, APM, PG, \%OL e PO $(\mathrm{P}<0,05)$ nas LSP, e somente para APM $(\mathrm{P}<0,05)$ nas LI. A interação anos x locais (A x L) foi significativa para todos os caracteres e CM, exceto para APM nas LST. A interação genótipos $\mathrm{x}$ anos $\mathrm{x}$ locais $(\mathrm{G} \times \mathrm{A} \times \mathrm{x}$ ) foi significativa para todos os caracteres, exceto para APM (LI e LST), Ac (LST), VA (LST) e \%OL (LP, LSP e LST). 
Os resultados mostraram que o quadrado médio para a interação genótipos $\mathrm{x}$ locais $(\mathrm{G} x \mathrm{~L})$ foi de menor magnitude, quando comparadas às demais interações $(\mathrm{A} \times \mathrm{L}$, G x A e G x A x L), sugerindo que o efeito isolado de locais não foi forte o suficiente para provocar mudanças significativas no comportamento das linhagens. Já a interação A x L mostrou alta magnitude para os quadrados médios em todos os caracteres e CM, indicando que os locais interagiram fortemente com os anos agrícolas. Isto mostra que os efeitos de anos, provavelmente, contribuíram mais para a interação $\mathrm{G} \times \mathrm{E}$. Isto corrobora com os resultados obtidos por Toledo et al. (1990) e Alliprandini et al. (1993,1994 e 1998). Esses autores também encontraram interações A x L e G x A x L significativas, e as destacaram como fatores essenciais no planejamento de experimentos no Estado do Paraná. Becker \& León (1988) defendem o uso da combinação de locais e anos como ambientes, por melhor representar a diversidade dos fatores ambientais. De acordo com esses autores, a regressão sobre ambientes envolvendo locais e anos é mais poderosa para avaliar a estabilidade dinâmica ou agronômica.

A grande magnitude das interações associadas com anos, segundo Allard \& Bradshaw (1964), sugere que os fatores imprevisíveis de anos (temperatura, umidade relativa, pluviosidade) contribuíram mais que os fatores previsíveis de locais (tipo de solo, topografia) para a interação $G$ x E. Esses resultados foram diferentes daqueles encontrados por Kang et al. (1989), nos quais os fatores previsíveis relacionados à fertilidade diferencial de locais foram mais importantes para a interação $\mathrm{G}$ x E.

Nesse sentido, as avaliações envolvendo mais de um ano foram importantes para melhor estimar as respostas dos genótipos com os ambientes. Quando as interações de genótipos com anos são mais fortes do que com locais, o zoneamento agronômico não se mostra uma estratégia efetiva para manejar a interação G x E. Um estudo sobre a adaptabilidade e estabilidade das linhagens representa uma estratégia mais indicada nos sentido de amenizar os efeitos da interação G x E. 


\subsection{Análise de médias}

As médias e resultados do teste de Dunnet envolvendo as linhagens e testemunhas, para todos os caracteres em cada CM, são apresentados nas Tabelas 12, 13 14 e 15.

\subsubsection{Linhagens precoces}

As LP apresentaram um ciclo médio de 125 dias para NDM; $112 \mathrm{~cm}$ para APM; 1,75 para Ac; 3,29 para VA; $2.421 \mathrm{Kg} /$ ha para PG; 21,39\% para \%OL; e $517 \mathrm{Kg} / \mathrm{ha}$ para PO (Tabela 12). A comparação das médias de cada linhagem em relação à média das testemunhas, para cada caráter, indica que as linhagens foram superiores para NDM, APM, AC, PG e PO $(\mathrm{P}<0,05)$, mas foram inferiores para VA e \%OL. Maior divergência foi verificada para os caracteres Ac, NDM e APM, sendo menor para os caracteres PG, \%OL e PO. Destacaram-se as linhagens $26=$ USP 94-1086 e $21=$ USP 94-1044, que apresentaram as maiores médias $(2.894 \mathrm{Kg} / \mathrm{ha}$ e $2.708 \mathrm{Kg} / \mathrm{ha}$, respectivamente) e superioridade para PG em relação às médias das linhagens e testemunhas (21\% e $13 \%$, respectivamente). A primeira linhagem também foi superior em termos de média para PO $(596 \mathrm{Kg} / \mathrm{ha})$. Também vale ressaltar a linhagem $2=$ USP 93-1042 que reuniu boa produtividade e alto teor de óleo $(2.629 \mathrm{Kg} / \mathrm{ha}$ e 22,39\%, respectivamente), quando comparada às médias de linhagens e testemunhas. Observouse que a superioridade em PG de cada linhagem em relação à média das linhagens e das testemunhas foi semelhante $(\% \mathrm{PGl} \cong \% \mathrm{PGt})$.

\subsubsection{Linhagens semiprecoces}

Observaram-se valores médios para as LSP de 133 dias para NDM; $103 \mathrm{~cm}$ para APM; 1,74 para Ac; 3,40 para VA; $2.383 \mathrm{Kg}$ /ha para PG; 21,68\% para \%OL; e 493 $\mathrm{Kg} /$ ha para PO (Tabela 13). As linhagens diferiram em superioridade em relação às testemunhas para os caracteres NDM, APM, Ac, VA e PO, sendo inferiores para PG e 
\%OL. Maior divergência em relação às testemunhas foi observada para os caracteres NDM, APM, VA, PG e PO, sendo menor para Ac e \%OL. Nenhuma linhagem superou a média das testemunhas para PG; no entanto, destacaram-se as linhagens 18 = USP 932316, 2 = USP 93-1106 e 10 = USP 93-2084 para Ac (1,23; 1,71 e 1,29; respectivamente), VA (3,92; 3,33 e 3,58; respectivamente) PG $(2.809 \mathrm{Kg} / \mathrm{ha} ; 2.726 \mathrm{Kg}$ e $2.710 \mathrm{Kg} / \mathrm{ha}$, respectivamente) e PO (561 Kg/ha; $586 \mathrm{Kg} / \mathrm{ha}$ e $571 \mathrm{Kg} / \mathrm{ha}$, respectivamente), que apresentaram médias superiores às médias das linhagens (18\%, $14 \%$ e $14 \%$, respectivamente), tendo a segunda, apresentado também um bom potencial para \%OL $(21,54 \%)$.

\subsubsection{Linhagens intermediárias}

As LI apresentaram ciclo médio de 141 dias; $111 \mathrm{~cm}$ para APM; 1,94 para Ac; 3,20 para VA; $2.302 \mathrm{Kg} /$ ha para PG; 20,30\% para \%OL; e $468 \mathrm{Kg} / \mathrm{ha}$ para PO (Tabela 14). Houve diferenças para superioridade em relação às testemunhas para os caracteres NDM, APM, VA e PO. Maior divergência em relação às testemunhas foi observada para os caracteres NDM, APM e PO. Não houve diferenças em relação às testemunhas para

os caracteres Ac, PG e \%OL, mostrando que as linhagens mostraram comportamento semelhante em relação às testemunhas para esses caracteres. Destacaram-se para os caracteres Ac, VA, PG, \%OL e PO, as seguintes linhagens:

13 = USP 93-5243 (1,42; 3,69; $2.940 \mathrm{Kg} / \mathrm{ha} ; 19,41 \%$; e $569 \mathrm{Kg} / \mathrm{ha}$, respectivamente); $6=\operatorname{USP} 93-2722$ (1,19; 4,10; $2.812 \mathrm{Kg} / \mathrm{ha} ; 19,63 \%$; e $555 \mathrm{Kg} / \mathrm{ha}$, respectivamente); 12 = USP 93-5082 (1,56; 3,54; $2.668 \mathrm{Kg} / \mathrm{ha} ; 20,31 \%$; e $542 \mathrm{Kg} / \mathrm{ha}$, respectivamente); 17 = USP 93-5549 (2,08; 3,29; $2.629 \mathrm{Kg} / \mathrm{ha} ; 20,52 \%$; e $541 \mathrm{Kg} / \mathrm{ha}$, respectivamente).

Essas linhagens foram superiores para PG em 35\%, 29\%, 22\% e 21\%, respectivamente, comparado à média das testemunhas. 


\subsubsection{Linhagens semitardias}

As LST exibiram ciclo médio de 151 dias; $111 \mathrm{~cm}$ para APM; 1,74 para Ac; 3,20 para VA; $2.158 \mathrm{Kg} / \mathrm{ha}$ para PG; 20,33\% para \%OL; e $442 \mathrm{Kg} / \mathrm{ha}$ para PO (Tabela 15). As linhagens foram superiores em relação às testemunhas para os caracteres NDM, APM, VA, PG, \%OL e PO, sendo inferiores para Ac. Maior divergência em relação às testemunhas foi observada para os caracteres NDM, PG e PO, sendo menor para VA, APM, Ac e \%OL. Destacaram-se para Ac, VA, PG, \%OL e PO, as seguintes linhagens: 5 = USP 93-5513 (1,56; 3,48; $2.380 \mathrm{Kg} / \mathrm{ha} ; 19,80 \%$; e $474 \mathrm{Kg} / \mathrm{ha}$; respectivamente); 4 = USP 93-5419 (1,73; 3,19; $2.268 \mathrm{Kg} / \mathrm{ha} ; 20,75 \%$; e $472 \mathrm{Kg} / \mathrm{ha}$; respectivamente); 6 = USP 93-5684 (2,00; 3,12; $2.204 \mathrm{Kg} / \mathrm{ha} ; 20,59 \%$; e $459 \mathrm{Kg} / \mathrm{ha}$; respectivamente).

Essas linhagens foram superiores para PG em 33\%, 27\% e 23\%, respectivamente, comparado à média das testemunhas.

As linhagens mais produtivas dentro de cada CM foram: LP: 26 = USP 941086, LSP: 18 = USP 93-2316, LI: 13 = USP 93-5243 e LST: 5 = USP 93-5513. Essas linhagens foram as mesmas identificadas como superiores na avaliação realizada no ano agrícola 1996/97 por Rocha (1998). Isto sugere que estas linhagens reúnem adaptabilidade e estabilidade, já que suas superioridades foram mantidas com os anos agrícolas.

As médias para PG obtidas pelas LP $(2.421 \mathrm{Kg} / \mathrm{ha})$, LSP $(2.383 \mathrm{Kg} / \mathrm{ha})$, LI $(2.302 \mathrm{Kg} / \mathrm{ha})$ e LST $(2.157 \mathrm{Kg} / \mathrm{ha})$ sugerem que as LP, LSP e LI foram igualmente adaptadas à época normal de cultivo (verão, semeadura em novembro) para o Estado de São Paulo, particularmente à região de Piracicaba, ao contrário das LST, que exibiram médias mais baixas. Bonato et al. (1998), avaliando cultivares de ciclo precoce, intermediário e semitardio, obtiveram comportamentos semelhantes entre os três CM para o caráter PG na época normal de cultivo da soja no Rio Grande do Sul.

Esses resultados discordam daqueles observados por Soldini (1993), LaínezMejía (1996) e Unêda-Trevisoli (1999), que detectaram maiores médias para as LST. Segundo Soldini (1993) e Lin \& Nelson (1988), quanto menor a sobreposição do 
desenvolvimento das fases vegetativa e reprodutiva do ciclo biológico da planta, melhor será a distribuição da energia, canalizada na fase reprodutiva exclusivamente para o desenvolvimento das flores e grãos e, conseqüentemente, incrementando a produtividade de grãos. Considerando os quatro CM, as LST são as linhagens que apresentam menor sobreposição das fases vegetativa e reprodutiva, esperando-se, teoricamente, que sejam as mais produtivas. No entanto, fatores não controláveis podem influir negativamente na produtividade de grãos, como é o caso da presença do CHS nos locais Areão e ESALQ no ano agrícola 1996/97, com maior nível de sintomas nas LST (Rocha \& Vello, 1999). Segundo esses autores, os genótipos de ciclo tardio ficam mais sujeitos ao ataque de pragas e doenças, pelo maior tempo que ficam no campo. Além disso, as LPs têm parentais comprovadamente resistentes ao CHS (Primavera e IAC-Foscarin-31), os quais podem ter transmitido o (s) alelo (s) dominante (s) de resistência paras suas progênies (Siviero et al., 1997). Assim, as LP, LSP e LI, passaram as ser as mais produtivas, já que apresentaram maior adaptabilidade aos fatores ambientais.

Os resultados de médias para a \%OL confirmam que as LP $(21,39 \%)$ e LSP $(21,68 \%)$ foram superiores às LI $(20,30 \%)$ e LST $(20,15 \%)$, concordando com os resultados obtidos por Rocha (1998). Essas médias foram inferiores àquelas obtidas nos trabalhos conduzidos por Rocha (1998) e Hamawaki \& Vello (2000), mas superiores àquelas obtidas nos trabalhos de Lazarini (1995), Billore \& Joshi (1997), Raut et al. (1997), Soldini (1998), Marega Filho et al. (2001) e Bonato et al. (2000).

\subsection{Adaptabilidade e estabilidade fenotípica}

A detecção de interações significativas entre linhagens e ambientes (locais e/ou anos), indicou a necessidade de se analisar a adaptabilidade e estabilidade das linhagens. Esta análise foi realizada apenas para o grupo de linhagens comuns aos quatro anos agrícolas, dentro de cada CM. Para este estudo, foram considerados apenas os caracteres produtividade de grãos (PG), porcentagem de óleo (\%OL) e produtividade de óleo (PO).

As análises foram realizadas com as médias obtidas nos 12 ambientes resultantes da combinação de três locais em quatro anos agrícolas. Como a análise foi realizada ao 
nível de médias, utilizou-se o quadrado médio do erro da análise conjunta geral, dividido pelo número de repetições, já que os experimentos eram balanceados.

\subsubsection{Método da ecovalência}

Os resultados da análise de estabilidade fenotípica avaliada pelo método da ecovalência (Wricke \& Weber, 1986) são apresentados nas Tabelas 16, 17, 18 e 19, bem como nas Figuras 2, 3, 4 e 5. Nas Figuras, as colunas representam a contribuição de cada linhagem, em porcentagem, para a interação G x E, obtidas pela ecovalência. Assim, linhagens com colunas baixas são mais estáveis e aquelas com colunas altas são mais instáveis. O número acima da coluna indica o ordenamento da linhagem com base na média, traduzido aqui, como um indicativo de adaptabilidade; quanto melhor sua classificação em termos de média, maior sua adaptabilidade.

\subsubsection{Linhagens precoces}

Para o caráter PG, as linhagens que apresentaram menores valores para 0 parâmetro ecovalência foram: 16 = USP 93-1195, 15 = USP 93-1188, 7 = USP 93-1069 e 27 = USP 94-1087, sendo consideradas como as mais estáveis (Tabela 16 e Figura 2a); destas, a linhagem 27 foi a que apresentou maior média $(2.497 \mathrm{Kg} / \mathrm{ha})$. Das linhagens mais produtivas (L2, L10, L21, L25 e L26), a linhagem $10=$ USP 93-1101 foi a mais estável $\left(\% \omega_{\mathrm{i}}=2,04\right)$.

As linhagens que apresentaram menores ecovalências para \%OL foram: $27=$ USP 94-1087, 3 = USP 93-1043, 14 = USP 93-1187 e 13 = USP 94-1122 (Tabela 16 e Figura 2b); a linhagem 3 aliou média alta (22,34\%) com estabilidade.

As linhagens 16 = USP 93-1195, 15 = USP 93-1188 e 23 = USP 94-1061, apresentaram menores ecovalências para PO, portanto, foram as mais estáveis (Tabela 16 e Figura 2c); entre estas, a linhagem 15 foi a que apresentou maior média (546 $\mathrm{Kg} / \mathrm{ha}$ ); das linhagens superiores em PO (L2, L10, L17, L19 e L26), a linhagem 2 = USP 93-1042 mostrou-se como a mais estável $\left(\% \omega_{i}=2,08\right)$. 


\subsubsection{Linhagens semiprecoces}

De acordo com a Tabela 18 e a Figura 3a, os menores valores de ecovalência para PG foram obtidos pelas linhagens $17=$ USP 93-2306, $3=$ USP 93-1119 e $21=$ USP 93-2479; entre essas, a linhagem 21 foi a que apresentou maior média $(2.581 \mathrm{Kg} / \mathrm{ha})$; das linhagens superiores em PG (L2, L6, L10, L18 e L35), a linhagem 18 = USP 932316 comportou-se como a mais estável $\left(\% \omega_{\mathrm{i}}=1,32\right)$ e de maior média entre as todas as LI.

Para a \%OL, os menores valores para o parâmetro ecovalência foram obtidos pelas linhagens 29 = USP 93-2727, 27 = USP 93-2697, 36 = USP 93-2909 e 3 = USP 93-1119 (Tabela 18 e Figura 3b); entre essas, a linhagem 29 apresentou maior média (21,38\%); das linhagens mais produtivas em \%OL (L2, L4, L22, L24 e L26), a linhagem 26 = USP 93-2693 exibiu maior estabilidade $\left(\% \omega_{\mathrm{i}}=2,18\right)$.

Os menores valores de ecovalências para PO foram obtidos pelas linhagens 17 = USP 93-2306, 3 = USP 93-1119 e 21 = USP 93-2479 (Tabela 18 e Figura 3c); entre essas, a linhagem 21 apresentou maior média (511 Kg/ha); das linhagens mais produtivas em PO (L2, L8, L10, L11 e L18), a linhagem 18 = USP 93-2316 mostrou-se a mais estável $\left(\% \omega_{i}=1,24\right)$, conforme verificado antes para PG.

\subsubsection{Linhagens intermediárias}

Para o caráter PG, os menores valores para o parâmetro ecovalência foram obtidos pelas linhagens $18=$ USP 93-5552, $5=$ USP 93-2643 e $20=$ USP 93-5585 (Tabela 17 e Figura 4a); entre essas, a linhagem 5 apresentou maior média (2.299 $\mathrm{Kg} / \mathrm{ha}$ ). Em relação às linhagens mais produtivas em PG (L6, L12, L13, L15 e L17), a linhagem 12 = USP 93-5082 foi a mais estável $\left(\% \omega_{\mathrm{i}}=2,69\right)$.

As menores ecovalências para a \%OL foram obtidas pelas linhagens $8=$ USP 93-2753, 12 = USP 93-5082, 9 = USP 93-2802 e 22 = USP 93-5597 (Tabela 17 e Figura 4b); entre essas, a linhagem 12 foi a que apresentou maior média (20,31\%); das 
linhagens mais produtivas em \%OL (L15, L18, L23, L25 e L26), a linhagem 18 = USP 93-5552 apresentou maior estabilidade $\left(\% \omega_{\mathrm{i}}=2,41\right)$.

Para PO, as menores estimativas de ecovalências foram obtidas pelas linhagens 5 = USP 93-2643, 20 = USP 93-5585 e 18 = USP 93-5552 (Tabela 17 e Figura 4c); entre essas, a linhagem 18 apresentou maior média (461 Kg/ha); das linhagens mais produtivas em PO (L6, L12, L13, L15 e L17), a linhagem 13 = USP 93-5243 foi a mais estável $\left(\% \omega_{i}=2,43\right)$. Observa-se que as mesmas linhagens superiores em adaptabilidade e estabilidade para PG também foram para PO.

\subsubsection{Linhagens semitardias}

Para a PG, os menores valores para o parâmetro ecovalência foram obtidos pelas linhagens 6 = USP 93-5684 e 1 = USP 93-2521 (Tabela 19 e Figura 5a); entre essas, a linhagem 6 foi a que apresentou maior média $(2.204 \mathrm{Kg} / \mathrm{ha})$. Em relação às linhagens mais produtivas em PG (L2, L3, L4, L5 e L6), a linhagem 2 = USP 93-5263 apresentou-se como a mais estável.

Em relação à \%OL, o menor valor para a ecovalência foi obtido pela linhagem 6 = USP 93-5684, com média de 20,59\% (Tabela 19 e Figura 5b). Das linhagens mais produtivas em \%OL (L3, L4, L5, L6 e L7), a linhagem 6 = USP 93-5684 foi a mais estável $\left(\% \omega_{\mathrm{i}}=8,84\right)$.

As menores estimativas de ecovalência para PO foram obtidas pelas linhagens 6 = USP 93-5684 e 1 = USP 93-2521 (Tabela 19 e Figura 5c); entre essas, a linhagem 6 apresentou maior média (459 Kg/ha); das linhagens mais produtivas em PO (L2, L3, L4, L5 e L6), a linhagem 6 = USP 93-5684, a exemplo da \%OL e da PG, foi a mais estável $\left(\% \omega_{i}=5,56\right)$.

Os resultados obtidos para $\mathrm{PG}$ em todos os $\mathrm{CM}$ relativos à amplitude das ecovalências foram maiores do que as encontradas por Yue et al. (1997), porém estiveram mais próximas daquelas obtidas por Yokomizo (1999) e Unêda-Trevisoli (1999). Observou-se em todos os CM que a grande maioria das linhagens mais estáveis 
não foram as mais produtivas em PG e PO. Isto sugere que a adaptabilidade e a estabilidade podem ter controles genéticos independentes, conforme sugerido por Verma et al. (1978) e Vencovsky \& Torres (1988). De fato, Miranda (1999) obteve correlações baixas e não significativas entre PG e estabilidade $\left(\omega_{\mathrm{i}}\right), \mathrm{r}=0,02$, sugerindo que são medidas independentes. No entanto, foram identificadas em todos os CM, linhagens que apresentavam alta adaptabilidade e estabilidade média (magnitudes para $\omega_{\mathrm{i}}$ próximas das obtidas pelas linhagens mais estáveis). Isso foi verificado com maior freqüência nas LI. Yokomizo (1999), Miranda (1999), Prado et al. (2001) e Unêda \& Vello ${ }^{1}$, avaliando genótipos de soja pelo método da ecovalência, também encontraram linhagens que reuniam estabilidade média e alta produtividade de grãos.

\subsubsection{Método de Eberhart \& Russel}

Os resultados da análise de adaptabilidade e estabilidade fenotípica avaliadas pelo método de regressão linear de Eberhart \& Russel (1966) são apresentados nas Tabelas 20, 21, 22, 23 e 24, bem como nas Figuras 6, 7, 8 e 9.

Foram observadas diferenças significativas pelo teste F (Tabela 20) para os efeitos de linhagens $(\mathrm{G})$, ambientes $(\mathrm{E})$ e interação $\mathrm{G}$ x E nos três caracteres (PG, PO e \%OL), sendo os maiores níveis de significância para as LP, LSP e LI (P < 0,01). Para as LST, o efeito de ambientes foi mais importante $(\mathrm{P}<0,01)$ que o efeito de linhagens, e este, maior que o efeito da interação $\mathrm{G}$ x $\mathrm{E}(\mathrm{P}<0,05)$. Isto sugere que as linhagens e os ambientes apresentaram variabilidade e que as linhagens comportaram-se diferencialmente com os ambientes, justificando um estudo mais aprofundado sobre o comportamento individual das linhagens no sentido de identificar suas magnitudes de interação com os ambientes.

Em todos os casos, o efeito de ambientes foi responsável pela maior parte da variação de tratamentos (51 a 70\%), seguida pelo efeito da interação G x E (16 a 41\%) e

\footnotetext{
${ }^{1}$ UNÊDA, S.H.; VELLO, N.A. Assesment of phenotypic stability using ecovalence in soybean progenies derived from multiple crosses. (Em elaboração)
} 
por último o efeito de linhagens ( 2 a 25\%), como mostram as estimativas de $\mathrm{R}^{2}$ (Tabela 20). O efeito de ambientes foi maior nas LST para PG e PO, e nas LSP para a \%OL. A grande magnitude para a soma de quadrados (SQ) de ambientes indica que eles foram variáveis, com grandes diferenças entre médias ambientais causando a maioria da variação para os três caracteres. Magnitudes semelhantes para os efeitos de genótipos, ambientes e interação G x E foram observadas nos trabalhos de Zobel et al. (1988) e Gauch \& Zobel (1990). O efeito de ambientes também foi mais importante no estudo conduzido por Prado et al. (2001); no entanto, neste último trabalho, o efeito de genótipos foi mais importante do que o efeito da interação $\mathrm{G}$ x E. Já no trabalho de Ariyo (1998), a variação explicada pela interação $\mathrm{G}$ x E foi preponderante em relação aos efeitos de ambientes e de genótipos.

$\mathrm{O}$ efeito de ambientes dentro de genótipos (E/G) foi significativo para os três caracteres em todos os CM, já os efeitos advindos de sua decomposição (E linear, G x E linear e desvio combinado) mostraram-se significativos para a maior parte dos caracteres e CM, exceto G x E linear para: \%OL (LP e LSP), PG (LST) e desvio combinado para a \%OL (LSP e LST). O efeito de E linear também foi importante, indicando que os ambientes apresentam variações significativas nas médias das linhagens, exceto para a $\% \mathrm{OL}$; efeitos significativos para $\mathrm{G} \times \mathrm{E}$ linear indicam a existência de diferenças entre os coeficientes de regressão e que uma grande parte da interação G x E pode ser explicada pela relação linear entre as linhagens e os ambientes. A alta significância para os desvios da regressão para PG e PO sugere que tanto os componentes lineares como não-lineares da estabilidade encontram-se envolvidos na performance fenotípica das linhagens nos ambientes, concordando com os resultados obtidos por Mauro et al. (2000).

As estimativas de $\mathrm{R}^{2}$ (variação explicada pela regressão) para as fontes resultantes da decomposição de $\mathrm{E} / \mathrm{G}$ mostraram que, considerando os quatros $\mathrm{CM}$, a regressão (E linear + G x E linear) explicou em média, 65\% para PG e PO, e 77\% para a $\%$ OL. Comparativamente, a regressão explicou menos nas LSP (57,60 e 58,85\%, para PG e PO, respectivamente) e mais nas LST (71,82 e 73,13\%, para PG e PO, respectivamente); resultados diferentes foram obtidos para a \%OL, sendo maior nas LSP $(81,93 \%)$ e menor nas LP $(70,84 \%)$. Embora tenha explicado melhor a variação das 
linhagens com os ambientes para a \%OL, a regressão para este caráter foi mais influenciada pelo efeito de ambientes do que pelo efeito da interação $\mathrm{G}$ x $\mathrm{E}$, relativamente aos caracteres PG e PO. No entanto, a magnitude em variação para o componente da interação foi menor, comparada àquelas observadas para PG e PO, exceto nas LST.

De maneira geral, grande parte da regressão foi explicada mais pelos efeitos de ambientais do que pelos efeitos da interação $\mathrm{G}$ x E, como mostra as estimativas de $\mathrm{R}^{2}$ maiores para E linear e menores para G x E linear (Tabela 20). Os resultados para PG corroboram com os reportados por Dashiell et al. (1994), no qual concluíram que em decorrência da baixa variação explicada pela regressão em relação à interação $\mathrm{G}$ x E, a performance dos genótipos pode não ser predita como uma função linear do ambiente.

A magnitude para os desvios combinados em relação à fonte $\mathrm{E} / \mathrm{G}$ foi em média de $35 \%$ para PG e PO, e $23 \%$ para a \%OL (Tabela 20). Comparativamente, as LSP apresentaram magnitudes maiores para os desvios (42,40 e 41,14\%; para PG e PO, respectivamente), enquanto as LST mostraram magnitudes menores (28,18 e 26,87\%; para PG e PO, respectivamente); para a \%OL, as LP exibiram magnitudes maiores $(29,22 \%)$, enquanto as LSP, magnitudes menores $(18,11 \%)$.

As Tabelas 21, 22, 23 e 24 mostram um baixo número de linhagens, por CM, apresentando $\mathrm{R}^{2}$ acima de $80 \%$, porcentagem essa considerada por Cruz \& Regazzi (1994) como referencial para que a regressão explique satisfatoriamente o comportamento de um genótipo em função do ambiente. Comparativamente, a regressão foi mais eficiente para a \%OL, do que para PG e PO, já que aquela apresentou maior número de estimativas para $\mathrm{R}^{2}>80 \%$. Isto sugere que a regressão pode não estar explicando satisfatoriamente o comportamento da maioria das linhagens com os ambientes, para PG e PO. Esse resultado foi diferente do encontrado por Mauro et al. (2000), no qual todas as estimativas para $\mathrm{R}^{2}$ dos genótipos para PG foram acima de $80 \%$, indicando que a regressão explicou satisfatoriamente a variação exibida pelos genótipos com os ambientes.

Foram observadas estimativas negativas para a variância dos desvios da regressão $\left(s^{2} d_{i}\right)$ para as linhagens mais estáveis em alguns caracteres e CM. Segundo 
Chaves (2001), pelo fato do parâmetro $s^{2} d_{i}$ ser estimado pela diferença entre quadrados médios (QM dos desvios - QM do resíduo), pode ocorrer, ocasionalmente, estimativas negativas; esse autor atribui tal fato a erros aleatórios de estimação, podendo-se considerar o valor negativo como zero. A magnitude das estimativas negativas obtidas para PG foi similar àquelas obtidas por Raut et al. (1997), Mauro et al. (2000) e Prado et al. (2001).

\subsubsection{Linhagens precoces}

Para o caráter PG (Tabela 21), sobressaíram com comportamento estável (previsível frente às variações ambientais) e de alta adaptabilidade (produtividade média alta), as linhagens 2 = USP 93-1042, 10 = USP 93-1101, 26 = USP 94-1086, pois exibiram $b_{i}$ e $s^{2} d_{i}$ não significativos. A linhagem 26 reuniu adaptabilidade geral (média mais alta, $b_{i}$ não significativo) com alta estabilidade $\left(s^{2} d_{i}\right.$ não significativo e $\left.\mathrm{R}^{2}=70 \%\right)$, respondendo bem tanto em ambientes favoráveis quanto desfavoráveis, como mostra a sua linha de regressão na Figura 6a. As linhagens 21 = USP 94-1044 e 25 = USP 941081, embora apresentem ampla adaptabilidade (média alta e b não significativo), são pouco previsíveis e melhor adaptadas a ambientes favoráveis, conforme mostram suas linhas de regressão na Figura 6a; entre as duas, a linhagem 21 teve sua variação mais bem explicada pela regressão $\left(\mathrm{R}^{2}=68 \%\right)$.

Para a \%OL (Tabela 21), as linhagens 2 = USP 93-1042, 3 = USP 93-1043, $4=$ USP 93-1044 e $15=$ USP 93-1188 apresentaram adaptabilidade geral e alta previsibilidade ( $b_{i}$ e $s^{2} d_{i}$ não significativos). A L15 aliou alta estabilidade com alta adaptabilidade, apresentando a maior média. A linhagem 20 = USP 94-1024 apresentou adaptabilidade geral ( $b_{i}$ não significativo), mas foi pouco previsível ( $s^{2} d_{i}$ significativo), respondendo melhor em ambientes favoráveis, conforme mostra sua linha de regressão na Figura 6b. Entre essas, a linhagem 3 teve sua variação para \%OL melhor explicada pela regressão $\left(\mathrm{R}^{2}=83 \%\right)$.

Em relação ao caráter PO (Tabela 21), destacaram-se as linhagens 2 = USP 931043, L10 = USP 93-1101, 17 = USP 93-1203, 19 = USP 94-1012 e 26 = USP 94-1086, 
pó $r$ terem exibido adaptabilidade geral ( $b_{i}$ não significativo) e alta estabilidade $\left(s^{2} d_{i}\right.$ não significativo). No entanto, nota-se pela Figura 6c, que a linhagem 19, comportou-se melhor em ambientes favoráveis, enquanto a linhagem 26 (melhor média) é melhor adaptada a ambientes desfavoráveis. Entre essas, a linhagem 10 teve sua variação mais bem explicada pela regressão $\left(\mathrm{R}^{2}=79 \%\right)$.

\subsubsection{Linhagens semiprecoces}

Para o caráter PG (Tabela 23), as linhagens 6 = USP 93-1211, 18 = USP 932316 (melhor média) e $35=$ USP 93-2897 reuniram adaptação geral ( $b_{i}$ não significativo), alta previsibilidade ( $\mathrm{s}^{2} \mathrm{~d}_{\mathrm{i}}$ não significativo) e as variações melhor explicadas pela regressão, principalmente as linhagens $6\left(\mathrm{R}^{2}=75 \%\right)$ e $18\left(\mathrm{R}^{2}=81 \%\right)$, com esta última apresentando a média mais alta. As linhagens $2=$ USP 93-1106 e $10=$ USP 93-2084, apesar de serem bem adaptadas ( $b_{i}$ não significativo), foram pouco previsíveis $\left(\mathrm{s}^{2} \mathrm{~d}_{\mathrm{i}}\right.$ significativo). A linhagem 2 é mais responsiva a ambientes desfavoráveis, enquanto que a linhagem 10 tende a comportar-se melhor em ambientes favoráveis, conforme mostram suas linhas de regressão na Figura 7a.

Das linhagens superiores em \%OL (Tabela 23), destacou-se a linhagem $26=$ USP 93-2693, por ser altamente previsível e apresentar adaptabilidade geral $\left(b_{i}\right.$ e $s^{2} d_{i}$ não significativos); seu comportamento foi melhor explicado pela regressão $\left(\mathrm{R}^{2}=90 \%\right)$. As linhagens 2 = USP 93-1106 e 4 = USP 93-1125 apresentaram adaptabilidade geral ( $b_{i}$ não significativo), mas foram pouco previsíveis ( $\mathrm{s}^{2} \mathrm{~d}_{\mathrm{i}}$ significativo) com os ambientes; já as linhagens 22 = USP 93-2529 (melhor média) e 24 = USP 93-2667 apresentaram adaptações específicas com os ambientes ( $b_{i}$ e $s^{2} d_{i}$ significativos). As linhagens 4, 22 e 24 tendem a ser mais adaptadas a ambientes favoráveis; já a linhagem 2 responde bem a ambientes desfavoráveis, mas decepciona em ambientes favoráveis (Figura 7b).

Para a PO (Tabela 23), as linhagens 8 = USP 93-2027, 11 = USP 93-2103 e 18 = USP 93-2316, destacaram-se por apresentarem adaptabilidade geral ( $b_{i}$ não significativo), alta previsibilidade ( $\mathrm{s}^{2} \mathrm{~d}_{\mathrm{i}}$ não significativo) e suas variações foram aquelas mais bem explicadas pela regressão, principalmente para as linhagens $8\left(\mathrm{R}^{2}=69 \%\right)$ e 18 
$\left(\mathrm{R}^{2}=77 \%\right)$, sendo esta última apresentando a média mais alta. Por serem pouco previsíveis ( $s^{2} d_{i}$ significativo), mas bem adaptadas ( $b_{i}$ não significativo), as linhagens 2 $=$ USP 93-1106 e $10=$ USP 93-2084 podem ser recomendadas para ambientes específicos, sendo a linhagem 2 para ambientes favoráveis e a linhagem 10 para ambientes desfavoráveis (Figura 7c).

\subsubsection{Linhagens intermediárias}

Para os caracteres PG e PO (Tabela 22), destacaram-se as linhagens $6=$ USP 93-2722, 12 = USP 93-5082, 13 = USP 93-5243, 15 = USP 93-5423 e 17 = USP 935549, pois apresentaram alta adaptabilidade (médias mais altas) e previsibilidade $\left(\mathrm{b}_{\mathrm{i}} \mathrm{e}\right.$ $\mathrm{s}^{2} \mathrm{~d}_{\mathrm{i}}$ não significativos). Entre essas, as linhagens 12, 13 e 17 tiveram suas variações melhor explicadas pela regressão $\left(R^{2}=77,80\right.$, e $80 \%$, respectivamente), enquanto que a variação explicada pela regressão para a L15 foi muito baixa $\left(\mathrm{R}^{2}=38 \%\right)$. Embora sejam indicadas como previsíveis pela $\mathrm{s}^{2} \mathrm{~d}_{\mathrm{i}}$, as linhagens 13 (melhor média) e 15 respondem melhor a ambientes favoráveis e desfavoráveis, respectivamente (Figuras 8a e 8c).

Quanto à \%OL (Tabela 22), sobressaíram-se as linhagens 15 = USP 93-5544 e 18 = USP 93-5552, pois apresentaram adaptabilidade geral e alta estabilidade $\left(b_{i}\right.$ e $s^{2} d_{i}$ não significativos) aos ambientes. A linhagem 18 teve sua variação melhor explicada pela regressão $\left(\mathrm{R}^{2}=81 \%\right)$. As linhagens $23=\mathrm{USP} 93-5690$ e $25=\mathrm{USP} 93-5860$ exibiram adaptabilidade geral, mas se comportaram como pouco previsíveis $\left(\mathrm{s}^{2} \mathrm{~d}_{\mathrm{i}}\right.$ significativos); já a L26 = USP 93-5860 (melhor média), embora previsível ( $\mathrm{s}^{2} \mathrm{~d}_{\mathrm{i}}$ não significativo), apresentou $\mathrm{R}^{2}<80 \%(64 \%)$ e $\mathrm{b}$ significativo, sugerindo uma melhor adaptação a ambientes específicos. A L23 responde melhor a ambientes desfavoráveis, enquanto que e as linhagens 25 e 26 são mais responsivas a ambientes favoráveis (Figura 8b).

Comportamento similar quanto à adaptabilidade e estabilidade foi observado pelas linhagens mais produtivas para os caracteres PG e PO, mostrando que a PG foi altamente influente sobre a PO, já que a classificação das melhores linhagens para 
adaptabilidade e estabilidade foi semelhante para PG e PO, e diferente em relação à $\% \mathrm{OL}$.

\subsubsection{Linhagens semitardias}

Para os caracteres PG e PO (Tabela 24), destacaram-se as linhagens $2=$ USP 93-5263, 4 = USP 93-5419 e 6 = USP 93-5684, por que mostrarem adaptabilidade geral ( $b_{i}$ não significativo) e alta previsibilidade $\left(\mathrm{s}^{2} \mathrm{~d}_{\mathrm{i}}\right.$ não significativo), bem como suas variações foram bem explicadas pela regressão, principalmente, para as linhagens $2\left(\mathrm{R}^{2}\right.$ $=80$ e $80 \%$, respectivamente) e $6\left(\mathrm{R}^{2}=91\right.$ e $90 \%$, respectivamente $)$. As linhagens $3=$ USP 93-5391 e 5 = USP 93-5513 foram pouco previsíveis ( $\mathrm{s}^{2} \mathrm{~d}_{\mathrm{i}}$ significativos). A linhagem 3 responde melhor a ambientes desfavoráveis, já a linhagem 5 (melhor média) é mais responsiva a ambientes de alta qualidade (Figuras 9a e 9c). A exemplo das LI, as melhores linhagens em PG e PO apresentaram comportamento similar em relação à adaptabilidade e estabilidade.

Em relação a \%OL (Tabela 24), as linhagens mais adaptadas e previsíveis $\left(b_{i}\right.$ e $\mathrm{s}^{2} \mathrm{~d}_{\mathrm{i}}$ não significativos) foram: 4 = USP 93-5419, 5 = USP 93-5513, 6 = USP 93-5684 e 7 = USP 93-5802, tendo as linhagens 4, 5 e 6 apresentado variações melhor explicadas pela regressão $\left(\mathrm{R}^{2}=84,72\right.$ e $80 \%$, respectivamente). A linhagem $3=$ USP 93-5391 (melhor média) comportou-se como previsível $\left(\mathrm{s}^{2} \mathrm{~d}_{\mathrm{i}}\right.$ não significativo), mas seu $\mathrm{b}_{\mathrm{i}}$ significativamente menor que um, indica que essa linhagem responderá melhor a ambientes de baixa qualidade, como mostra sua linha de regressão na Figura 9b.

\subsubsection{Método AMMI}

Os resultados referentes ao método AMMI são apresentados nas Tabelas 25 a 29, bem como nas Figuras 10 a 18. Os efeitos principais de genótipos e ambientes diagnosticados pela tradicional análise de variância (ANAVA) e testados pelo teste $F$, já foram discutidos na análise de Eberhart \& Russel (1966), mostrada na Tabela 20. O efeito multiplicativo da interação genótipos $\mathrm{x}$ ambientes $(\mathrm{G} \times \mathrm{E})$ foi diagnosticado 
através da análise de componentes principais (ACP), pela decomposição da soma de quadrados da interação $\mathrm{G}$ x E ( $\left(\mathrm{SQ}_{\mathrm{GxE}}\right.$ ) em eixos ou componentes principais da interação (CPI), sendo adotado o critério "posdictivo" (uso de testes de hipóteses) através do teste $F_{R}$ apresentado por Cornelius et al (1992) e Piepho (1995), para a seleção de modelos AMMI mais preditivos e parcimoniosos. A $\mathrm{SQ}_{\mathrm{GxE}}$ foi decomposta em 11 CPIs para as LP, LSP e LI, e em seis CPIs para as LST; no entanto, apenas os CPIs que exibiram significância pelo teste $F$ são mostrados nas tabelas, sendo os demais eixos incluídos no resíduo AMMI do último CPI significativo.

O critério preditivo de seleção de modelos por validação cruzada não foi adotado nesta análise, devido ao baixo número de repetições por ambiente. Segundo Taye et al. (2000) e Ortiz et al. (2001), com apenas duas repetições por ambiente não é possível utilizar a seleção preditiva do melhor modelo AMMI por validação cruzada.

\subsubsection{Linhagens precoces}

A análise da interação $\mathrm{G} \times \mathrm{E}$ pela $\mathrm{ACP}$ mostrou que somente os quatro primeiros CPIs para PG e $\mathrm{PO}$, e somente os dois primeiros CPIs para a \%OL foram significativos ( $\mathrm{P}<0,01)$. Para PG e PO, os quatro eixos juntos explicaram 66\% e 66\%, respectivamente, da $\mathrm{SQ}_{\mathrm{GxE}}$; já no caso da $\% \mathrm{OL}$, os dois primeiros CPIs explicaram juntos 53\% da $\mathrm{SQ}_{\mathrm{GxE}}\left(\right.$ Tabela 25). Os demais eixos representaram variações da $\mathrm{SQ}_{\mathrm{GxE}}$ mais preponderantemente ricas em ruídos. Assim, pelo critério de Cornelius et al. (1992), os modelos AMMI4 (PG e PO) e AMMI1 (\%OL) foram selecionados, como aqueles que melhor descrevem o padrão inerente à interação $\mathrm{G}$ x E. No caso da \%OL, vale esclarecer que, embora pelo critério de Gollob (1968), o modelo selecionado fosse o AMMI2, pelo critério de Cornelius et al. (1992), o ponto de parada para a seleção do modelo é aquele no qual o resíduo do CPI mostre não significância; neste caso, o modelo selecionado é o AMMI1.

Para o caráter PG, nota-se pelo biplot AMMI1 (Figura 10a) que 18 linhagens (64\% das LP) superaram a média das testemunhas $(\mathrm{MT}=2.384 \mathrm{Kg} / \mathrm{ha})$. Dessas, destacaram-se as cinco melhores para PG em ordem decrescente de estabilidade: L26 = 
USP 94-1086, L2 = USP 93-1042, L10 = USP 93-1101, L21 = USP 94-1044 e L25 = USP 94-1081, como mostram seus escores no biplot AMMI2 (Figura 10b) e as estimativas de A/linhagem preditas pelo modelo AMMI4, apresentadas na Tabela 29. As linhagens 26, 2 e 10, por apresentarem interações mais baixas com os ambientes, podem ser indicadas para os três locais. As linhagens 21 e 25, por terem interagido mais com os ambientes, e de forma positiva, respondem melhor a ambientes favoráveis como Anhembi e ESALQ, como mostram as médias obtidas pelos ambientes relacionados com esses locais (Tabela 29). No biplot AMMI2 (Figura 10b), distinguiu-se três grupos de linhagens com magnitudes mais semelhantes para a interação G x E: grupo 1 (linhagens mais estáveis): L1, L2, L7, L8, L9, L10, L11, L13, L14, L15, L16, L19, L23, L24 e L27; grupo 2 (linhagens com estabilidades intermediárias): L21 e L26; e grupo 3 (linhagens instáveis): L4, L6, e L28. As linhagens 3, 5, 12, 17, 18, 20, 22 e 25 não formaram grupos, com as linhagens 3,5 e 22 apresentando maior instabilidade em relação às demais LP. Isto mostra que $53 \%$ das linhagens foram estáveis com os ambientes. Distinguiu-se três grupos de ambientes com interações mais similares: grupo 1 (ambientes mais estáveis): AN97, AR97, AR98, AR99, ES98; grupo 2 (ambientes com estabilidades intermediárias): AR96 e ES99; e grupo 3 (ambientes mais instáveis): AN98, ES96 e ES97. Os ambientes AN96 e AN99 foram divergentes e instáveis em relação aos demais ambientes.

O biplot AMMI1 (Figura 11a) mostra que dez linhagens (36\% das LP) foram superiores à média das testemunhas (MT $=21,62 \%)$ em \%OL. Destacaram-se as cinco com maiores \%OL em ordem decrescente de estabilidade: L3 = USP 93-1043, L4 = USP 93-1044, L15 = USP 93-1188, L2 = USP 93-1042 e L20 = 94-1024, como mostram seus escores no biplot AMMI1 (Figuras 11a) e as estimativas de A/linhagem preditas pelo modelo AMMI1, apresentadas na Tabela 30. As linhagens 3, 4 e 15, por apresentaram interações mais baixas com os ambientes, podem ser indicadas para os três locais. As linhagens 2 e 20, por terem interagido mais com os ambientes, e de forma positiva, respondem melhor a ambientes favoráveis para a \%OL (p. ex. o local Anhembi), como mostram as médias obtidas pelos ambientes relacionados com esses locais (Tabela 30). No biplot AMMI1, distinguiu-se quatro grandes grupos de linhagens com 
comportamentos mais semelhantes para a interação $G \times$ E: grupo 1 (linhagens mais estáveis): L3, L4, L5, L7, L9, L12, L13, L14, L19, L21, L24, L25, L26, L27 e L28; grupos 2 e 3 (linhagens com estabilidades intermediárias): L6, L7, L22 e L23; e L1, L2, L8, L10, L15 e L20, respectivamente; e grupo 4 (linhagens mais instáveis): L11 e L16. Isto mostra que 53\% das linhagens foram estáveis com os ambientes. Distinguiu-se dois grupos de ambientes com interações mais similares: grupo 1 (ambientes estáveis): AN96, AN97, AN98, AR97, AR98, AR99, ES96, ES97 e ES98; e o grupo 2 (ambientes instáveis): AN99 e ES99. Os ambiente AR96 foi dissimilar e imprevisível em relação aos demais.

O biplot AMMI1 (Figura 12a) mostra que 17 linhagens (61\% das LP) superaram a média das testemunhas $(\mathrm{MT}=516 \mathrm{Kg} / \mathrm{ha})$ em PO. Dessas 17, destacaramse as cinco melhores para PO em ordem decrescente de estabilidade: L2 = USP 93-1042, L19 = USP 94-1012, L10 = USP 93-1101, L26 = 94-1086 e L17 = USP 93-1203, como mostram seus escores no biplot AMMI2 (Figura 12b) e as estimativas de A/linhagem preditas pelo modelo AMMI4, apresentadas na Tabela 31. As linhagens 2, 19 e 10, apresentarem interações mais baixas com os ambientes, podendo ser indicadas para os três locais. As linhagens 21 e 25, por terem interagido mais com os ambientes, e de forma positiva, respondem melhor a ambientes favoráveis como Anhembi e ESALQ, sendo que a L17 responde melhor no local Anhembi; já a L26 respondeu igualmente favorável ao local ESALQ e não desapontou no local Areão, como mostram as médias obtidas pelos ambientes relacionados com esses locais (Tabela 31). No biplot AMMI2 (Figura 12b), distinguiu-se quatro grupos de linhagens com magnitudes mais semelhantes para a interação G x E: grupo 1 (linhagens mais estáveis): L1, L2, L7, L8, L10, L11, L13, L14, L15, L16, L19, L21, L23, L24 e L27; grupos 2 e 3 (linhagens com estabilidades intermediárias): L4, L6, L18, L20 e L28; e L12 e L22, respectivamente; e grupo 4 (linhagens instáveis): L17 e L26. As linhagens 3, 5, 9 e 25 não formaram grupos, sendo as linhagens 3 e 5 mais dissimilares e instáveis em relação às demais LP. Isto evidencia que 53\% das LP foram estáveis com os ambientes. Distinguiu-se três grupos de ambientes com interações mais similares: grupo 1 (ambientes mais estáveis): AN97, AR96, AR97, AR99 e ES98; grupo 2 (ambientes com estabilidades 
intermediárias): AN98, ES96 e ES97; e grupo 3 (ambientes mais instáveis): AR98 e ES99. Os ambientes AN96 e AN99 foram divergentes e mais instáveis em relação aos demais, com AN96 apresentando a maior instabilidade do grupo. O agrupamento de ambientes foi semelhante ao obtido para a PG.

Os resultados mostraram que as LP reuniram uma porcentagem igual de linhagens $(53 \%)$ com alta estabilidade para os três caracteres. Das cinco linhagens superiores em PO, três (L2, L10 e L26) também o foram para PG e somente uma (L2) foi superior em \%OL. Essa maior influência de PG sobre a PO, concorda com os resultados obtidos por Soldini (1998), o qual concluiu em seu trabalho que os incrementos para PO dependem muito mais das freqüências alélicas para PG do que da \%OL. Soldini (1993), Laínez-Mejía (1996) e Rocha (1998) também encontraram resultados semelhantes aos obtidos no presente trabalho.

\subsubsection{Linhagens semiprecoces}

A análise da interação G x E pela ACP mostrou que apenas os quatro primeiros CPIs foram significativos $(\mathrm{P}<0,01)$ para $\mathrm{PG}$ e $\mathrm{PO}$, e somente os dois primeiros CPIs para a \%OL. Para PG e PO, os quatro eixos juntos explicaram 68\% e 69\%, respectivamente, da $\mathrm{SQ}_{\mathrm{GxE}}$; já no caso da \%OL, os dois primeiros CPIs explicaram juntos $53 \%$ da $\mathrm{SQ}_{\mathrm{GxE}}$ (Tabela 26). Os demais eixos representaram variações da $\mathrm{SQ}_{\mathrm{GxE}}$ mais preponderantemente ricas em ruídos. Assim, pelo critério de Cornelius et al. (1992), como a partir do resíduo AMMI4 (PG e PO) e AMMI1 (\%OL) não foi obtido significância, os modelos selecionados foram AMMI4 (PG e PO) e AMMI1 (\%OL). Esses resultados foram semelhantes aos obtidos pelas LP; no entanto, para PG e PO, o modelo AMMI4 explicou mais da interação G x E, quando comparado às LP.

Observa-se pelo biplot AMMI1 (Figura 13a) que nenhuma linhagem superou a média das testemunhas $(\mathrm{MT}=2.928 \mathrm{Kg} / \mathrm{ha})$ em PG. No entanto, 26 linhagens $(68 \%$ das LSP) foram superiores à média das linhagens $(\mathrm{ML}=2.383 \mathrm{Kg} / \mathrm{ha})$; entre essas, destacaram-se cinco superiores em PG, em ordem decrescente de estabilidade: L18 = USP 93-2316, L35 = USP 93-2897, L7 = USP 93-2002, L10 = USP 93-2084 e L2 = USP 
93-1106, como mostram seus escores no biplot AMMI2 (Figura 13b) e as estimativas de $\mathrm{A}_{\mathrm{i}} /$ linhagem preditas pelo modelo AMMI4, apresentadas na Tabela 32. As linhagens 18, 35 e 7, por apresentarem interações mais baixas com os ambientes, podem ser indicadas para os três locais. As linhagens 2 e 10, por terem interagido mais com os ambientes e de forma positiva, respondem melhor a ambientes favoráveis como o local Anhembi, como mostram as médias obtidas pelos ambientes relacionados com esses locais (Tabela 32). No biplot AMMI2 (Figura 13b), distinguiu-se seis grupos de linhagens com magnitudes mais semelhantes para a interação G x E: grupo 1 (linhagens mais estáveis): L3, L4, L5, L6, L7, L8, L11, L14, L18, L19, L20, L21, L23, L24, L26, L29, L31, L32, L33, L35 e L36; grupos 2, 3, 4 e 5 (linhagens com estabilidades intermediárias): L1, L6 e L38; L12, L15 e L16; L10 e L22; e L28 e L37, respectivamente; e o grupo 6 (linhagens instáveis): L27 e L30. As linhagens 2, 9, 13, 25 e 34 não formaram grupos, sendo as linhagens 25 e 34 mais dissimilares e instáveis em relação às demais LSP. Isto evidencia que $55 \%$ das LSP foram estáveis com os ambientes. Distinguiu-se três grupos de ambientes com interações de mesma magnitude: grupo 1 (ambientes mais estáveis): AN98, AR96 e ES96; grupo 2 (ambientes com estabilidades intermediárias): ES97 e ES98; e grupo 3 (ambientes instáveis): AN97 e AR97. Os ambientes AN96, AN99, AR98 e AR99 não formaram grupos, sendo que AN96 e AN99 foram os mais divergentes e instáveis em relação aos demais ambientes deste CM.

O biplot AMMI1 (Figura 11b) mostra que apenas três (8\% das LSP) foram superiores à média das testemunhas $(\mathrm{MT}=21,44 \%)$ em \%OL. Estas três linhagens são as seguintes em ordem decrescente de estabilidade: L24 = USP 93-2667, L22 = USP 932565 e L2 = USP 93-1106, como mostram seus escores no biplot AMMI1 (Figura 11b) e as estimativas de $\mathrm{A}_{\mathrm{i}} /$ linhagem preditas pelo modelo AMMI1, apresentadas na Tabela 33. As linhagens 22 e 24, por apresentarem interações mais baixas com os ambientes, podem ser indicadas para os três locais. No entanto, a L2, por ter interagido mais com os ambientes, e de forma positiva, responde melhor a ambientes favoráveis para a \%OL como AN97, AR98 e ES98, como mostram as médias preditas para esses ambientes na Tabela 33 e as adaptações mostradas no biplot AMMI1 (Figura 11b). Distinguiu-se quatro grupos de linhagens com magnitudes mais semelhantes para a interação $\mathrm{G}$ x E: 
grupo 1 (linhagens mais estáveis): L3, L6, L8, L10, L11, L12, L18, L19, L20, L27, L29, L30, L33, L36 e L38; grupos 2 e 3 (linhagens com estabilidades intermediárias): L5, L9, L14, L15, L16, L17, L23, L28, L31, L34, L35 e L37; L7, L12, L13, L22, L23, L24 e L26, respectivamente; e o grupo 4 (linhagens instáveis): L1 e L21. As linhagens 2 e 4 foram as mais divergentes e instáveis em relação às demais LSP. Isto mostra que 39\% das LSP foram estáveis com os ambientes. Distinguiu-se três grupos de ambientes com interações mais similares: grupo 1 (ambientes mais estáveis): AN96, AR96, AR97, AR99, ES96, ES97 e ES98; grupo 2 (ambientes mais instáveis): AN99 e ES99; e grupo 3: AN97, AN98 e AR98 (linhagens com estabilidades intermediárias).

O biplot AMMI1 (Figura 14a) mostra que, a exemplo da PG, nenhuma linhagem superou a média das testemunhas $(\mathrm{MT}=626 \mathrm{Kg} / \mathrm{ha})$ em PO. No entanto, 20 linhagens (53\% das LSP) apresentaram médias acima da média das linhagens (ML = 493 $\mathrm{Kg} / \mathrm{ha}$ ). Dessas, destacaram-se as cinco melhores para PO em ordem decrescente de estabilidade: L11 = USP 93-2103, L18 = USP 93-2316, L8 = USP 93-2027, L10 = 932084 e L2 = USP 93-1106, como mostram seus escores no biplot AMMI2 (Figura 14b) e as estimativas de $\mathrm{A}_{\mathrm{i}} /$ linhagem preditas pelo modelo AMMI4, apresentadas na Tabela 34. As linhagens 11, 18 e 8, por apresentarem interações mais baixas com os ambientes, podem ser indicadas para os três locais; já as linhagens 10 e 2, respondem melhor aos ambientes ESALQ e Anhembi, respectivamente, como mostram as médias preditas pelos ambientes relacionados com esses locais (Tabela 34). No biplot AMMI2 (Figura 14b), distinguiu-se quatro grupos de linhagens com magnitudes mais semelhantes para a interação G x E: grupo 1 (linhagens mais estáveis): L3, L7, L8, L11, L14, L17, L19, L20, L23, L24, L29, L30, L31, L32, L36; grupos 2 e 3 (linhagens com estabilidades intermediárias): L1, L2, L4, L6, L12, L15, L21, L33, L35 e L38; L5, L10, L18, L22, L26, L27, L28 e L37, respectivamente; e o grupo 4 (linhagens instáveis): L9 e L13. As linhagens 16, 25 e 34 foram mais dissimilares e instáveis em relação às demais LSP. Isto indica que 39\% das LSP foram estáveis com ambientes. Distinguiu-se quatro grupos de ambientes com magnitudes para a interação G x E mais similares: grupo 1 (ambientes mais estáveis): AR96 e ES96; grupos 2 e 3: AN98 e AR98; AN97 e AR97, respectivamente; e o grupo 4 (ambientes instáveis): ES97 e ES98. Os ambientes AN96, 
AN99, AR99 e ES99 foram divergentes, sendo os ambientes AN96 e AN99, os mais instáveis em relação aos demais ambientes deste CM.

\subsubsection{Linhagens intermediárias}

A análise da interação G x E pela ACP mostrou que apenas os dois primeiros CPIs foram significativos $(\mathrm{P}<0,01)$ para os três caracteres. Para PG e PO, os quatro eixos juntos explicaram $44 \%$ e $60 \%$, respectivamente, da $\mathrm{SQ}_{\mathrm{GxE}}$; já no caso da $\% \mathrm{OL}$, os dois primeiros CPIs explicaram juntos $46 \%$ da $\mathrm{SQ}_{\mathrm{GxE}}$ (Tabela 27). Os demais eixos representaram variações da $\mathrm{SQ}_{\mathrm{GxE}}$ mais preponderantemente ricas em ruídos. Assim, pelo critério de Cornélius et al. (1992), como a partir do resíduo AMMI1 (PG) e AMMI2 (\%OL e PO) não foi obtido significância, os modelos selecionados foram AMMI1 (PG) e AMMI2 (\%OL e PO). Esses modelos são, portanto, aqueles que melhor descrevem a interação G x E padrão.

O biplot AMMI1 (Figura 15a) mostra que 14 linhagens (52\% das LI) foram superiores à média das testemunhas $(\mathrm{MT}=2.177 \mathrm{Kg} / \mathrm{ha})$; entre essas, destacaram-se as cinco melhores para PG em ordem decrescente de estabilidade: L12 = USP 93-5082, L13 = USP 93-5243, L17 = USP 93-5549, L6 = USP 93-2722 e L15 = USP 93-5539, como mostram seus escores no biplot AMMI1 (Figura 15a) e as estimativas de $\mathrm{A}_{\mathrm{i}} /$ linhagem preditas pelo modelo AMMI1 apresentadas na Tabela 35. As linhagens 12, 13 e 17, por apresentarem interações mais baixas com os ambientes, podem ser indicadas para os três locais. A L6 é melhor indicada para o local ESALQ e a L15 responde melhor ao local Areão, como mostram as médias preditas para os ambientes associados com esses locais na Tabela 35 e as adaptações mostradas no biplot AMMI1 (Figura 15a). Distinguiu-se três grupos de linhagens com comportamentos mais similares para a interação G x E: grupo 1 (linhagens mais estáveis): L1, L3, L4, L5, L8, L9, L10, L11, L12, L13, L16, L18, L19, L20, L21, L22, L25 e L27; grupo 2 (linhagens com estabilidades intermediárias): L14, L17, L23, L24 e L26; e o grupo 3 (linhagens instáveis): L2, L6 e L15. A L7 foi a mais divergente e instável em relação às demais LI. Isto indica que 67\% das LI foram estáveis com ambientes. Distinguiu-se dois grupos de 
ambientes com interações mais similares (ambientes estáveis): AN97, AN98, AN99, AR97, AR98, AR99, ES96 e ES97; e o grupo 2 (ambientes com estabilidades intermediárias): AR96 e AN97. Os ambientes AN96, ES98 e ES99 não formaram grupos e foram os mais dissimilares e instáveis deste CM.

Para o caráter \%OL, o biplot AMMI1 (Figura 16a) mostra que, com exceção da L9, todas as demais (99\% das LI) superaram a média das testemunhas $(\mathrm{MT}=18,80 \%)$. Entre essas, destacaram-se as cinco que apresentaram maior \%OL em ordem decrescente de estabilidade: L15 = USP 93-5539, L18 = USP 93-5552, L26 = USP 93-5680, L25 = USP 93-5843 e L23 = 93-5690, como mostram seus escores no biplot AMMI2 (Figura 16b) e as estimativas de A /linhagem preditas pelo modelo AMMI2, apresentadas na Tabela 36. As linhagens 15, 18 e 26, por apresentarem menor interação com os ambientes, podem ser recomendadas para os três locais. A L23 tende a ser mais adaptada ao local Areão, enquanto a L25 responde melhor aos locais Anhembi ou ESALQ (Figura 16b e Tabela 36). Distinguiu-se cinco grupos de linhagens com magnitudes para a interação G x E mais similares: grupo 1 (linhagens mais estáveis): L2, L4, L7, L8, L11, L12, L15, L18, L21, L22, L24, L26 e L27; grupos 2, 3 e 4 (linhagens com estabilidades intermediárias): L5, L6, L13 e L16; L10 e L20; L9 e L19, respectivamente; e o grupo 5: L1 e L14 (linhagens instáveis). As linhagens 3, 17, 23 e 25 não formaram grupos, sendo as linhagens 23 e 25 as mais divergentes e instáveis em relação às demais LI (Figura 16b). Isto evidencia que $48 \%$ das LI foram estáveis com os ambientes. No geral, os ambientes foram muito divergentes entre si; no entanto, distinguiu-se dois grupos com magnitudes mais similares para a interação G x E: grupo 1: AR96 e ES97, e o grupo 2: AN96 e AR98 1 (ambientes com estabilidades intermediárias). Os demais ambientes não formaram grupos, sendo AN97, AN99, AR97, ES96, ES98 e ES99 dissimilares entre si. O ambiente ES98 foi o mais estável, enquanto que os demais foram os mais instáveis dentre todos os ambientes deste CM.

O biplot AMMI1 (Figura 17a) mostra que 24 linhagens (89\% das LI) superaram a média das testemunhas $(\mathrm{MT}=412 \mathrm{Kg} / \mathrm{ha}$ ) para PO. Entre essas, destacaram-se as cinco melhores para PO em ordem decrescente de estabilidade: L13 = USP 93-5243, L12 = USP 93-5082, L17 = USP 93-5549, L6 = 93-2722 e L15 = USP 93-5539, como 
mostram seus escores no biplot AMMI2 (Figura 17b) e as estimativas de A/linhagem apresentadas na Tabela 37. As linhagens 12, 13 e 17, por apresentarem interações mais baixas com os ambientes, podem ser indicadas para os três locais. As L6 e 15 respondem bem à melhoria do ambiente, sendo mais bem indicadas para o local Anhembi. A L15 apresentou a melhor adaptação com o local Areão, como mostram as médias preditas para os ambientes associados com esses locais na Tabela 37 e as adaptações mostradas no biplot AMMI2 (Figura 17b). No biplot AMMI2 (Figura 17b), distinguiu-se seis grupos de linhagens com magnitudes mais similares para a interação $\mathrm{G}$ x E: grupo 1 (linhagens mais estáveis): L4, L8, L10, L11, L12, L13, L18, L20 e L22 ; grupos 2, 3, 4 e 51 (ambientes com estabilidades intermediárias): L1, L2, L6, L9 e L27; L5, L16, L19, L21 e L25; L3 e L17; L23 e L24, respectivamente; e o grupo 6: L14 e L26 (linhagens instáveis). As linhagens 7 e 15 foram as mais divergentes e instáveis em relação às demais LI. Isto mostra que 33\% das LI foram estáveis com os ambientes. Distinguiu-se um grande grupo de ambientes com magnitude similar para a interação G x E (ambientes mais estáveis): AN96, AN98, AN99, AR96, AR97, AR99, ES96 e ES97. Os ambientes AN97, AR98, ES96, ES98 e ES99 não formaram grupos, sendo AR98, ES98 e ES99 os mais dissimilares e instáveis em relação aos demais ambientes deste CM.

Observa-se que a complexidade da interação G x E para a \%OL (modelo AMMI2) foi altamente influente sobre a PO (modelo AMMI2), quando comparada à PG (modelo AMMI1). Como conseqüência, o número de linhagens estáveis para PO foi menor do que para PG.

\subsubsection{Linhagens semitardias}

A análise da interação G x E pela ACP mostrou que apenas o primeiro CPI foi significativo $(\mathrm{P}<0,01)$ para os três caracteres, explicando 39\% (PG e PO) e 38\% (\%OL), respectivamente, da $\mathrm{SQ}_{\mathrm{GxE}}$ (Tabela 28). Os cinco eixos remanescentes representaram variações da $\mathrm{SQ}_{\mathrm{GxE}}$ mais preponderantemente ricas em ruídos. Assim, pelo critério de Cornelius et al. (1992), como a partir do resíduo AMMI1 não foi obtida 
significância, o modelo selecionado para os três caracteres foi o AMMI1, como sendo aquele que melhor descreve a interação G x E padrão.

O biplot AMMI1 (Figura 15b) mostra que quatro linhagens (57\% das LST) foram superiores à média das testemunhas $(\mathrm{MT}=1.788 \mathrm{Kg} / \mathrm{ha})$, destacando-se na seguinte ordem decrescente de estabilidade: L6 = USP 93-5684, L4 = USP 93-5419, L5 = USP 93-5513 e L2 = USP 93-5263, como mostram seus escores no biplot AMMI1 (Figura 15b) e as estimativas de $\mathrm{A}_{\mathrm{i}} /$ linhagem preditas pelo modelo AMMI1 apresentadas na Tabela 38. As linhagens 4 e 6, por apresentarem interações mais baixas com os ambientes, podem ser indicadas para os três locais. As linhagens 2 e 5 apresentaram adaptações a ambientes particulares. A L2 é mais indicada para o local Anhembi (AN96 e AN99) e a L5 responde melhor ao local Areão (AR97, AR98 e AR99), como mostram as médias preditas para os ambientes associados com esses locais na Tabela 38 e as adaptações apresentadas no biplot AMMI1 (Figura 15b). Distinguiu-se três grupos de linhagens com magnitudes mais semelhantes para a interação G x E: grupo 1 (linhagens mais estáveis): L1 e L6; grupo 2 (linhagens mais instáveis): L3 e L5; e grupo 3: L4 e L7 1 (linhagens com estabilidades intermediárias). A L2 manteve-se isolada em relação às demais LST, apresentando-se instável. Distinguiu-se um grande grupo de ambientes com interações similaridades (ambientes mais estáveis): AN97, AN99, AR96, AR97, AR98, AR99, ES96, ES97, ES97 e ES99. Os ambientes AN96, AN98, AN99 e ES98 foram dissimilares e os mais instáveis em relação aos demais deste CM.

Para o caráter \%OL, o biplot AMMI1 (Figura 18a) mostra que quatro linhagens (57\% das LST) foram superiores à média das testemunhas (MT $=20,15 \%)$. Essas linhagens podem ser classificadas na seguinte ordem decrescente de estabilidade: L6 = USP 93-5684, L4 = USP 93-5419, L5 = USP 93-5513 e L7 = USP 93-5802, como mostram seus escores no biplot AMMI1 (Figura 18a) e as estimativas de A/linhagem preditas pelo modelo AMMI1, apresentadas na Tabela 38. As linhagens 4 e 6, por apresentarem interações mais baixas com os ambientes, podem ser indicadas para os três locais. As linhagens 3 e 7 apresentaram adaptações positivas com ambientes particulares. A L3 é melhor indicada para o local ESALQ (adaptações mais altas com os ambientes ES97 e ES98) e a L7 responde melhor ao local Areão (adaptações mais altas 
com os ambientes AR97, AR98 e AR99), como mostram as médias preditas para os ambientes associados com esses locais na Tabela 38 e as adaptações mostradas no biplot AMMI1 (Figura 18a). Distinguiu-se dois grupos de linhagens com interação $\mathrm{G}$ x E similares: grupos 1 e 2 (linhagens com estabilidades intermediárias): L4 e L5; L1 e L7, respectivamente. As linhagem 2, 3 e 6 foram dissimilares para a interação G x E, com a L6 exibindo alta previsibilidade e as linhagens 2 e 3, alta instabilidade. Distinguiu-se três grupos de ambientes com interações similares: grupo 1 (ambientes mais estáveis): AN96, AR96, AR97, AR99, ES97 e ES98; grupo 2 (ambientes com estabilidades intermediárias): AN99, ES96 e AR98; e o grupo 3 (ambientes mais instáveis): AN97 e ES99. O ambiente AN98 foi dissimilar quanto à interação $\mathrm{G}$ x E em relação aos demais grupos de ambientes.

O biplot AMMI1 (Figura 18b) mostra que todas as sete linhagens, ou seja, $100 \%$ foram superiores à média das testemunhas para PO $(\mathrm{MT}=364 \mathrm{Kg} / \mathrm{ha})$. Entre essas, destacaram-se as cinco melhores para PO em ordem decrescente de estabilidade: L6 = USP 93-5684, L1 = USP 93-2521, L4 = USP 93-5419, L5 = USP 93-5513 e L2 = 93-5263, como mostram seus escores no biplot AMMI1 (Figura 18b) e as estimativas de $\mathrm{A}_{\mathrm{i}} /$ linhagem preditas pelo modelo AMMI1, apresentadas na Tabela 38. As linhagens 1, 4 e 6, por apresentarem interações mais baixas com os ambientes, podem ser indicadas para os três locais. As L2 e L5 foram mais bem adaptadas ao local Anhembi, como mostram as médias preditas para os ambientes associados com esses locais na Tabela 38 e as adaptações mostradas no biplot AMMI1 (Figura 18b). Distingui-se dois grupos de linhagens com magnitudes mais semelhantes para a interação G x E: grupo 1 (linhagens mais estáveis): L1, L4 e L6; e o grupo 2: L2 e L7 (linhagens instáveis). As linhagens 3 e 5 ficaram isoladas, sendo a L3 mais divergente e instável em relação às demais LST. Distinguem-se três grupos de ambientes com interações mais similares: grupo 1 (ambientes mais estáveis): AR96, AR98, AR99, ES97 e ES99; e os grupo 2 e 3 (ambientes com estabilidades intermediárias): AN97 e ES98; AN99 e AR97, respectivamente. Os ambientes AN96 e AN98 foram divergentes e os mais instáveis deste CM. 


\subsubsection{Análise AMMI para os quatro ciclos de maturação}

No geral, os biplots AMMI1 (Figuras 10a, 11a, 11b, 12a, 13a, 14a, 15a, 15b, 16a, 17a, 18a e 18b) referentes aos três caracteres e aos quatro CM, mostraram que os ambientes apresentaram maior variabilidade do que as linhagens, tanto em efeitos principais quanto multiplicativos (variação para efeitos principais e multiplicativos são visualizados nos sentidos horizontal e vertical do gráfico, respectivamente). Isso confirma os resultados para as magnitudes das SQ evidenciados pela ANAVA (Tabela 20) com relação a essas fontes de variação.

Os ambientes associados com o local Anhembi apresentaram altos valores de escores para PG e PO, mostrando que este local interagiu fortemente com os anos, principalmente no ano agrícola 1996/97 (LP, LSP e LST), mas também nos anos de 1998/99 (LST) e 1999/00 (LSP); os ambientes associados com o local Areão apresentaram escores mais próximos de zero, evidenciando que este local interagiu pouco com os anos, sendo então mais previsível (estável); os ambientes relacionados com o local ESALQ mostraram comportamento intermediário (Figuras 10b, 12b, 13b, 14b, 15b e 18b). As estimativas para A:/local (Tabelas 29, 31, 32 e 34) preditas pelo modelo AMMI4 (LP e LSP) e pelo modelo AMMI1 (LST)(Tabela 38) confirmam maior média e maior interação para o local Anhembi e menores valores de média e de interação para o local Areão; o local ESALQ apresentou estimativas intermediárias de média e interação.

Resultados diferentes foram obtidos para as LI, para as quais os ambientes associados com o local Anhembi foram os mais estáveis e também apresentaram as médias mais altas para PG e PO, enquanto que os ambientes associados com os locais ESALQ mostraram interações altas, principalmente ES98 e ES99, e apresentaram médias intermediárias; os ambientes associados com o local Areão exibiram interações intermediárias e médias baixas (Figuras 15a e 17b). As estimativas para $\mathrm{A}_{\mathrm{i}} /$ local (Tabelas 35 e 37) preditas pelos modelos AMMI1 (PG) e AMMI2 (PO) confirmam maior média e menor interação para o local Anhembi, maior interação e média intermediária para o local ESALQ e menor média e interação intermediária para o local 
Areão. Observou-se que os ambientes associados com o local Anhembi reuniram estabilidade com adaptabilidade, diferentemente do que ocorreu com as LP, LSP e LST, as quais sempre associaram alta adaptabilidade (médias altas) com baixa estabilidade (interações altas).

Para a \%OL, os ambientes associados com o local Anhembi apresentaram os mais altos valores de escores para as LSP, LI e LST, mostrando que este local interagiu fortemente com os anos, principalmente nos anos agrícolas de 1996/97 (LSP), 1997/98 (LST) e 1999/00 (LSP e LI); os ambientes associados com o local Areão apresentaram escores mais próximos de zero, evidenciando que este local interagiu pouco com os anos, sendo, portanto, mais previsível com os anos agrícolas; os ambientes associados com o local ESALQ apresentaram interações intermediárias (Figuras 11b, 16b e 18a). As estimativas de $\mathrm{A}_{\mathrm{i}} /$ local preditas pelos modelos AMMI1 (LSP e LST) e AMMI2 (LI) (Tabelas 33, 36 e 38) confirmam médias alta (LSP e LI) e intermediária (LST) e interação intermediária para o local ESALQ; maior interação e médias baixas (LI e LST) e intermediária (LSP) para o local Anhembi; o local Areão apresentou menores estimativas de interação e médias variáveis baixa (LSP), intermediária (LI) e alta (LST). Para as LP, os ambientes associados com o local Areão apresentaram os mais altos valores de escores para a \%OL, mostrando que este local interagiu fortemente com os anos, principalmente nos anos agrícolas de 1996/97 e 1997/98; os ambientes associados com o local Anhembi apresentaram escores mais próximos de zero, evidenciando que este local interagiu pouco com os anos, sendo então mais previsível com os anos agrícolas; os ambientes associados com o local ESALQ apresentaram interações intermediárias (Figura 11a). As estimativas de $\mathrm{A}_{\mathrm{i}} /$ local preditas pelo modelo AMMI1 (Tabela 30) confirmam maior média e maior interação para o local Areão e menor média e interação para o local Anhembi. Observou-se que o local Areão apresentou interação alta e positiva e o local Anhembi interação baixa e negativa, resultados esses, diferentes daqueles obtidos para as LSP, LI e LST, para as quais o local Areão sempre esteve associado com interações baixas e o local Anhembi com interações altas.

Os resultados para as LP e LSP relacionados aos caracteres PG e PO, cujo modelo selecionado foi o AMMI4, foram diferentes dos encontrados por Zobel et al. 
(1988), Gauch \& Zobel (1990) e Ariyo (1998) para o caráter PG, nos quais os modelos selecionados foram AMMI1, AMMI2 e AMMI1, respectivamente. Tais resultados, são mais parecidos com os obtidos para as LI e LST; no entanto, nesses trabalhos, a maior porcentagem de variação da $S_{\text {GxE }}$ padrão foi concentrada nos primeiros CPIs (71, 70 e $86 \%$, respectivamente). Os resultados do presente trabalho foram mais concordantes com aquele obtido por Sneller \& Dombek (1995), no qual o CPI1 explicou apenas 23\% da $S_{\text {GxE }}$ para PG. Resultados sobre o uso da análise AMMI para o caráter \%OL para a cultura da soja não foram encontrados na literatura consultada.

Pelos resultados dos trabalhos antes citados, o padrão adjacente à interação $\mathrm{G} x$ E foi alto nos primeiros eixos, ao contrário dos resultados obtidos no presente trabalho, no qual o padrão se mostrou baixo e distribuído em mais de dois eixos, nos casos das LP e LSP. Essa distribuição em mais de dois eixos pode sugerir maior complexidade da interação G x E, relativamente as LI e LST. Segundo Romagosa \& Fox (1993), modelos que incluem altas dimensões ou muitos eixos da ACP estão muito associados com ruídos, porque a falta de habilidade preditiva, pode em alguns casos ser um artefato para aplicar modelos para situações além do limite de sua capacidade para explicar a interação G x E. Seguindo este mesmo raciocínio, Sharma et al. (1998) comentam que a seleção de modelos que incluem muitos CPIs pode sugerir a presença de uma variação complexa e multidimensional para a interação G x E; no entanto, pode envolver muito mais ruídos do que propriamente interações complexas entre genótipos e ambientes. Lavoranti et al (2001) comentam que, a princípio, a representação gráfica em biplot desses resultados não se justificaria, devido à proporção relativamente baixa da $\mathrm{SQ}_{\mathrm{GxE}}$ explicada pelos primeiros eixos singulares. Entretanto, este autor argumenta que, teoricamente, a análise AMMI apresenta como característica principal a captação da maior parte do padrão nos primeiros CPIs.

Com base nas argumentações dos autores citados acima, as interpretações do presente trabalho foram feitas considerando a variação padrão concentrada no CPI1 e/ou CPI2. Neste caso, utilizou-se das médias e interações preditas pelo modelo AMMI4 (LP e LSP) para confirmar as adaptações específicas e as estabilidades observadas nos

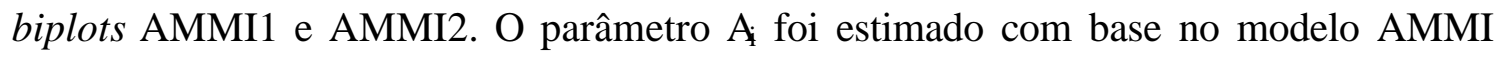


selecionado com o objetivo de confirmar as estabilidades mostradas nos gráficos. Para as LI e LST, isto não era extremamente necessário, já que a porção significativa da interação padrão se concentrava no máximo no CPI2. Neste caso, a interpretação com base nos biplots AMM11 e AMMI2 atendia perfeitamente o propósito do método. Como uma forma de padronização, adotou-se esse critério para todos os CM.

O baixo número de repetições por ambientes pode ter contribuído para uma baixa precisão nas estimativas das médias das linhagens em cada ambiente, influenciando o resíduo da ANAVA com efeitos não relacionados com o fenômeno da interação $\mathrm{G}$ x E, o que pode resultar numa $S Q_{\mathrm{GxE}}$ contendo mais ruído do que padrão.

Em um trabalho conduzido com ervilha por Taye et al. (2000), foram utilizadas médias obtidas de duas repetições e o modelo selecionado foi o AMMI5. Os resultados evidenciaram que a interação complexa requereria no mínimo dois eixos para explicar uma considerável variação da interação $G$ x E. Esta complexidade pode estar associada com a natureza da cultura, características ambientais e base genética obtida a partir de diferentes fontes. Segundo esses autores, a adição do CPI3 poderia contribuir para a acurácia das estimativas da produtividade de grãos, porém, este não seria imprescindível como os dois primeiros eixos considerados para suficiente dimensionalidade na análise gráfica; ademais, o CPI3 complica a observação gráfica visual do efeito da interação $\mathrm{G}$ x E. Com base em métodos usados para selecionar ótima dimensionalidade, os resultados indicaram que os CPIs 4 e 5 não apresentavam real contribuição em representar a interação G x E, sendo maior contribuição atribuível a ruídos. Também relataram que as somas de quadrados obtidas a partir dos CPIs 6 e 7 foram compostas puramente pelo componente ruído; assim, concluíram que as somas de quadrados que compreendiam do terceiro ao sétimo eixo poderiam ser somadas e classificadas como ruído, já que elas não tiveram real poder preditivo.

Quando a $S Q_{\mathrm{GxE}}$ contém mais ruído do que padrão, e o padrão importante se concentra nos primeiros CPIs, a análise AMMI torna-se mais efetiva do que as demais metodologias, já que a análise descarta essa variação G x E preponderantemente rica em ruídos; variação essa, sem interesse agronômico e que só contribui para diminuir a acurácia das estimativas das interações e respostas dos genótipos com os ambientes. Em 
um trabalho conduzido com a cultura do milho por Crossa et al. (1990), estes concluíram que médias preditas pelo modelo AMMI a partir de duas repetições foram tão precisas quanto aquelas estimadas pela ANAVA com base no modelo completo (AMMIF) e a partir de cinco repetições. Gauch \& Zobel (1988) comentam que no uso do processo "posdictivo" (uso de testes de hipóteses, como por exemplo, o teste $F_{\text {Gollob }}$ ) existe o perigo de selecionar um grande número de eixos e de superajustar os dados. Em particular, o modelo AMMIF completo foi encontrado ser um pobre preditor do grupo de validação, segundo a abordagem da validação cruzada. Em geral, o critério de validação cruzada mostrou que dados relacionados à interação $G$ x E são melhor descritos pelos modelos AMMI contendo um ou dois termos multiplicativos; neste sentido, Romagosa \& Fox (1993) recomendam o uso da validação cruzada como uma estratégia mais preditiva para a seleção de modelos da família AMMI.

\subsection{Comparações entre as metodologias}

As estimativas dos coeficientes de correlação de Spearman aplicados às ordens crescentes para os parâmetros de estabilidade $\left(\omega_{i}, s^{2} d_{i}, R^{2}\right.$ e $\left.A_{i}\right)$ e ordens decrescentes para os parâmetros de adaptabilidade $\left(m_{i}\right.$ e $\left.b_{i}\right)$, para cada par de parâmetros, são apresentadas nas Tabelas 39 e 40. Os resultados mostraram que a maioria das correlações estimadas apresentou significância $(P<0,01)$, evidenciando um alto grau de associação no conjunto dos parâmetros considerados. No caso das LST, ocorreram estimativas de correlações altas ( $\mathrm{r}>0,50)$, no entanto, sem exibir significância. Isso talvez possa ser explicado pelo baixo número de graus de liberdade considerado no teste da hipótese de que os dois parâmetros fossem independentes, para o referido CM.

Analisando as correlações entre os diversos parâmetros e a média para PG e PO $\left(\mathrm{m}_{\mathrm{i}}\right)$, observou-se que a mais alta delas ocorreu com $b_{\mathrm{i}}$. Os valores foram maiores para as LI ( $\mathrm{r}=0,62$ e 0,66, respectivamente) e menores para as $\operatorname{LSP}(\mathrm{r}=0,17$ e 0,31, respectivamente). Valores intermediários foram encontrados para as $\operatorname{LP}(\mathrm{r}=0,21$ e 0,22, respectivamente) e $\operatorname{LST}(0,32$ e 0,28, respectivamente). Essa tendência positiva de associação entre $m_{i}$ e $b_{i}$ era esperada, uma vez que o parâmetro $b_{i}$ eleva-se à medida que 
a linhagem possui valores médios de PG e PO maiores na maioria dos ambientes. $\mathrm{O}$ parâmetro $\mathrm{m}$ apresentou associação baixa com os parâmetros de estabilidade $\left(\omega_{\mathrm{i}}, \mathrm{s}^{2} \mathrm{~d}_{\mathrm{i}}\right.$, $\mathrm{R}^{2}$ e $\mathrm{A}_{\mathrm{i}}$ ), sendo que em vários casos ocorreu associação negativa (LST). Isto sugere que a seleção simultânea para alta PG e PO e estabilidade, no geral, torna-se difícil, mas não impossível; realmente, no presente trabalho, várias linhagens associaram adaptação ampla com alta previsibilidade.

O parâmetro de estabilidade que mais apresentou tendência de associação positiva com $\mathrm{m}_{\mathrm{i}}$ foi $\mathrm{R}^{2}$, seguido de $\mathrm{A}_{\mathrm{i}}$. Para $\mathrm{PG}, \mathrm{m}_{\mathrm{i}}$ apresentou as mais baixas associações com os parâmetros $\omega_{i}(r=-0,64$ a 0,15$)$ e $s^{2} d_{i}(r=-0,64$ a 0,15$)$. Segundo Duarte (1988), considerando que $\omega_{\mathrm{i}}$ é usado isoladamente, a sua não associação linear com m indica a possibilidade de uso conjunto dos dois parâmetros, no sentido de aumentar a segurança da utilização do método prático da ecovalência. Resultados semelhantes foram obtidos por outros autores. Dashiel et al. (1994), estudando a correlação entre parâmetros de adaptabilidade $\left(m_{i}\right.$ e $\left.b_{i}\right)$ e estabilidade $\left(s^{2} d_{i}\right)$ para PG em soja, também encontraram resultados semelhantes entre $m_{i}$ e os parâmetros $b_{i}(r=0,50)$ e $s^{2} d_{i}(r=0,03)$. Em outro estudo com soja, Miranda (1999) também obteve baixa estimativa para o coeficiente de correlação entre m e $\omega_{i}(r=0,02)$. Observa-se que para PO, as estimativas do coeficiente de correlação entre $\mathrm{m}_{\mathrm{i}}$ e os parâmetros de estabilidade foram mais altas do que para PG, exceto para as LST. Isto indica que a probabilidade de selecionar linhagens com alta PO e alta estabilidade é maior do que no caso de PG, principalmente para as LP e LI.

Resultados diferentes em relação às associações dos parâmetros com $\mathrm{m}_{\mathrm{i}}$, foram observados para o caráter \%OL. Este apresentou associação positiva com bi (LP e LI) e negativa com a maioria dos parâmetros de estabilidade, principalmente com $\omega_{\mathrm{i}}, \mathrm{s}^{2} \mathrm{~d}_{\mathrm{i}} \mathrm{e}$ $\mathrm{A}_{\mathrm{i}}$. Isto sugere que, para este grupo de linhagens, selecionar para adaptabilidade e estabilidade com base nesses parâmetros para a \%OL é mais difícil do que para os caracteres PG e PO. A baixa associação entre esses parâmetros indica que a utilização de ambos será mais informativa na identificação e seleção de linhagens que reúnam adaptabilidade e estabilidade para a \%OL. 
Entre as estimativas de correlação de $b_{i}$ e os parâmetros de estabilidade $\left(\omega_{i}, s^{2} d_{i}\right.$, $\mathrm{R}^{2}$ e $\mathrm{A}_{\mathrm{i}}$ ), destacam-se como fortes e positivas para PG e PO, apenas aquelas com $\mathrm{R}^{2}$, nas LI ( $\mathrm{r}=0,78$; e 0,89; respectivamente); já para a \%OL, houve destaque apenas nas LST ( $\mathrm{r}$ = 0,93). Associações baixas, positivas (LI e LST) e negativas (LP e LSP) para PG e PO, foram observadas entre $b_{1}$ e os parâmetros $s^{2} d_{i}$ e $A_{i}$. Para a \%OL, a maioria dos $C M$ apresentaram correlações negativas entre $b_{1}$ e os parâmetros $s^{2} d_{i}$ e $A_{i}$. Segundo Duarte (1988), o parâmetro $R^{2}$ sugerido por Pinthus (1973) não é adequado para selecionar para estabilidade, já que este é linearmente associado ao parâmetro $b_{i}$. Os resultados do presente trabalho corroboram com essa afirmação, evidenciando que entre $\mathrm{R}^{2}$ e $\mathrm{s}^{2} \mathrm{~d}_{\mathrm{i}}$, este último é mais adequado como parâmetro de medida de estabilidade.

Correlações altas, positivas e significativas foram observadas entre os parâmetros de estabilidade $\omega_{i}, s^{2} d_{i}, R^{2}$ e $A_{i}$ para a maioria das estimativas dos caractres e CM. O parâmetro $\omega_{\mathrm{i}}$ apresentou maior associação com $\mathrm{s}^{2} \mathrm{~d}_{\mathrm{i}}$ para os caracteres PG, PO (r $=0,91$ a 1,00$)$ e $\% \mathrm{OL}(\mathrm{r}=0,41$ a 0,99$)$, em todos os CM, sugerindo que esses dois parâmetros são fortemente correlacionados. De acordo com Becker (1981), a magnitude da ecovalência geralmente depende principalmente da magnitude do quadrado médio dos desvios; assim, é esperado que a $\mathrm{s}^{2} \mathrm{~d}_{\mathrm{i}}$ e $\omega_{\mathrm{i}}$ sejam altamente correlacionados. Portanto, recomenda-se o uso de um desses parâmetros como medida da estabilidade agronômica. Como s ${ }^{2} \mathrm{~d}_{\mathrm{i}}$ é um parâmetro associado à regressão, garante maiores informações a respeito do comportamento individual de cada genótipo e é preferível em relação ao parâmetro $\omega_{\mathrm{i}}$, por ser este menos informativo.

Correlações entre $\omega_{i}$ e $\mathrm{R}^{2}$ geralmente foram altas para os três caracteres em todos os CM ( $\mathrm{r}=0,54$ a 0,89), exceto para a \%OL nas LST; já entre $\omega_{i}$ e $A_{i}$, as correlações variaram de 0,59 a 0,91 , sendo não significativa apenas para PO nas LST. Associações altas e significativas também foram observadas entre $s^{2} d_{i}$ e $R^{2}(r=0,62$ a $0,90)$ e entre $s^{2} d_{i}$ e $A_{i}(r=0,56$ a 0,89$)$, neste último caso, exceto para a \%OL e a PO nas LST. O parâmetro $R^{2}$ apresentou estimativas de $r>0,50$ e significativas com $A_{i}$, apresentando uma média de $\mathrm{r}=0,60$, exceto para PG nas LI e \%OL nas LST, que apresentaram correlações baixas e não significativas. 
Observou-se que as correlações entre $A_{i} \operatorname{com} \omega_{i}$ e $s^{2} d_{i}$, no geral, foram positivas, altas, significativas, e de certa forma similares. Observa-se que nos casos em que o modelo AMMI selecionado foi maior (AMMI4), as correlações tenderam a ser mais altas. Uma explicação, no caso de $\mathrm{A}_{\mathrm{i}}(\mathrm{AMMI})$ e $\omega_{\mathrm{i}}$, é que as estimativas preditas por esse modelo são mais próximas daquelas estimadas pela ecovalência. Ambas, foram estimadas com base na $\mathrm{SQ}_{\mathrm{GxE}}$; no entanto, no cálculo da ecovalência é considerada a $\mathrm{SQ}_{\mathrm{GxE}}$ total, enquanto no cálculo de $\mathrm{A}_{\mathrm{i}}$ (AMMI4) considera-se apenas a parte que contém a maior parte do padrão adjacente à interação $G$ x E, representando a porção verdadeiramente importante da SQ GxE. Assim, modelos que englobam muitos componentes da ACP tendem a se aproximar do modelo completo ( $\mathrm{SQ}_{\mathrm{GxE}}$ total), que é a base de cálculo da ecovalência. No caso de $\mathrm{A}_{\mathrm{i}}$ (AMMI4) e $\mathrm{s}^{2} \mathrm{~d}_{\mathrm{i}}$, essa explicação é válida em parte, já que a obtenção de $\mathrm{s}^{2} \mathrm{~d}_{\mathrm{i}}$ também envolve a $S \mathrm{Q}_{\mathrm{GxE}}$, mas também engloba a $\mathrm{SQ}$ de ambientes (E). Nota-se que não houve uma tendência em termos de magnitude para as correlações entre $A_{i}$ com $\omega_{i}$ ou $s^{2} d_{i}$. Para os diferentes caracteres e CM, ora a correlação foi maior entre $A_{i}$ e $\omega_{i}$, ora foi maior entre $A_{i}$ e $s^{2} d_{i}$, ora ela foi baixa, como a observada para \%OL nas LST.

Segundo Gauch \& Zobel (1989), Crossa et al. (1990), Crossa et al. (1991) e Nachit et al. (1992), o ordenamento dos genótipos em cada ambiente estimado por modelos que englobam poucos eixos da ACP, por exemplo AMMI1, foi diferente daquele que englobava todos os eixos (AMMIF). Esses autores, trabalhando com culturas diferentes (trigo, soja e milho), encontraram que a porcentagem para diferenças no ordenamento dos genótipos foi sempre maior em modelos reduzidos, quando comparados com o ordenamento realizado com médias não ajustadas (modelo completo), estimadas com base na $\mathrm{SQ}_{\mathrm{GxE}}$ total. No presente trabalho, observou-se também essa tendência, já que nos casos em que os modelos eram mais reduzidos, a correlação entre $A_{i}$ e os parâmetros estimados com base na $S Q_{G x E}$ total $\left(s^{2} d_{i}\right.$ e $\left.\omega_{i}\right)$ foram sempre mais baixas, como mostram as estimativas entre $A$ com $s^{2} d_{i}$ e $\omega_{i}$ em todos os caracteres nas LP, LSP e LI (Tabelas 39 e 40). 
Lin et al. (1986) apontaram que o uso de parâmetros pertencentes a diferentes conceitos pode levar a diferentes ordenamentos de genótipos em termos de sua estabilidade. Os resultados de correlações observadas entre os parâmetros $\omega_{i}$, s ${ }^{2} d_{i}$ e $A_{i}$ indicaram que estes ordenam as linhagens de forma similar, evidenciando que pertencem a um mesmo tipo de conceito em termos de estabilidade. De fato, Lin et al. (1986) sugeriram que a $s^{2} d_{i}$ apresenta estabilidade tipo 3 (alta confiabilidade de resposta estimada). Duarte \& Zimmermann (1995) comentam que a estabilidade avaliada pela ecovalência, não somente reflete a estabilidade tipo 2, como sugerido por Lin et al. (1986), mas também reflete o conceito de estabilidade tipo 3. Em relação ao parâmetro $A_{i}$, por ser estimado da mesma forma que $\omega_{i}$, este também pode refletir a estabilidade tipo 3, diferindo apenas na vantagem adicional deste avaliar melhor o padrão subjacente à interação $\mathrm{G}$ x E.

Os resultados mostraram que a interação $G$ x E foi mais bem explicada pela análise AMMI do que pelas metodologias da ecovalência (Wricke \& Weber, 1986) e de Eberhart \& Russel. No caso de AMMI e Eberhart \& Russel, os resultados mostraram que a regressão linear (RL) explicou pouco da interação $G$ x E, como mostram as estimativas de $\mathrm{R}^{2}$ apresentadas na Tabela 20. A interação explicada pelos CPIs 1 da análise AMMI foi sempre maior do que aquela explicada pela fonte de variação $\mathrm{G} \times \mathrm{E}$ linear em todos os caracteres e CM (Tabelas 25, 26, 27 e 28), concordando com os resultados obtidos por: Zobel et al. (1988) em soja; Nachit et al. (1992), Yau (1995) e Annicchiarico (1997b) em trigo; Fox et al. (1990) em triticale; Argiller et al. (1994) em milho; e Pereira \& Costa (1998) em batata. Em todos esses trabalhos, ficou evidenciado que a análise AMMI foi mais eficiente em explicar a interação $\mathrm{G}$ x E nos primeiros eixos da ACP do que a toda a variação $G$ x E explicada pela regressão. De acordo com Yau (1995), a efetividade da análise de regressão linear para análise da interação G x E também decresce à medida que o número de dados aumenta.

O método AMMI também foi superior aos métodos da ecovalência (Wricke \& Weber, 1986) e de Eberhart \& Russel em relação à facilidade de interpretação e pelo ganho em acurácia para as estimativas da interação G x E e, conseqüentemente, para as médias dos ambientes. Como os modelos AMMI selecionados descartam a variação 
presente na $\mathrm{SQ}_{\mathrm{GxE}}$ rica em ruídos e considerando que os resultados do presente trabalho evidenciaram que existia mais ruído do que padrão na estrutura dos dados, acredita-se que as interações preditas pelos modelos AMMI foram adequadas e que aquelas preditas pela ANAVA para os métodos da ecovalência (Wricke \& Weber, 1986) e de Eberhart \& Russel (1966) foram sub ou superajustadas, dependendo da interação individual de cada linhagem com os ambientes. Segundo Nachit et al. (1992), em um estudo conduzido com genótipos de ervilha em vários ambientes, após eliminar a variação aleatória, o modelo AMMI selecionado estimou de forma mais precisa as médias dentro de ambientes do que as médias não ajustadas; e o aumento em precisão foi equivalente ao aumento do número de repetições por um fator de 3,7. Conseqüentemente, o ganho em acurácia pode ser usado para reduzir os custos por reduzir o número de repetições, incluir mais tratamentos no experimento ou melhorar a eficiência de seleção de genótipos superiores (Crossa, 1990).

É importante ressaltar que o volume de dados a serem analisados por AMMI dever ser tal que não prejudique a interpretação na análise gráfica em biplot. Neste estudo, observou-se que a interpretação foi mais fácil para as LI e LST (menor número de linhagens), quando comparado às LP e LSP (maior número de linhagens). Nestas, o maior numero de pontos no biplot prejudicou a distinção entre genótipos e ambientes e de suas relações adaptativas.

No que diz respeito à avaliação da estabilidade, a análise AMMI foi eficiente, mesmo nos casos para os quais o modelo selecionado incluía mais de dois eixos da ACP e a interpretação gráfica foi realizada com base em modelos reduzidos (AMMI1 ou AMMI2), de acordo com as considerações feitas por Lavoranti et al., 2001. Com relação às relações adaptativas, estas foram melhor compreendidas quando se associou a visualização gráfica por modelos reduzidos (LP e LSP) com as estimativas preditas pelos modelos AMMI selecionados, pelo uso do parâmetro $A_{i}$ para linhagens, ambientes e locais. 


\subsection{Considerações finais}

As diferenças significativas encontradas para a interação linhagens $\mathrm{x}$ locais $\mathrm{x}$ anos evidenciam a necessidade de as linhagens serem submetidas a um adequado número de locais e anos. Estes devem representar as possíveis variações de ambiente que as linhagens testadas encontrarão, quando recomendadas como cultivares.

Com base nas médias dos doze ambientes, das dez linhagens superiores em PG, $50 \%$ também o foram em PO, mas com ordens de classificação diferentes para os dois caracteres. Estas linhagens mostraram ausência ou baixa intensidade de sintomas de CHS (Rocha, 1998) e são relatadas a seguir, juntamente com suas genealogias, CM e médias para PG:

$\begin{array}{llll}\text { USP 93-5243 } & \text { FT 81-2.706 x PI 371610 } & \text { LI } & 2.940 \mathrm{Kg} / \mathrm{ha} \\ \text { USP 94-1086 } & \text { Década x FT 81-1835 } & \text { LP } & 2.894 \mathrm{Kg} / \mathrm{ha} \\ \text { USP 93-2722 } & \text { IAC-12 x GO 81-11.646 } & \text { LI } & 2.812 \mathrm{Kg} / \mathrm{ha} \\ \text { USP 93-2316 } & \text { Bossier x GO 81-11.646 } & \text { LSP } & 2.952 \mathrm{Kg} / \mathrm{ha} \\ \text { USP 93-1106 } & \text { Primavera x FT 81-1835 } & \text { LSP } & 2.726 \mathrm{Kg} / \mathrm{ha} \\ \text { USP 93-2084 } & \text { Bossier x Viçoja } & \text { LSP } & 2.710 \mathrm{Kg} / \mathrm{ha} \\ \text { USP 94-1044 } & \text { Coker 136 x Hale 321 } & \text { LP } & 2.708 \mathrm{Kg} / \mathrm{ha} \\ \text { USP 93-5082 } & \text { GO 81-11.646 x SOC 81-228 } & \text { LI } & 2.668 \mathrm{Kg} / \mathrm{ha} \\ \text { USP 93-2897 } & \text { GO 81-11.646 x FT 81-2706 } & \text { LSP } & 2.634 \mathrm{Kg} / \mathrm{ha} \\ \text { USP 93-1042 } & \text { IAC-Foscarin-31 x Primavera } & \text { LP } & 2.629 \mathrm{Kg} / \mathrm{ha}\end{array}$

$\ddot{E}$ interessante notar que esses cruzamentos já estavam entre os selecionados como de alto potencial para produção de genótipos superiores nos trabalhos conduzidos por Freire Filho (1988), Krieger (1992) e Zimback (1992). Esses resultados evidenciam que a predição dos melhores cruzamentos em gerações precoces pode antecipar aqueles que fornecerão os melhores genótipos em gerações avançadas de endogamia. Conforme observações feitas por Triller \& Toledo (1996), quando esta predição é feita no começo do programa, os cruzamentos menos promissores podem ser descartados antes que sejam 
conduzidos os experimentos finais de produtividade, os quais têm custo elevado. Das dez linhagens identificadas como superiores por Rocha (1998) no ano agrícola 1996/97, quatro foram comuns às dez antes citadas (USPs 93-5243, 93-2316, 94-1086 e 93-5082). Isto evidencia que estas linhagens reúnem adaptabilidade e estabilidade fenotípica, pois apresentaram as maiores médias e as mantiveram nos diversos ambientes. Dessas, duas pertencem ao $\mathrm{CM}$ intermediário e as outras duas aos CM precoce e semiprecoce.

A probabilidade de obtenção de linhagens superiores é função da frequiência gênica da população, significando que melhores linhagens são mais facilmente obtidas em populações básicas formadas através da recombinação de cultivares elites. De fato, das dez linhagens mais produtivas, nove tiveram origem a partir de cruzamentos envolvendo parentais adaptados. No entanto, a LI USP 93-5243 que apresentou alta adaptabilidade e estabilidade, pertence a um cruzamento misto (FT 81-2.706 x PI 371.610)(Apêndice 1). As similaridades observadas para os grupos de linhagens que apresentavam alta estabilidade na análise gráfica em biplot AMMI, também evidenciaram a presença de algumas linhagens advindas de cruzamentos mistos.

Vello (1985) comenta que, apesar do efeito negativo que os parentais exóticos possam exercer na média da população resultante de cruzamentos mistos, é possível obter genótipos superiores mesmo nestes cruzamentos, desde que o parental exótico apresente boa adaptação ao ambiente de cultivo. Provavelmente, as referidas linhagens devem ter concentrado, com o avanço das gerações, maior número de genes para adaptação vindos do parental adaptado, em detrimento ao parental exótico; no entanto, este último pode ter contribuído com genes para estabilidade. Tal resultado concorda com aquele obtido por Rocha (1998).

Os efeitos de ambientes foram mais importantes em magnitude do que os efeitos da interação G x E, e esta mais importante do que os efeitos de linhagens, para a variação total de tratamentos. Comparativamente, as LSP apresentaram magnitudes maiores do que os demais CM, enquanto as LST exibiram menores estimativas para a interação G x E para PG e PO. Resultados contrários foram observados para o caráter \%OL, para a qual as LSP apresentaram menor magnitude e os demais CM mostraram maiores estimativas para a interação $G$ x E (Tabela 20). A alta concentração de 
linhagens por CM apresentando baixos escores para a interação G x E e que superaram a média das testemunhas para as LI, relativamente as LP, LSP e LST (biplots AMMI), sugere que as LI concentraram maior quantidade de genes para estabilidade e adaptabilidade do que os demais CM. Isto explica em parte, porque o local Anhembi foi mais estável para este grupo e se mostrou instável para os demais CM. Alta estabilidade para as LI também foram obtidas em outros materiais em trabalhos conduzidos por Soldini (1993), Laínez-Mejía (1996) e Rocha (1998).

Os ambientes associados com os locais Anhembi (principalmente) e ESALQ foram mais favoráveis para a adaptabilidade das linhagens, mas se mostraram muito instáveis, ao passo que os ambientes relacionados com o local Areão foram desfavoráveis para a adaptabilidade, mas favorável para a estabilidade, exceto para as LI, para os caracteres PG e PO. Para a \%OL, o local Areão tendeu a ser mais favorável, comparativamente os locais Anhembi e ESALQ.

Dentre os fatores bióticos e abióticos que podem ter contribuído para a interação $\mathrm{G}$ x E, a presença do CHS e a pluviosidade parece ter tido maior influência, quando comparados com outros fatores climáticos como fotoperíodo, temperatura e umidade relativa, que praticamente não variaram com os anos agrícolas. $\mathrm{O}$ ano agrícola 1996/97 foi associado com estresse ambiental para os locais ESALQ e Areão, principalmente para PG e PO, devido à grande infestação pelo CHS, considerado por Rocha (1998) um fator que deve ter contribuído para a baixa adaptabilidade das linhagens nesses locais nos quais ocorreu infestação e alta adaptabilidade no local Anhembi, no qual não ocorreu a doença. Os biplots AMMI mostraram que os ambientes associados com este ano agrícola foram os mais instáveis, sugerindo que este estresse ambiental contribuiu de forma intensa para a interação $G$ x E. O baixo índice pluviométrico observado neste ano em relação aos demais anos, também pode ter contribuído como um fator de estresse adicional. Segundo Annicchiarico (1997b), ambientes localizados em regiões tropicais são mais propensos à ocorrência de estresses ambientais, o que pode sugerir padrões adaptativos de genótipos bastante complexos; provavelmente, tais padrões sejam melhor descritos por um método analítico multivariado. 
As linhagens apresentaram comportamento para \%OL diferente de PG e PO. Das cinco melhores linhagens em PG e PO, apenas uma também o foi para a \%OL, dentro de CM, exceto para as LST, que das sete, três foram também ricas em \%OL. No entanto, o maior número de linhagens se destacando em PG, \%OL e PO nas LST, pode ter ocorrido mais em função do baixo número de linhagens do que devido a uma tendência do CM. Das dez linhagens superiores em PG, apenas duas foram comuns e também se destacaram entre as dez melhores em \%OL, ambas pertencentes às LP (USP 93-1042, com 22,42\%) e LSP (USP 94-1044, com 22,33\%). Para este grupo de linhagens, o teor de óleo decresceu com o aumento do CM. Resultados similares foram obtidos por Rocha (1998). Este caráter também apresentou interação G x E menos complexa, quando comparado aos caracteres PG e PO, já que suas magnitudes para a $\mathrm{SQ}_{\mathrm{GxE}}$ foram sempre menores e os modelos selecionados na análise AMMI sempre envolveram um baixo número de eixos (CPI1 ou no máximo o CPI2).

A análise de correlação mostrou que os parâmetros que avaliam a estabilidade $\left(\omega_{i}, s^{2} d_{i}\right.$ e $\left.A_{i}\right)$ para as três metodologias comparadas ordenaram as linhagens de forma similar, com pequenas mudanças no ordenamento de poucas linhagens determinada principalmente pelo parâmetro A, já que este apresentou magnitudes menores para os coeficientes de correlação obtidos com $\omega_{i}$ e $s^{2} d_{i}$, comparado com aqueles obtidos entre $\omega_{\mathrm{i}}$ e s $^{2} \mathrm{~d}_{\mathrm{i}}$, de forma que as correlações não foram tão perfeitas $(\mathrm{r}=1,00)$, mas podem ser consideradas altas, sugerindo que estes parâmetros pertencem a um mesmo conceito de estabilidade, provavelmente o conceito tipo 3 preconizado por Lin et al. (1986).

Os baixos valores percentuais explicados pelos componentes principais em relação à $S Q_{\mathrm{GxE}}$ têm sido, em muitos casos, motivo de conclusões equivocadas, no sentido da análise ter limitações para a interpretação e não ser efetiva. É pertinente comentar que a ACP utilizada para diagnosticar a interação G x E na análise AMMI apresenta uma abordagem um pouco diferente daquela comumente verificada para estudos de divergência entre genótipos. $\mathrm{O}$ conceito de padrão e ruído inerente à análise AMMI é a grande diferença neste enfoque e deve ser melhor explorado, pois em certos casos, um baixo percentual explicado pelo CPI pode ser suficiente e importante, quando a variação que este explica contém a maior parte do padrão e a variação remanescente 
(não significativa) é rica em ruídos. É bom lembrar que, nem tudo que está dentro da $\mathrm{SQ}_{\mathrm{GxE}}$ é importante para explicar o padrão adjacente à interação $\mathrm{G} \times \mathrm{E}$; isto depende muito da precisão experimental na obtenção das médias utilizadas para a análise, principalmente do nível de influência de fatores micro-ambientais, que pode determinar uma menor ou maior presença de ruídos nos dados; como também da estrutura da interação G x E determinada pelos genótipos com os ambientes.

Os resultados do presente trabalho mostraram que mesmo explicando abaixo de $50 \%$ (LI e LST) da variação total da $\mathrm{SQ}_{\mathrm{GxE}}$, esta variação mostrou ser importante em termos de padrão, sendo suficiente para descrever o comportamento dos genótipos com os ambientes. No caso das LP e LSP, para as quais a seleção recaiu muito em cima de modelos que englobavam quatro CPIs, o uso de modelos reduzidos (CPI1 e CPI2) e a interpretação pelos biplots AMMI1 e AMMI2 foi suficiente para descrever o comportamento da interação padrão para este grupo de linhagens e ambientes, sendo que suas relações adaptativas foram melhor interpretadas com o auxílio das médias e interações preditas pelos modelos AMMI selecionados.

Os resultados da análise de correlação entre os parâmetros que avaliam a estabilidade foram similares quanto ao ordenamento das linhagens. No entanto, as metodologias diferiram quanto à precisão, explicação e informação sobre a interação $\mathrm{G} \mathrm{x}$ E e a adaptabilidade das linhagens com os ambientes.

O método da ecovalência pode ser usado com o auxilio das médias quando o objetivo for apenas selecionar para adaptabilidade e estabilidade, sem o interesse de obter informações adicionais da qualidade dos ambientes nem sobre recomendações de genótipos, sendo indicado principalmente quando se dispõe de poucos genótipos e ambientes.

O método de Eberhart \& Russel (1966) baseado na regressão linear é indicado quando o objetivo é avaliar a adaptabilidade e a estabilidade e, simultaneamente, obter informações adicionais sobre recomendações de genótipos para determinados ambientes. Este método é eficiente quando o comportamento dos materiais tende a ser linear com os ambientes. Para casos onde isso não ocorra, Lin et al. (1986) reiteram que o modelo de regressão linear para estimar a estabilidade não é apropriado e outras alternativas devem 
ser investigadas. Isto foi confirmado no presente trabalho. Gauch (1990) comenta que a vantagem da regressão linear sobre outros métodos diminui com o tamanho do grupo de dados. Segundo Duarte \& Vencovsky (1999), a despeito das críticas feitas por diversos autores a esse método com relação à falta de independência entre a variável dependente (média do caráter) e o índice ambiental (Lin et al., 1986 e Crossa, 1990), essa pressuposição do método parece não ter muita relevância quando o número de genótipos é grande. No presente trabalho, este aspecto pode ter tido maior relevância para as LST, nas quais o número de linhagens era relativamente baixo.

O uso da análise AMMI é recomendado para estudos de adaptabilidade e estabilidade, com um interesse adicional na identificação de relações importantes no discernimento das verdadeiras causas da interação G x E em si (Duarte \& Vencovsky, 1999). Isto é particularmente importante quando não se têm medidas sobre variáveis ambientais externas que contribuem para as interações G x E (Vargas et al., 2001). Vários autores têm recomendado o método AMMI para analisar experimentos regionais e internacionais, os quais envolvem muitos dados (Zobel et al., 1988; Gauch, 1990 e Yau, 1995). No entanto, este método tem mostrado também ser eficiente mesmo nos casos em que o número de genótipos é baixo (Ariyo, 1998). Neste sentido, no presente trabalho, isso foi comprovado, particularmente, no caso das LST. Este método foi mais informativo, pois explicou melhor a interação $G$ x E e as relações adaptativas das linhagens com os ambientes de forma mais precisa e específica, quando comparado aos métodos da ecovalência e de regressão linear de Eberhart \& Russel (1966). Assim, os objetivos do presente trabalho foram melhor atendidos pelo método AMMI. 


\section{CONCLUSÕES}

Os resultados obtidos nesta pesquisa permitem as seguintes conclusões:

a) $\mathrm{O}$ efeito de ambientes foi mais importante do que o efeito da interação genótipos $\mathrm{x}$ ambientes ( $\mathrm{G} \times \mathrm{E}$ ), e este mais importante do que o efeito de genótipos (linhagens).

b) A magnitude da interação $\mathrm{G}$ x E para a produtividade de grãos (PG) e a produtividade de óleo (PO) foi maior do que para a porcentagem de óleo (\%OL), indicando que este último caráter foi mais estável.

c) As linhagens precoces e semiprecoces foram mais adaptadas, mas exibiram interações $\mathrm{G} x$ E mais complexas e foram mais instáveis do que as linhagens intermediárias e semitardias.

d) As linhagens intermediárias associaram alta adaptabilidade com estabilidade média para PG e PO, ao contrário das linhagens precoces, semiprecoces e semitardias, nas quais a alta adaptabilidade esteve sempre associada com baixa estabilidade.

e) Os anos agrícolas associados com o local Anhembi e ESALQ foram mais favoráveis que os ambientes relacionados com o local Areão, mas estes apresentaram maior previsibilidade (estabilidade).

f) A seleção de linhagens com média e previsibilidade altas foi mais difícil para a \%OL do que para PG e PO, em decorrência das correlações negativas entre as médias e os parâmetros de estabilidade; a utilização desses parâmetros em conjunto mostrou-se mais eficiente na a seleção simultânea para adaptabilidade e estabilidade; 
g) A seleção para estabilidade deve envolver apenas um dos parâmetros; já a seleção simultânea para adaptabilidade e estabilidade requer associar um parâmetro de estabilidade com outro de adaptabilidade.

h) As metodologias foram similares quanto ao ordenamento das linhagens; no entanto, diferiram quanto à precisão, explicação e informação sobre a interação $\mathrm{G}$ x E e a adaptabilidade das linhagens.

i) O método da ecovalência pode ser utilizado para selecionar para estabilidade e, quando associado com a média, também para adaptabilidade, sempre que o melhorista não esteja interessado em obter informações adicionais sobre recomendações de genótipos para ambientes específicos.

j) A regressão linear de Eberhart \& Russel foi mais influenciada pelos efeitos ambientais do que pelos efeitos da interação $\mathrm{G}$ x E, não explicando satisfatoriamente o comportamento das linhagens.

1) $\mathrm{O}$ padrão adjacente àinteração $\mathrm{G} x \mathrm{E}$ foi baixo e a presença de ruídos foi alta, evidenciando que apenas parte da variação total observada para a interação G x E foi importante para explicar o comportamento das linhagens.

m) A interpretação gráfica da análise AMMI através dos biplots AMMI1 e AMMI2, para modelos que incluem mais de dois eixos, foi eficiente em explicar a estabilidade das linhagens e os ambientes; no entanto, a adaptabilidade foi melhor compreendida com o auxílio das médias preditas para linhagens e ambientes pelo modelo selecionado.

n) O método AMMI foi mais eficiente do que os métodos da ecovalência e da regressão linear de Eberhart \& Russel, pois permitiu analisar com mais detalhes os efeitos da interação G x E, ganhando por essa via, precisão e melhorando o processo de seleção.

o) As linhagens que reuniram mais adaptabilidade com estabilidade para PG e PO dentro de cada ciclo de maturação foram: USP 94-1086 (precoce), USP 93-2316 (semiprecoce), USP 93-5243 (intermediária) e USP 93-5684 (semitardia). 
ANEXOS 
Tabela 1. Testemunhas Precoces: quadrados médios obtidos na análise de variância conjunta, média geral e coeficiente de variação (C.V.) referentes aos caracteres número de dias para maturidade (NDM), altura da planta na maturidade (APM), acamamento (Ac), valor agronômico (VA), produtividade de grãos (PG), porcentagem de óleo (\%OL) e produtividade de óleo (PO). Soja, semeaduras em 20/11/96, 16/11/97, 17/11/98, 23/11/99 (Anhembi), 12/11/96, 13/11/97, 05/11/98, 30/11/99 (Areão), 06/11/96, 12/11/97, 05/11/98, 08/11/99 (ESALQ). Piracicaba, SP.

\begin{tabular}{|c|c|c|c|c|c|c|c|c|}
\hline \multirow{3}{*}{$\begin{array}{c}\text { Fontes } \\
\text { de } \\
\text { Variação }\end{array}$} & \multirow[t]{3}{*}{ GL } & \multicolumn{7}{|c|}{ Quadrados Médios } \\
\hline & & \multirow{2}{*}{$\begin{array}{c}\text { NDM } \\
\text { dias }\end{array}$} & \multirow{2}{*}{$\begin{array}{c}\text { APM } \\
\mathrm{cm}\end{array}$} & \multirow{2}{*}{$\begin{array}{l}\mathrm{Ac}^{\mathrm{a}} \\
\text { nota }\end{array}$} & \multirow{2}{*}{$\begin{array}{l}\mathrm{VA}^{\mathrm{a}} \\
\text { nota }\end{array}$} & \multirow{2}{*}{$\begin{array}{c}\mathrm{PG} \\
\mathrm{Kg} / \mathrm{ha}\end{array}$} & \multirow{2}{*}{$\begin{array}{c}\% \mathrm{OL} \\
\%\end{array}$} & \multirow{2}{*}{$\begin{array}{c}\mathrm{PO} \\
\mathrm{Kg} / \mathrm{ha}\end{array}$} \\
\hline & & & & & & & & \\
\hline \multicolumn{9}{|c|}{ ANOS AGRÍCOLAS: 1996/97, 1997/98 e 1998/99 } \\
\hline Conjuntos $(\mathrm{C}) / \mathrm{L} / \mathrm{A}$ & & $5,83^{\mathrm{ns}}$ & $35,71^{\mathrm{ns}}$ & $0,0074^{\mathrm{ns}}$ & $0,0253^{\mathrm{ns}}$ & $86248^{\text {ns }}$ & $2,5926^{\mathrm{ns}}$ & $4501^{\mathrm{ns}}$ \\
\hline Anos (A) & & $291,52^{\mathrm{ns}}$ & $713,27^{\mathrm{ns}}$ & $0,0294^{\mathrm{ns}}$ & $0,1873^{\mathrm{ns}}$ & $6711132^{\mathrm{ns}}$ & $21,8376^{\mathrm{ns}}$ & $342026^{\mathrm{ns}}$ \\
\hline Locais $(\mathrm{L})$ & & $214,08^{\mathrm{ns}}$ & $3322,94 * *$ & $0,1022^{\mathrm{ns}}$ & $0,2375^{\mathrm{ns}}$ & $13371419^{\text {ns }}$ & $16,3161^{\mathrm{ns}}$ & $551800^{\mathrm{ns}}$ \\
\hline Testemunhas (T) & & $895,69 * *$ & $11309,01 * *$ & $0,3896 * *$ & $1,0667 * *$ & $12334979 * *$ & $2,5607^{\mathrm{ns}}$ & $607637 * *$ \\
\hline $\mathrm{CxT}$ & & $2,86^{\mathrm{ns}}$ & $83,86^{\text {ns }}$ & $0,0038^{\mathrm{ns}}$ & $0,0018^{\mathrm{ns}}$ & $163746^{\mathrm{ns}}$ & $0,6490^{\mathrm{ns}}$ & $4088^{\mathrm{ns}}$ \\
\hline A x L & & $409,23 * *$ & $1080,30 * *$ & $0,0552^{\mathrm{ns}}$ & $0,0754^{\mathrm{ns}}$ & $3110677 *$ & $23,7249 * *$ & $120592^{\mathrm{ns}}$ \\
\hline $\mathrm{T} \times \mathrm{A}$ & । & $30,87^{\mathrm{ns}}$ & $465,88 * *$ & $0,0157^{\mathrm{ns}}$ & $0,0287^{\text {ns }}$ & $617766^{\mathrm{ns}}$ & $0,6061^{\mathrm{ns}}$ & $31865^{\mathrm{ns}}$ \\
\hline $\mathrm{T} \times \mathrm{L}$ & I & $26,57^{\mathrm{ns}}$ & $154,27^{\mathrm{ns}}$ & $0,0093^{\mathrm{ns}}$ & $0,0788^{\mathrm{ns}}$ & $240127^{\mathrm{ns}}$ & $2,6781^{\mathrm{ns}}$ & $17031^{\text {ns }}$ \\
\hline $\mathrm{T} \times \mathrm{A} \times \mathrm{L}$ & 1: & $43,36 * *$ & $79,63^{\text {ns }}$ & $0,0233^{\mathrm{ns}}$ & $0,0521^{\mathrm{ns}}$ & $659035^{* *}$ & $2,3489 *$ & $38233 * *$ \\
\hline Resíduo médio & 9 & 3,86 & 57,81 & 0,0131 & 0,0333 & 159567 & 1,1965 & 7759 \\
\hline Média Geral & & 119,98 & 89,64 & 1,32 & 3,35 & 2042 & 22,07 & 447 \\
\hline C.V. (\%) & & 1,64 & 8,54 & 8,56 & 9,38 & 19,56 & 4,96 & 19,70 \\
\hline \multicolumn{9}{|c|}{ ANO AGRÍCOLA: 1999/00 } \\
\hline Conjuntos $(\mathrm{C}) / \mathrm{L}$ & & $4,64^{\mathrm{ns}}$ & $300,58^{\mathrm{ns}}$ & $0,0186^{\mathrm{ns}}$ & $0,0025^{\mathrm{ns}}$ & $4713^{\mathrm{ns}}$ & $7,8116^{\mathrm{ns}}$ & $1553^{\mathrm{ns}}$ \\
\hline Locais (L) & & $375,64 * *$ & $2406,08^{*}$ & $0,2539 *$ & $0,0507 *$ & $12639894 * *$ & $24,2774^{\text {ns }}$ & $775207 * *$ \\
\hline Testemunhas (T) & & $98,74 * *$ & $4222,92 * *$ & $0,1682 * *$ & $0,0419 * *$ & $79877^{\text {ns }}$ & $2,4637^{\mathrm{ns}}$ & $1458^{\mathrm{ns}}$ \\
\hline $\mathrm{CxT}$ & & $2,52^{\mathrm{ns}}$ & $24,05^{\text {ns }}$ & $0,0152^{\mathrm{ns}}$ & $0,0128^{\text {ns }}$ & $195069^{\text {ns }}$ & $4,0598^{\mathrm{ns}}$ & $7589^{\mathrm{ns}}$ \\
\hline $\mathrm{T} \times \mathrm{L}$ & 1 & $20,62 * *$ & $164,83 *$ & $0,0232^{\mathrm{ns}}$ & $0,0119^{\mathrm{ns}}$ & $254248^{\text {ns }}$ & $9,2411^{\mathrm{ns}}$ & $20026^{\mathrm{ns}}$ \\
\hline Resíduo médio & 31 & 5,59 & 61,88 & 0,0165 & 0,0091 & 166999 & 10,2953 & 13178 \\
\hline Média Geral & & 122,10 & 104,21 & 1,74 & 3,45 & 2704 & 21,09 & 579 \\
\hline C.V. $(\%)$ & & 1,94 & 7,55 & 8,65 & 4,80 & 15,11 & 5,21 & 19,81 \\
\hline
\end{tabular}

a: análise realizada com dados transformados para $\sqrt{\mathrm{x}+0,5}, \operatorname{com} \mathrm{x}=1$ a 5 .

*, **: significativo ao nível de 5\% e $1 \%$ de probabilidade, respectivamente, pelo teste $\mathrm{F}$; ns: não significativo pelo teste $\mathrm{F}$.

Tabela 2. Testemunhas Semiprecoces: quadrados médios obtidos na análise de variância conjunta, média geral e coeficiente de variação (C.V.) referentes aos caracteres número de dias para maturidade (NDM), altura da planta na maturidade (APM), acamamento (Ac), valor agronômico (VA), produtividade de grãos (PG), porcentagem de óleo (\%OL) e produtividade de óleo (PO). Soja, semeaduras em 20/11/96, 16/11/97, 17/11/98, 23/11/99 (Anhembi), 12/11/96, 13/11/97, 05/11/98, 30/11/99 (Areão), 06/11/96, 12/11/97, 05/11/98, 08/11/99 (ESALQ). Piracicaba, SP.

\begin{tabular}{|c|c|c|c|c|c|c|c|c|}
\hline \multirow[t]{3}{*}{ Fontes de Variação } & \multirow[t]{3}{*}{ GL } & \multicolumn{7}{|c|}{ Quadrados Médios } \\
\hline & & NDM & APM & $\mathrm{Ac}^{\mathrm{a}}$ & $\mathrm{VA}^{\mathrm{a}}$ & $P G$ & $\% \mathrm{OL}$ & $\mathrm{PO}$ \\
\hline & & Dias & $\mathrm{Cm}$ & nota & nota & $\mathrm{Kg} / \mathrm{ha}$ & $\%$ & $\mathrm{Kg} / \mathrm{ha}$ \\
\hline \multicolumn{9}{|c|}{ ANOS AGRÍCOLAS: 1996/97, 1997/98 e 1998/99 } \\
\hline Conjuntos $(\mathrm{C}) / \mathrm{L} / \mathrm{A}$ & 12 & $2,28^{\mathrm{ns}}$ & $73,33^{\mathrm{ns}}$ & $0,0053^{\mathrm{ns}}$ & $0,0109^{\mathrm{ns}}$ & $184377^{\mathrm{ns}}$ & $0,5522^{\mathrm{ns}}$ & $7063^{\mathrm{ns}}$ \\
\hline Anos (A) & - & $1303,45^{*}$ & $4340,72^{\mathrm{ns}}$ & $0,0349^{\mathrm{ns}}$ & $0,0240^{\mathrm{ns}}$ & $3754968^{\text {ns }}$ & $18,7554^{\text {ns }}$ & $258999^{\text {ns }}$ \\
\hline Locais (L) & 2 & $855,62^{\mathrm{ns}}$ & $869,63^{\mathrm{ns}}$ & $0,1001^{\mathrm{ns}}$ & $0,0704^{\mathrm{ns}}$ & $20620118^{\text {ns }}$ & $5,6975^{\mathrm{ns}}$ & $817526^{\mathrm{ns}}$ \\
\hline Testemunhas (T) & 2 & $438,59 * *$ & $22366,00 * *$ & $0,0653^{\mathrm{ns}}$ & $0,0848^{\mathrm{ns}}$ & $768733^{\text {ns }}$ & $19,2259 *$ & $77029^{\text {ns }}$ \\
\hline $\mathrm{CxT}$ & $t$ & $1,39^{\mathrm{ns}}$ & $77,96^{\mathrm{ns}}$ & $0,0029^{\mathrm{ns}}$ & $0,0113^{\mathrm{ns}}$ & $205668^{\text {ns }}$ & $0,6329^{\mathrm{ns}}$ & $5753^{\mathrm{ns}}$ \\
\hline A x L & $\angle$ & $124,97 * *$ & $1388,21 * *$ & $0,0562^{\mathrm{ns}}$ & $0,0990^{\mathrm{ns}}$ & $5738062^{\mathrm{ns}}$ & $39,6775^{* *}$ & $193422^{\text {ns }}$ \\
\hline $\mathrm{T} \times \mathrm{A}$ & $t$ & $42,89^{\text {ns }}$ & $283,76^{*}$ & $0,0144^{\mathrm{ns}}$ & $0,1740^{\mathrm{ns}}$ & $2569588^{\text {ns }}$ & $2,8215^{\mathrm{ns}}$ & $195603^{\mathrm{ns}}$ \\
\hline $\mathrm{T} \times \mathrm{L}$ & $t$ & $10,78^{\text {ns }}$ & $167,05^{\mathrm{ns}}$ & $0,0145^{\mathrm{ns}}$ & $0,0240^{\mathrm{ns}}$ & $1603330^{\mathrm{ns}}$ & $0,7749^{\mathrm{ns}}$ & $73973^{\text {ns }}$ \\
\hline $\mathrm{T} \times \mathrm{A} \times \mathrm{L}$ & 12 & $16,31 * *$ & $64,17^{\mathrm{ns}}$ & $0,0219 * *$ & $0,1389 * *$ & $2253599 * *$ & $1,3995 * *$ & 98906** \\
\hline Resíduo médio & 135 & 2,73 & 55,02 & 0,0056 & 0,0128 & 210256 & 0,5163 & 10341 \\
\hline Média Geral & & 130,55 & 78,94 & 1,13 & 3,95 & 2861 & 20,81 & 596 \\
\hline C.V. $(\%)$ & & 1,27 & 9,40 & 5,88 & 5,38 & 16,03 & 3,45 & 17,06 \\
\hline \multicolumn{9}{|c|}{ ANO AGRÍCOLA: 1999/00 } \\
\hline Conjuntos $(\mathrm{C}) / \mathrm{L}$ & 2 & $4,33^{\mathrm{ns}}$ & $10,56^{\mathrm{ns}}$ & $0,0129^{\mathrm{ns}}$ & $0,0089^{\mathrm{ns}}$ & $205672^{\mathrm{ns}}$ & $0,2971^{\mathrm{ns}}$ & $7303^{\mathrm{ns}}$ \\
\hline Locais (L) & 2 & $567,75^{* *}$ & $1674,77 *$ & $0,0463^{\mathrm{ns}}$ & $0,1293^{*}$ & $18949209^{* *}$ & $35,2499 * *$ & $1058754 * *$ \\
\hline Testemunhas (T) & 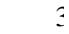 & $387,64 * *$ & $5071,02 * *$ & $0,0391^{*}$ & $0,0142 *$ & $821116^{* *}$ & $12,1571 * *$ & $60896 * *$ \\
\hline $\mathrm{CxT}$ & 2 & $1,86^{\mathrm{ns}}$ & $33,58^{\mathrm{ns}}$ & $0,0135^{\mathrm{ns}}$ & $0,0042^{\mathrm{ns}}$ & $33036^{\mathrm{ns}}$ & $1,3050^{\mathrm{ns}}$ & $8468^{\mathrm{ns}}$ \\
\hline $\mathrm{T} \times \mathrm{L}$ & $t$ & $13,14 * *$ & $168,60^{\mathrm{ns}}$ & $0,0173^{\mathrm{ns}}$ & $0,0096^{\mathrm{ns}}$ & $617925 * *$ & $1,4435^{\text {ns }}$ & $56365 * *$ \\
\hline Resíduo médio & 30 & 2,85 & 82,57 & 0,0128 & 0,0046 & 137662 & 1,7623 & 10702 \\
\hline Média Geral & & 129,12 & 92,27 & 1,26 & 3,80 & 2677 & 21,01 & 574 \\
\hline C.V. $(\%)$ & & 1,31 & 9,85 & 8,58 & 3,26 & 13,86 & 6,32 & 18,03 \\
\hline
\end{tabular}

a: análise realizada com dados transformados para $\sqrt{\mathrm{x}+0,5}, \operatorname{com} \mathrm{x}=1$ a 5 .

*,**: significativo ao nível de $5 \%$ e $1 \%$ de probabilidade, respectivamente, pelo teste $\mathrm{F}$; ns: não significativo pelo teste $\mathrm{F}$.

Tabela 3. Testemunhas Intermediárias: quadrados médios obtidos na análise de variância conjunta (Anos agrícolas: 1996/97,1997/98, 1998/99 e 1999/00), média geral e coeficiente de variação (C.V.) referentes aos caracteres número de dias para maturidade (NDM), altura da planta na maturidade (APM), acamamento (Ac), valor agronômico (VA), produtividade de grãos (PG), porcentagem de óleo (\%OL) e produtividade de óleo (PO). Soja, semeaduras em 20/11/96, 16/11/97, 17/11/98, 23/11/99 (Anhembi), 12/11/96, 13/11/97, 05/11/98, 30/11/99 (Areão), 06/11/96, 12/11/97, 05/11/98, 08/11/99 (ESALQ). Piracicaba, SP. 


\begin{tabular}{|c|c|c|c|c|c|c|c|c|}
\hline & & & & & & & & \\
\hline & & NDM & APM & $\mathrm{Ac}^{\mathrm{a}}$ & $\mathrm{VA}^{\mathrm{a}}$ & $\overline{\mathrm{PG}}$ & $\% \mathrm{OL}$ & $\mathrm{PO}$ \\
\hline & & dias & $\mathrm{Cm}$ & nota & nota & $\mathrm{Kg} / \mathrm{ha}$ & $\%$ & $\mathrm{Kg} / \mathrm{ha}$ \\
\hline Conjuntos (C)/L/A & 12 & $7,06^{\mathrm{ns}}$ & $34,57^{\mathrm{ns}}$ & $0,0088^{\mathrm{ns}}$ & $0,0183^{\text {ns }}$ & $349238^{\text {ns }}$ & $1,4741^{\mathrm{ns}}$ & $16601^{\mathrm{ns}}$ \\
\hline Anos (A) & 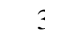 & $957,58^{*}$ & $5509,77 *$ & $0,3656^{\mathrm{ns}}$ & $0,0446^{\mathrm{ns}}$ & $180326^{\mathrm{ns}}$ & $54,3215^{\mathrm{ns}}$ & $50404^{\mathrm{ns}}$ \\
\hline Locais (L) & 2 & $400,42^{\mathrm{ns}}$ & $4098,68^{\text {ns }}$ & $0,4328 *$ & $0,0495^{\mathrm{ns}}$ & $13826173^{\text {ns }}$ & $10,8351^{\mathrm{ns}}$ & $484150^{\text {ns }}$ \\
\hline Testemunhas (T) & 2 & $1404,03 * *$ & $7708,83^{* *}$ & $0,2425 * *$ & $0,1148^{\mathrm{ns}}$ & $1798344^{\mathrm{ns}}$ & $81,3013 * *$ & $110630^{\text {ns }}$ \\
\hline $\mathrm{CxT}$ & $t$ & $2,72^{\mathrm{ns}}$ & $39,81^{\text {ns }}$ & $0,0054^{\mathrm{ns}}$ & $0,0130^{\mathrm{ns}}$ & $292881^{\mathrm{ns}}$ & $0,1762^{\mathrm{ns}}$ & $11074^{\mathrm{ns}}$ \\
\hline$A \times L$ & $\theta$ & $147,48^{*}$ & $927,40 * *$ & $0,0791 *$ & $0,1612 * *$ & $5824487 * *$ & $14,1805^{* *}$ & $256575^{* *}$ \\
\hline $\mathrm{T} \times \mathrm{A}$ & c & $70,08^{\mathrm{ns}}$ & $297,40 *$ & $0,0208^{\mathrm{ns}}$ & $0,1279 * *$ & $1975192 * *$ & $2,2467^{\mathrm{ns}}$ & $69170 * *$ \\
\hline$T \times L$ & $t$ & $73,69^{\text {ns }}$ & $44,61^{\mathrm{ns}}$ & $0,0288^{\mathrm{ns}}$ & $0,0121^{\mathrm{ns}}$ & $497797^{\text {ns }}$ & $3,2110^{\mathrm{ns}}$ & $23982^{\mathrm{ns}}$ \\
\hline $\mathrm{T} \times \mathrm{A} \times \mathrm{L}$ & $1 \varepsilon$ & $44,59 * *$ & $89,61^{\mathrm{ns}}$ & $0,0277 *$ & $0,0348 * *$ & $250851^{\mathrm{ns}}$ & $1,8015^{*}$ & $12823^{\text {ns }}$ \\
\hline Resíduo médio & 147 & 5,76 & 78,90 & 0,0162 & 0,0141 & 233935 & 1,0552 & 8733 \\
\hline Média Geral & & 138,95 & 90,30 & 1,50 & 3,36 & 2177 & 18,80 & 412 \\
\hline C.V. $(\%)$ & & 1,73 & 9,84 & 9,06 & 6,06 & 22,22 & 5,46 & 22,68 \\
\hline
\end{tabular}

a: análise realizada com dados transformados para $\sqrt{\mathrm{x}+0,5}, \operatorname{com} \mathrm{x}=1$ a 5 .

*, **: significativo ao nível de $5 \%$ e $1 \%$ de probabilidade, respectivamente, pelo teste $\mathrm{F}$.

ns: não significativo pelo teste $\mathrm{F}$.

Tabela 4. Testemunhas Semitardias: quadrados médios obtidos na análise de variância conjunta (Ano agrícola: 1996/97), média geral e coeficiente de variação (C.V.) referentes aos caracteres número de dias para maturidade (NDM), altura da planta na maturidade (APM), acamamento (Ac), valor agronômico (VA), produtividade de grãos (PG), porcentagem de óleo (\%OL) e produtividade de óleo (PO). Soja, semeaduras em 20/11/96 (Anhembi), 12/11/96 (Areão), 06/11/96 (ESALQ). Piracicaba, SP.

\begin{tabular}{|c|c|c|c|c|c|c|c|c|}
\hline \multirow[t]{3}{*}{ Fontes de Variação } & \multirow[t]{3}{*}{ GL } & \multicolumn{7}{|c|}{ Quadrados Médios } \\
\hline & & NDM & $\overline{\mathrm{APM}}$ & $\mathrm{Ac}^{\mathrm{a}}$ & $\mathrm{VA}^{\mathrm{a}}$ & $\overline{P G}$ & $\% \mathrm{OL}$ & $\mathrm{PO}$ \\
\hline & & dias & $\mathrm{Cm}$ & nota & nota & $\mathrm{Kg} / \mathrm{ha}$ & $\%$ & $\mathrm{Kg} / \mathrm{ha}$ \\
\hline Conjuntos $(\mathrm{C}) / \mathrm{L}$ & 3 & $4,69^{\mathrm{nS}}$ & $144,27^{\mathrm{ns}}$ & $0,0514^{\mathrm{ns}}$ & $0,0317^{\mathrm{ns}}$ & $13522^{\mathrm{ns}}$ & $0,3339^{\mathrm{ns}}$ & $1454^{\mathrm{ns}}$ \\
\hline Locais (L) & 2 & $100,02 *$ & $1144,27^{\mathrm{ns}}$ & $0,1044^{\mathrm{ns}}$ & $0,1956^{\mathrm{ns}}$ & $7447413 * *$ & $0,4343^{\mathrm{ns}}$ & $270937 * *$ \\
\hline Testemunhas (T) & 3 & $32,30 *:$ & $1075,69 * *$ & $0,0623 * *$ & $0,0216^{\mathrm{ns}}$ & $795951 *$ & $3,0744 *$ & $31265^{*}$ \\
\hline $\mathrm{CxT}$ & 3 & $0,41^{\mathrm{ns}}$ & $26,39^{\mathrm{ns}}$ & $0,0138^{\mathrm{ns}}$ & $0,0103^{\mathrm{ns}}$ & $120845^{\mathrm{ns}}$ & $0,0136^{\mathrm{ns}}$ & $4452^{\mathrm{ns}}$ \\
\hline $\mathrm{L} \times \mathrm{T}$ & 6 & $20,21 *:$ & $47,05^{\mathrm{ns}}$ & $0,0123^{\mathrm{ns}}$ & $0,0057^{\mathrm{ns}}$ & $364929^{\mathrm{ns}}$ & $1,5599^{\mathrm{ns}}$ & $16507^{\mathrm{ns}}$ \\
\hline Resíduo médio & 30 & 2,28 & 40,80 & 0,0132 & 0,0178 & 240134 & 0,8691 & 9486 \\
\hline Média Geral & & 142,98 & 92,29 & 1,47 & 2,91 & 1637 & 19,25 & 316 \\
\hline C.V. $(\%)$ & & 1,06 & 6,92 & 8,23 & 7,27 & 29,94 & 4,84 & 30,77 \\
\hline
\end{tabular}

a: análise realizada com dados transformados para $\sqrt{\mathrm{x}+0,5}, \operatorname{com} \mathrm{x}=1$ a 5 .

*,**: significativo ao nível de $5 \%$ e $1 \%$ de probabilidade, respectivamente, pelo teste $\mathrm{F}$.

ns: não significativo pelo teste $\mathrm{F}$. 
Tabela 5. Linhagens Precoces: quadrados médios obtidos na análise de variância individual em blocos ao acaso, média geral e coeficiente de variação (C.V.) referentes aos caracteres número de dias para maturidade (NDM), altura da planta na maturidade (APM), acamamento (Ac), valor agronômico (VA), produtividade de grãos (PG), porcentagem de óleo (\%OL) e produtividade de óleo (PO). Soja, semeaduras em 20/11/96, 16/11/97, 17/11/98, 23/11/99 (Anhembi), 12/11/96, 13/11/97, 05/11/98, 30/11/99 (Areão), 06/11/96, 12/11/97, 05/11/98, 08/11/99 (ESALQ). Piracicaba, SP.

\begin{tabular}{|c|c|c|c|c|c|c|c|c|}
\hline \multirow{2}{*}{ Fontes de Variação } & \multirow[t]{2}{*}{ GL } & \multicolumn{7}{|c|}{ Quadrados Médios } \\
\hline & & \multirow{2}{*}{$\begin{array}{c}\text { NDM } \\
\text { dias }\end{array}$} & \multirow{2}{*}{$\begin{array}{l}\text { APM } \\
\mathrm{cm}\end{array}$} & \multirow{2}{*}{$\begin{array}{l}\mathrm{Ac}^{\mathrm{a}} \\
\text { nota }\end{array}$} & \multirow{2}{*}{$\begin{array}{l}\mathrm{VA}^{\mathrm{a}} \\
\text { nota }\end{array}$} & \multirow{2}{*}{$\begin{array}{c}\mathrm{PG} \\
\mathrm{Kg} / \mathrm{ha}\end{array}$} & $\% \mathrm{OL}$ & $\mathrm{PO}$ \\
\hline Ambiente: ANHEMBI 96/97 & & & & & & & $\%$ & $\mathrm{Kg} / \mathrm{ha}$ \\
\hline Repetições (R) & 1 & $6,15^{\mathrm{ns}}$ & $279,36^{* *}$ & $0,0081^{\mathrm{ns}}$ & $0,1801 * *$ & $5232211 * *$ & $8,8512 * *$ & $175306^{* * *}$ \\
\hline Linhagens (G) & 42 & $5,59 * *$ & $118,04 * *$ & $0,0206^{*}$ & $0,0933 * *$ & $1056186^{* * *}$ & $2,2250 * *$ & $49341 * *$ \\
\hline Resíduo & 42 & 2,65 & 26,97 & 0,0106 & 0,0119 & 282026 & 0,6632 & 12970 \\
\hline Média Geral & & 120,17 & 88,89 & 1,52 & 2,62 & 2181 & 21,12 & 462 \\
\hline $\begin{array}{l}\text { C.V. }(\%) \\
\text { Ambiente: AREÃO } 96 / 97\end{array}$ & & 1,37 & 5,84 & 7,31 & 6,23 & 24,35 & 3,85 & 24,65 \\
\hline Repetições (R) & 1 & $24,60 * *$ & $615,12 * *$ & $0,0116^{\mathrm{ns}}$ & $0,0396^{\mathrm{ns}}$ & $69086^{\mathrm{ns}}$ & $95,1092 * *$ & $5408^{\mathrm{ns}}$ \\
\hline Linhagens (G) & 42 & $11,29 * *$ & $268,15^{* *}$ & $0,0528 * *$ & $0,0427 * *$ & $121235^{* *}$ & $3,7009^{\mathrm{ns}}$ & $8184 * *$ \\
\hline Resíduo & 42 & 2,10 & 44,28 & 0,0199 & 0,0204 & 54318 & 2,6584 & 2810 \\
\hline Média Geral & & 119,23 & 97,44 & 1,64 & 3,28 & 1493 & 21,55 & 324 \\
\hline C.V. $(\%)$ & & 1,18 & 6,83 & 9,71 & 7,37 & 15,61 & 7,56 & 16,37 \\
\hline Ambiente: ESALQ 96/97 & & & & & & & & \\
\hline Repetições (R) & 1 & $15,07^{\mathrm{ns}}$ & $61,96^{\mathrm{ns}}$ & $0,0052^{\mathrm{ns}}$ & $0,0622^{\mathrm{ns}}$ & $76056^{\mathrm{ns}}$ & $0,1507^{\mathrm{ns}}$ & $6596^{\mathrm{ns}}$ \\
\hline Linhagens (G) & 42 & $35,20 * *$ & $288,67 * *$ & $0,0871 * *$ & $0,1218 * *$ & $1139216^{* * *}$ & $3,7074 * *$ & $49168 * *$ \\
\hline Resíduo & 42 & 5,14 & 49,77 & 0,0361 & 0,0382 & 252956 & 0,5710 & 9797 \\
\hline Média Geral & & 125,49 & 103,27 & 2,01 & 2,75 & 2476 & 19,33 & 483 \\
\hline C.V. $(\%)$ & & 1,81 & 6,83 & 12,13 & 10,98 & 20,87 & 3,91 & 20,47 \\
\hline Ambiente: ANHEMBI 97/98 & & & & & & & & \\
\hline Repetições (R) & 1 & $9,60^{\mathrm{ns}}$ & $721,06^{* *}$ & $0,0046^{\mathrm{ns}}$ & $0,0142^{\mathrm{ns}}$ & $77221^{\mathrm{ns}}$ & $0,2857^{\mathrm{ns}}$ & $2980^{\mathrm{ns}}$ \\
\hline Linhagens (G) & 29 & $18,17 * *$ & $180,54 * *$ & $0,0289^{* *}$ & $0,0307^{\mathrm{ns}}$ & $228979 * *$ & $1,9966 * *$ & $16709 * *$ \\
\hline Resíduo & 29 & 4,05 & 59,89 & 0,0113 & 0,0173 & 91770 & 0,6032 & 6231 \\
\hline Média Geral & & 113,36 & 106,73 & 1,46 & 3,76 & 2676 & 22,59 & 606 \\
\hline C.V. $(\%)$ & & 1,77 & 7,25 & 7,63 & 6,40 & 11,32 & 3,44 & 13,01 \\
\hline Ambiente: AREÃO 97/98 & & & & & & & & \\
\hline Repetições (R) & 1 & $9,60^{\mathrm{ns}}$ & $224,27^{\mathrm{ns}}$ & $0,0060^{\mathrm{ns}}$ & $0,000017^{\mathrm{ns}}$ & $43740^{\mathrm{ns}}$ & $0,3420^{\mathrm{ns}}$ & $3269^{\mathrm{ns}}$ \\
\hline Linhagens (G) & 29 & $19,12 * *$ & $222,25 * *$ & $0,0461 *$ & $0,017838^{\mathrm{ns}}$ & $187488^{\mathrm{ns}}$ & $2,2208 * *$ & $9560^{\mathrm{ns}}$ \\
\hline Resíduo & 29 & 4,36 & 73,02 & 0,0234 & 0,010800 & 149156 & 0,5375 & 6199 \\
\hline Média Geral & & 129,70 & 115,80 & 1,62 & 3,35 & 2504 & 20,90 & 523 \\
\hline C.V. $(\%)$ & & 1,61 & 7,38 & 10,57 & 5,31 & 15,42 & 3,51 & 15,04 \\
\hline Ambiente: ESALQ 97/98 & & & & & & & & \\
\hline Repetições (R) & 1 & $0,42^{\mathrm{ns}}$ & $138,02^{\mathrm{ns}}$ & $0,0019^{\mathrm{ns}}$ & $0,0174^{\mathrm{ns}}$ & $344284^{\mathrm{ns}}$ & $0,1793^{\mathrm{ns}}$ & $13086^{\mathrm{ns}}$ \\
\hline Linhagens (G) & 29 & $5,60 * *$ & $283,89^{* *}$ & $0,0457 * *$ & $0,0210 * *$ & $757900 * *$ & $1,9679 * *$ & $32298^{*} *$ \\
\hline Resíduo & 29 & 1,04 & 99,43 & 0,0113 & 0,0086 & 252433 & 0,6049 & 9252 \\
\hline Média Geral & & 127,82 & 112,98 & 1,58 & 3,62 & 2877 & 21,07 & 604 \\
\hline C.V. $(\%)$ & & 0,80 & 8,82 & 7,40 & 4,57 & 17,46 & 3,69 & 15,91 \\
\hline Ambiente: ANHEMBI 98/99 & & & & & & & & \\
\hline Repetições (R) & 1 & $0,16^{\mathrm{ns}}$ & $4482,10 * * 7$ & $0,6012 * *$ & $0,0513^{\mathrm{ns}}$ & $337125^{\mathrm{ns}}$ & $4,5201 *$ & $23253^{\mathrm{ns}}$ \\
\hline Linhagens (G) & 27 & $9,54^{\mathrm{ns}}$ & $483,89 *$ & $0,0631^{\mathrm{ns}}$ & $0,0411^{\mathrm{ns}}$ & $546144^{\mathrm{ns}}$ & $2,6211 * *$ & $20899^{\mathrm{ns}}$ \\
\hline Resíduo & 27 & 8,79 & 228,56 & 0,0343 & 0,0321 & 476989 & 0,7419 & 16851 \\
\hline Média Geral & & 126,73 & 114,33 & 1,96 & 3,02 & 2451 & 19,35 & 473 \\
\hline C.V. $(\%)$ & & 2,34 & 13,22 & 11,95 & 9,61 & 27,66 & 4,45 & 27,41 \\
\hline Ambiente: ARE & & & & & & & & \\
\hline Repetições (R) & 1 & $56,00^{* *}$ & $297,16^{\mathrm{ns}}$ & $0,0160^{\mathrm{ns}}$ & $0,1353^{\text {ns }}$ & $184288^{\text {ns }}$ & $0,6007^{\mathrm{ns}}$ & $10876^{\mathrm{ns}}$ \\
\hline Linhagens $(\mathrm{G})$ & 27 & $26,57 * *$ & $257,31 *$ & $0,0107^{\mathrm{ns}}$ & $0,0669^{\mathrm{ns}}$ & $431384 * *$ & $1,9401 * *$ & $21038 * *$ \\
\hline Resíduo & 27 & 5,70 & 128,60 & 0,0067 & 0,0661 & 140982 & 0,4235 & 7740 \\
\hline Média Geral & & 132,28 & 94,73 & 1,20 & 3,23 & 1449 & 22,66 & 328 \\
\hline C.V. $(\%)$ & & 1,80 & 11,97 & 6,30 & 13,42 & 25,92 & 2,87 & 26,85 \\
\hline Ambiente: ESALQ 98/99 & & & & & & & & \\
\hline Repetições (R) & 1 & $5,16^{*}$ & $18,28^{\text {ns }}$ & $0,00003^{\mathrm{ns}}$ & $0,0038^{\mathrm{ns}}$ & $391950^{\text {ns }}$ & $0,9568^{\mathrm{ns}}$ & $12221^{\mathrm{ns}}$ \\
\hline Linhagens (G) & 27 & $10,01 * *$ & $173,37^{\mathrm{ns}}$ & $0,04638 * *$ & $0,0386^{* *}$ & $336445 * *$ & $1,3240 * *$ & $17411 * *$ \\
\hline Resíduo & 27 & 1,01 & 115,06 & 0,01290 & 0,0129 & 116697 & 0,3650 & 5484 \\
\hline Média Geral & & 131,80 & 126,32 & 1,95 & 3,15 & 2400 & 22,01 & 528 \\
\hline C.V. $(\%)$ & & 0,76 & 8,49 & 7,30 & 5,39 & 14,23 & 2,74 & 14,02 \\
\hline Ambiente: ANHEMBI 99/00 & & & & & & & & \\
\hline Repetições (R) & 1 & $7,87^{\mathrm{ns}}$ & $30,01^{\mathrm{ns}}$ & $0,0482^{\text {ns }}$ & $0,0002^{\text {ns }}$ & $1942587 * *$ & $1,0560^{\mathrm{ns}}$ & $80276^{*}$ \\
\hline Linhagens $(G)$ & 27 & $25,67 * *$ & $289,57 * *$ & $0,0488 * *$ & $0,0208 * *$ & $408499 *$ & $3,0790^{\mathrm{ns}}$ & $20739^{\mathrm{ns}}$ \\
\hline Resíduo & 27 & 5,35 & 78,24 & 0,0186 & 0,0062 & 179538 & 2,0357 & 12622 \\
\hline Média Geral & & 121,44 & 127,37 & 1,92 & 3,33 & 3535 & 22,68 & 801 \\
\hline C.V.(\%) & & 1,90 & 6,94 & 8,81 & 4,03 & 11,98 & 6,29 & 14,03 \\
\hline Ambiente: AREÃO 99/00 & & & & & & & & \\
\hline Repetições (R) & 1 & $3,50^{\mathrm{ns}}$ & $120,07^{\mathrm{ns}}$ & $0,0076^{\mathrm{ns}}$ & $0,0013^{\text {ns }}$ & $6590^{\mathrm{ns}}$ & $3,5550^{\mathrm{ns}}$ & $20^{\mathrm{ns}}$ \\
\hline Linhagens $(\mathrm{G})$ & 27 & $35,08^{* * *}$ & $273,29 * *$ & $0,0358 * *$ & $0,0105^{\mathrm{ns}}$ & $475387^{\mathrm{ns}}$ & $0,0071 * *$ & $18028^{\mathrm{ns}}$ \\
\hline Resíduo & 27 & 6,80 & 78,44 & 0,0124 & 0,0119 & 266548 & 1,2757 & 10315 \\
\hline Média Geral & & 123,82 & 107,86 & 1,46 & 3,71 & 2410 & 20,09 & 483 \\
\hline C.V.(\%) & & 2,10 & 8,21 & 8,00 & 5,32 & 21,41 & 5,62 & 21,02 \\
\hline Ambiente: ESALQ 99/00 & & & & & & & & \\
\hline Repetições (R) & 1 & $23,14 * *$ & $66,45^{\text {ns }}$ & $7,0991^{\mathrm{ns}}$ & $0,0233^{\mathrm{ns}}$ & $348075^{\mathrm{ns}}$ & $3,5250^{\mathrm{ns}}$ & $26893^{\mathrm{ns}}$ \\
\hline Linhagens (G) & 27 & $26,26^{* *}$ & $371,87 * *$ & $0,0879 * *$ & $0,0142^{\mathrm{ns}}$ & $243098 *$ & $3,8143^{\mathrm{ns}}$ & $13372^{\mathrm{ns}}$ \\
\hline Resíduo & 27 & 2,36 & 88,63 & 0,0244 & 0,0084 & 126967 & 2,1170 & 7064 \\
\hline Média Geral & & 129,96 & 137,12 & 2,56 & 3,31 & 1947 & 22,25 & 433 \\
\hline C.V. $(\%)$ & & 1,18 & 6,86 & 9,01 & 4,70 & 18,30 & 6,54 & 19,38 \\
\hline
\end{tabular}

a: análise realizada com dados transformados para $\sqrt{\mathrm{x}+0,5}, \operatorname{com} \mathrm{x}=1$ a 5 .

*, **: significativo ao nível de $5 \%$ e $1 \%$ de probabilidade, respectivamente, pelo teste $\mathrm{F}$.

ns: não significativo pelo teste $\mathrm{F}$. 
Tabela 6. Linhagens Semiprecoces: quadrados médios obtidos na análise de variância individual em blocos ao acaso, média geral e coeficiente de variação (C.V.) referentes aos caracteres número de dias para maturidade (NDM), altura da planta na maturidade (APM), acamamento (Ac), valor agronômico (VA), produtividade de grãos (PG), porcentagem de óleo (\%OL) e produtividade de óleo (PO). Soja, semeaduras em 20/11/96, 16/11/97, 17/11/98, 23/11/99 (Anhembi), 12/11/96, 13/11/97, 05/11/98, 30/11/99 (Areão), 06/11/96, 12/11/97, 05/11/98, 08/11/99 (ESALQ). Piracicaba, SP.

\begin{tabular}{|c|c|c|c|c|c|c|c|c|}
\hline \multirow{2}{*}{ Fontes de Variação } & \multirow[t]{2}{*}{ GL } & \multicolumn{7}{|c|}{ Quadrados Médios } \\
\hline & & \multirow{2}{*}{$\begin{array}{l}\text { NDM } \\
\text { dias }\end{array}$} & \multirow{2}{*}{$\begin{array}{c}\text { APM } \\
\mathrm{cm}\end{array}$} & \multirow{2}{*}{$\begin{array}{l}\mathrm{Ac}^{\mathrm{a}} \\
\text { Nota }\end{array}$} & \multirow{2}{*}{$\begin{array}{l}\mathrm{VA}^{\mathrm{a}} \\
\text { nota }\end{array}$} & \multirow{2}{*}{$\begin{array}{c}\mathrm{PG} \\
\mathrm{Kg} / \mathrm{ha}\end{array}$} & $\% \mathrm{OL}$ & $\mathrm{PO}$ \\
\hline Ambiente: ANHEMBI 96/97 & & & & & & & $\%$ & $\mathrm{Kg} / \mathrm{ha}$ \\
\hline Repetições (R) & 1 & $40,01 * *$ & $0,51^{\mathrm{ns}}$ & $0,1576^{* *}$ & $0,0849^{*}$ & $238989^{\mathrm{ns}}$ & $0,1600^{\mathrm{ns}}$ & $10855^{\mathrm{ns}}$ \\
\hline Linhagens (G) & 62 & $8,81 * *$ & $637,69 * *$ & $0,0285^{* *}$ & $0,0801 * *$ & $919512 * *$ & $1,9307 * *$ & $33878 * *$ \\
\hline Resíduo & 62 & 2,07 & 22,52 & 0,0078 & 0,0123 & 201977 & 0,8597 & 8964 \\
\hline Média Geral & & 123,64 & 83,87 & 1,50 & 3,20 & 2460 & 20,15 & 493 \\
\hline C.V.(\%) & & 1,16 & 5,66 & 6,27 & 5,80 & 18,27 & 4,60 & 19,21 \\
\hline Ambiente: AREÃO 96/97 & & & & & & & & \\
\hline Repetições (R) & 1 & $10,86^{\text {ns }}$ & $216,07^{\mathrm{ns}}$ & $0,0028^{\mathrm{ns}}$ & $0,4718 * *$ & $425548^{\mathrm{ns}}$ & $26,1853^{* *}$ & $2338^{\mathrm{ns}}$ \\
\hline Linhagens (G) & 62 & $36,74 * *$ & $597,16^{* *}$ & $0,0287 * *$ & $0,0666 * *$ & $193620^{*}$ & $1,7485^{*}$ & $7011^{*}$ \\
\hline Resíduo & 62 & 4,28 & 75,75 & 0,0095 & 0,0274 & 107391 & 0,9891 & 4379 \\
\hline Média Geral & & 128,66 & 88,13 & 1,41 & 3,20 & 1485 & 19,00 & 282 \\
\hline C.V. $(\%)$ & & 1,61 & 9,87 & 7,08 & 8,66 & 22,07 & 5,23 & 23,48 \\
\hline Ambiente: ESALQ 96/97 & & & & & & & & \\
\hline Repetições (R) & 1 & $36,70 * *$ & $928,28 * *$ & $0,0188^{\mathrm{ns}}$ & $0,0210^{\mathrm{ns}}$ & $1348502 *$ & $51,0225^{* *}$ & $149577 * *$ \\
\hline Linhagens (G) & 62 & $134,57 * *$ & $664,92 * *$ & $0,1050 * *$ & $0,1226 * *$ & $1694078 * *$ & $3,0478 * *$ & $68550 * *$ \\
\hline Resíduo & 62 & 5,00 & 92,54 & 0,0196 & 0,0197 & 206242 & 0,5240 & 8552 \\
\hline Média Geral & & 133,20 & 94,43 & 1,94 & 2,77 & 2244 & 19,61 & 444 \\
\hline C.V.(\%) & & 1,68 & 10,19 & 9,09 & 7,84 & 20,24 & 3,69 & 20,80 \\
\hline Ambiente: ANHEMBI 97/98 & & & & & & & & \\
\hline Repetições (R) & 1 & $2,33^{\mathrm{ns}}$ & $377,19 * *$ & $0,0045^{\mathrm{ns}}$ & $0,0096^{\mathrm{ns}}$ & $9483^{\text {ns }}$ & $9,1608 * *$ & $10693^{\mathrm{ns}}$ \\
\hline Linhagens (G) & 41 & $18,52 * *$ & $261,85^{* *}$ & $0,0247 * *$ & $0,0335^{*}$ & $310126^{*}$ & $2,6305^{* *}$ & $16512 *$ \\
\hline Resíduo & 41 & 2,77 & 51,55 & 0,0101 & 0,0165 & 184799 & 0,2276 & 9186 \\
\hline Média Geral & & 128,64 & 99,12 & 1,47 & 3,62 & 2717 & 21,86 & 594 \\
\hline C.V.(\%) & & 1,29 & 7,24 & 7,20 & 6,34 & 15,44 & 2,18 & 16,14 \\
\hline Ambiente: AREÃO 97/98 & & & & & & & & \\
\hline Repetições (R) & 1 & $10,01^{*}$ & $867,86 * *$ & $0,0112^{\mathrm{ns}}$ & $0,0059^{\mathrm{ns}}$ & $741096^{*}$ & $2,8050 *$ & $44812 *$ \\
\hline Linhagens (G) & 41 & $6,83 * *$ & $323,77 * *$ & $0,0401 * *$ & $0,0199 * *$ & $406235 * *$ & $1,5987 * *$ & $18497 * *$ \\
\hline Resíduo & 41 & 1,52 & 78,83 & 0,0101 & 0,0094 & 156905 & 0,4803 & 6905 \\
\hline Média Geral & & 132,27 & 107,88 & 1,37 & 3,39 & 2368 & 20,10 & 477 \\
\hline C.V. $(\%)$ & & 0,93 & 8,23 & 7,41 & 4,93 & 16,73 & 3,45 & 17,41 \\
\hline Ambiente: ESALQ 97/98 & & & & & & & & \\
\hline Repetições (R) & 1 & $3,05^{\mathrm{ns}}$ & $312,43^{\mathrm{ns}}$ & $0,0053^{\mathrm{ns}}$ & $0,0048^{\mathrm{ns}}$ & $55800^{\mathrm{ns}}$ & $7,4882 * *$ & $15520^{\mathrm{ns}}$ \\
\hline Linhagens (G) & 41 & $12,61 * *$ & $443,43 * *$ & $0,0432 * *$ & $0,0320 * *$ & $421950^{\mathrm{ns}}$ & $1,7933 * *$ & $19856 *$ \\
\hline Resíduo & 41 & 1,39 & 129,31 & 0,0082 & 0,0088 & 255452 & 0,3737 & 10494 \\
\hline Média Geral & & 138,19 & 102,33 & 1,45 & 3,83 & 2914 & 20,50 & 597 \\
\hline C.V.(\%) & & 0,88 & 11,11 & 6,53 & 4,52 & 17,34 & 2,98 & 17,14 \\
\hline Ambiente: ANHEMBI 98/99 & & & & & & & & \\
\hline Repetições (R) & 1 & $11,84^{\mathrm{ns}}$ & $60,84^{\mathrm{ns}}$ & $0,0660^{\mathrm{ns}}$ & $0,0660^{\mathrm{ns}}$ & $22237^{\text {ns }}$ & $12,8495^{* *}$ & $13355^{\mathrm{ns}}$ \\
\hline Linhagens (G) & 37 & $34,92 * *$ & $480,89^{* *}$ & $0,0467 * *$ & $0,0467 * *$ & $425336^{*}$ & $2,2541^{* *}$ & $16471 *$ \\
\hline Resíduo & 37 & 11,49 & 207,60 & 0,0177 & 0,0177 & 226004 & 0,6191 & 9072 \\
\hline Média Geral & & 133,52 & 108,50 & 3,56 & 2,95 & 2556 & 18,31 & 469 \\
\hline C.V. $(\%)$ & & 2,54 & 13,28 & 7,19 & 7,20 & 18,60 & 4,30 & 20,31 \\
\hline Ambiente: AREÃO 98/99 & & & & & & & & \\
\hline Repetições (R) & 1 & $0,01^{\mathrm{ns}}$ & $308,01^{\mathrm{ns}}$ & $0,0472^{*}$ & $0,0371^{\mathrm{ns}}$ & $381201^{\mathrm{ns}}$ & $1,6124^{\mathrm{ns}}$ & $13436^{\mathrm{ns}}$ \\
\hline Linhagens (G) & 37 & $36,08^{* *}$ & $574,33 * *$ & $0,0270 * *$ & $0,0422 * *$ & $428981 * *$ & $1,1955^{*}$ & $21471 * *$ \\
\hline Resíduo & 37 & 5,50 & 96,07 & 0,0095 & 0,0124 & 172096 & 0,6063 & 8296 \\
\hline Média Geral & & 140,43 & 103,56 & 1,37 & 3,72 & 2103 & 21,98 & 462 \\
\hline C.V.(\%) & & 1,67 & 9,46 & 7,15 & 5,44 & 19,72 & 3,54 & 19,72 \\
\hline Ambiente: ESALQ 98/99 & & & & & & & & \\
\hline Repetições (R) & 1 & $22,12 *$ & $3,37^{\mathrm{ns}}$ & $0,0088^{\mathrm{ns}}$ & $0,0103^{\mathrm{ns}}$ & $486000^{\mathrm{ns}}$ & $3,0922 * *$ & $12725^{\mathrm{ns}}$ \\
\hline Linhagens (G) & 37 & $45,97 * *$ & $628,23 * *$ & $0,0323 * *$ & $0,0203 * *$ & $302077^{\mathrm{ns}}$ & $0,6225^{*}$ & $15363^{\mathrm{ns}}$ \\
\hline Resíduo & 37 & 3,68 & 136,83 & 0,0085 & 0,0055 & 254740 & 0,3001 & 12528 \\
\hline Média Geral & & 138,85 & 112,42 & 1,87 & 3,11 & 2501 & 22,07 & 552 \\
\hline C.V.(\%) & & 1,38 & 10,40 & 6,00 & 3,90 & 20,18 & 2,48 & 20,28 \\
\hline Ambiente: ANHEMBI 99/00 & & & & & & & & \\
\hline Repetições (R) & 1 & $0,64^{\mathrm{ns}}$ & $0,21^{\mathrm{ns}}$ & $0,0863^{*}$ & $4,6688^{\mathrm{ns}}$ & $224161^{\mathrm{ns}}$ & $7,8529 * *$ & $643^{\mathrm{ns}}$ \\
\hline Linhagens (G) & 37 & $63,37 * *$ & $603,17 * *$ & $0,0729 * *$ & $0,0204 * *$ & $853594 * *$ & $3,6903 * *$ & $44940 * *$ \\
\hline Resíduo & 37 & 4,10 & 133,26 & 0,0179 & 0,0064 & 105774 & 0,9682 & 6162 \\
\hline Média Geral & & 129,28 & 116,68 & 1,81 & 3,55 & 2852 & 21,86 & 625 \\
\hline C.V.(\%) & & 1,57 & 9,89 & 8,87 & 3,98 & 11,40 & 4,50 & 12,56 \\
\hline Ambiente: AREÃO 99/00 & & & & & & & & \\
\hline Repetições (R) & 1 & $0,01^{\mathrm{ns}}$ & $212,22^{\mathrm{ns}}$ & $0,0358^{*}$ & $2,7373^{\mathrm{ns}}$ & $305055^{\mathrm{ns}}$ & $0,4335^{\mathrm{ns}}$ & $9158^{\mathrm{ns}}$ \\
\hline Linhagens $(\mathrm{G})$ & 37 & $30,74 * *$ & $454,23 * *$ & $0,0325 * *$ & $0,0173 *$ & $308787 *$ & $1,5008^{*}$ & $12312 * *$ \\
\hline Resíduo & 37 & 2,04 & 55,25 & 0,0056 & 0,0086 & 149285 & 0,6971 & 5640 \\
\hline Média Geral & & 129,49 & 102,46 & 1,40 & 3,38 & 1590 & 20,07 & 319 \\
\hline C.V.(\%) & & 1,10 & 7,25 & 5,47 & 4,71 & 24,29 & 4,16 & 23,57 \\
\hline Ambiente: ESALQ 99/00 & & & & & & & & \\
\hline Repetições (R) & 1 & $6,37^{\mathrm{ns}}$ & $84,21^{\mathrm{ns}}$ & $0,0082^{\mathrm{ns}}$ & $0,0007^{\mathrm{ns}}$ & $601284^{\mathrm{ns}}$ & $1,3770^{\mathrm{ns}}$ & $33306^{\mathrm{ns}}$ \\
\hline Linhagens (G) & 37 & $66,62 * *$ & $519,93 * *$ & $0,0556^{* *}$ & $0,0179 *$ & $466430 * *$ & $3,0919 *$ & $24720 * *$ \\
\hline Resíduo & 37 & 7,12 & 113,99 & 0,0188 & 0,0096 & 172750 & 1,5184 & 9532 \\
\hline Média Geral & & 140,65 & 122,92 & 2,03 & 3,20 & 1775 & 22,63 & 402 \\
\hline C.V. $(\%)$ & & 1,90 & 8,69 & 8,68 & 5,11 & 23,41 & 5,44 & 24,30 \\
\hline
\end{tabular}

a: análise realizada com dados transformados para $\sqrt{\mathrm{x}+0,5}, \operatorname{com} \mathrm{x}=1$ a 5 .

*, **: significativo ao nível de $5 \%$ e $1 \%$ de probabilidade, respectivamente, pelo teste $\mathrm{F}$.

ns: não significativo pelo teste $\mathrm{F}$. 
Tabela 7. Linhagens Intermediárias: quadrados médios obtidos na análise de variância individual em blocos ao acaso, média geral e coeficiente de variação (C.V.) referentes aos caracteres número de dias para maturidade (NDM), altura da planta na maturidade (APM), acamamento (Ac), valor agronômico (VA), produtividade de grãos (PG), porcentagem de óleo (\%OL) e produtividade de óleo (PO). Soja, semeaduras em 20/11/96, 16/11/97, 17/11/98, 23/11/99 (Anhembi), 12/11/96, 13/11/97, 05/11/98, 30/11/99 (Areão), 06/11/96, 12/11/97, 05/11/98, 08/11/99 (ESALQ). Piracicaba, SP.

\begin{tabular}{|c|c|c|c|c|c|c|c|c|}
\hline \multirow{2}{*}{ Fontes de Variação } & \multirow[t]{2}{*}{ GL } & \multicolumn{7}{|c|}{ Quadrados Médios } \\
\hline & & \multirow{2}{*}{$\begin{array}{c}\text { NDM } \\
\text { dias }\end{array}$} & \multirow{2}{*}{$\begin{array}{c}\mathrm{APM} \\
\mathrm{cm}\end{array}$} & \multirow{2}{*}{$\begin{array}{l}\mathrm{Ac}^{\mathrm{a}} \\
\text { nota }\end{array}$} & \multirow{2}{*}{$\begin{array}{l}\mathrm{VA}^{\mathrm{a}} \\
\text { nota }\end{array}$} & \multirow{2}{*}{$\begin{array}{c}\mathrm{PG} \\
\mathrm{Kg} / \mathrm{ha}\end{array}$} & $\% \mathrm{OL}$ & PO \\
\hline Ambiente: ANHEMBI 96/97 & & & & & & & $\%$ & $\mathrm{Kg} / \mathrm{ha}$ \\
\hline Repetições (R) & 1 & $2,00^{\mathrm{ns}}$ & $43,11^{\mathrm{ns}}$ & $0,1419 * *$ & $0,0718^{*}$ & $1674^{\mathrm{ns}}$ & $5,9512 *$ & $5343^{\text {ns }}$ \\
\hline Linhagens $(\mathrm{G})$ & 48 & $4,31^{\mathrm{ns}}$ & $571,39 * *$ & $0,0436 * *$ & $0,0346^{* *}$ & $605236^{*}$ & $1,6132^{\mathrm{ns}}$ & $21022 * *$ \\
\hline Resíduo & 48 & 3,42 & 43,11 & 0,0176 & 0,0170 & 341386 & 1,1757 & 10349 \\
\hline Média Geral & & 133,82 & 91,38 & 1,86 & 3,09 & 2550 & 17,63 & 449 \\
\hline C.V. $(\%)$ & & 1,38 & 7,18 & 8,70 & 6,91 & 22,90 & 6,15 & 22,63 \\
\hline Ambiente: AREÃO 96/97 & & & & & & & & \\
\hline Repetições (R) & 1 & $1,02^{\mathrm{ns}}$ & $44,45^{\mathrm{ns}}$ & $0,0020^{\mathrm{ns}}$ & $0,0363^{\mathrm{ns}}$ & $59759^{\mathrm{ns}}$ & $5,4780 *$ & $5586^{\mathrm{ns}}$ \\
\hline Linhagens (G) & 48 & $45,36^{* *}$ & $621,00 * *$ & $0,0394 *$ & $0,0757 * *$ & $538055^{* *}$ & $2,7569 * *$ & $20748 * *$ \\
\hline Resíduo & 48 & 3,50 & 146,74 & 0,0211 & 0,0181 & 167424 & 0,7607 & 6632 \\
\hline Média Geral & & 137,55 & 79,45 & 1,45 & 2,79 & 1354 & 18,73 & 257 \\
\hline C.V. $(\%)$ & & 1,36 & 15,25 & 10,46 & 7,47 & 30,21 & 4,66 & 31,07 \\
\hline Ambiente: ESALQ 96/97 & & & & & & & & \\
\hline Repetições (R) & 1 & $25,51^{*}$ & $493,88^{*}$ & $0,0770^{\mathrm{ns}}$ & $0,0739^{\mathrm{ns}}$ & $153^{\mathrm{ns}}$ & $25,3675^{* *}$ & $12157^{\mathrm{ns}}$ \\
\hline Linhagens (G) & 48 & $74,02 * *$ & $584,21 * *$ & $0,1124 * *$ & $0,0920 * *$ & $1251793 * *$ & $2,2161 * *$ & $53260 * *$ \\
\hline Resíduo & 48 & 4,76 & 77,73 & 0,0277 & 0,0235 & 157093 & 0,4537 & 6546 \\
\hline Média Geral & & 139,73 & 94,08 & 2,05 & 2,42 & 2429 & 19,40 & 474 \\
\hline C.V. $(\%)$ & & 1,56 & 9,37 & 10,55 & 9,06 & 16,32 & 3,47 & 17,05 \\
\hline Ambiente: ANHEMBI 97/98 & & & & & & & & \\
\hline Repetições (R) & 1 & $14,02^{\mathrm{ns}}$ & $96,27^{\mathrm{ns}}$ & $0,0447 *$ & $0,0447 *$ & $238140^{\mathrm{ns}}$ & $19,3347 * *$ & $43022 *$ \\
\hline Linhagens (G) & 29 & $12,44^{\mathrm{ns}}$ & $274,56^{* *}$ & $0,0174 *$ & $0,0174 *$ & $427114^{*}$ & $1,4846^{\mathrm{ns}}$ & $19989^{*}$ \\
\hline Resíduo & 29 & 8,53 & 95,09 & 0,0084 & 0,0084 & 192771 & 0,9327 & 8413 \\
\hline Média Geral & & 139,12 & 104,83 & 1,32 & 1,32 & 2287 & 20,08 & 461 \\
\hline C.V. $(\%)$ & & 2,10 & 9,30 & 6,82 & 6,82 & 19,19 & 4,81 & 19,91 \\
\hline Ambiente: Areão 97/98 & & & & & & & & \\
\hline Repetições (R) & 1 & $7,35^{\mathrm{ns}}$ & $336,07^{\mathrm{ns}}$ & $0,0072^{\mathrm{ns}}$ & $0,0350^{\mathrm{ns}}$ & $405082^{\mathrm{ns}}$ & $3,8355^{\mathrm{ns}}$ & $27869^{\mathrm{ns}}$ \\
\hline Linhagens (G) & 29 & $51,11^{* *}$ & $336,87 *$ & $0,0395 * *$ & $0,0216^{*}$ & $464708^{\mathrm{ns}}$ & $2,5841 *$ & $19907^{\mathrm{ns}}$ \\
\hline Resíduo & 29 & 9,80 & 169,86 & 0,0141 & 0,0105 & 290664 & 1,0840 & 11879 \\
\hline Média Geral & & 143,15 & 110,67 & 1,44 & 3,14 & 1822 & 19,64 & 359 \\
\hline C.V. $(\%)$ & & 2,19 & 11,78 & 8,57 & 5,37 & 29,60 & 5,30 & 30,38 \\
\hline Ambiente: ESALQ 97/98 & & & & & & & & \\
\hline Repetições (R) & 1 & $1,07^{\mathrm{ns}}$ & $88,82^{\mathrm{ns}}$ & $0,0517^{\mathrm{ns}}$ & $0,0149^{\mathrm{ns}}$ & $37750^{\mathrm{ns}}$ & $0,0008^{\mathrm{ns}}$ & $2151^{\mathrm{ns}}$ \\
\hline Linhagens (G) & 29 & $15,13^{* *}$ & $774,92 * *$ & $0,0707 * *$ & $0,0215 * *$ & $636280 * *$ & $1,7351 * *$ & $28871 * *$ \\
\hline Resíduo & 29 & 1,65 & 89,19 & 0,0153 & 0,0075 & 261277 & 0,2337 & 10322 \\
\hline Média Geral & & 139,37 & 115,78 & 1,72 & 3,70 & 2925 & 20,61 & 603 \\
\hline C.V. $(\%)$ & & 0,92 & 8,16 & 8,36 & 4,23 & 17,47 & 2,34 & 16,84 \\
\hline Ambiente: ANHEMBI 98/99 & & & & & & & & \\
\hline Repetições (R) & 1 & $18,96^{\mathrm{ns}}$ & $1075,57 * *$ & $0,0769^{*}$ & $0,0010^{\mathrm{ns}}$ & $152801^{\mathrm{ns}}$ & $0,0193^{\mathrm{ns}}$ & $5938^{\mathrm{ns}}$ \\
\hline Linhagens (G) & 26 & $68,37 * *$ & $395,14^{* *}$ & $0,1043^{* *}$ & $0,0373^{*}$ & $368465^{\mathrm{ns}}$ & $1,7943 * *$ & $14773^{\mathrm{ns}}$ \\
\hline Resíduo & 26 & 10,85 & 65,27 & 0,0169 & 0,0165 & 304001 & 0,6794 & 12488 \\
\hline Média Geral & & 145,63 & 115,13 & 2,37 & 3,04 & 2238 & 19,69 & 440 \\
\hline C.V.(\%) & & 2,26 & 7,02 & 7,75 & 6,87 & 24,63 & 4,18 & 25,35 \\
\hline Ambiente: AREÃO 98/99 & & & & & & & & \\
\hline Repetições (R) & 1 & $58,07 * *$ & $647,57^{*}$ & $0,0177^{\mathrm{ns}}$ & $0,0149^{\mathrm{ns}}$ & $1036118^{*}$ & $4,9565 * *$ & $32143^{\mathrm{ns}}$ \\
\hline Linhagens $(G)$ & 26 & $48,53 * *$ & $480,62 * *$ & $0,0551 * *$ & $0,0524 * *$ & $649253 * *$ & $0,9467 *$ & $31331 * *$ \\
\hline Resíduo & 26 & 2,38 & 101,03 & 0,0092 & 0,0189 & 172382 & 0,4687 & 7771 \\
\hline Média Geral & & 150,96 & 115,20 & 1,66 & 3,39 & 2316 & 21,91 & 506 \\
\hline C.V. $(\%)$ & & 1,02 & 8,72 & 6,57 & 7,00 & 17,93 & 3,12 & 17,41 \\
\hline Ambiente: ESALQ 98/99 & & & & & & & & \\
\hline Repetições (R) & 1 & $1,50^{\mathrm{ns}}$ & $2,67^{\mathrm{ns}}$ & $0,0293^{\mathrm{ns}}$ & $0,0084^{\mathrm{ns}}$ & $154668^{\mathrm{ns}}$ & $0,3834^{\mathrm{ns}}$ & $6490^{\mathrm{ns}}$ \\
\hline Linhagens (G) & 26 & $52,13 * *$ & $824,07 * *$ & $0,0508 * *$ & $0,0424 * *$ & $823668^{\mathrm{ns}}$ & $1,0418^{*}$ & $40078^{\text {ns }}$ \\
\hline Resíduo & 26 & 6,77 & 97,90 & 0,0094 & 0,0061 & 448887 & 0,5123 & 23824 \\
\hline Média Geral & & 148,05 & 128,04 & 2,31 & 2,93 & 2329 & 22,09 & 515 \\
\hline C.V. $(\%)$ & & 1,76 & 7,73 & 5,84 & 4,24 & 28,76 & 3,24 & 29,97 \\
\hline Ambiente: ANHEMBI 99/00 & & & & & & & & \\
\hline Repetições (R) & 1 & $4,74 *$ & $58,07^{\mathrm{ns}}$ & $0,0057^{\mathrm{ns}}$ & $0,0018^{\mathrm{ns}}$ & $137007^{\text {ns }}$ & $6,2220^{*}$ & $188^{\mathrm{ns}}$ \\
\hline Linhagens $(G)$ & 26 & $32,65^{* *}$ & $625,20^{* *}$ & $0,0828 * *$ & $0,0160^{\mathrm{ns}}$ & $331099 *$ & $2,9525^{*}$ & $18861^{*}$ \\
\hline Resíduo & 26 & 1,05 & 89,77 & 0,0135 & 0,0094 & 152402 & 1,2633 & 7820 \\
\hline Média Geral & & 137,85 & 125,30 & 2,11 & 3,38 & 2957 & 22,11 & 654 \\
\hline C.V.(\%) & & 0,74 & 7,56 & 7,26 & 4,94 & 13,20 & 5,08 & 13,52 \\
\hline Ambiente: AREÃO 99/00 & & & & & & & & \\
\hline Repetições (R) & 1 & $2,16^{\mathrm{ns}}$ & $66,67^{\mathrm{ns}}$ & $0,0018^{\mathrm{ns}}$ & $0,0274^{*}$ & $709557 * *$ & $12,0417 * *$ & $55002 * *$ \\
\hline Linhagens $(G)$ & 26 & $13,43^{* *}$ & $416,19 * *$ & $0,0348 * *$ & $0,0157 *$ & $319249 * *$ & $2,6294^{*}$ & $14227 * *$ \\
\hline Resíduo & 26 & 2,61 & 76,40 & 0,0108 & 0,0063 & 89515 & 1,3088 & 4687 \\
\hline Média Geral & & 133,22 & 113,33 & 1,65 & 3,48 & 1783 & 20,51 & 366 \\
\hline C.V.(\%) & & 1,21 & 7,71 & 7,13 & 3,98 & 16,77 & 5,58 & 18,68 \\
\hline Ambiente: ESALQ 99/00 & & & & & & & & \\
\hline Repetições (R) & 1 & $18,96^{\mathrm{ns}}$ & $109,80^{\mathrm{ns}}$ & $0,0775^{*}$ & $0,0760^{\mathrm{ns}}$ & $212817^{\mathrm{ns}}$ & $11,0795 * *$ & $24343^{*}$ \\
\hline Linhagens (G) & 26 & $27,08^{* *}$ & $618,17^{\text {ns }}$ & $0,0875^{* *}$ & $0,0411^{\mathrm{ns}}$ & $692871 * *$ & $2,3318 * *$ & $26769 * *$ \\
\hline Resíduo & 26 & 5,35 & 351,10 & 0,0168 & 0,0219 & 145874 & 0,7984 & 5302 \\
\hline Média Geral & & 147,81 & 133,22 & 2,99 & 2,88 & 1585 & 20,29 & 320 \\
\hline C.V. $(\%)$ & & 1,56 & 14,01 & 6,98 & 8,09 & 24,10 & 4,40 & 22,77 \\
\hline
\end{tabular}

a: análise realizada com dados transformados para $\sqrt{\mathrm{x}+0,5}, \operatorname{com} \mathrm{x}=1$ a 5 .

*, **: significativo ao nível de $5 \%$ e $1 \%$ de probabilidade, respectivamente, pelo teste $\mathrm{F}$.

ns: não significativo pelo teste $\mathrm{F}$. 
Tabela 8. Linhagens Semitardias: quadrados médios obtidos na análise de variância individual em blocos ao acaso, média geral e coeficiente de variação (C.V.) referentes aos caracteres número de dias para maturidade (NDM), altura da planta na maturidade (APM), acamamento (Ac), valor agronômico (VA), produtividade de grãos (PG), porcentagem de óleo (\%OL) e produtividade de óleo (PO). Soja, semeaduras em 20/11/96, 16/11/97, 17/11/98, 23/11/99 (Anhembi), 12/11/96, 13/11/97, 05/11/98, 30/11/99 (Areão), 06/11/96, 12/11/97, 05/11/98, 08/11/99 (ESALQ). Piracicaba, SP

\begin{tabular}{|c|c|c|c|c|c|c|c|c|}
\hline \multirow[t]{2}{*}{ Fontes de Variação } & \multirow[t]{2}{*}{ GL } & \multicolumn{7}{|c|}{ Quadrados Médios } \\
\hline & & \multirow{2}{*}{$\begin{array}{l}\text { NDM } \\
\text { dias }\end{array}$} & \multirow{2}{*}{$\begin{array}{c}\mathrm{APM} \\
\mathrm{cm}\end{array}$} & \multirow{2}{*}{$\begin{array}{r}\mathrm{Ac}^{\mathrm{a}} \\
\text { nota }\end{array}$} & \multirow{2}{*}{$\begin{array}{l}\mathrm{VA}^{\mathrm{a}} \\
\text { nota }\end{array}$} & \multirow{2}{*}{$\begin{array}{c}\mathrm{PG} \\
\mathrm{Kg} / \mathrm{ha}\end{array}$} & $\% \mathrm{OL}$ & $\mathrm{PO}$ \\
\hline Ambiente: ANHEMBI 96/97 & & & & & & & $\%$ & $\mathrm{Kg} / \mathrm{ha}$ \\
\hline Repetições (R) & 1 & $10,24^{\mathrm{ns}}$ & $0,38^{\text {ns }}$ & $0,0015^{\mathrm{ns}}$ & $0,0038^{\mathrm{ns}}$ & $550466^{\mathrm{ns}}$ & $5,0796 * *$ & $11365^{\mathrm{ns}}$ \\
\hline Linhagens (G) & 32 & $24,81 * *$ & $199,24 * *$ & $0,0434 * *$ & $0,0370 * *$ & $627923 *$ & $2,9461 * *$ & $27733^{* *}$ \\
\hline Resíduo & 32 & 3,43 & 28,50 & 0,0175 & 0,0154 & 336451 & 0,3730 & 11089 \\
\hline Média Geral & & 142,18 & 101,44 & 1,94 & 3,04 & 2285 & 18,50 & 425 \\
\hline C.V. $(\%)$ & & 1,30 & 5,26 & 8,53 & 6,62 & $25,0 \mathrm{C}$ & 3,30 & 24,77 \\
\hline Ambiente: AREÃO 96/97 & & & & & & & & \\
\hline Repetições (R) & 1 & $4,91^{\mathrm{ns}}$ & $1230,68 * *$ & $0,0190^{\mathrm{ns}}$ & $0,1092 *$ & $596600 * *$ & $0,0662^{\mathrm{ns}}$ & $20415 * *$ \\
\hline Linhagens $(\mathrm{G})$ & 32 & $111,64 * *$ & $439,80 * *$ & $0,0388^{* *}$ & $0,1231 * *$ & $353094 * *$ & $2,2772^{\mathrm{ns}}$ & $14987 * *$ \\
\hline Resíduo & 32 & 6,16 & 87,71 & 0,0126 & 0,0204 & 36335 & 1,5860 & 1427 \\
\hline Média Geral & & 142,15 & 85,98 & 1,54 & 2,22 & 769 & 19,09 & 149 \\
\hline C.V.(\%) & & 1,74 & 10,89 & 7,89 & 8,78 & $24,7 \mathrm{c}$ & 6,60 & 25,33 \\
\hline Ambiente: ESALQ 96/97 & & & & & & & & \\
\hline Repetições (R) & 1 & $3,41^{\mathrm{ns}}$ & $0,38^{\mathrm{ns}}$ & $0,00008^{\mathrm{ns}}$ & $0,0004^{\mathrm{ns}}$ & $376518^{\mathrm{ns}}$ & $18,5606^{* *}$ & $37672 *$ \\
\hline Linhagens (G) & 32 & $100,90 * *$ & $196,19 * *$ & $0,06526^{*}$ & $0,0633 * *$ & $1857660 * *$ & $2,8907 * *$ & $81151 * *$ \\
\hline Resíduo & 32 & 3,81 & 69,91 & 0,03538 & 0,0108 & 181058 & 0,8665 & 8483 \\
\hline Média Geral & & 144,89 & 101,29 & 2,46 & 1,98 & 1582 & 19,54 & 316 \\
\hline C.V.(\%) & & 1,35 & 8,25 & 11,00 & 6,65 & $26,9 C$ & 4,84 & 29,18 \\
\hline Ambiente: ANHEMBI 97/98 & & & & & & & & \\
\hline Repetições (R) & 1 & $4,00^{\mathrm{ns}}$ & $0,25^{\mathrm{ns}}$ & $0,0090^{\mathrm{ns}}$ & $0,0262 *$ & $209306^{\mathrm{ns}}$ & $0,2970^{\mathrm{ns}}$ & $11277^{\mathrm{ns}}$ \\
\hline Linhagens $(G)$ & 7 & $12,86^{* * *}$ & $233,96^{*}$ & $0,0051^{\mathrm{ns}}$ & $0,0348 * *$ & $1034749^{*}$ & $1,4688 * *$ & $42797 *$ \\
\hline Resíduo & 7 & 1,43 & 46,25 & 0,0090 & 0,0022 & 261635 & 0,1844 & 8392 \\
\hline Média Geral & & 146,00 & 101,87 & 1,12 & 3,41 & 2491 & 19,34 & 483 \\
\hline C.V. $(\%)$ & & 0,82 & 6,67 & 7,48 & 2,41 & 20,54 & 2,22 & 18,97 \\
\hline Ambiente: AREÃO 97/98 & & & & & & & & \\
\hline Repetições (R) & 1 & $33,06^{*}$ & $18,06^{\mathrm{ns}}$ & $7,8886^{* *}$ & $0,0214^{\mathrm{ns}}$ & $31064^{\mathrm{ns}}$ & $0,1936^{\mathrm{ns}}$ & $723^{\text {ns }}$ \\
\hline Linhagens (G) & 7 & $9,56^{\mathrm{ns}}$ & $163,42^{\mathrm{ns}}$ & $0,0221^{\mathrm{ns}}$ & $0,0283^{\mathrm{ns}}$ & $418638 *$ & $0,9469 *$ & $18570 * *$ \\
\hline Resíduo & 7 & 3,49 & 146,78 & 0,0284 & 0,0318 & 61875 & 0,1713 & 2292 \\
\hline Média Geral & & 157,19 & 106,69 & 1,37 & 2,25 & 826 & 19,39 & 162 \\
\hline C.V.(\%) & & 1,19 & 11,35 & 12,38 & 10,81 & 30,12 & 2,13 & 29,49 \\
\hline Ambiente: ESALQ 97/98 & & & & & & & & \\
\hline Repetições (R) & 1 & $3,06^{\mathrm{ns}}$ & $105,06^{\mathrm{ns}}$ & $0,0839 *$ & $0,0148^{\mathrm{ns}}$ & $194701^{\mathrm{ns}}$ & $1,2432^{\mathrm{ns}}$ & $4074^{\mathrm{ns}}$ \\
\hline Linhagens $(G)$ & 7 & $45,99 * *$ & $298,92^{\mathrm{ns}}$ & $0,0156^{\mathrm{ns}}$ & $0,0101^{\mathrm{ns}}$ & $293544 *$ & $1,0080^{\mathrm{ns}}$ & $13492 *$ \\
\hline Resíduo & 7 & 2,49 & 79,49 & 0,0099 & 0,0041 & 72519 & 0,5002 & 3077 \\
\hline Média Geral & & 151,81 & 114,44 & 1,84 & 3,69 & 2782 & 21,22 & 589 \\
\hline C.V.(\%) & & 1,04 & 7,79 & 6,52 & 3,13 & $9,6 \varepsilon$ & 3,33 & 9,41 \\
\hline Ambiente: ANHEMBI 98/99 & & & & & & & & \\
\hline Repetições (R) & 1 & $4,57^{\mathrm{ns}}$ & $23,14^{\mathrm{ns}}$ & $0,0016^{\mathrm{ns}}$ & $0,0107^{\mathrm{ns}}$ & $959445^{*}$ & $0,4322^{\mathrm{ns}}$ & $37781 *$ \\
\hline Linhagens (G) & 6 & $25,12 * *$ & $320,98^{\mathrm{ns}}$ & $0,0239^{*}$ & $0,0157 *$ & $415574 *$ & $0,5517^{\mathrm{ns}}$ & $17556^{*}$ \\
\hline Resíduo & 6 & 2,07 & 99,98 & 0,0054 & 0,0024 & 87036 & 0,3513 & 3072 \\
\hline Média Geral & & 156,14 & 121,28 & 2,18 & 3,25 & 1989 & 20,83 & 413 \\
\hline C.V. $(\%)$ & & 0,92 & 8,24 & 4,51 & 2,52 & 14,82 & 2,84 & 13,42 \\
\hline Ambiente: AREÃO 98/99 & & & & & & & & \\
\hline Repetições (R) & 1 & $1,78^{\mathrm{ns}}$ & $138,28^{\mathrm{ns}}$ & $0,1103^{*}$ & $0,1273^{*}$ & $303850^{\mathrm{ns}}$ & $0,1400^{\mathrm{ns}}$ & $11553^{\mathrm{ns}}$ \\
\hline Linhagens (G) & 6 & $10,81^{* *}$ & $423,07^{\mathrm{ns}}$ & $0,0196^{\mathrm{ns}}$ & $0,0167^{\mathrm{ns}}$ & $348774^{\mathrm{ns}}$ & $1,0980^{\mathrm{ns}}$ & $15977^{\mathrm{ns}}$ \\
\hline Resíduo & 6 & 0,09 & 330,12 & 0,0144 & 0,0156 & 263488 & 0,4710 & 14810 \\
\hline Média Geral & & 160,21 & 110,57 & 1,39 & 4,03 & 1978 & 21,64 & 429 \\
\hline C.V.(\%) & & 0,61 & 16,43 & 8,76 & 5,88 & 25,94 & 3,17 & 28,36 \\
\hline Ambiente: ESALQ 98/99 & & & & & & & & \\
\hline Repetições (R) & 1 & $5,78^{\mathrm{ns}}$ & $87,50^{\mathrm{ns}}$ & $0,00004^{\mathrm{ns}}$ & $0,0048^{\mathrm{ns}}$ & $391114^{\mathrm{ns}}$ & $1,5180^{\mathrm{ns}}$ & $289923^{\text {ns }}$ \\
\hline Linhagens $(G)$ & 6 & $19,31 * *$ & $512,95^{* *}$ & $0,03309^{\mathrm{ns}}$ & $0,0203^{\mathrm{ns}}$ & $346506^{\mathrm{ns}}$ & $0,2574^{\mathrm{ns}}$ & $13533^{\mathrm{ns}}$ \\
\hline Resíduo & 6 & 0,45 & 43,67 & 0,03206 & 0,0306 & 364531 & 0,4320 & 18065 \\
\hline Média Geral & & 159,78 & 126,64 & 1,71 & 3,50 & 2777 & 21,84 & 606 \\
\hline C.V. $(\%)$ & & 0,42 & 5,22 & 12,11 & 8,78 & 21,74 & 3,01 & 22,17 \\
\hline Ambiente: ANHEMBI 99/00 & & & & & & & & \\
\hline Repetições (R) & 1 & $0,28^{\mathrm{ns}}$ & $301,78^{\mathrm{ns}}$ & $0,0016^{\mathrm{ns}}$ & $0,0009^{\mathrm{ns}}$ & $54375^{\mathrm{ns}}$ & $0,0501 *$ & $142^{\mathrm{ns}}$ \\
\hline Linhagens $(G)$ & 6 & $1,90^{\mathrm{ns}}$ & $559,17 *$ & $0,0249^{\mathrm{ns}}$ & $0,0085^{\mathrm{ns}}$ & $229402^{\text {ns }}$ & $0,8858^{\mathrm{ns}}$ & $10508^{\mathrm{ns}}$ \\
\hline Resíduo & 6 & 0,62 & 108,12 & 0,0105 & 0,0085 & 254127 & 0,4832 & 10604 \\
\hline Média Geral & & 145,57 & 123,50 & 1,89 & 3,53 & 2707 & 21,74 & 587 \\
\hline C.V.(\%) & & 0,54 & 8,42 & 6,63 & 4,59 & 18,62 & 3,20 & 17,53 \\
\hline Ambiente: AREÃO 99/00 & & & & & & & & \\
\hline Repetições (R) & 1 & $14,00^{\mathrm{ns}}$ & $1,14^{\mathrm{ns}}$ & $0,0480^{\mathrm{ns}}$ & $0,0125^{\mathrm{ns}}$ & $212545^{\mathrm{ns}}$ & $3,1969^{\mathrm{ns}}$ & $4549^{\mathrm{ns}}$ \\
\hline Linhagens $(G)$ & 6 & $23,95 *$ & $450,48 * *$ & $0,0267^{\mathrm{ns}}$ & $0,0419^{\mathrm{ns}}$ & $552208^{\mathrm{ns}}$ & $3,1064^{\mathrm{ns}}$ & $26448 *$ \\
\hline Resíduo & 6 & 5,00 & 38,48 & 0,0340 & 0,0185 & 154382 & 1,5530 & 3704 \\
\hline Média Geral & & 146,86 & 116,71 & 1,75 & 3,25 & 2022 & 20,35 & 410 \\
\hline C.V.(\%) & & 1,52 & 5,31 & 12,37 & 7,05 & 19,42 & 6,12 & 14,85 \\
\hline Ambiente: ESALQ 99/00 & & & & & & & & \\
\hline Repetições (R) & 1 & $0,07^{\text {ns }}$ & $1,94^{\mathrm{ns}}$ & $0,0072^{\mathrm{ns}}$ & $0,0163^{\mathrm{ns}}$ & $12302^{\mathrm{ns}}$ & $0,2524^{\mathrm{ns}}$ & $430^{\mathrm{ns}}$ \\
\hline Linhagens (G) & 6 & $26,14 *$ & $411,07 * *$ & $0,0115^{\mathrm{ns}}$ & $0,0267^{\mathrm{ns}}$ & $126950^{\mathrm{ns}}$ & $2,9458^{\mathrm{ns}}$ & $5615^{\mathrm{ns}}$ \\
\hline Resíduo & 6 & 5,57 & 10,50 & 0,0068 & 0,0434 & 64806 & 1,3564 & 3117 \\
\hline Média Geral & & 156,68 & 122,43 & 2,14 & 2,68 & 997 & 19,11 & 192 \\
\hline C.V.(\%) & & 1,50 & 2,65 & 5,08 & 11,75 & 25,52 & 6,09 & 29,08 \\
\hline
\end{tabular}

a: análise realizada com dados transformados para $\sqrt{\mathrm{x}+0,5}$, com $\mathrm{x}=1$ a 5 .

*, **: significativo ao nível de $5 \%$ e $1 \%$ de probabilidade, respectivamente, pelo teste $\mathrm{F}$.

ns: não significativo pelo teste $\mathrm{F}$. 
Tabela 9. Linhagens Precoces e Semiprecoces: quadrados médios obtidos na análise de variância conjunta/ano em blocos ao acaso, média geral e coeficiente de variação (C.V.\%) referentes aos caracteres número de dias para maturidade (NDM), altura da planta na maturidade (APM), acamamento (Ac), valor agronômico (VA), produtividade de grãos (PG), porcentagem de óleo (\%OL) e produtividade de óleo (PO). Soja, semeaduras em 20/11/96, 16/11/97, 17/11/98, 23/11/99 (Anhembi), 12/11/96, 13/11/97, 05/11/98, 30/11/99 (Areão), 06/11/96, 12/11/97, 05/11/98, 08/11/99 (ESALQ). Piracicaba, SP.

\begin{tabular}{|c|c|c|c|c|c|c|c|c|}
\hline \multirow{2}{*}{$\begin{array}{c}\text { Fontes } \\
\text { de } \\
\text { Variação }\end{array}$} & \multirow[t]{2}{*}{ GL } & \multicolumn{7}{|c|}{ Quadrados Médios } \\
\hline & & $\begin{array}{c}\text { NDM } \\
\text { dias }\end{array}$ & $\begin{array}{c}\text { APM } \\
\mathrm{cm}\end{array}$ & $\begin{array}{l}\mathrm{Ac}^{\mathrm{a}} \\
\text { nota }\end{array}$ & $\begin{array}{l}\mathrm{VA}^{\mathrm{a}} \\
\text { Nota } \\
\end{array}$ & $\begin{array}{c}\mathrm{PG} \\
\mathrm{Kg} / \mathrm{ha}\end{array}$ & $\begin{array}{c}\% \mathrm{OL} \\
\%\end{array}$ & $\begin{array}{c}\mathrm{PO} \\
\mathrm{Kg} / \mathrm{ha}\end{array}$ \\
\hline \multicolumn{9}{|c|}{ LINHAGENS PRECOCES } \\
\hline \multicolumn{9}{|c|}{ ANO $96 / 97$} \\
\hline Locais $(\mathrm{L})$ & 2 & $978,40 * *$ & $4494,03 *$ & $0,5296^{* *}$ & $0,8683^{\mathrm{ns}}$ & $21888619^{*}$ & $118,7168^{\mathrm{ns}}$ & $645730 *$ \\
\hline Repetições (R)/ L & 2 & $15,27 * *$ & $318,81 * *$ & $0,0083^{\mathrm{ns}}$ & $0,0939 * *$ & $1792451^{* * *}$ & $34,7037 * *$ & $62433 * *$ \\
\hline Linhagens $(\mathrm{G})$ & 42 & $22,46 * *$ & $458,78^{* *}$ & $0,1045^{* *}$ & $0,1328 * *$ & $775439 * *$ & $4,7747 * *$ & $37891 * *$ \\
\hline $\mathrm{G} \times \mathrm{L}$ & 84 & $14,81^{* *}$ & $108,04 * *$ & $0,0280^{\mathrm{ns}}$ & $0,0625^{* *}$ & $770599 * *$ & $2,4293 * *$ & $34399 * *$ \\
\hline Resíduo & $12 \epsilon$ & 3,27 & 40,34 & 0,0222 & 0,0235 & 196433 & 1,2975 & 8525 \\
\hline Média Geral & & 121,63 & 96,53 & 1,72 & 2,88 & 2050 & 20,67 & 423 \\
\hline C.V. $(\%)$ & & 1,49 & 6,58 & 10,09 & 8,41 & 21,62 & 5,51 & 21,82 \\
\hline \multicolumn{9}{|l|}{ ANO 97/98 } \\
\hline Locais (L) & 2 & $4791,27 * *$ & $1292,00^{\mathrm{ns}}$ & $0,0475^{*}$ & $0,1536^{*}$ & $2082853^{*}$ & $52,2684 * *$ & $134644 *$ \\
\hline Repetições (R)/ L & 2 & $6,53^{\mathrm{ns}}$ & $361,12 * *$ & $0,0042^{\mathrm{ns}}$ & $0,0105^{\mathrm{ns}}$ & $1555081^{\mathrm{ns}}$ & $0,2690^{\mathrm{ns}}$ & $6445^{\mathrm{ns}}$ \\
\hline Linhagens (G) & 25 & $23,41 * *$ & $444,06 * *$ & $0,0700^{* * *}$ & $0,0223^{*}$ & $549400 * *$ & $5,3096 * *$ & $31343 * *$ \\
\hline $\mathrm{G} \times \mathrm{L}$ & $5 \varepsilon$ & $9,74 * *$ & $120,91 *$ & $0,0254^{*}$ & $0,0237 * *$ & $312484 * *$ & $0,4378^{\mathrm{ns}}$ & $13612 * *$ \\
\hline Resíduo & 87 & 3,15 & 77,45 & 0,0153 & 0,0122 & 164453 & 0,5819 & 7227 \\
\hline Média Geral & & 123,62 & 111,84 & 1,55 & 3,57 & 2686 & 21,52 & 578,13 \\
\hline C.V. $(\%)$ & & 1,43 & 7,87 & 8,69 & 5,49 & 15,10 & 3,54 & 14,70 \\
\hline \multicolumn{9}{|l|}{ ANO 98/99 } \\
\hline Locais (L) & 2 & $530,08^{*}$ & $14241,68^{\mathrm{ns}}$ & $1,1720^{\mathrm{ns}}$ & $0,0371^{\mathrm{ns}}$ & $17854716^{* *}$ & $172,1281^{* *}$ & $602212 * *$ \\
\hline Repetições (R)/ L & 2 & $20,44^{*}$ & $1599,20 * *$ & $0,2058 * *$ & $0,0635^{\mathrm{ns}}$ & $304455^{\mathrm{ns}}$ & $2,0259 *$ & $15450^{\mathrm{ns}}$ \\
\hline Linhagens $(\mathrm{G})$ & $2 \%$ & $29,53 * *$ & $492,98 * *$ & $0,0704 * *$ & $0,0341^{\mathrm{ns}}$ & $491013 * *$ & $4,3946^{* *}$ & $21004 * *$ \\
\hline $\mathrm{G} \times \mathrm{L}$ & 54 & $8,29 *$ & $210,80^{\mathrm{ns}}$ & $0,0249^{\mathrm{ns}}$ & $0,0563^{*}$ & $411480^{*}$ & $0,7453^{\mathrm{ns}}$ & $19172 * *$ \\
\hline Resíduo & 81 & 5,17 & 157,41 & 0,0180 & 0,0363 & 239085 & 0,5101 & 10025 \\
\hline Média Geral & & 130,27 & 111,80 & 1,70 & 3,13 & 2100 & 21,34 & 443,19 \\
\hline C.V. $(\%)$ & & 1,74 & 11,22 & 9,13 & 10,05 & 23,28 & 3,35 & 22,59 \\
\hline \multicolumn{9}{|l|}{ ANO $99 / 00$} \\
\hline Locais (L) & 2 & $1082,00 * *$ & $12437,75^{* *}$ & $1,6356^{* * *}$ & $0,1813^{*}$ & $37410852 * *$ & $107,4087 * *$ & $2228233^{* *}$ \\
\hline Repetições (R)/ L & 2 & $11,50^{\mathrm{ns}}$ & $72,18^{\mathrm{ns}}$ & $0,0186^{\mathrm{ns}}$ & $0,0082^{\mathrm{ns}}$ & $760812 *$ & $1,4814^{\mathrm{ns}}$ & $35377^{*}$ \\
\hline Linhagens $(\mathrm{G})$ & 27 & $71,38^{* *}$ & $561,94 * *$ & $0,0888^{* *} *$ & $0,0271 * *$ & $606186^{* * *}$ & $8,4746^{* * *}$ & $27550 * *$ \\
\hline $\mathrm{G} \times \mathrm{L}$ & 54 & $7,81^{*}$ & $186,40 * *$ & $0,0419 * *$ & $0,0092^{\mathrm{ns}}$ & $262467^{\mathrm{ns}}$ & $0,9964^{\mathrm{ns}}$ & $12424^{\mathrm{ns}}$ \\
\hline Resíduo & 81 & 4,84 & 81,77 & 0,0185 & 0,0088 & 191145 & 1,8107 & 10009 \\
\hline Média Geral & & 125,07 & 124,12 & 1,98 & 3,45 & 2630 & 21,67 & 572 \\
\hline C.V. $(\%)$ & & 1,76 & 7,28 & 8,73 & 4,74 & 16,62 & 6,21 & 17,48 \\
\hline \multicolumn{9}{|c|}{ LINHAGENS SEMIPRECOCES } \\
\hline Locais (L) & 2 & $2883,30 * *$ & $3553,06^{\mathrm{ns}}$ & $0,9731^{*}$ & $0,6173^{\mathrm{ns}}$ & $33015055^{* *}$ & $41,7948^{\mathrm{ns}}$ & 1539394* \\
\hline Repetições (R)/ L & 2 & $29,19 * *$ & $381,62 * *$ & $0,0597 * *$ & $0,1926^{* *}$ & $671013^{* *}$ & $25,7893 * *$ & $54257 * *$ \\
\hline Linhagens (G) & 62 & $103,60 * *$ & $1655,59 * *$ & $0,1127 * *$ & $0,1679 * *$ & $1554989^{* * *}$ & $3,8974 * *$ & $60540 * *$ \\
\hline $\mathrm{G} \times \mathrm{L}$ & 124 & $38,26 * *$ & $122,09 * *$ & $0,0247 * *$ & $0,0507 * *$ & $626110 * *$ & $1,4148 * *$ & $24450 * *$ \\
\hline Resíduo & $18 t$ & 3,79 & 63,60 & 0,0123 & 0,0198 & 171870 & 0,7910 & 7298 \\
\hline Média Geral & & 128,50 & 88,81 & 1,62 & 3,06 & 2063 & 19,59 & 406 \\
\hline C.V. $(\%)$ & & 1,51 & 8,98 & 7,69 & 7,52 & 20,10 & 4,54 & 21,02 \\
\hline \multicolumn{9}{|l|}{ ANO 97/98 } \\
\hline Locais (L) & 2 & $485,87 * *$ & $1550,30^{\mathrm{ns}}$ & $0,0358^{\mathrm{ns}}$ & $0,2362 * *$ & $6433873^{*}$ & $71,1900^{*}$ & $393879 *$ \\
\hline Repetições (R)/ L & 2 & $5,13^{*}$ & $519,16^{* *}$ & $0,0070^{\mathrm{ns}}$ & $0,0068^{\mathrm{ns}}$ & $268793^{\mathrm{ns}}$ & $6,4847 * *$ & $23675^{\mathrm{ns}}$ \\
\hline Linhagens (G) & 42 & $31,11 * *$ & $770,70 * *$ & $0,0776^{* *}$ & $0,0475^{* *}$ & $508069 * *$ & $4,8829 * *$ & $25499 * *$ \\
\hline $\mathrm{G} \times \mathrm{L}^{\circ}$ & 82 & $3,42 * *$ & $129,17 *$ & $0,0152 * *$ & $0,0189 * *$ & $312789 * *$ & $0,5698 *$ & $14683^{* * *}$ \\
\hline Resíduo & $12:$ & 1,89 & 86,56 & 0,0095 & 0,0115 & 196118 & 0,3606 & 8862 \\
\hline Média Geral & & 131,37 & 103,11 & 1,43 & 3,61 & 2666 & 20,82 & 556 \\
\hline C.V. $(\%)$ & & 1,05 & 9,02 & 7,05 & 5,31 & 16,61 & 2,88 & 16,92 \\
\hline ANO 98/99 & & & & & & & & \\
\hline Locais (L) & 2 & $995,72 * *$ & $1496,40 *$ & $1,0815^{*}$ & $0,8052 *$ & $4198188^{*}$ & $346,8097 * *$ & $177859 *$ \\
\hline Repetições (R)/ L & 2 & $11,32^{\mathrm{ns}}$ & $124,07^{\mathrm{ns}}$ & $0,0595^{* *}$ & $0,0378^{*}$ & $233247^{\mathrm{ns}}$ & $5,6497 * *$ & $12203^{\mathrm{ns}}$ \\
\hline Linhagens (G) & 37 & $103,30 * *$ & $1235,10^{* *}$ & $0,0604 * *$ & $0,0566 * *$ & $636817 * *$ & $2,5806^{* *}$ & $29236 * *$ \\
\hline $\mathrm{G} \times \mathrm{L}^{\circ}$ & 74 & $6,84^{\mathrm{ns}}$ & $224,17 *$ & $0,0259 * *$ & $0,0263 * *$ & $231374^{\mathrm{ns}}$ & $0,7607 *$ & $10580^{\mathrm{ns}}$ \\
\hline Resíduo & 111 & 6,89 & 146,83 & 0,0137 & 0,0119 & 228590 & 0,5327 & 10403 \\
\hline Média Geral & & 137,60 & 108,16 & 2,27 & 3,26 & 2394 & 20,78 & 496 \\
\hline C.V. $(\%)$ & & 1,91 & 11,20 & 8,02 & 5,64 & 19,97 & 3,51 & 20,56 \\
\hline ANO 99/00 & & & & & & & & \\
\hline Locais (L) & 2 & $3222,11 * *$ & $8358,03 * *$ & $0,8469^{*}$ & $0,1503 * *$ & $35315989 * *$ & $131,2519 * *$ & $1903571 * *$ \\
\hline Repetições (R)/ L & 2 & $2,34^{\mathrm{ns}}$ & $98,88^{\mathrm{ns}}$ & $0,0434 *$ & $0,0002^{\mathrm{ns}}$ & $376834^{\mathrm{ns}}$ & $3,2212 *$ & $14370^{\mathrm{ns}}$ \\
\hline Linhagens (G) & 37 & $142,05 * *$ & $1285,38^{* *}$ & $0,1241^{* *}$ & $0,0345^{* *}$ & $838472 * *$ & $5,8391 * *$ & $41843 * *$ \\
\hline $\mathrm{G} \times \mathrm{L}^{\circ}$ & 74 & $9,34 * *$ & $145,98^{*}$ & $0,0185^{\mathrm{ns}}$ & $0,0106^{\mathrm{ns}}$ & $395169 * *$ & $1,2220^{\mathrm{ns}}$ & $20065^{* *}$ \\
\hline Resíduo & 111 & 4,42 & 100,84 & 0,0141 & 0,0082 & 142603 & 1,0612 & 7111 \\
\hline Média Geral & & 133,14 & 114,02 & 1,75 & 3,37 & 2072 & 21,52 & 448 \\
\hline C.V. $(\%)$ & & 1,58 & 8,81 & 7,99 & 4,61 & 18,22 & 4,79 & 18,81 \\
\hline
\end{tabular}

a: análise realizada com dados transformados para $\sqrt{\mathrm{x}+0,5}, \operatorname{com} \mathrm{x}=1$ a 5 .

$*$, ** : significativo ao nível de $5 \%$ e $1 \%$ de probabilidade, respectivamente, pelo teste $\mathrm{F}$;

ns: não significativo pelo teste $\mathrm{F}$. 
Tabela 10. Linhagens Intermediárias e Semitardias: quadrados médios obtidos na análise de variância conjunta/ano em blocos ao acaso, média geral e coeficiente de variação (C.V.\%) referentes aos caracteres número de dias para maturidade (NDM), altura da planta na maturidade (APM), acamamento (Ac), valor agronômico (VA), produtividade de grãos (PG), porcentagem de óleo (\%OL) e produtividade de óleo (PO). Soja, semeaduras em 20/11/96, 16/11/97, 17/11/98, 23/11/99 (Anhembi), 12/11/96, 13/11/97, 05/11/98, 30/11/99 (Areão), 06/11/96, 12/11/97, 05/11/98, 08/11/99 (ESALQ). Piracicaba, SP.

\begin{tabular}{|c|c|c|c|c|c|c|c|c|}
\hline \multirow{3}{*}{$\begin{array}{c}\text { Fontes } \\
\text { de } \\
\text { Variação }\end{array}$} & \multirow[t]{3}{*}{ GL } & \multicolumn{7}{|c|}{ Quadrados Médios } \\
\hline & & NDM & APM & $\mathrm{Ac}^{\mathrm{a}}$ & $\mathrm{VA}^{\mathrm{a}}$ & $\mathrm{PG}$ & $\% \mathrm{OL}$ & $\mathrm{PO}$ \\
\hline & & dias & $\mathrm{Cm}$ & nota & nota & $\mathrm{Kg} / \mathrm{ha}$ & $\%$ & $\mathrm{Kg} / \mathrm{ha}$ \\
\hline \multicolumn{9}{|c|}{ LINHAGENS INTERMEDIÁRIAS } \\
\hline \multicolumn{9}{|c|}{ ANO 96/97 } \\
\hline Locais (L) & 2 & $877,81 * *$ & $5940,72 *$ & $0,9419^{*}$ & $0,9399 *$ & $42485439 * *$ & $77,8481^{\mathrm{ns}}$ & $1394732 * *$ \\
\hline Repetições (R)/ L & 2 & $9,51^{\mathrm{ns}}$ & $193,81^{\mathrm{ns}}$ & $0,0736^{*}$ & $0,0607 *$ & $20436^{\mathrm{ns}}$ & $12,1859 * *$ & $7601^{\mathrm{ns}}$ \\
\hline Linhagens $(\mathrm{G})$ & $4 \varepsilon$ & $75,87 * *$ & $1482,98 * *$ & $0,1393 * *$ & $0,1179 * *$ & $1482783 * *$ & $4,5244 * *$ & $58381 * *$ \\
\hline $\mathrm{G} \times \mathrm{L}$ & 96 & $23,91 * *$ & $146,81 * *$ & $0,0280^{\mathrm{ns}}$ & $0,0422 * *$ & $456246 * *$ & $1,0360^{\mathrm{ns}}$ & $18339 * *$ \\
\hline Resíduo & 144 & 3,89 & 89,19 & 0,0221 & 0,0196 & 221965 & 0,7975 & 7752 \\
\hline Média Geral & & 137,03 & 88,30 & 1,79 & 2,77 & 2111 & 18,59 & 394 \\
\hline C.V. $(\%)$ & & 1,44 & 10,69 & 9,94 & 7,80 & 22,31 & 4,80 & 22,37 \\
\hline \multicolumn{9}{|l|}{ ANO $97 / 98$} \\
\hline Locais (L) & 2 & $306,44 * *$ & $1801,10^{*}$ & $0,2740^{\mathrm{ns}}$ & $0,3171^{\mathrm{ns}}$ & $18427543 * *$ & $14,3741^{\mathrm{ns}}$ & $905009 * *$ \\
\hline Repetições (R)/ L & 2 & $7,48^{\mathrm{ns}}$ & $173,72^{\mathrm{ns}}$ & $0,0345^{*}$ & $0,0395^{* *}$ & $226991^{\mathrm{ns}}$ & $7,7237 * *$ & $24347^{\mathrm{ns}}$ \\
\hline Linhagens (G) & $2 C$ & $55,42 * *$ & $1115,75^{* *}$ & $0,0744 * *$ & $0,0467 * *$ & $947779 * *$ & $3,5475 * *$ & $40692 * *$ \\
\hline Gx L & $5 \varepsilon$ & $11,63 * *$ & $135,30^{\mathrm{ns}}$ & $0,0266^{* *}$ & $0,0146^{*}$ & $290162^{\mathrm{ns}}$ & $1,1282^{*}$ & $14038^{\mathrm{ns}}$ \\
\hline Resíduo & 87 & 6,66 & 118,05 & 0,0126 & 0,0095 & 248237 & 0,7502 & 10205 \\
\hline Média Geral & & 140,54 & 110,43 & 1,50 & 3,46 & 2345 & 20,11 & 474 \\
\hline C.V. $(\%)$ & & 1,84 & 9,84 & 8,00 & 4,92 & 21,25 & 4,31 & 21,30 \\
\hline \multicolumn{9}{|l|}{ ANO 98/99 } \\
\hline Locais (L) & 2 & $385,04 *$ & $2981,71^{\mathrm{ns}}$ & $0,8052 *$ & $0,1999 *$ & $130188^{\mathrm{ns}}$ & $96,3600 * *$ & $88856^{\mathrm{ns}}$ \\
\hline Repetições (R)/ L & 2 & $126,18^{*}$ & $575,27 * *$ & $0,0413^{*}$ & $0,0081^{\mathrm{ns}}$ & $447863^{\mathrm{ns}}$ & $1,7864 *$ & $14857^{\mathrm{ns}}$ \\
\hline Linhagens $(\mathrm{G})$ & 26 & $146,95 * *$ & $1307,52 * *$ & $0,1528^{*} *$ & $0,0828 * *$ & $771761 * *$ & $2,6260 * *$ & $36958 * *$ \\
\hline $\mathrm{G} \times \mathrm{L}$ & 52 & $11,04 *$ & $196,16^{* *}$ & 0,0287 ** & $0,0247 *$ & $534812 *$ & $0,5784^{\mathrm{ns}}$ & $24612 *$ \\
\hline Resíduo & $7 \varepsilon$ & 6,67 & 88,06 & 0,0119 & 0,0139 & 308423 & 0,5535 & 14694 \\
\hline Média Geral & & 148,22 & 119,46 & 2,12 & 3,12 & 2294 & 21,23 & 487 \\
\hline C.V. $(\%)$ & & 1,74 & 7,85 & 6,80 & 6,21 & 24,20 & 3,50 & 24,87 \\
\hline \multicolumn{9}{|l|}{ ANO $99 / 00$} \\
\hline Locais (L) & 2 & $3002,74 * *$ & $5668,34 * *$ & $2,1748 * *$ & $0,4133^{*}$ & $30046000 * *$ & $53,2618^{\mathrm{ns}}$ & $1784202 * *$ \\
\hline Repetições (R)/ L & 2 & $7,90^{\mathrm{ns}}$ & $78,18^{\mathrm{ns}}$ & $0,0284^{\mathrm{ns}}$ & $0,0351 *$ & $381944^{\mathrm{ns}}$ & $9,7810 * *$ & $28314 * *$ \\
\hline Linhagens (G) & $2 \epsilon$ & $60,25 * *$ & $1444,65 * *$ & 0,1414 ** & $0,0373 * *$ & $484413 * *$ & $3,8117 * *$ & $24351 * *$ \\
\hline $\mathrm{G} \times \mathrm{L}$ & 52 & $6,46 * *$ & $107,45^{\mathrm{ns}}$ & $0,0318^{* *}$ & $0,0177^{\mathrm{ns}}$ & $410721 * *$ & $2,0509 * *$ & $17074 * *$ \\
\hline Resíduo & $7 \varepsilon$ & 3,00 & 172,42 & 0,0137 & 0,0125 & 136394 & 1,1235 & 6212 \\
\hline Média Geral & & 139,63 & 124,11 & 2,25 & 3,25 & 2105 & 20,97 & 446 \\
\hline C.V. $(\%)$ & & 1,24 & 10,58 & 7,14 & 5,80 & 17,55 & 5,05 & 17,67 \\
\hline \multicolumn{9}{|c|}{ LINHAGENS SEMITARDIAS } \\
\hline \multicolumn{9}{|c|}{ ANO 96/97 } \\
\hline Locais (L) & 2 & $163,65^{*}$ & $5203,48^{*}$ & $1,3480^{* *}$ & $1,7846^{* *}$ & $38518810^{* *} *$ & $17,8682^{\mathrm{ns}}$ & $1293874 * *$ \\
\hline Repetições (R)/ L & 3 & $6,19^{\mathrm{ns}}$ & $410,48 * *$ & $0,0069^{\mathrm{ns}}$ & $0,0378^{\mathrm{ns}}$ & $468228^{\mathrm{ns}}$ & $7,9177 * *$ & $21727 *$ \\
\hline Linhagens (G) & 32 & $160,97 * *$ & $660,45^{* *}$ & $0,0722 * *$ & $0,1313 * *$ & $1732836 * *$ & $5,0415 * *$ & $74646 * *$ \\
\hline $\mathrm{G} \times \mathrm{L}$ & 64 & $38,19 * *$ & $87,39^{\mathrm{ns}}$ & $0,0376^{* *}$ & $0,0461 * *$ & $553000 * *$ & $1,5365^{*}$ & $24623 * *$ \\
\hline Resíduo & 96 & 4,48 & 62,04 & 0,0218 & 0,0155 & 183792 & 0,9545 & 7096 \\
\hline Média Geral & & 143,07 & 96,24 & 1,98 & 2,41 & 1542 & 19,04 & 296 \\
\hline C.V. $(\%)$ & & 1,47 & 8,18 & 9,46 & 7,38 & 27,80 & 5,13 & 28,46 \\
\hline ANO 97/98 & & & & & & & & \\
\hline Locais (L) & 2 & $500,89 * *$ & $642,77 *$ & $0,2645^{\mathrm{ns}}$ & $0,7058^{* *}$ & $17827655^{* * *}$ & $18,4126^{* *}$ & $791015^{* *}$ \\
\hline Repetições (R)/ L & 2 & $13,37 * *$ & $41,12^{\mathrm{ns}}$ & $0,0310^{\mathrm{ns}}$ & $0,0208^{\mathrm{ns}}$ & $145024^{\mathrm{ns}}$ & $0,0578^{\mathrm{ns}}$ & $5358^{\text {ns }}$ \\
\hline Linhagens (G) & 7 & $55,24 * *$ & $487,76^{* *}$ & $0,0098^{\mathrm{ns}}$ & $0,0194^{\mathrm{ns}}$ & $502563 * *$ & $2,8287 * *$ & $26740 * *$ \\
\hline Gx L & 14 & $6,59 *$ & $104,27^{\mathrm{ns}}$ & $0,0165^{\mathrm{ns}}$ & $0,0269^{\mathrm{ns}}$ & $622184 * *$ & $0,2976^{\mathrm{ns}}$ & $24060 * *$ \\
\hline Resíduo & 21 & 2,47 & 90,84 & 0,0157 & 0,0127 & 132010 & 0,2853 & 4587 \\
\hline Média Geral & & 151,67 & 107,67 & 1,45 & 3,11 & 2033 & 19,98 & 412 \\
\hline C.V. $(\%)$ & & 1,04 & 8,85 & 9,05 & 5,97 & 17,87 & 2,67 & 16,45 \\
\hline ANO 98/99 & & & & & & & & \\
\hline Locais (L) & 2 & $70,07 *$ & $937,50 *$ & $0,2482^{\mathrm{ns}}$ & $0,1321^{\mathrm{ns}}$ & $2938587^{\text {ns }}$ & $3,9645^{\mathrm{ns}}$ & $160777^{\mathrm{ns}}$ \\
\hline Repetições (R)/ L & 2 & $4,05^{*}$ & $82,98^{\mathrm{ns}}$ & $0,0373^{\mathrm{ns}}$ & $0,0476^{\mathrm{ns}}$ & $551470^{\mathrm{ns}}$ & $0,6967^{\mathrm{ns}}$ & $26109^{\mathrm{ns}}$ \\
\hline Linhagens $(\mathrm{G})$ & $\epsilon$ & $37,37 * *$ & $1005,39 * *$ & $0,0364^{\mathrm{ns}}$ & $0,0229^{\mathrm{ns}}$ & $584877^{\mathrm{ns}}$ & $0,8520^{\mathrm{ns}}$ & $22799^{\mathrm{ns}}$ \\
\hline $\mathrm{G}^{\mathrm{L}} \mathrm{L}^{\circ}$ & 12 & $8,93 * *$ & $125,80^{\mathrm{ns}}$ & $0,0230^{\mathrm{ns}}$ & $0,0149^{\mathrm{ns}}$ & $262988^{\mathrm{ns}}$ & $0,5276^{\mathrm{ns}}$ & $12133^{\mathrm{ns}}$ \\
\hline Resíduo & $1 \varepsilon$ & 1,16 & 157,92 & 0,0173 & 0,0162 & 238352 & 0,4181 & 11982 \\
\hline Média Geral & & 158,71 & 119,50 & 1,76 & 3,59 & 2248 & 21,44 & 483 \\
\hline C.V. $(\%)$ & & 0,68 & 10,52 & 8,80 & 6,31 & 21,72 & 3,02 & 22,67 \\
\hline ANO $99 / 00$ & & & & & & & & \\
\hline Locais (L) & 2 & $527,31 * *$ & $186,31^{\mathrm{ns}}$ & $0,0629^{\mathrm{ns}}$ & $0,1971 *$ & $10367788 * *$ & $24,2990 *$ & $549213^{* *}$ \\
\hline Repetições (R)/ L & 3 & $4,78^{\mathrm{ns}}$ & $100,98^{\mathrm{ns}}$ & $0,0189^{\mathrm{ns}}$ & $0,0099^{\mathrm{ns}}$ & $93074^{\mathrm{ns}}$ & $2,4998^{\mathrm{ns}}$ & $1707^{\mathrm{ns}}$ \\
\hline Linhagens $(\mathrm{G})$ & $\epsilon$ & $28,60 * *$ & $1219,598 * *$ & $0,0270^{\mathrm{ns}}$ & $0,0441^{\mathrm{ns}}$ & $322909^{\mathrm{ns}}$ & $3,6585^{*}$ & $20260^{*}$ \\
\hline Gx L & 12 & $11,70^{*}$ & $100,56^{\mathrm{ns}}$ & $0,0180^{\mathrm{ns}}$ & $0,0165^{\mathrm{ns}}$ & $292825^{\mathrm{ns}}$ & $1,6397^{\mathrm{ns}}$ & $11155^{\mathrm{ns}}$ \\
\hline Resíduo & $1 \varepsilon$ & 3,73 & 52,36 & 0,0171 & 0,0235 & 157772 & 1,1309 & 5808 \\
\hline Média Geral & & 149,74 & 120,88 & 1,93 & 3,15 & 1909 & 20,40 & 396 \\
\hline C.V. (\%) & & 1,29 & 5,99 & 8,42 & 8,05 & 20,81 & 5,21 & 19,22 \\
\hline
\end{tabular}

a: análise realizada com dados transformados para $\sqrt{\mathrm{x}+0,5}, \operatorname{com} \mathrm{x}=1$ a 5 .

*, ** : significativo ao nível de $5 \%$ e $1 \%$ de probabilidade, respectivamente, pelo teste $\mathrm{F}$;

ns: não significativo pelo teste $\mathrm{F}$. 
Tabela 11. Quadrados médios obtidos na análise de variância conjunta geral, em blocos ao acaso, média geral e coeficiente de variação (C.V.) para os caracteres número de dias para maturidade (NDM), altura da planta na maturidade (APM), acamamento (Ac), valor agronômico (VA), produtividade de grãos (PG), porcentagem de óleo (\%OL) e produtividade de óleo (PO). Soja, semeaduras em 20/11/96, 16/11/97, 17/11/98, 23/11/99 (Anhembi), 12/11/96, 13/11/97, 05/11/98, 30/11/99 (Areão), 06/11/96, 12/11/97, 05/11/98, 08/11/99 (ESALQ). Piracicaba, SP.

\begin{tabular}{|c|c|c|c|c|c|c|c|c|}
\hline \multirow{2}{*}{\multicolumn{2}{|c|}{ Fontes de Variação $\quad$ GL }} & \multicolumn{7}{|c|}{ Quadrados Médios } \\
\hline & & $\begin{array}{c}\text { NDM } \\
\text { dias }\end{array}$ & $\begin{array}{c}\text { APM } \\
\mathrm{cm}\end{array}$ & $\begin{array}{l}\mathrm{Ac}^{\mathrm{a}} \\
\text { nota }\end{array}$ & $\begin{array}{l}\text { VA }^{a} \\
\text { nota }\end{array}$ & $\begin{array}{c}\mathrm{PG} \\
\mathrm{Kg} / \mathrm{ha}\end{array}$ & $\begin{array}{c}\% \mathrm{OL} \\
\%\end{array}$ & $\begin{array}{c}\mathrm{PO} \\
\mathrm{Kg} / \mathrm{ha}\end{array}$ \\
\hline \multicolumn{9}{|l|}{ LINHAGENS PRECOCES } \\
\hline $\begin{array}{l}\text { (Repetições/Anos)/Locais } \\
\text { Anos (A) }\end{array}$ & & $\begin{array}{r}14,78^{* *} \\
2029,44^{\text {ns }}\end{array}$ & $\begin{array}{r}538,97 * * \\
18525,82^{\text {ns }}\end{array}$ & $\begin{array}{l}0,0616^{* *} \\
0,5006^{\mathrm{ns}}\end{array}$ & $\begin{array}{l}0,0309^{\mathrm{ns}} \\
0,8510^{* *}\end{array}$ & $\begin{array}{r}588859^{* *} \\
14980232^{\mathrm{ns}}\end{array}$ & $\begin{array}{l}7,7826^{* *} \\
22,8603^{\text {ns }}\end{array}$ & $\begin{array}{l}24884^{* *} \\
907580^{\text {ns }}\end{array}$ \\
\hline Locais $(\mathrm{L})$ & & $4362,68^{\mathrm{ns}}$ & $15156,18^{\text {ns }}$ & $1,7342^{\mathrm{ns}}$ & $0,1382^{\mathrm{ns}}$ & $36899291^{\mathrm{ns}}$ & $3,5079^{\mathrm{ns}}$ & $1900523^{\mathrm{ns}}$ \\
\hline Linhagens $(\mathrm{G})$ & $\therefore$ & $77,87 * *$ & $1277,14 * *$ & $0,2504 * *$ & $0,1057 * *$ & $1028336 * *$ & $15,4753 * *$ & $49574 * *$ \\
\hline $\mathrm{G} \times \mathrm{A}$ & $\imath$ & $19,22 * *$ & $240,91 * *$ & $0,0275^{\mathrm{ns}}$ & $0,0306^{\mathrm{ns}}$ & $3338777^{\mathrm{ns}}$ & $1,9220 * *$ & $15302^{\text {ns }}$ \\
\hline$G \times L$ & $\vdots$ & $10,04^{\mathrm{ns}}$ & $165,59^{\mathrm{ns}}$ & $0,0338^{\mathrm{ns}}$ & $0,0377^{\mathrm{ns}}$ & $296986^{\mathrm{ns}}$ & $1,1586^{\mathrm{ns}}$ & $15070^{\mathrm{ns}}$ \\
\hline$A \times L$ & & $892,93 * *$ & $5356,07 * *$ & $0,0527 * *$ & $0,1463^{*}$ & $14837083 * *$ & $127,7497 * *$ & $614351 * *$ \\
\hline $\mathrm{G} \times \mathrm{A} \times \mathrm{L}$ & 11 & $8,04 * *$ & $150,37 * *$ & $0,0284 * *$ & $0,0329 * *$ & $419853^{* *}$ & $0,9710^{\mathrm{ns}}$ & $18904 * *$ \\
\hline Resíduo médio & 3: & 3,90 & 88,94 & 0,0175 & 0,0190 & 190768 & 1,0550 & 8744 \\
\hline Média Geral & & 125,35 & 111,60 & 1,75 & 3,29 & 2421 & 21,38 & 517 \\
\hline C.V. $(\%)$ & & 1,57 & 8,45 & 8,91 & 7,11 & 18,04 & 4,80 & 18,09 \\
\hline \multicolumn{9}{|c|}{ LINHAGENS SEMIPRECOCES } \\
\hline Anos (A) & & $2746,90^{\mathrm{ns}}$ & $24107,35 *$ & $0,8207^{\mathrm{ns}}$ & $0,4503^{\mathrm{ns}}$ & $15246491^{\mathrm{ns}}$ & $155,5308^{\text {ns }}$ & $607845^{\mathrm{ns}}$ \\
\hline Locais (L) & & $5567,37 *$ & $5212,71^{\mathrm{ns}}$ & $1,6750 *$ & $0,1229^{\mathrm{ns}}$ & $48408745^{*}$ & $74,9739^{\text {ns }}$ & $2278416^{\mathrm{ns}}$ \\
\hline Linhagens $(\mathrm{G})$ & & $278,58 * *$ & $4077,24 * *$ & $0,2909 * *$ & $0,1376 * *$ & $890999 * *$ & $11,9530 * *$ & $43553 * *$ \\
\hline $\mathrm{G} \times \mathrm{A}$ & 1 & $21,18^{* * *}$ & $186,63^{\text {ns }}$ & $0,0208^{\mathrm{ns}}$ & $0,0367 * *$ & $493454 * *$ & $1,3559 * *$ & $23016 * *$ \\
\hline $\mathrm{G} \times \mathrm{L}$ & & $9,41 *$ & $212,56^{*}$ & $0,0206^{\mathrm{ns}}$ & $0,0244^{\mathrm{ns}}$ & $449908 *$ & $1,0809^{*}$ & $20292 *$ \\
\hline A $\times L$ & & $756,99 * *$ & $3081,35^{* *}$ & $0,2449 * *$ & $0,3808 * *$ & $8723832 * *$ & $165,7772 * *$ & $496155^{* *}$ \\
\hline $\mathrm{G} \times \mathrm{A} \times \mathrm{L}$ & 2 . & $6,68 * *$ & $143,66 * *$ & $0,0192 * *$ & $0,0237 * *$ & $310317 * *$ & $0,7818^{\mathrm{ns}}$ & $13942 * *$ \\
\hline Resíduo médio & 4 & 4,04 & 98,20 & 0,0117 & 0,0129 & 183164 & 0,7037 & 8376 \\
\hline Média Geral & & 132,90 & 103,55 & 1,74 & 3,40 & 2383 & 20,68 & 493 \\
\hline C.V. $(\%)$ & & 1,51 & 9,57 & 7,51 & 5,76 & 17,95 & 4,06 & 18,56 \\
\hline \multicolumn{9}{|c|}{ LINHAGENS INTERMEDIÁRIAS } \\
\hline Repetições/Anos)/Locais & & $11,25^{*}$ & $243,59 *$ & $0,0329 *$ & $0,0235^{\mathrm{ns}}$ & $280269^{\text {ns }}$ & $5,1841 * *$ & $17180^{*}$ \\
\hline Anos (A) & & $3472,92^{\text {ns }}$ & $30701,05 * *$ & $1,7424^{\mathrm{ns}}$ & $0,6570^{\mathrm{ns}}$ & $3560410^{\mathrm{ns}}$ & $193,2496^{\mathrm{ns}}$ & $77553^{\text {ns }}$ \\
\hline Locais $(\mathrm{L})$ & & $1337,76^{\text {ns }}$ & $8878,30 *$ & $2,7362 *$ & $0,2826^{\mathrm{ns}}$ & $26612257^{\text {ns }}$ & $34,1233^{\text {ns }}$ & $1009513^{\text {ns }}$ \\
\hline Linhagens $(\mathrm{G})$ & ؛ & $215,37 * *$ & $4711,38 * *$ & $0,4506 * *$ & $0,1969^{* *}$ & $1442905 * *$ & $11,1466^{* *}$ & $65729 * *$ \\
\hline $\mathrm{G} \times \mathrm{A}$ & & $24,39 * *$ & $179,81^{*}$ & $0,0329^{\mathrm{ns}}$ & $0,0322^{* *}$ & $363114^{\mathrm{ns}}$ & $1,3178^{\mathrm{ns}}$ & $15883^{\text {ns }}$ \\
\hline $\mathrm{G} \times \mathrm{L}$ & $\because$ & $9,89^{\mathrm{ns}}$ & $190,45^{*}$ & $0,0279^{\mathrm{ns}}$ & $0,0256^{\mathrm{ns}}$ & $267866^{\text {ns }}$ & $1,1963^{\mathrm{ns}}$ & $11722^{\text {ns }}$ \\
\hline A x L & & $1007,79 * *$ & $1207,92 * *$ & $0,3833 * *$ & $0,2918^{* *}$ & $15286769 * *$ & $62,0917 * *$ & $878245^{* *}$ \\
\hline $\mathrm{G} \times \mathrm{A} \times \mathrm{L}$ & $1:$ & $10,88^{* *}$ & $122,92^{\mathrm{ns}}$ & $0,0291 * *$ & $0,0199 *$ & $428034 * *$ & $1,1491 * *$ & $19308 * *$ \\
\hline Resíduo médio & 3 & 5,04 & 119,11 & 0,0157 & 0,0145 & 253856 & 0,7534 & 10664 \\
\hline Média Geral & & 141,45 & 111,43 & 1,94 & 3,20 & 2302 & 20,29 & 468 \\
\hline C.V. $(\%)$ & & 1,59 & 9,79 & 8,11 & 6,29 & 21,88 & 4,28 & 22,05 \\
\hline \multicolumn{9}{|c|}{ LINHAGENS SEMITARDIAS } \\
\hline Anos (A) & & $1209,05^{*}$ & $5967,59 * *$ & $0,2928^{\mathrm{ns}}$ & $0,2562^{\mathrm{ns}}$ & $2039992^{\text {ns }}$ & $29,8443^{\text {ns }}$ & $83147^{\text {ns }}$ \\
\hline Locais (L) & & $994,35^{*}$ & $1680,41^{\mathrm{ns}}$ & $0,4229^{\mathrm{ns}}$ & $0,0326^{\mathrm{ns}}$ & $12951701^{\mathrm{ns}}$ & $3,4712^{\mathrm{ns}}$ & $538199^{\mathrm{ns}}$ \\
\hline Linhagens (G) & & $144,26 * *$ & $3155,39 * *$ & $0,0643 *$ & $0,0420^{\mathrm{ns}}$ & $496177^{\text {ns }}$ & $10,3680 * *$ & $24155^{\text {ns }}$ \\
\hline $\mathrm{G} \times \mathrm{A}$ & & $21,70^{*}$ & $149,70^{\text {ns }}$ & $0,0225^{\mathrm{ns}}$ & $0,0324^{\mathrm{ns}}$ & $427357^{\mathrm{ns}}$ & $1,5699 *$ & $19444^{\text {ns }}$ \\
\hline $\mathrm{G} \times \mathrm{L}$ & & $21.68^{\mathrm{ns}}$ & $129.86^{\text {ns }}$ & $0,0198^{\mathrm{ns}}$ & $0,0354^{\mathrm{ns}}$ & $778236^{\text {ns }}$ & $1.2410^{\mathrm{ns}}$ & $31012^{\mathrm{ns}}$ \\
\hline A $\times L$ & & $178,26 * *$ & $348,31^{\mathrm{ns}}$ & $0,1048 *$ & $0,2916 * *$ & $8441654 * *$ & $17,8333 * *$ & $414495 * *$ \\
\hline $\mathrm{G} \times \mathrm{A} \times \mathrm{L}$ & & $10,93 * *$ & $110,24^{\mathrm{ns}}$ & $0,0186^{\mathrm{ns}}$ & $0,0231^{\mathrm{ns}}$ & $505024 *$ & $0,7733^{\text {ns }}$ & $21687 *$ \\
\hline Resíduo médio & & 2,32 & 96,89 & 0,0146 & 0,0161 & 315803 & 0,7194 & 13176 \\
\hline Média Geral & & 151,34 & 111,36 & 1,74 & 3,20 & 2158 & 20,33 & 442 \\
\hline C.V. $(\%)$ & & 1,00 & 8,84 & 8,11 & 6,63 & 26,04 & 4,17 & 25,95 \\
\hline
\end{tabular}

a: a: análise realizada com dados transformados para $\sqrt{\mathrm{x}+0,5}, \operatorname{com} \mathrm{x}=1$ a 5 .

*,**: significativo ao nível de $5 \%$ e $1 \%$ de probabilidade, respectivamente, pelo teste $\mathrm{F}$. ns: não significativo pelo teste $\mathrm{F}$. 
Tabela 12. Linhagens Precoces: médias para os caracteres número de dias para maturidade (NDM), altura da planta na maturidade (APM), acamamento (Ac), valor agronômico (VA), produtividade de grãos $(\mathrm{PG})$, porcentagem de óleo $(\% \mathrm{OL})$ e produtividade de óleo $(\mathrm{PO})$; $\%$ da média de PG de cada linhagem individual sobre a média geral de PG das linhagens (\%PGl) e testemunhas (\%PGt). Soja, semeaduras em 20/11/96, 16/11/97, 17/11/98, 23/11/99 (Anhembi), 12/11/96, 13/11/97, 05/11/98, 30/11/99 (Areão), 06/11/96, 12/11/97, 05/11/98, 08/11/99 (ESALQ). Piracicaba, SP.

\begin{tabular}{|c|c|c|c|c|c|c|c|c|c|c|}
\hline \multirow[b]{2}{*}{$\mathrm{N}$} & \multirow[b]{2}{*}{ № USP } & \multirow{2}{*}{$\frac{\mathrm{NDM}}{\mathrm{dias}}$} & \multirow{2}{*}{$\frac{\mathrm{APM}}{\mathrm{cm}}$} & \multirow{2}{*}{$\frac{\text { Ac }}{\text { nota }}$} & \multirow{2}{*}{$\frac{\text { VA }}{\text { nota }}$} & \multirow{2}{*}{$\begin{array}{c}\mathrm{PG} \\
\mathrm{Kg} / \mathrm{ha}\end{array}$} & \multirow{2}{*}{$\frac{\% \mathrm{OL}}{\%}$} & \multirow{2}{*}{$\begin{array}{c}\mathrm{PO} \\
\mathrm{Kg} / \mathrm{ha}\end{array}$} & \multicolumn{2}{|c|}{$\% \mathrm{PG}$} \\
\hline & & & & & & & & & $\% \mathrm{PGl}$ & $\% \mathrm{PGt}$ \\
\hline 1 & 93-1002 & 123,29 & 108,46 & 1,67 & 3,12 & 2118 & 21,67 & 461 & 0,87 & 0,88 \\
\hline 2 & $93-1042$ & $127,83^{*}$ & $123,83^{*}$ & $2,12 *$ & 3,14 & 2629 & 22,39 & $590 *$ & 1,08 & 1,10 \\
\hline 3 & $93-1043$ & $128,08 *$ & $123,42^{*}$ & 1,92 & 3,25 & 2541 & 22,34 & 561 & 1,05 & 1,06 \\
\hline 4 & $93-1044$ & 124,29 & 102,92 & 1,42 & 3,79 & 2353 & 22,29 & 525 & 0,97 & 0,99 \\
\hline 5 & $93-1050$ & 125,29 & 110,71 & $2,10^{*}$ & $2,94 *$ & 2238 & 21,73 & 491 & 0,92 & 0,94 \\
\hline 6 & $93-1051$ & $125,33^{*}$ & 103,04 & $1,23^{*}$ & 3,75 & 2284 & 21,32 & 484 & 0,94 & 0,96 \\
\hline 7 & $93-1069$ & 124,33 & $101,75^{*}$ & 1,50 & 3,46 & 2150 & 21,56 & 461 & 0,89 & 0,90 \\
\hline 8 & $93-1072$ & $129,54 *$ & 112,87 & 1,64 & 3,17 & $2055^{*}$ & 21,50 & $441 *$ & 0,85 & 0,86 \\
\hline 9 & $93-1077$ & 124,62 & $93,71 *$ & $1,27 *$ & 3,60 & 2470 & 21,34 & 526 & 1,02 & 1,03 \\
\hline 10 & $93-1101$ & 123,62 & 112,17 & 1,67 & 3,41 & 2617 & 21,61 & 565 & 1,08 & 1,10 \\
\hline 11 & $93-1107$ & 123,42 & 104,50 & $1,21 *$ & 3,77 & 2331 & 20,91 & 482 & 0,96 & 0,98 \\
\hline 12 & $93-1109$ & 123,46 & 107,83 & 1,44 & 3,69 & 2586 & 20,75 & 539 & 1,07 & 1,08 \\
\hline 13 & $93-1122$ & 123,12 & 112,79 & $2,00 *$ & $3,04 *$ & 2257 & 21,54 & 486 & 0,93 & 0,95 \\
\hline 14 & $93-1187$ & $126,08 *$ & 106,29 & $2,00 *$ & 3,23 & 2436 & $20,35^{*}$ & 492 & 1,00 & 1,02 \\
\hline 15 & $93-1188$ & $127,00 *$ & $116,46^{*}$ & $2,25^{*}$ & $2,92 *$ & 2441 & 22,45 & 546 & 1,01 & 1,02 \\
\hline 16 & $93-1195$ & $127,75^{*}$ & 111,83 & 1,50 & 3,42 & 2378 & 22,15 & 523 & 0,98 & 0,99 \\
\hline 17 & $93-1203$ & $127,08 *$ & 114,04 & 1,81 & 3,19 & 2578 & 22,04 & 566 & 1,06 & 1,08 \\
\hline 18 & 94-1004 & 124,83 & $123,33 *$ & 1,73 & $3,04 *$ & 2513 & 21,55 & 540 & 1,04 & 1,05 \\
\hline 19 & 94-1012 & $127,37 *$ & $119,21^{*}$ & $1,96^{*}$ & 3,27 & 2560 & 22,26 & 569 & 1,06 & 1,07 \\
\hline 20 & $94-1024$ & 124,96 & 110,62 & $2,10^{*}$ & 3,00 & 2255 & 22,45 & 510 & 0,93 & 0,94 \\
\hline 21 & $94-1044$ & $127,12 *$ & 113,04 & 1,39 & 3,54 & $2708 *$ & 20,69 & 555 & 1,12 & 1,13 \\
\hline 22 & $94-1055$ & 124,58 & 107,08 & $1,96^{*}$ & $2,96^{*}$ & $1967 *$ & 21,12 & $417 *$ & 0,69 & 0,70 \\
\hline 23 & 94-1061 & 123,17 & 104,71 & $1,31 *$ & 3,48 & 2415 & $20,50 *$ & 491 & 0,99 & 1,01 \\
\hline 24 & $94-1070$ & $125,67 *$ & $122,12^{*}$ & 1,89 & 3,19 & 2534 & 21,52 & 547 & 1,05 & 1,06 \\
\hline 25 & $94-1081$ & $126,62 *$ & $115,62^{*}$ & $2,04 *$ & $3,00 *$ & 2587 & $20,42 *$ & 529 & 1,07 & 1,08 \\
\hline 26 & $94-1086$ & 123,29 & 110,37 & 1,83 & 3,29 & $2894^{*}$ & 20,65 & $596 *$ & 1,19 & 1,21 \\
\hline 27 & $94-1087$ & 124,17 & 113,83 & 1,89 & 3,23 & 2497 & $20,29 *$ & 511 & 1,03 & 1,05 \\
\hline 28 & $94-1097$ & 124,00 & $118,33^{*}$ & $2,04 *$ & 3,1 & 2404 & $19,26^{*}$ & 461 & 0,99 & 1,01 \\
\hline $\mathrm{Ml}^{1}$ & & 125,35 & 111,60 & 1,75 & 3,29 & 2421 & 21,39 & 517 & & \\
\hline \multicolumn{11}{|c|}{ TESTEMUNHAS } \\
\hline IA & Foscarin-31 & 126,00 & 112,50 & 1,84 & 3,2 & 2454 & 21,65 & 535 & & \\
\hline & Primavera & 121,15 & 105,02 & 1,39 & 3,7 & 2315 & 21,60 & 497 & & \\
\hline $\mathrm{Mt}^{2}$ & & 123,57 & 108,76 & 1,62 & 3,4 & 2384 & 21,62 & 516 & & \\
\hline
\end{tabular}

*: Significativo ao nível de 5\% de probabilidade pelo teste de Dunnett.

1: Média geral das linhagens.

2: Média geral das testemunhas. 
Tabela 13. Linhagens Semiprecoces: médias para os caracteres número de dias para maturidade (NDM), altura da planta na maturidade (APM), acamamento (Ac), valor agronômico (VA), produtividade de grãos (PG), porcentagem de óleo (\%OL) e produtividade de óleo (PO); \% da média de PG de cada linhagem individual sobre a média geral de PG das linhagens (\%PGl) e testemunhas (\%PGt). Soja, semeaduras em 20/11/96, 16/11/97, 17/11/98, 23/11/99 (Anhembi), 12/11/96, 13/11/97, 05/11/98, 30/11/99 (Areão), 06/11/96, 12/11/97, 05/11/98, 08/11/99 (ESALQ). Piracicaba, SP.

\begin{tabular}{|c|c|c|c|c|c|c|c|c|c|c|}
\hline \multirow[b]{2}{*}{$\mathrm{N}$} & \multirow[b]{2}{*}{ № USP } & \multirow{2}{*}{$\begin{array}{l}\text { NDM } \\
\text { dias }\end{array}$} & \multirow{2}{*}{$\begin{array}{c}\mathrm{APM} \\
\mathrm{cm}\end{array}$} & \multirow{2}{*}{$\begin{array}{l}\text { Ac } \\
\text { nota }\end{array}$} & \multirow{2}{*}{$\begin{array}{l}\text { VA } \\
\text { nota }\end{array}$} & \multirow{2}{*}{$\begin{array}{c}\mathrm{PG} \\
\mathrm{Kg} / \mathrm{ha}\end{array}$} & \multirow{2}{*}{$\frac{\% \mathrm{OL}}{\%}$} & \multirow{2}{*}{$\begin{array}{c}\mathrm{PO} \\
\mathrm{Kg} / \mathrm{ha}\end{array}$} & \multicolumn{2}{|c|}{$\% \mathrm{PG}$} \\
\hline & & & & & & & & & $\% \mathrm{PGl}$ & $\% \mathrm{PGt}$ \\
\hline 1 & 93-1052 & 129,25 & 110,45 & 1,60 & $3,27 *$ & $2325^{*}$ & $20,51 *$ & $478^{*}$ & 0,97 & 0,79 \\
\hline 2 & $93-1106$ & 128,96 & $114,12:$ & 1,71 & $3,33^{*}$ & 2726 & 21,54 & 586 & 1,14 & 0,93 \\
\hline 3 & $93-1119$ & 131,71 & $109,37:$ & 1,46 & 3,48 & $2444 *$ & 20,90 & $509^{*}$ & 1,02 & 0,83 \\
\hline 4 & $93-1125$ & $127,83^{*}$ & 113,25 & 1,35 & 3,62 & $2318^{*}$ & 21,42 & $494 *$ & 0,97 & 0,79 \\
\hline 5 & 93-1202 & $132,37^{*}$ & $117,67:$ & $1,89^{*}$ & $3,21 *$ & $2331^{*}$ & $18,54^{*}$ & $433^{*}$ & 0,98 & 0,80 \\
\hline 6 & 93-1211 & 128,25 & $119,54:$ & 1,85 & $3,33^{*}$ & 2611 & $19,61 *$ & $511^{*}$ & 1,09 & 0,99 \\
\hline 7 & 93-2002 & $135,58^{*}$ & $121,54:$ & $1,92 *$ & $3,25^{*}$ & $2364 *$ & 20,95 & $494 *$ & 0,99 & 0,81 \\
\hline 8 & 93-2027 & $135,46^{*}$ & $97,21^{*}$ & 1,56 & 3,54 & 2590 & 21,04 & $547 *$ & 1,09 & 0,88 \\
\hline 9 & 93-2072 & $135,58^{*}$ & 86,58 & 1,46 & $3,23 *$ & $2130^{*}$ & $20,73^{*}$ & $442 *$ & 0,89 & 0,73 \\
\hline 10 & $93-2084$ & $134,33^{*}$ & 85,17 & 1,29 & 3,58 & 2710 & 21,00 & 571 & 1,14 & 0,92 \\
\hline 11 & $93-2103$ & $137,37^{*}$ & 83,83 & 1,14 & 4,04 & 2582 & 21,08 & $546^{*}$ & 1,08 & 0,88 \\
\hline 12 & 93-2104 & $127,29^{*}$ & $114,79:$ & 1,85 & $3,31 *$ & $2444^{*}$ & $20,52 *$ & $499 *$ & 1,02 & 0,83 \\
\hline 13 & $93-225 \mathrm{C}$ & $135,25^{*}$ & $105,67:$ & 1,69 & $3,17^{*}$ & $2260 *$ & 21,07 & $475^{*}$ & 0,95 & 0,77 \\
\hline 14 & $93-2259$ & 128,62 & 92,42 & 1,21 & 4,00 & $2435^{*}$ & 21,04 & $513^{*}$ & 1,02 & 0,83 \\
\hline 15 & 93-2294 & 128,54 & 91,96 & 1,46 & $3,48^{*}$ & $2342 *$ & 20,97 & $492 *$ & 0,98 & 0,80 \\
\hline 16 & $93-2302$ & 129,12 & 92,79 & 1,31 & 3,75 & $2492 *$ & 20,85 & $524 *$ & 1,04 & 0,85 \\
\hline 17 & $93-2306$ & 128,37 & 95,33 & 1,37 & 3,73 & $2336^{*}$ & 21,05 & $493^{*}$ & 0,98 & 0,80 \\
\hline 18 & $93-2316$ & $132,12^{*}$ & 85,00 & 1,23 & 3,92 & 2809 & $20,01 *$ & 561 & 1,18 & 0,96 \\
\hline 19 & $93-2419$ & $138,12 *$ & 111,75 & 1,83 & $3,08^{*}$ & $1970 *$ & $20,36^{*}$ & $399^{*}$ & 0,83 & 0,67 \\
\hline 20 & 93-2475 & $134,83^{*}$ & $113,79:$ & $2,10^{*}$ & $3,00^{*}$ & $2474^{*}$ & $19,97 *$ & $492^{*}$ & 1,04 & 0,84 \\
\hline 21 & $93-2479$ & 128,83 & 123,50 & $2,10^{*}$ & $3,12 *$ & 2581 & $19,82 *$ & $511^{*}$ & 1,08 & 0,88 \\
\hline 22 & $93-2529$ & $137,37^{*}$ & 111,75 & $1,96^{*}$ & $3,21 *$ & $2242^{*}$ & 21,90 & $494 *$ & 0,94 & 0,76 \\
\hline 23 & $93-2565$ & 131,25 & 109,87: & $1,96^{*}$ & $3,02 *$ & $2121^{*}$ & $19,51^{*}$ & $414^{*}$ & 0,88 & 0,72 \\
\hline 24 & 93-2667 & $138,17^{*}$ & $98,25=$ & $1,94^{*}$ & 3,04 & $2055^{*}$ & 21,46 & $440^{*}$ & 0,86 & 0,70 \\
\hline 25 & $93-268 \mathrm{C}$ & $132,21^{*}$ & 76,25 & 1,17 & 3,52 & $2403^{*}$ & $20,73^{*}$ & $499^{*}$ & 1,01 & 0,82 \\
\hline 26 & $93-2693$ & $135,29 *$ & $113,17:$ & 1,77 & $3,27 *$ & $2348^{*}$ & 21,42 & $506^{*}$ & 0,98 & 0,80 \\
\hline 27 & $93-2697$ & $133,00^{*}$ & 87,37 & 1,17 & 3,87 & $2541^{*}$ & $20,29 *$ & $519^{*}$ & 1,07 & 0,87 \\
\hline 28 & $93-2699$ & $137,33^{*}$ & $123,62:$ & $2,06^{*}$ & $3,02 *$ & $2338^{*}$ & $19,32 *$ & $451^{*}$ & 0,98 & 0,80 \\
\hline 29 & $93-2727$ & $136,87^{*}$ & 91,58 & 1,44 & $3,46^{*}$ & $2204 *$ & 21,38 & $471^{*}$ & 0,92 & 0,75 \\
\hline 30 & $93-2756$ & $134,62^{*}$ & 83,04 & 1,10 & 3,75 & $2269 *$ & 20,97 & $477 *$ & 0,95 & 0,77 \\
\hline 31 & $93-2781$ & $133,62 *$ & 90,92 & 1,25 & 3,64 & $2143^{*}$ & $19,68^{*}$ & $422^{*}$ & 0,90 & 0,73 \\
\hline 32 & $93-279 c$ & 129,75 & $112,67:$ & 1,71 & $3,31 *$ & $2431 *$ & 20,80 & $509^{*}$ & 1,02 & 0,83 \\
\hline 33 & $93-2857$ & $136,83^{*}$ & $108,08:$ & 1,42 & 3,64 & $2353^{*}$ & $20,59 *$ & $484 *$ & 0,99 & 0,80 \\
\hline 34 & $93-2858$ & $135,04 *$ & 108,50 & 1,73 & $3,04 *$ & $2106^{*}$ & 20,89 & $437 *$ & 0,88 & 0,72 \\
\hline 35 & $93-2897$ & 128,75 & 112,46 & 1,85 & $3,27 *$ & 2634 & $20,38 *$ & $539 *$ & 1,10 & 0,90 \\
\hline 36 & $93-2909$ & $133,96^{*}$ & $106,17:$ & 1,60 & $3,39 *$ & $2479 *$ & 20,86 & $517 *$ & 1,04 & 0,85 \\
\hline 37 & 93-2916 & $135,62^{*}$ & 101,92: & 1,48 & 3,58 & $2375^{*}$ & 21,26 & $508^{*}$ & 1,00 & 0,81 \\
\hline 38 & 94-1017 & $132,67 *$ & $113,54:$ & $2,42^{*}$ & $2,85^{*}$ & $2241 *$ & 21,30 & $478^{*}$ & 0,94 & 0,76 \\
\hline $\mathrm{Ml}^{1}$ & & 132,90 & 03,55 & 1,74 & 3,40 & 2383 & 21,68 & 493 & & \\
\hline \multicolumn{11}{|c|}{ TESTEMUNHAS } \\
\hline & 00 & 133,25 & 110,52 & 1,22 & 3,87 & 2819 & 21,29 & 594 & & \\
\hline & FT-Iramaia & 125,78 & 57,63 & 1,01 & 4,19 & 3038 & 21,60 & 657 & & \\
\hline $\mathrm{Mt}^{2}$ & & 129,52 & 84,07 & 1,11 & 4,03 & 2928 & 21,44 & 626 & & \\
\hline
\end{tabular}

*: Significativo ao nível de $5 \%$ de probabilidade pelo teste de Dunnett.

1: Média geral das linhagens; 2: Média geral das testemunhas. 
Tabela 14. Linhagens Intermediárias: médias para os caracteres número de dias para maturidade (NDM), altura da planta na maturidade (APM), acamamento (Ac), valor agronômico (VA), produtividade de grãos (PG), porcentagem de óleo (\%OL) e produtividade de óleo (PO); \% da média de PG de cada linhagem individual sobre a média geral de PG das linhagens (\% PGl) e testemunhas (\% PGt). Soja, semeaduras em 20/11/96, 16/11/97, 17/11/98, 23/11/99 (Anhembi), 12/11/96, 13/11/97, 05/11/98, 30/11/99 (Areão), 06/11/96, 12/11/97, 05/11/98, 08/11/99 (ESALQ). Piracicaba, SP.

\begin{tabular}{|c|c|c|c|c|c|c|c|c|c|c|}
\hline \multirow[b]{2}{*}{$\mathrm{N}$} & \multirow[b]{2}{*}{ № USP } & \multirow{2}{*}{$\frac{\text { NDM }}{\text { dias }}$} & \multirow{2}{*}{$\begin{array}{c}\mathrm{APM} \\
\mathrm{cm}\end{array}$} & \multirow{2}{*}{$\frac{\text { Ac }}{\text { nota }}$} & \multirow{2}{*}{$\frac{\text { VA }}{\text { nota }}$} & \multirow{2}{*}{$\begin{array}{c}\mathrm{PG} \\
\mathrm{Kg} / \mathrm{ha}\end{array}$} & \multirow{2}{*}{$\frac{\% \mathrm{OL}}{\%}$} & \multirow{2}{*}{$\frac{\mathrm{PO}}{\mathrm{Kg} / \mathrm{ha}}$} & \multicolumn{2}{|c|}{$\% \mathrm{PG}$} \\
\hline & & & & & & & & & $\% \mathrm{PGl}$ & $\% \mathrm{PGt}$ \\
\hline 1 & $93-2258$ & $142,87^{*}$ & 94,29 & 1,39 & 3,42 & 2148 & 20 & 429 & 0,93 & 0,99 \\
\hline 2 & $93-2266$ & 142,00 & $125,33^{*}$ & 1,98 & 3,10 & 2102 & 20 & 429 & 0,91 & 0,96 \\
\hline 3 & $93-2514$ & 140,96 & $109,17^{*}$ & 2,15 & 3,04 & 2185 & 19 & 428 & 0,95 & 1,00 \\
\hline 4 & $93-2530$ & $143,04 *$ & 95,54 & 1,54 & 3,29 & 2195 & 19 & 432 & 0,95 & 1,01 \\
\hline 5 & $93-2643$ & $144,37 *$ & 100,17 & 1,94 & 3,19 & 2299 & 20 & 460 & 1,00 & 1,05 \\
\hline 6 & $93-2722$ & $143,21 *$ & 91,67 & 1,19 & $4,10^{*}$ & 2812 & 19 & $555^{*}$ & 1,22 & 1,29 \\
\hline 7 & $93-2725$ & $145,83^{*}$ & $108,04^{*}$ & 1,98 & 2,89 & 1859 & 19 & 368 & 0,81 & 0,85 \\
\hline 8 & $93-2753$ & $143,04 *$ & $104,83^{*}$ & 1,44 & 3,29 & 2018 & 19 & 393 & 0,88 & 0,93 \\
\hline 9 & $93-2802$ & 142,50 & $113,54^{*}$ & 1,73 & 3,33 & 2137 & 18 & 402 & 0,93 & 0,98 \\
\hline 10 & $93-2825$ & $144,71 *$ & $129,12^{*}$ & 2,14 & 3,02 & 2096 & 20 & 425 & 0,91 & 0,96 \\
\hline 11 & $93-2870$ & $142,92 *$ & $113,67^{*}$ & 1,92 & 3,21 & 2233 & 19 & 447 & 0,97 & 1,02 \\
\hline 12 & $93-5082$ & $144,29 *$ & 95,54 & 1,56 & 3,54 & 2668 & 20 & $542 *$ & 1,16 & 1,22 \\
\hline 13 & $93-5243$ & 136,37 & 92,62 & 1,42 & 3,69 & 2940 & 19 & $569^{*}$ & 1,28 & 1,35 \\
\hline 14 & $93-5423$ & $143,29 *$ & 98,46 & 1,60 & 3,50 & 2426 & 20 & $491 *$ & 1,05 & 1,11 \\
\hline 15 & $93-5539$ & 140,92 & $123,25^{*}$ & 2,15 & 3,21 & 2533 & 21 & $541 *$ & 1,10 & 1,16 \\
\hline 16 & $93-5544$ & $146,21 *$ & $130,42^{*}$ & 2,39 & 2,94 & 2190 & 20 & 448 & 0,95 & 1,01 \\
\hline 17 & $93-5549$ & 137,96 & 84,42 & 2,08 & 3,29 & 2629 & 20 & $541 *$ & 1,14 & 1,21 \\
\hline 18 & $93-5552$ & 136,58 & $126,29 *$ & 2,73 & $2,67 *$ & 2189 & 21 & 461 & 0,95 & 1,00 \\
\hline 19 & $93-5582$ & 135,92 & $114,29 *$ & 2,58 & $2,79 *$ & 2291 & 20 & 474 & 0,99 & 1,05 \\
\hline 20 & $93-5585$ & $142,83^{*}$ & $117,00 *$ & 1,60 & 3,44 & 2128 & 20 & 436 & 0,92 & 0,98 \\
\hline 21 & $93-5586$ & 137,33 & $115,42 *$ & 2,75 & $2,67 *$ & 2147 & 20 & 451 & 0,93 & 0,99 \\
\hline 22 & $93-5597$ & 138,42 & $115,96^{*}$ & 2,56 & $2,67 *$ & 2244 & 20 & 473 & 0,97 & 1,03 \\
\hline 23 & $93-5690$ & 142,04 & $118,50 *$ & 1,96 & 3,02 & 2216 & 21 & 462 & 0,96 & 1,02 \\
\hline 24 & $93-5692$ & 138,96 & $103,42 *$ & 1,47 & $3,62 *$ & 2461 & 20 & $500^{*}$ & 1,07 & 1,13 \\
\hline 25 & $93-5843$ & 141,46 & $132,29 *$ & 2,23 & 3,02 & 2393 & 21 & $509^{*}$ & 1,04 & 1,10 \\
\hline 26 & $93-5860$ & 137,58 & $134,29 *$ & 2,37 & 2,96 & 2414 & 21 & $528 *$ & 1,05 & 1,11 \\
\hline 27 & $93-5884$ & $143,62 *$ & $121,00 *$ & 1,58 & $3,62 *$ & 2202 & 20 & 444 & 0,96 & 1,01 \\
\hline $\mathrm{Ml}^{1}$ & & 141,45 & 111,43 & 1,94 & 3,20 & 2302 & 20 & 468 & & \\
\hline \multicolumn{11}{|c|}{ TESTEMUNHAS } \\
\hline 1 & IAC-4 & 143,78 & 95,85 & 1,80 & 3,23 & 2094 & 19 & 412 & & \\
\hline 2 & IAC-12 & 132,89 & 78,68 & 1,29 & 3,64 & 2591 & 19 & 509 & & \\
\hline 3 & IAC- 100 & 133,05 & 76,15 & 1,32 & 3,46 & 2115 & 16 & 346 & & \\
\hline 4 & Stwart & 146,07 & 110,50 & 1,63 & 3,12 & 1908 & 19 & 381 & & \\
\hline $\mathrm{Mt}^{2}$ & & 138,95 & 90,30 & 1,51 & 3,36 & 2177 & 18 & 412 & & \\
\hline
\end{tabular}

*: Significativo ao nível de 5\% de probabilidade pelo teste de Dunnett.

1: Média geral das linhagens; 2: Média geral das testemunhas.

Tabela 15. Linhagens Semitardias: médias para os caracteres número de dias para maturidade (NDM), altura da planta na maturidade (APM), acamamento (Ac), valor agronômico (VA), produtividade de grãos (PG), porcentagem de óleo (\%OL) e produtividade de óleo (PO); \% da média de PG de cada linhagem individual sobre a média geral de PG das linhagens (\% PGl) e testemunhas (\% PGt). Soja, semeaduras em 20/11/96, 16/11/97, 17/11/98, 23/11/99 (Anhembi), 12/11/96, 13/11/97, 05/11/98, 30/11/99 (Areão), 06/11/96, 12/11/97, 05/11/98, 08/11/99 (ESALQ). Piracicaba, SP.

\begin{tabular}{|c|c|c|c|c|c|c|c|c|c|c|}
\hline \multirow[b]{2}{*}{$\mathrm{N}$} & \multirow[b]{2}{*}{ No- USP } & \multirow{2}{*}{$\frac{\mathrm{NDM}}{\text { dias }}$} & \multirow{2}{*}{$\frac{\mathrm{APM}}{\mathrm{cm}}$} & \multirow{2}{*}{$\frac{\text { Ac }}{\text { nota }}$} & \multirow{2}{*}{$\frac{\mathrm{VA}}{\mathrm{nota}}$} & \multirow{2}{*}{$\frac{\mathrm{PG}}{\mathrm{Kg} / \mathrm{ha}}$} & \multirow{2}{*}{$\begin{array}{c}\% \mathrm{OL} \\
\%\end{array}$} & \multirow{2}{*}{$\begin{array}{c}\mathrm{PO} \\
\mathrm{Kg} / \mathrm{ha}\end{array}$} & \multicolumn{2}{|c|}{$\% \mathrm{PG}$} \\
\hline & & & & & & & & & $\% \mathrm{PGl}$ & $\% \mathrm{PGt}$ \\
\hline 1 & $93-2521$ & $150,29 *$ & 112,21 & $1,60^{*}$ & 3,21 & 2047 & $19,71 *$ & 409 & 0,95 & 1,14 \\
\hline 2 & $93-5263$ & $152,21 *$ & $119,54 *$ & 1,79 & 3,17 & 2088 & $19,47^{*}$ & 411 & 0,97 & 1,17 \\
\hline 3 & $93-5391$ & $154,50 *$ & $95,46^{*}$ & $1,64 *$ & 3,31 & $2166 *$ & $21,15^{*}$ & $463 *$ & 1,00 & 1,21 \\
\hline 4 & $93-5419$ & $151,25^{*}$ & 101,83 & 1,73 & 3,19 & $2268 *$ & 20,75 & $472 *$ & 1,05 & 1,27 \\
\hline 5 & $93-5513$ & $153,58 *$ & 115,75 & $1,56^{*}$ & $3,48^{*}$ & $2380 *$ & 19,80 & $474 *$ & 1,10 & 1,33 \\
\hline 6 & $93-5684$ & $150,54 *$ & $129,33^{*}$ & 2,00 & 3,12 & $2204 *$ & 20,59 & $459 *$ & 1,02 & 1,23 \\
\hline 7 & $93-5802$ & $147,04 *$ & 105,42 & 1,87 & 2,96 & 1951 & 20,82 & 407 & 0,90 & 1,09 \\
\hline $\mathrm{Ml}^{1}$ & & 151,34 & 111,36 & 1,74 & 3,20 & 2158 & 20,33 & 442 & & \\
\hline & & & & TEST & UNHAS & & & & & \\
\hline 1 & IAC-4 & 147,37 & 99,23 & 1,92 & 3,20 & 2109 & 20,22 & 429 & & \\
\hline 2 & IAC-11 & 146,63 & 104,73 & 1,72 & 2,77 & 1650 & 20,30 & 339 & & \\
\hline 3 & Stwart & 149,07 & 117,60 & 1,80 & 3,08 & 1605 & 19,94 & 323 & & \\
\hline $\mathrm{Mt}^{2}$ & & 147,69 & 107,19 & 1,81 & 3,02 & 1788 & 20,15 & 364 & & \\
\hline
\end{tabular}

*: Significativo ao nível de 5\% de probabilidade pelo teste de Dunnett.

1: Média geral das linhagens; 2: Média geral das testemunhas. 
Tabela 16. Linhagens Precoces: média, ecovalência $\left(\omega_{i}\right)$ e porcentagem da ecovalência $\left(\% \omega_{i}\right)$ para os caracteres produtividade de grãos (PG), porcentagem de óleo (\%OL) e produtividade de óleo (PO). Soja, semeaduras em 20/11/96, 16/11/97, 17/11/98, 23/11/99 (Anhembi), 12/11/96, 13/11/97, 05/11/98, 30/11/99 (Areão), 06/11/96, 12/11/97, 05/11/98, 08/11/99 (ESALQ). Piracicaba, SP.

\begin{tabular}{|c|c|c|c|c|c|c|c|c|c|c|}
\hline \multirow[b]{2}{*}{$\mathrm{N}$} & \multirow[b]{2}{*}{ № USP } & \multicolumn{3}{|c|}{ PG (Kg/ha) } & \multicolumn{3}{|c|}{$\% \mathrm{OL}$} & \multicolumn{3}{|c|}{ PO (Kg/ha) } \\
\hline & & Média & $\omega_{\mathrm{i}}$ & $\% \omega_{\mathrm{i}}$ & Média & $\omega_{\mathrm{i}}$ & $\% \omega_{\mathrm{i}}$ & Média & $\omega_{\mathrm{i}}$ & $\% \omega_{\mathrm{i}}$ \\
\hline 1 & 93-1002 & 2118 & 368711 & 3,312 & 21,6 & 13,37 & 3,5 & 461 & 168349 & 3,2 \\
\hline 2 & $93-1042$ & 2629 & 24111: & 2,170 & $22,3 !$ & 17,56 & 4,6 & 590 & 106413 & 2,0 \\
\hline 3 & $93-1043$ & 2541 & 75941: & 6,835 & 22,3 & 5,57 & 1,4 & 561 & 346901 & $6,7 i$ \\
\hline 4 & $93-1044$ & 2353 & 33903: & 3,051 & $22,2 !$ & 8,24 & 2,1 & 525 & 189552 & 3,7 \\
\hline 5 & $93-1050$ & 2238 & 534471 & 4,811 & 21,7 . & 11,54 & $3, \mathrm{C}$ & 491 & 261852 & 5,1 \\
\hline 6 & $93-1051$ & 2284 & $53951^{\prime}$ & 4,856 & 21,3 . & 15,08 & $4, \mathrm{C}$ & 484 & 240166 & 4,6 \\
\hline 7 & $93-1069$ & 2150 & $19304 !$ & 1,738 & 21,51 & 17,38 & 4,6 & 461 & 105694 & 2,0 \\
\hline 8 & $93-1072$ & 2055 & 42840 & 3,856 & 21,51 & 15,59 & 4,1 & 441 & 195057 & 3,8 \\
\hline 9 & $93-1077$ & 2470 & 234661 & 2,112 & 21,3 & 13,29 & 3,5 & 526 & 113311 & 2,2 \\
\hline 10 & 93-1101 & 2617 & 22617' & 2,036 & 21,6 & 12,45 & 3,2 & 565 & 107775 & 2,11 \\
\hline 11 & $93-1107$ & 2331 & 315721 & 2,841 & 20,9 & 28,79 & 7,6 & 482 & 164355 & 3,2 \\
\hline 12 & 93-1109 & 2586 & 548511 & 4,937 & 20,7 & 8,29 & 2,2 & 539 & 274075 & 5,3 . \\
\hline 13 & $93-1122$ & 2257 & 36326 & 3,270 & 21,5 & 7,15 & $1, \mathrm{C}$ & 486 & 174712 & 3,4 \\
\hline 14 & $93-1187$ & 2436 & 691661 & 6,226 & 20,3 & 7,150 & $1, \mathrm{C}$ & 492 & 308040 & 6,0 \\
\hline 15 & $93-1188$ & 2441 & $19464 i$ & 1,752 & 22,4 & 11,38 & $3, \mathrm{C}$ & 546 & 74402 & 1,4 \\
\hline 16 & $93-1195$ & 2378 & 13002: & 1,170 & $22,1:$ & 32,25 & 8,5 & 523 & 65013 & $1,2^{\prime}$ \\
\hline 17 & $93-1203$ & 2578 & $35480 r$ & 3,194 & 22,0 & 16,90 & 4,5 & 566 & 131273 & 2,5 \\
\hline 18 & 94-1004 & 2513 & 53886' & 4,850 & 21,5 . & 16,85 & 4,4 & 540 & 203186 & $3,9^{\prime}$ \\
\hline 19 & 94-1012 & 2560 & 24456 & 2,201 & 22,21 & 10,60 & $2, \varepsilon$ & 569 & 037920 & 2,6 \\
\hline 20 & $94-1024$ & 2255 & 300731 & 2,707 & 22,4 & 22,16 & $5,$, & 510 & 179765 & 3,5 \\
\hline 21 & 94-1044 & 2708 & 49864 & 4,488 & $20,6 !$ & 12,59 & 3,2 & 555 & 165129 & 3,2 \\
\hline 22 & $94-1055$ & 1967 & 53798: & 4,842 & $21,1^{\prime}$ & 8,97 & 2,2 & 417 & 274132 & 5,3 . \\
\hline 23 & $94-1061$ & 2415 & 23133: & 2,082 & 20,51 & 13,94 & $3, \pi$ & 491 & 87480 & 1,7 \\
\hline 24 & $94-1070$ & 2534 & $53401 i$ & 4,807 & 21,5 & 11,01 & 2,4 & 547 & 291086 & 5,6 \\
\hline 25 & 94-1081 & 2587 & 657441 & 5,918 & 20,4 & 10,05 & $2, t$ & 529 & 295717 & $5,7 i$ \\
\hline 26 & 94-1086 & 2894 & $29953^{\prime}$ & 2,696 & 20,6 & 9,46 & 2,2 & 596 & 142588 & 2,7 \\
\hline 27 & 94-1087 & 2497 & $21552 i$ & 1,940 & 20,71 & 5,12 & 1,2 & 511 & 103247 & 2,0 \\
\hline 28 & 94-1097 & 2404 & 58788 & 5,291 & 19,21 & 12,69 & 3,2 & 461 & 208454 & $4,0^{\prime}$ \\
\hline
\end{tabular}

Tabela 17. Linhagens Intermediárias: média, ecovalência $\left(\omega_{i}\right)$ e porcentagem da ecovalência $\left(\% \omega_{i}\right)$ para os caracteres produtividade de grãos (PG), porcentagem de óleo (\%OL) e produtividade de óleo (PO). Soja, semeaduras em 20/11/96, 16/11/97, 17/11/98, 23/11/99 (Anhembi), 12/11/96, 13/11/97, 05/11/98, 30/11/99 (Areão), 06/11/96, 12/11/97, 05/11/98, 08/11/99 (ESALQ). Piracicaba, SP.

\begin{tabular}{|c|c|c|c|c|c|c|c|c|c|c|}
\hline \multirow[b]{2}{*}{$\mathrm{N}$} & \multirow[b]{2}{*}{ № USP } & \multicolumn{3}{|c|}{ PG (Kg/ha) } & \multicolumn{3}{|c|}{$\% \mathrm{OL}$} & \multicolumn{3}{|c|}{ PO (Kg/ha) } \\
\hline & & Média & $\omega_{\mathrm{i}}$ & $\% \omega_{i}$ & Média & $\omega_{\mathrm{i}}$ & $\% \omega_{\mathrm{i}}$ & Média & $\omega_{\mathrm{i}}$ & $\% \omega_{\mathrm{i}}$ \\
\hline 1 & $93-2258$ & 2148 & $72753 !$ & & 20,13 & 11,790 & 3,4 & 429 & 312898 & 6 , \\
\hline 2 & $93-2266$ & 2102 & $51446 !$ & & 20,34 & 7,255 & 2,11 & 429 & 234464 & 4, \\
\hline 3 & $93-2514$ & 2185 & $31397 i$ & & 19,40 & 20,147 & 5,8 : & 428 & 186377 & 3 , \\
\hline 4 & $93-2530$ & 2195 & 38043: & & 19,68 & 9,273 & $2,6 !$ & 432 & 171983 & 3 , \\
\hline 5 & $93-2643$ & 2299 & 230981 & & 20,04 & 10,009 & 2,9 & 460 & 106264 & 2 , \\
\hline 6 & $93-2722$ & 2812 & $34054 i$ & & 19,63 & 10,262 & 2,98 & 555 & 157862 & 3 , \\
\hline 7 & $93-2725$ & 1859 & 758371 & & 19,80 & 8,109 & 2,3 & 368 & 332283 & 6 , \\
\hline 8 & $93-2753$ & 2018 & 348491 & & 19,35 & 2,204 & 0,6 & 393 & 155867 & 3 , \\
\hline 9 & $93-2802$ & 2137 & 263061 & & 18,90 & 4,737 & 1,3 & 402 & 117924 & 2, \\
\hline 10 & $93-2825$ & 2096 & 40471' & & 20,04 & 18,061 & 5,2 & 425 & 188992 & 3 , \\
\hline 11 & $93-2870$ & 2233 & 398071 & & 19,93 & 9,493 & 2,7 . & 447 & 169362 & 3, \\
\hline 12 & $93-5082$ & 2668 & 292881 & & 20,31 & 4,350 & $1,2 \mathrm{\imath}$ & 542 & 129376 & 2 , \\
\hline 13 & $93-5243$ & 2940 & 36650 . & & 19,41 & 15,712 & $4,5 \mathrm{r}$ & 569 & 118140 & 2, \\
\hline 14 & $93-5423$ & 2426 & 61110 & & 20,21 & 13,048 & 3,7 ? & 491 & 249417 & 5 , \\
\hline 15 & $93-5539$ & 2533 & 48795: & & 21,39 & 10,945 & $3,1^{\prime}$ & 541 & 226316 & 4, \\
\hline 16 & $93-5544$ & 2190 & 420951 & & 20,45 & 18,309 & 5,3 & 448 & 168908 & 3, \\
\hline 17 & $93-5549$ & 2629 & $36288 !$ & & 20,52 & 13,631 & 3,9 : & 541 & 149361 & 3 , \\
\hline 18 & $93-5552$ & 2189 & 22127 . & & 21,08 & 8,286 & 2,41 & 461 & 113273 & 2 , \\
\hline 19 & $93-5582$ & 2291 & 398: & & 20,73 & 9,292 & $2,6 !$ & 474 & $1656 i$ & 3 \\
\hline 20 & $93-5585$ & 2128 & 246 & & 20,36 & 13,758 & 3,9 ! & 436 & 1107: & 2 \\
\hline 21 & $93-5586$ & 2147 & 2511 & & 20,84 & 8,149 & $2,3 \mathrm{e}$ & 451 & $1241 i$ & 2 \\
\hline 22 & $93-5597$ & 2244 & $379:$ & & 20,03 & 5,716 & $1,6 \mathrm{t}$ & 473 & 1666: & 3 \\
\hline 23 & $93-5690$ & 2216 & 704 & & 21,07 & 37,330 & 10,8 & 462 & $2909^{\prime}$ & 5 \\
\hline 24 & $93-5692$ & 2461 & 4211 & & 20,25 & 11,918 & $3,4 \mathrm{c}$ & 500 & $1696:$ & 3 \\
\hline 25 & $93-5843$ & 2393 & $296 !$ & & 21,07 & 30,181 & $8,7 \mathrm{c}$ & 509 & 1722 & 3 \\
\hline 26 & $93-5860$ & 2414 & 478 & & 21,76 & 13,853 & $4,0^{\prime}$ & 528 & 2399'. & 4 \\
\hline 27 & $93-5884$ & 2202 & $281\}$ & & 20,25 & 18,440 & $5,3:$ & 444 & $1313^{\prime}$ & 2 \\
\hline
\end{tabular}


Tabela 18. Linhagens Semiprecoces: média, ecovalência $\left(\omega_{i}\right)$ e porcentagem da ecovalência $\left.\% \omega_{i}\right)$ para os caracteres produtividade de grãos (PG), porcentagem de óleo (\%OL) e produtividade de óleo (PO). Soja, semeaduras em 20/11/96, 16/11/97, 17/11/98, 23/11/99 (Anhembi), 12/11/96, 13/11/97, 05/11/98, 30/11/99 (Areão), 06/11/96, 12/11/97, 05/11/98, 08/11/99 (ESALQ). Piracicaba, SP.

\begin{tabular}{|c|c|c|c|c|c|c|c|c|c|c|}
\hline \multirow[b]{2}{*}{$\mathrm{N}$} & \multirow[b]{2}{*}{ № USP } & \multicolumn{3}{|c|}{ PG (Kg/ha) } & \multicolumn{3}{|c|}{$\% \mathrm{OL}$} & \multicolumn{3}{|c|}{ PO (Kg/ha) } \\
\hline & & Média & $\omega_{\mathrm{i}}$ & $\% \omega_{\mathrm{i}}$ & Média & $\omega_{\mathrm{i}}$ & $\% \omega_{i}$ & Média & $\omega_{\mathrm{i}}$ & $\% \omega_{\mathrm{i}}$ \\
\hline 1 & $93-1052$ & $232 !$ & 6964636 & 4,4 & 20,5 & 23 & 5, & 478 & 3123 & 4,3 \\
\hline 2 & $93-1106$ & 2721 & $969278 \subseteq$ & 6,1 & 21,5 & 22 & 5, & 586 & 40541 & 5,6 \\
\hline 3 & $93-1119$ & 244 & 1377573 & 0,8 & 20,9 & 4 & 1, & 509 & 5621 & 0,7 \\
\hline 4 & $93-1125$ & 231 & 1930692 & 1,2 & 21,4 & 24 & 6 & 494 & 940؛ & 1,3 \\
\hline 5 & $93-1202$ & 233 & 4197494 & 2,6 & 18,5 & $\varepsilon$ & 2,1 & 433 & 1714 & 2,3 \\
\hline 6 & $93-1211$ & 261 & 3835536 & 2,4 & 19,6 & 6 & 1, & 511 & $1724 !$ & 2,4 \\
\hline 7 & $93-2002$ & 236 & 1630635 & 1,0 & 20,9 & 12 & 3, & 494 & 739: & 1,0 \\
\hline 8 & $93-2027$ & 2591 & 2379637 & 1,5 & 21,0 & 5 & 1, & 547 & 1013: & 1,4 \\
\hline 9 & $93-2072$ & $212 !$ & 7619006 & 4,8 & 20,7 & $1 \mathrm{C}$ & 4, & 442 & $3679 !$ & 5,1 \\
\hline 10 & $93-2084$ & 2711 & $495435 C$ & 3,1 & 21,0 & 5 & 1, & 571 & $2569 !$ & 3,5 \\
\hline 11 & $93-2103$ & $258^{\prime}$ & 2882917 & 1,8 & 21,0 & c & 2, & 546 & $1450 r$ & 2,0 \\
\hline 12 & $93-2104$ & 244 & 3584553 & 2,2 & 20,5 & 11 & 2, & 499 & $1476 i$ & 2,0 \\
\hline 13 & $93-2250$ & 2261 & $516606 C$ & 3,2 & 21,0 & $1 \mathrm{C}$ & 2, & 475 & 2594. & 3,6 \\
\hline 14 & $93-2259$ & $243:$ & 2850107 & 1,8 & 21,0 & $\varepsilon$ & 2 & 513 & 1369 & 1,9 \\
\hline 15 & $93-2294$ & 234 & 3219333 & 2,0 & 20,9 & c & 2, & 492 & 1619! & 2,2 \\
\hline 16 & $93-2302$ & $249 \prime$ & 5290775 & 3,3 & 20,8 & 16 & 4 & 524 & $2754 !$ & 3,8 \\
\hline 17 & $93-2306$ & 2331 & $76568 \mathrm{C}$ & 0,4 & 21,0 & 13 & 3, & 493 & $520 !$ & 0,7 \\
\hline 18 & $93-2316$ & $280 !$ & 206961C & 1,3 & 20,0 & 11 & 2, & 561 & 887: & 1,2 \\
\hline 19 & $93-2419$ & 1971 & 2227864 & 1,4 & 20,3 & $\varepsilon$ & 2,1 & 399 & 1016 & 1,4 \\
\hline 20 & $93-2475$ & 247 & 2412585 & 1,5 & 19,9 & 5 & 1, & 492 & $913^{\prime}$ & 1,2 \\
\hline 21 & $93-2479$ & 258 & 1412612 & 0,9 & 19,8 & $\varepsilon$ & 2,1 & 511 & 587 & 0,8 \\
\hline 22 & $93-2529$ & 224 & $284639 C$ & 1,8 & 21,9 & 14 & 3,1 & 494 & $1121<$ & 1,5 \\
\hline 23 & $93-2565$ & 212 & 4341994 & 2,7 & 19,5 & 17 & 4,'. & 414 & 1867( & 2,6 \\
\hline 24 & $93-2667$ & 205 & $385522 €$ & 2,4 & 21,4 & 21 & 5 & 440 & 2189 & 3,0 \\
\hline 25 & $93-2680$ & 240 & $1481895 \mathrm{C}$ & 9,4 & 20,7 & 5 & 1, & 499 & $6058^{\prime}$ & 8,4 \\
\hline 26 & $93-2693$ & $234 i$ & $771314 C$ & 4,9 & 21,4 & $\varepsilon$ & 2 & 506 & 3400 & 4,7 \\
\hline 27 & $93-2697$ & 254 & 5258725 & 3,3 & 20,2 & 3 & 0 & 519 & $2418 i$ & 3,3 \\
\hline 28 & $93-2699$ & $233 i$ & 3323977 & 2,1 & 19,3 & $\epsilon$ & 1,1 & 451 & $1568^{\circ}$ & 2,1 \\
\hline 29 & $93-2727$ & 220 & $164705 t$ & 1,0 & 21,3 & 3 & $0, i$ & 471 & 704 & 0,9 \\
\hline 30 & $93-2756$ & $226 !$ & 4295891 & 2,7 & 20,9 & 13 & 3, & 477 & 1566 & 2,1 \\
\hline 31 & $93-2781$ & 214 & 1748412 & 1,1 & 19,6 & 12 & 3,1 & 422 & $826^{\circ}$ & 1,1 \\
\hline 32 & $93-2790$ & 243 & $356938 \mathrm{C}$ & 2,2 & 20,8 & 5 & 1, & 509 & 1904' & 2,6 \\
\hline 33 & $93-2857$ & 235 & 2222997 & 1,4 & 20,5 & C & 2, & 484 & $1230^{\prime}$ & 1,7 \\
\hline 34 & $93-2858$ & $210 t$ & 11102073 & 7,0 & 20,8 & 7,1 & 1,7 & $4:$ & 4402: & 6,1 \\
\hline 35 & $93-2897$ & 263 & 3353023 & 2,1 & 20,3 & 6,3 & 1,5 & 5 & $1485:$ & 2,0 \\
\hline 36 & $93-2909$ & $247 !$ & 1644024 & 1,0 & 20,8 & 4,1 & 1,0 & 5 & 780 & 1,0 \\
\hline 37 & $93-2916$ & $237:$ & 3495801 & 2,2 & 21,2 & 10,7 & 2,6 & 51 & 1878: & 2,6 \\
\hline 38 & 94-1017 & 224 & 5255394 & 3,3 & 21,3 & 8,4 & 2,0 & 4 & $2800:$ & 3,9 \\
\hline
\end{tabular}

Tabela 19. Linhagens Semitardias: média, ecovalência $\left(\omega_{i}\right)$ e porcentagem da ecovalência $\left.\% \omega_{i}\right)$ para os caracteres produtividade de grãos (PG), porcentagem de óleo (\%OL) e produtividade de óleo (PO). Soja, semeaduras em 20/11/96, 16/11/97, 17/11/98, 23/11/99 (Anhembi), 12/11/96, 13/11/97, 05/11/98, 30/11/99 (Areão), 06/11/96, 12/11/97, 05/11/98, 08/11/99 (ESALQ). Piracicaba, SP.

\begin{tabular}{|c|c|c|c|c|c|c|c|c|c|c|}
\hline \multirow[b]{2}{*}{$\mathrm{N}$} & \multirow[b]{2}{*}{ № USP } & \multicolumn{3}{|c|}{ PG (Kg/ha) } & \multicolumn{3}{|c|}{$\% \mathrm{OL}$} & \multicolumn{3}{|c|}{$\mathrm{PO}(\mathrm{Kg} / \mathrm{ha})$} \\
\hline & & Média & $\omega_{i}$ & $\% \omega_{i}$ & Média & $\omega_{\mathrm{i}}$ & $\% \omega_{i}$ & Média & $\omega_{i}$ & $\% \omega_{i}$ \\
\hline 1 & $93-2521$ & 2047 & 2002617 & 5,686 & 19,71 & 8,541 & 11,8 & 409 & 74266 & 4 \\
\hline 2 & $93-5263$ & 2088 & 5305558 & 15,064 & 19,47 & 9,186 & 12,7 & 411 & 194592 & 12 \\
\hline 3 & $93-5391$ & 2166 & 8071843 & 22,918 & 21,15 & 15,185 & 21,1 & 463 & 375138 & 24 \\
\hline 4 & $93-5419$ & 2268 & 5907209 & 16,772 & 20,75 & 7,562 & 10,5 & 472 & 250892 & 16 \\
\hline 5 & $93-5513$ & 2380 & 7015792 & 19,919 & 19,80 & 9,954 & 13,8 & 474 & 277224 & 18 \\
\hline 6 & $93-5684$ & 2204 & 1416419 & 4,021 & 20,59 & 6,355 & 8,8 & 459 & 83645 & 5 \\
\hline 7 & $93-5802$ & 1951 & 5501267 & 15,619 & 20,82 & 15,132 & 21,0 & 407 & 248031 & 16 \\
\hline
\end{tabular}


Tabela 20. Análise de variância para os caracteres produtividade de grãos (PG), porcentagem de óleo (\%OL) e produtividade de óleo (PO), segundo a metodologia de Eberhart \& Russel (1966). Soja, semeaduras em 20/11/96, 16/11/97, 17/11/98, 23/11/99 (Anhembi), 12/11/96, 13/11/97, 05/11/98, 30/11/99 (Areão), 06/11/96, 12/11/97, 05/11/98, 08/11/99 (ESALQ). Piracicaba, SP.

\begin{tabular}{|c|c|c|c|c|c|c|c|}
\hline \multirow[b]{2}{*}{ Fontes de Variação } & \multirow[b]{2}{*}{ GL } & \multicolumn{6}{|c|}{ Quadrados Médios } \\
\hline & & $\begin{array}{c}\mathrm{PG} \\
(\mathrm{Kg} / \mathrm{ha})\end{array}$ & $\begin{array}{c}\mathrm{R}^{2 \mathrm{a}} \\
\%\end{array}$ & $\begin{array}{c}\% \mathrm{OL} \\
\%\end{array}$ & $\begin{array}{c}\mathrm{R}^{2 \mathrm{a}} \\
\%\end{array}$ & $\begin{array}{c}\mathrm{PO} \\
(\mathrm{Kg} / \mathrm{ha})\end{array}$ & $\begin{array}{l}\mathrm{R}^{2 \mathrm{a}} \\
\%\end{array}$ \\
\hline \multicolumn{8}{|l|}{ LINHAGENS PRECOCES } \\
\hline Linhagens $(\mathrm{G})$ & 27 & $1028336 * *$ & 8,01 & $15,47 * *$ & 25,56 & $49574 * *$ & 8,03 \\
\hline Ambientes (E) & 11 & $18887434 * *$ & 59,94 & $76,55 * *$ & 51,53 & $928172 * *$ & 61,27 \\
\hline $\mathrm{G} \times \mathrm{E}$ & 297 & $374065 * *$ & 32,05 & $1,26 * *$ & 22,90 & $17224 * *$ & 30,70 \\
\hline $\mathrm{E} / \mathrm{G}$ & 308 & $1035257 * *$ & & $3,95 * *$ & & $49758 * *$ & \\
\hline E linear & 1 & 207761776 ** & 65,00 & $842,09 * *$ & 69,22 & $10209891 * *$ & 66,62 \\
\hline $\mathrm{G} \times \mathrm{E}$ linear & 27 & $317553 *$ & 2,69 & $0,73^{\mathrm{ns}}$ & 1,62 & $13953 *$ & 2,46 \\
\hline Desvio combinado (E/G) & 280 & $366155^{* *}$ & 32,15 & $1,27 *$ & 29,22 & $16925 * *$ & 30,92 \\
\hline Resíduo médio & 324 & 190768 & & 1,05 & & 8744 & \\
\hline \multicolumn{8}{|c|}{ LINHAGENS SEMIPRECOCES } \\
\hline Linhagens $(\mathrm{G})$ & 37 & $890999 * *$ & 8,57 & $11,95 * *$ & 18,00 & $43553 * *$ & 8,89 \\
\hline Ambientes (E) & 11 & $17718178 * *$ & 50,65 & $146,47 * *$ & 65,59 & $850664 * *$ & 51,64 \\
\hline $\mathrm{G} \times \mathrm{E}$ & 407 & $385643 * *$ & 40,79 & $0,99 * *$ & 16,40 & $17572 * *$ & 39,47 \\
\hline $\mathrm{E} / \mathrm{G}$ & 418 & $841763 * *$ & & $4,82 * *$ & & $39495 * *$ & \\
\hline E linear & 1 & $194899959 * *$ & 55,39 & $1611,20 * *$ & 79,97 & $9357303 * *$ & 56,68 \\
\hline $\mathrm{G} \times \mathrm{E}$ linear & 37 & $209793 * *$ & 2,21 & $1,07^{\mathrm{ns}}$ & 1,96 & $9703 * *$ & 2,17 \\
\hline Desvio combinado (E/G) & 380 & $392617 * *$ & 42,40 & $0,96^{\mathrm{ns}}$ & 18,11 & $17875^{* *}$ & 41,14 \\
\hline Resíduo médio & 444 & 91582 & & 0,35 & & 4188 & \\
\hline \multicolumn{8}{|c|}{ LINHAGENS INTERMEDIÁRIAS } \\
\hline Linhagens $(\mathrm{G})$ & 26 & $1442905^{* *}$ & 12,41 & $11,15^{* *}$ & 17,53 & $65729 * *$ & 12,13 \\
\hline Ambientes (E) & 11 & $14147851 * *$ & 51,50 & $92,78 * *$ & 61,71 & $683741 * *$ & 53,38 \\
\hline $\mathrm{G} \times \mathrm{E}$ & 286 & $381207 * *$ & 36,08 & $1,20 * *$ & 20,75 & $16995 * *$ & 34,49 \\
\hline $\mathrm{E} / \mathrm{G}$ & 297 & $891083^{* *}$ & & $4,59 * *$ & & $41689 * *$ & \\
\hline E linear & 1 & $155626360 * *$ & 58,80 & $1020,54 * *$ & 74,86 & $7521156^{* *}$ & 60,74 \\
\hline $\mathrm{G} \times \mathrm{E}$ linear & 26 & $369826^{* *}$ & 3,63 & $1,23 * *$ & 2,34 & $18682 * *$ & 3,93 \\
\hline Desvio combinado (E/G) & 270 & $368184 * *$ & 37,56 & $1,16^{* *}$ & 22,97 & $16203 * *$ & 35,33 \\
\hline Resíduo médio & 312 & 126928 & & 0,38 & & 5332 & \\
\hline \multicolumn{8}{|l|}{ LINHAGENS SEMITARDIAS } \\
\hline Linhagens $(G)$ & 6 & $493897 *$ & 2,45 & $10,33 * *$ & 18,39 & $23917 * *$ & 2,62 \\
\hline Ambientes (E) & 11 & $7523829 * *$ & 68,43 & $18,46^{* *}$ & 60,26 & $346960 * *$ & 69,85 \\
\hline $\mathrm{G} \times \mathrm{E}$ & 66 & $533647 *$ & 29,12 & $1,09 *$ & 21,35 & $22785^{*}$ & 27,52 \\
\hline $\mathrm{E} / \mathrm{G}$ & 77 & $1532244 * *$ & & $3,57 * *$ & & $69095 * *$ & \\
\hline E linear & 1 & $82762117 * *$ & 70,15 & $203,12 * *$ & 73,89 & $3816566^{* *}$ & 71,73 \\
\hline G x E linear & 6 & $328911^{\mathrm{ns}}$ & 1,67 & $1,70 * *$ & 3,71 & $12396^{\mathrm{ns}}$ & 1,40 \\
\hline Desvio combinado (E/G) & 70 & $474960 * *$ & 28,18 & $0,88^{\mathrm{ns}}$ & 22,40 & $20420 * *$ & 26,87 \\
\hline Resíduo médio & 72 & 158032 & & 0,36 & & 6599 & \\
\hline
\end{tabular}

****: significativo ao nível de $5 \%$ e $1 \%$, respectivamente, pelo teste $\mathrm{F}$.

a: $\% \mathrm{SQ}_{\text {Tratamentos }} / \mathrm{SQ}_{\mathrm{G}}, \mathrm{SQ}_{\mathrm{E}}$ e $\mathrm{SQ}_{\mathrm{GxE}} ; \% \mathrm{SQ}_{\mathrm{GxE}} / \mathrm{SQ}_{\mathrm{GxElinear}}$.

obs: os quadrados médios estão multiplicados pelo número de repetições. 
Tabela 21. Linhagens Precoces: média, coeficiente de regressão $\left(b_{i}\right)$, variância dos desvios da regressão $\left(S^{2} d_{i}\right)$ e coeficiente de determinação $\left(\mathrm{R}^{2}\right)$ para os caracteres produtividade de grãos (PG), porcentagem de óleo (\%OL) e produtividade de óleo (PO). Soja, semeaduras em 20/11/96, 16/11/97, 17/11/98, 23/11/99 (Anhembi), 12/11/96, 13/11/97, 05/11/98, 30/11/99 (Areão), 06/11/96, 12/11/97, 05/11/98, 08/11/99 (ESALQ). Piracicaba, SP.

\begin{tabular}{|c|c|c|c|c|c|c|c|c|c|c|c|c|c|}
\hline \multirow[b]{2}{*}{$\mathrm{N}$} & \multirow[b]{2}{*}{ № USP } & \multicolumn{4}{|c|}{$\mathrm{PG}(\mathrm{Kg} / \mathrm{ha})$} & \multicolumn{4}{|c|}{$\% \mathrm{OL}$} & \multicolumn{4}{|c|}{$\mathrm{PO}(\mathrm{Kg} / \mathrm{ha})$} \\
\hline & & Média & $\mathrm{b}_{\mathrm{i}}$ & $\mathrm{s}^{2} \mathrm{~d}_{\mathrm{i}}$ & $\mathrm{R}^{2}$ & Média & $\mathrm{b}_{\mathrm{i}}$ & $\mathrm{s}^{2} \mathrm{~d}_{\mathrm{i}}$ & $\mathrm{R}^{2}$ & Média & $\mathrm{b}_{\mathrm{i}}$ & $\mathrm{s}^{2} \mathrm{~d}_{\mathrm{i}}$ & $\mathrm{R}^{2}$ \\
\hline 1 & $93-1002$ & 2118 & $1,11^{\mathrm{ns}}$ & 84144* & $\overline{71,9}$ & $21,6^{6}$ & $0,88^{\text {ns }}$ & $0,124^{\mathrm{ns}}$ & $\overline{64}, 4$ ? & 461 & $1,25^{\mathrm{ns}}$ & $2906^{\mathrm{ns}}$ & $\overline{79,6}$ \\
\hline 2 & 93-1042 & 2629 & $0,80^{\mathrm{ns}}$ & $11018^{\mathrm{ns}}$ & 69,3 & 22,36 & $0,87^{\mathrm{ns}}$ & $0,329^{\mathrm{ns}}$ & $57,2]$ & 590 & $0,93^{\mathrm{ns}}$ & $872^{\mathrm{ns}}$ & 75,2 \\
\hline 3 & $93-1043$ & 2541 & $1,28^{*}$ & $255346^{* *}$ & 63,3 & $22,3<$ & $0,96^{\text {ns }}$ & $-0,249^{\text {ns }}$ & 83,3 & 561 & $1,13^{\mathrm{ns}}$ & $12658 * *$ & 57,8 \\
\hline 4 & 93-1044 & 2353 & $1,09^{\mathrm{ns}}$ & $70923^{\text {ns }}$ & 72,7 & 22,2 ? & $0,86^{\text {ns }}$ & $-0,142^{\text {ns }}$ & 74,$3 ;$ & 525 & $1,16^{\mathrm{ns}}$ & $4609 *$ & 73,3 \\
\hline 5 & $93-1050$ & 2238 & $0,70^{\text {ns }}$ & $138883^{* *}$ & 43,8 & $21,7:$ & $1,20^{\mathrm{ns}}$ & $-0,008^{\text {ns }}$ & $80,7^{\prime}$ & 491 & $0,90^{\mathrm{ns}}$ & $8547 * *$ & 53,4 \\
\hline 6 & 93-1051 & 2284 & $1,32+$ & 135919 ** & 73,7 & 21,3 & $0,98^{\text {ns }}$ & $0,227^{\mathrm{ns}}$ & $65,7($ & 484 & $1,18^{\mathrm{ns}}$ & $7020 * *$ & 69,1 \\
\hline 7 & 93-1069 & 2150 & $1,04^{\mathrm{ns}}$ & $650^{\text {ns }}$ & 80,5 & $21,5 t$ & $0,99^{\text {ns }}$ & $0,344^{\mathrm{ns}}$ & $62,8=$ & 161 & $1,00^{\mathrm{ns}}$ & $912^{\mathrm{ns}}$ & 77,5 \\
\hline 8 & 93-1072 & 2055 & $0,42++$ & $-6966^{\mathrm{ns}}$ & 42,2 & $21,5($ & $1,15^{\mathrm{ns}}$ & $0,222^{\text {ns }}$ & $72,7:$ & 441 & $0,44++$ & $-408^{\text {ns }}$ & 46,7 \\
\hline 9 & 93-1077 & 2470 & $1,11^{\mathrm{ns}}$ & $16986^{\mathrm{ns}}$ & 80,4 & $21,3<$ & $0,79^{\mathrm{ns}}$ & $0,077^{\mathrm{ns}}$ & $61,1<$ & 526 & $1,06^{\mathrm{ns}}$ & $1220^{\mathrm{ns}}$ & 78,6 \\
\hline 10 & 93-1101 & 2617 & $1,04^{\mathrm{ns}}$ & $17157^{\text {ns }}$ & 78,0 & $21,6]$ & $1,05^{\mathrm{ns}}$ & $0,092^{\mathrm{ns}}$ & $72,7:$ & 565 & $1,06^{\mathrm{ns}}$ & $939^{\text {ns }}$ & 79,5 \\
\hline 11 & 93-1107 & 2331 & $0,99^{\mathrm{ns}}$ & $62457^{\mathrm{ns}}$ & 69,8 & $20,9]$ & $1,04^{\mathrm{ns}}$ & $0,914 * *$ & $53,0\{$ & 482 & $0,82^{\mathrm{ns}}$ & $3281^{\mathrm{ns}}$ & 61,8 \\
\hline 12 & 93-1109 & 2586 & $0,94^{\mathrm{ns}}$ & $177599 * *$ & 54,6 & 20,7 ? & $1,13^{\text {ns }}$ & $-0,137^{\text {ns }}$ & 83,2 & 539 & $0,99^{\mathrm{ns}}$ & $9328 * *$ & 56,4 . \\
\hline 13 & $93-1122$ & 2257 & $0,66++$ & $43644^{\mathrm{ns}}$ & 53,8 & $21,5<$ & $1,03^{\text {ns }}$ & $-0,167^{\mathrm{ns}}$ & $81,7($ & 486 & $0,72^{\mathrm{ns}}$ & $2932^{\text {ns }}$ & 56,3 \\
\hline 14 & 93-1187 & 2436 & $0,73^{\mathrm{ns}}$ & $224240 * *$ & 38,4 & 20,3 & $1,20^{\mathrm{ns}}$ & $-0,230^{\text {ns }}$ & $88,1^{\prime}$ & 492 & $0,66^{*}$ & $8965 * *$ & 37,5 \\
\hline 15 & $93-1188$ & 2441 & $0,89^{\mathrm{ns}}$ & $-2486^{\mathrm{ns}}$ & 76,0 & 22,4 . & $0,83^{\text {ns }}$ & $0,003^{\mathrm{ns}}$ & 66,4 & 546 & $0,96^{\mathrm{ns}}$ & $-675^{\text {ns }}$ & 82,1 \\
\hline 16 & 93-1195 & 2378 & $1,06^{\mathrm{ns}}$ & $-31562^{\mathrm{ns}}$ & 86,6 & $22,1<$ & $0,65^{\mathrm{ns}}$ & $0,899 * *$ & 30,4 & 523 & $0,99^{\mathrm{ns}}$ & $-1123^{\text {ns }}$ & 84,6 \\
\hline 17 & $93-1203$ & 2578 & $0,94^{\mathrm{ns}}$ & $80648^{\text {ns }}$ & 65,0 & $22,0<$ & $1,23^{\text {ns }}$ & $0,239^{\text {ns }}$ & $74,9]$ & 566 & $1,05^{\mathrm{ns}}$ & $2137^{\mathrm{ns}}$ & 75,7 \\
\hline 18 & 94-1004 & 2113 & $1,14^{\mathrm{ns}}$ & $166158 * *$ & 65,0 & 21,5 & $0,94^{\mathrm{ns}}$ & $0,310^{\mathrm{ns}}$ & 61,4 & 540 & $1,15^{\mathrm{ns}}$ & $5360 *$ & 71,3 \\
\hline 19 & 94-1012 & 1560 & $1,03^{\mathrm{ns}}$ & $26496^{\mathrm{ns}}$ & 76,4 & $22,2 t$ & $0,86^{\mathrm{ns}}$ & $-0,023^{\text {ns }}$ & 69,0 ك & 569 & $1,10^{\mathrm{ns}}$ & $2327^{\mathrm{ns}}$ & 76,8 \\
\hline 20 & 94-1024 & 2255 & $1,08^{\mathrm{ns}}$ & $52811^{\text {ns }}$ & 74,3 & 22,46 & $0,95^{\mathrm{ns}}$ & $0,580 *$ & 55,2 ; & 510 & $1,32+$ & $2784^{\mathrm{ns}}$ & 81,5 \\
\hline 21 & 94-1044 & 2708 & $1,17^{\mathrm{ns}}$ & 143100 ** & 68,0 & 20,6 ? & $1,19^{\text {ns }}$ & $0,052^{\mathrm{ns}}$ & 78,6 & 555 & $1,04^{\mathrm{ns}}$ & $3857 *$ & 70,5 \\
\hline 22 & 94-1055 & 1967 & $0,78^{\mathrm{ns}}$ & $156558 * *$ & 47,6 & $21,1^{\prime}$ & $1,17^{\mathrm{ns}}$ & $-0,121^{\mathrm{ns}}$ & 83,6 & 417 & $0,85^{\mathrm{ns}}$ & $8922 * *$ & 49,7 \\
\hline 23 & 94-1061 & 2415 & $1,02^{\mathrm{ns}}$ & $20064^{\mathrm{ns}}$ & 77,1 & $20,5($ & $0,85^{\mathrm{ns}}$ & $0,138^{\mathrm{ns}}$ & 62,05 & 491 & $0,91^{\mathrm{ns}}$ & $-148^{\mathrm{ns}}$ & 78,1 \\
\hline 24 & 94-1070 & 2534 & $1,33+$ & $131637 * *$ & 74,2 & 21,5 & $1,11^{\mathrm{ns}}$ & $0,010^{\mathrm{ns}}$ & 77,5 & 547 & $1,35+$ & $7962 * *$ & 72,9 \\
\hline 25 & 94-1081 & 2587 & $1,10^{\mathrm{ns}}$ & $229398 * *$ & 58,1 & 20,4 & $0,95^{\mathrm{ns}}$ & $-0,025^{\mathrm{ns}}$ & 73,15 & 529 & $1,03^{\mathrm{ns}}$ & $10397 * *$ & 56,7 \\
\hline 26 & 94-1086 & 2894 & $0,95^{\mathrm{ns}}$ & $53462^{\mathrm{ns}}$ & 69,2 & $20,6:$ & $0,82^{\text {ns }}$ & $-0,100^{\text {ns }}$ & $70,5]$ & 596 & $0,85^{\mathrm{ns}}$ & $2354^{\mathrm{ns}}$ & 66,2 \\
\hline 27 & 94-1087 & 2497 & $1,06^{\mathrm{ns}}$ & $11047^{\text {ns }}$ & 79,6 & 20,2 & $1,04^{\text {ns }}$ & $-0,273^{\text {ns }}$ & 86,6 & 511 & $0,95^{\mathrm{ns}}$ & $747^{\text {ns }}$ & 76,3 \\
\hline 28 & 94-1097 & 2404 & $1,18^{\mathrm{ns}}$ & $186092 * *$ & 64,8 & $19,2 t$ & $1,25^{\mathrm{ns}}$ & $0,011^{\mathrm{ns}}$ & $81,4 t$ & 461 & $1,11^{\mathrm{ns}}$ & $5845^{*}$ & 68,5 \\
\hline
\end{tabular}

ns: não significativo pelo teste t ou F.

Tabela 22. Linhagens Intermediárias: média, coeficiente de regressão $\left(b_{i}\right)$, variância dos desvios da regressão $\left(S^{2} d_{i}\right)$ e coeficiente de determinação $\left(\mathrm{R}^{2}\right)$ para os caracteres produtividade de grãos (PG), porcentagem de óleo (\%OL) e produtividade de óleo (PO). Soja, semeaduras em 20/11/96, 16/11/97, 17/11/98, 23/11/99 (Anhembi), 12/11/96, 13/11/97, 05/11/98, 30/11/99 (Areão), 06/11/96, 12/11/97, 05/11/98, 08/11/99 (ESALQ). Piracicaba, SP.

\begin{tabular}{|c|c|c|c|c|c|c|c|c|c|c|c|c|c|}
\hline \multirow[b]{2}{*}{$\mathrm{N}$} & \multirow[b]{2}{*}{ № USP } & \multicolumn{4}{|c|}{ PG (Kg/ha) } & \multicolumn{4}{|c|}{$\% \mathrm{OL}$} & \multicolumn{4}{|c|}{ PO (Kg/ha) } \\
\hline & & Média & $\mathrm{b}_{\mathrm{i}}$ & $\mathrm{s}^{2} \mathrm{~d}_{\mathrm{i}}$ & $\mathrm{R}^{2}$ & Média & $\overline{b_{i}}$ & $\mathrm{~s}^{2} \mathrm{~d}_{\mathrm{i}}$ & $\mathrm{R}^{2}$ & Média & $\overline{b_{i}}$ & $\mathrm{~s}^{2} \mathrm{~d}_{\mathrm{i}}$ & $\mathrm{R}^{2}$ \\
\hline 1 & $93-2258$ & 21 & 0,68 & $208063 * *$ & $\overline{28}$ & 20,13 & $0,91^{\mathrm{ns}}$ & $0,200^{\mathrm{ns}}$ & 73,23 & 429 & $0,62+$ & $8290 * *$ & $\overline{28}$ \\
\hline 2 & $93-2266$ & 21 & $0,59+$ & $81470^{\mathrm{ns}}$ & 32 & 20,34 & $1,10^{\mathrm{ns}}$ & $-0,033^{\mathrm{ns}}$ & 87,07 & 429 & $0,62^{\text {ns }}$ & $4436^{\mathrm{ns}}$ & 35 \\
\hline 3 & $93-2514$ & 21 & $1,10^{\mathrm{ns}}$ & $27091^{\mathrm{ns}}$ & 69 & 19,40 & $0,86^{\mathrm{ns}}$ & $0,594 *$ & 58,89 & 428 & $1,03^{\text {ns }}$ & $3972^{\mathrm{ns}}$ & 61 \\
\hline 4 & $93-2530$ & 21 & $0,84^{\mathrm{ns}}$ & $55718^{\mathrm{ns}}$ & 52 & 19,68 & $1,08^{\text {ns }}$ & $0,076^{\mathrm{ns}}$ & 83,11 & 432 & $0,79^{\mathrm{ns}}$ & $2654^{\mathrm{ns}}$ & 52 \\
\hline 5 & $93-2643$ & 22 & $1,02^{\mathrm{ns}}$ & $-11608^{\mathrm{ns}}$ & 72 & 20,04 & $1,13^{\text {ns }}$ & $0,094^{\mathrm{ns}}$ & 83,68 & 460 & $1,02^{\text {ns }}$ & $-24^{\mathrm{ns}}$ & 73 \\
\hline 6 & $93-2722$ & 28 & $1,05^{\mathrm{ns}}$ & $42715^{\mathrm{ns}}$ & 65 & 19,63 & $1,07^{\mathrm{ns}}$ & $0,129^{\mathrm{ns}}$ & 81,02 & 555 & $1,03^{\text {ns }}$ & $2545^{\mathrm{ns}}$ & 65 \\
\hline 7 & $93-2725$ & 18. & $0,73^{\text {ns }}$ & $231372 * *$ & 30 & 19,80 & $0,94^{\mathrm{ns}}$ & $0,025^{\mathrm{ns}}$ & 80,84 & 368 & $0,67^{\mathrm{ns}}$ & $9794 * *$ & 29 \\
\hline 8 & $93-2753$ & 20 & $0,78^{\text {ns }}$ & $33537^{\mathrm{ns}}$ & 52 & 19,35 & $1,00^{\mathrm{ns}}$ & $-0,265^{\mathrm{ns}}$ & 94,46 & 393 & $0,82^{\mathrm{ns}}$ & $2010^{\mathrm{ns}}$ & 56 \\
\hline 9 & $93-2802$ & 21 . & $0,64^{\mathrm{ns}}$ & $-33000^{\mathrm{ns}}$ & 55 & 18,90 & $1,12^{\mathrm{ns}}$ & $-0,166^{\mathrm{ns}}$ & 91,93 & 402 & $0,56+$ & $-2086^{\mathrm{ns}}$ & 57 \\
\hline 10 & $93-2825$ & 20 & $0,86^{\mathrm{ns}}$ & $70241^{\mathrm{ns}}$ & 52 & 20,04 & $1,31+$ & $0,340^{*}$ & 82,08 & 425 & $1,01^{\mathrm{ns}}$ & $4116^{\mathrm{ns}}$ & 60 \\
\hline 11 & $93-2870$ & 22 & $1,11^{\mathrm{ns}}$ & $68738^{\text {ns }}$ & 64 & 19,93 & $1,29+$ & $-0,061^{\mathrm{ns}}$ & 90,93 & 447 & $1,11^{\mathrm{ns}}$ & $2970^{\mathrm{ns}}$ & 67 \\
\hline 12 & $93-5082$ & 26 & $1,23^{\mathrm{ns}}$ & $4080^{\mathrm{ns}}$ & 76 & 20,31 & $0,94^{\mathrm{ns}}$ & $-0,164^{\mathrm{ns}}$ & 88,83 & 542 & $1,17^{\mathrm{ns}}$ & $712^{\mathrm{ns}}$ & 76 \\
\hline 13 & $93-5243$ & 29. & $1,40^{\mathrm{ns}}$ & $10277^{\mathrm{ns}}$ & 80 & 19,41 & $0,99^{\mathrm{ns}}$ & $0,410^{*}$ & 70,26 & 569 & $1,17^{\mathrm{ns}}$ & $147^{\mathrm{ns}}$ & 77 \\
\hline 14 & $93-5423$ & 24 & $1,43+$ & $124320 *$ & 70 & 20,21 & $0,81^{\mathrm{ns}}$ & $0,211^{\mathrm{ns}}$ & 68,04 & 491 & $1,40+$ & $4943^{\mathrm{ns}}$ & 72 \\
\hline 15 & $93-5539$ & 25 . & $0,68^{\text {ns }}$ & $88023^{\text {ns }}$ & 38 & 21,39 & $0,79^{\mathrm{ns}}$ & $0,091^{\mathrm{ns}}$ & 71,82 & 541 & $0,74^{\mathrm{ns}}$ & $5040 *$ & 42 \\
\hline 16 & $93-5544$ & $21^{\prime}$ & $0,96^{\mathrm{ns}}$ & $83027^{\mathrm{ns}}$ & 55 & 20,45 & $0,81^{\mathrm{ns}}$ & $0,471^{*}$ & 59,35 & 448 & $0,93^{\text {ns }}$ & $3050^{\mathrm{ns}}$ & 59 \\
\hline 17 & $93-5549$ & 26 & $1,39^{\mathrm{ns}}$ & $9394^{\text {ns }}$ & 80 & 20,52 & $0,97^{\mathrm{ns}}$ & $0,305^{\mathrm{ns}}$ & 72,43 & 541 & $1,39+$ & $-15^{\mathrm{ns}}$ & 83 \\
\hline 18 & $93-5552$ & 21 & $1,25^{\mathrm{ns}}$ & $-34397^{\mathrm{ns}}$ & 82 & 21,08 & $0,99^{\mathrm{ns}}$ & $0,039^{\mathrm{ns}}$ & 81,64 & 461 & $1,23^{\mathrm{ns}}$ & $-418^{\mathrm{ns}}$ & 81 \\
\hline 19 & $93-5582$ & 22 & $1,09^{\mathrm{ns}}$ & $69687^{\mathrm{ns}}$ & 63 & 20,73 & $1,23^{\mathrm{ns}}$ & $-0,011^{\mathrm{ns}}$ & 88,72 & 474 & $1,08^{\text {ns }}$ & $2857^{\mathrm{ns}}$ & 66 \\
\hline 20 & $93-5585$ & 21 & $0,73^{\text {ns }}$ & $-24022^{\mathrm{ns}}$ & 60,2 & 20,36 & $0,27^{\mathrm{ns}}$ & $0,176^{\mathrm{ns}}$ & 84,69 & 436 & $0,87^{\mathrm{ns}}$ & $-24^{\mathrm{ns}}$ & 66,6 \\
\hline 21 & $93-5586$ & 21. & $0,95^{\mathrm{ns}}$ & $-2123^{\mathrm{ns}}$ & 67,5 & 20,84 & $1,11^{\mathrm{ns}}$ & $0,008^{\mathrm{ns}}$ & 86,00 & 451 & $1,09^{\mathrm{ns}}$ & $761^{\mathrm{ns}}$ & 73,1 . \\
\hline 22 & $93-5597$ & 22 & $1,19^{\mathrm{ns}}$ & $51817^{\mathrm{ns}}$ & 69,7 & 20,03 & $0,93^{\text {ns }}$ & $-0,096^{\mathrm{ns}}$ & 85,67 & 473 & $1,19^{\mathrm{ns}}$ & $2465^{\mathrm{ns}}$ & 71,8 \\
\hline 23 & $93-5690$ & 22 & $1,06^{\mathrm{ns}}$ & $224391 * *$ & 47,9 & 21,07 & $0,64 *$ & $1,254 *$ & 32,59 & 462 & $0,88^{\mathrm{ns}}$ & $9017 * *$ & 42,9 \\
\hline 24 & $93-5692$ & 24 & $0,88^{\text {ns }}$ & $80026^{\mathrm{ns}}$ & 52,1 & 20,25 & $1,23^{\text {ns }}$ & $0,120^{\mathrm{ns}}$ & 85,25 & 500 & $0,93^{\text {ns }}$ & $3083^{\text {ns }}$ & 58,8 \\
\hline 25 & $93-5843$ & $23^{\prime}$ & $1,37^{\mathrm{ns}}$ & $-17994^{\mathrm{ns}}$ & 83,2 & 21,07 & $0,96^{\mathrm{ns}}$ & 1,131 * & 53,53 & 509 & $1,54++$ & $-804^{\mathrm{ns}}$ & 87,9 \\
\hline 26 & $93-5860$ & 24 & $1,18^{\mathrm{ns}}$ & $103100^{\mathrm{ns}}$ & 63,4 & 21,76 & $0,72+$ & $0,172^{\mathrm{ns}}$ & 64,33 & 528 & $1,34^{\mathrm{ns}}$ & $5080 *$ & 70,5 \\
\hline 27 & $93-5884$ & 22 & $0,77^{\mathrm{ns}}$ & $-510^{\mathrm{ns}}$ & 57,8 & 20,25 & $0,76^{\mathrm{ns}}$ & $0,437 *$ & 57,25 & 444 & $0,73^{\text {ns }}$ & $203^{\mathrm{ns}}$ & 57,1 \\
\hline
\end{tabular}

,+++ : significativo ao nível de $5 \%$ e $1 \%$, respectivamente, pelo teste $\mathrm{t} ;{ }^{*}, * *$ : significativo ao nível de $5 \%$ e $1 \%$, respectivamente, pelo teste $\mathrm{F}$. ns: não significativo pelo teste $\mathrm{t}$ ou $\mathrm{F}$. 
Tabela 23. Linhagens Semiprecoces: média, coeficiente de regressão $\left(b_{i}\right)$, variância dos desvios da regressão $\left(\mathrm{S}^{2} \mathrm{~d}_{\mathrm{i}}\right)$ e coeficiente de determinação $\left(\mathrm{R}^{2}\right)$ para os caracteres produtividade de grãos (PG), porcentagem de óleo (\%OL) e produtividade de óleo (PO). Soja, semeaduras em 20/11/96, 16/11/97, 17/11/98, 23/11/99 (Anhembi), 12/11/96, 13/11/97, 05/11/98, 30/11/99 (Areão), 06/11/96, 12/11/97, 05/11/98, 08/11/99 (ESALQ). Piracicaba, SP.

\begin{tabular}{|c|c|c|c|c|c|c|c|c|c|c|c|c|c|}
\hline \multirow[b]{2}{*}{$\mathrm{N}$} & \multirow[b]{2}{*}{ № USP } & \multicolumn{4}{|c|}{ PG (Kg/ha) } & \multicolumn{4}{|c|}{$\% \mathrm{OL}$} & \multicolumn{4}{|c|}{ PO (Kg/ha) } \\
\hline & & Média & $\mathrm{b}_{\mathrm{i}}$ & $\frac{\mathrm{s}^{2} \mathrm{~d}_{\mathrm{i}}}{4}$ & $\mathrm{R}^{2}$ & Média & $\mathrm{b}_{\mathrm{i}}$ & $\overline{s^{2} d_{i}}$ & $\overline{\mathrm{R}^{2}}$ & Média & $\mathrm{b}_{\mathrm{i}}$ & $\frac{\mathrm{s}^{2} \mathrm{~d}_{\mathrm{i}}}{4}$ & $\mathrm{R}^{2}$ \\
\hline 1 & $93-1052$ & 23 & $1,15^{\mathrm{ns}}$ & $251005^{* *}$ & $\overline{49}$ & 20,51 & $0,90^{\text {ns }}$ & $0,815^{* *}$ & $59,6 i$ & 478 & $1,19^{\text {ns }}$ & $11000 * *$ & $\overline{53,3}$ \\
\hline 2 & 93-1106 & $27:$ & $0,99^{\text {ns }}$ & $393051 * *$ & 34 & 21,54 & $0,64++$ & $0,490 * *$ & 51,2 : & 586 & $1,01^{\mathrm{ns}}$ & $16081 * *$ & 38,1 . \\
\hline 3 & $93-1119$ & 24 & $1,19^{\text {ns }}$ & $-32132^{\mathrm{ns}}$ & 85 & 20,90 & $0,93^{\text {ns }}$ & $-0,126^{\text {ns }}$ & 89,2 & 509 & $1,08^{\text {ns }}$ & $-1457^{\text {ns }}$ & 84,0 \\
\hline 4 & $93-1125$ & 23 & $1,13^{\mathrm{ns}}$ & $753^{\text {ns }}$ & 77 & 21,42 & $1,44++$ & $0,490 * *$ & 83,9 & 494 & $1,14^{\mathrm{ns}}$ & $269^{\text {ns }}$ & 78,2 \\
\hline 5 & $93-1202$ & 23. & $0,93^{\mathrm{ns}}$ & $116969 * *$ & 51 & 18,54 & $0,96^{\mathrm{ns}}$ & $0,051^{\mathrm{ns}}$ & 83,0 & 433 & $0,88^{\text {ns }}$ & $4211 *$ & 53,2 \\
\hline 6 & $93-1211$ & 26 & $1,36^{\mathrm{ns}}$ & $66011^{\mathrm{ns}}$ & 75 & 19,61 & $0,88^{\mathrm{ns}}$ & $-0,033^{\text {ns }}$ & 83,9 . & 511 & $1,17^{\text {ns }}$ & $4066^{*}$ & 67,2 \\
\hline 7 & $93-2002$ & 23 & $1,04^{\mathrm{ns}}$ & $-10431^{\mathrm{ns}}$ & 77 & 20,95 & $1,24^{\mathrm{ns}}$ & $0,156^{\mathrm{ns}}$ & 86,61 & 494 & $1,06^{\mathrm{ns}}$ & $-542^{\mathrm{ns}}$ & 79,2 \\
\hline 8 & $93-2027$ & 25 & $0,80^{\text {ns }}$ & $17725^{\mathrm{ns}}$ & 60 & 21,04 & $1,06^{\mathrm{ns}}$ & $-0,079^{\text {ns }}$ & 89,8 & 547 & $0,96^{\mathrm{ns}}$ & $856^{\mathrm{ns}}$ & 69,1 \\
\hline 9 & $93-2072$ & $21:$ & $1,24^{\mathrm{ns}}$ & $274043 * *$ & 52 & 20,73 & $1,09^{\mathrm{ns}}$ & $0,603 * *$ & 72,5 & 442 & $1,07^{\text {ns }}$ & $14155^{* *}$ & 43,3 \\
\hline 10 & $93-2084$ & 27 & $1,20^{\text {ns }}$ & $146084 * *$ & 60 & 21,00 & $1,18^{\mathrm{ns}}$ & $-0,165^{\mathrm{ns}}$ & 94,11 & 571 & $1,33^{\text {ns }}$ & $7341 * *$ & 65,3 \\
\hline 11 & 03 & 25 & $0,95^{\mathrm{ns}}$ & $51901^{\mathrm{ns}}$ & 61 & 21,08 & $0,97^{\mathrm{ns}}$ & $0,145^{\mathrm{ns}}$ & $80,0^{\prime}$ & 546 & $0,95^{\mathrm{ns}}$ & $3036^{\mathrm{ns}}$ & 60,6 \\
\hline 12 & 04 & 24 & $1,06^{\mathrm{ns}}$ & $86663^{*}$ & 61 & 20,52 & $0,98^{\text {ns }}$ & $0,200^{\mathrm{ns}}$ & $78,7$. & 499 & $0,98^{\text {ns }}$ & $3193^{\text {ns }}$ & 61,7 \\
\hline 13 & $93-2250$ & 22 & $0,81^{\mathrm{ns}}$ & $157708^{* * *}$ & 40 & 21,07 & $1,09^{\mathrm{ns}}$ & $0,139^{\mathrm{ns}}$ & $83,7^{\prime}$ & 475 & $0,71^{\mathrm{ns}}$ & $7781 * *$ & 34,4 \\
\hline 14 & $93-2259$ & 24 & $1,00^{\text {ns }}$ & $50921^{\mathrm{ns}}$ & 64 & 21,04 & $0,85^{\mathrm{ns}}$ & $0,047^{\mathrm{ns}}$ & $79,5 !$ & 513 & $1,02^{\text {ns }}$ & $2653^{\mathrm{ns}}$ & 65,1 \\
\hline 15 & $93-2294$ & 23. & $0,85^{\text {ns }}$ & $63760^{\text {ns }}$ & 54 & 20,97 & $0,84^{\mathrm{ns}}$ & $0,079^{\text {ns }}$ & 77,7 : & 492 & $0,86^{\mathrm{ns}}$ & $3674^{\text {ns }}$ & 53,7 \\
\hline 16 & 02 & 24 & $0,69^{\text {ns }}$ & $148876 * *$ & 33 & 20,85 & $1,06^{\mathrm{ns}}$ & $0,483^{* *}$ & 74,11 & 524 & $0,83^{\text {ns }}$ & $9246 * *$ & 38,9 \\
\hline 17 & & 23 & $0,94^{\text {ns }}$ & $-54163^{\text {ns }}$ & 85 & 21,05 & $0,88^{\text {ns }}$ & $0,283^{\text {ns }}$ & 72,3 & 493 & $0,98^{\text {ns }}$ & $-1588^{\text {ns }}$ & $81,9^{\prime}$ \\
\hline 18 & 316 & 28 & $1,23^{\text {ns }}$ & $-2202^{\mathrm{ns}}$ & 81 & 20,01 & $1,23^{\text {ns }}$ & $0,096^{\mathrm{ns}}$ & 87,8 & 561 & $1,10^{\text {ns }}$ & $134^{\mathrm{ns}}$ & 77,4 \\
\hline 19 & 19 & 19 & $0,86^{\text {ns }}$ & $15099^{\mathrm{ns}}$ & 6 & 20,36 & $0,83^{\text {ns }}$ & $0,010^{\text {ns }}$ & 80,4 & 399 & $0,76^{\mathrm{ns}}$ & $181^{\mathrm{ns}}$ & 61,8 \\
\hline 20 & $93-2475$ & 24 & $0,88^{\text {ns }}$ & $25729^{\text {ns }}$ & 63 & 19,97 & $0,90^{\mathrm{ns}}$ & $-0,111^{\mathrm{ns}}$ & 87,71 & 492 & $0,81^{\mathrm{ns}}$ & $-49^{\mathrm{ns}}$ & 66,3 \\
\hline 21 & $93-2479$ & 25 & $1,18^{\mathrm{ns}}$ & $-28964^{\mathrm{ns}}$ & 85 & 19,82 & $1,16^{\mathrm{ns}}$ & $0,001^{\mathrm{ns}}$ & 89,0 & 511 & $1,07^{\mathrm{ns}}$ & $-1312^{\text {ns }}$ & 83,0 \\
\hline 22 & $93-2529$ & 22 & $0,79^{\text {ns }}$ & $39009^{\mathrm{ns}}$ & 54 & 21,90 & $1,05^{\mathrm{ns}}$ & $0,370^{*}$ & 76,41 & 494 & $0,98^{\text {ns }}$ & $1416^{\mathrm{ns}}$ & 68,0 \\
\hline 23 & 65 & $21:$ & $0,62^{\mathrm{ns}}$ & $88471 *$ & 35 & 19,51 & $0,93^{\text {ns }}$ & $0,489 * *$ & 68,4 & 414 & $0,60+$ & $3177^{\mathrm{ns}}$ & 37,5 \\
\hline 24 & & 20 & $1,16^{\mathrm{ns}}$ & $94350 *$ & 6. & 21,46 & $1,22^{\mathrm{ns}}$ & $1 * *$ & $76,7:$ & 440 & $1,17^{\text {ns }}$ & $6405^{* *}$ & 61,3 \\
\hline 25 & 80 & 24 & $1,29+$ & $628045^{* *}$ & 37 & 20,73 & $0,98^{\text {ns }}$ & $-0,093^{\text {ns }}$ & $88,7 !$ & 499 & $1,33^{\text {ns }}$ & $24785^{* *}$ & 42,8 \\
\hline 26 & 93 & 23. & $1,02^{\mathrm{ns}}$ & 29398 & 40 & 21,42 & $1,22^{\mathrm{ns}}$ & $-0,009^{\text {ns }}$ & 90,21 & 506 & $1,20^{\mathrm{ns}}$ & $12306 * *$ & 51,9 \\
\hline 27 & $93-2697$ & 25. & $1,13^{\mathrm{ns}}$ & $167068 * *$ & 55 & 20,29 & $1,04^{\mathrm{ns}}$ & $-0,179^{\mathrm{ns}}$ & 93,0 & 519 & $1,26^{\mathrm{ns}}$ & $7052 * *$ & 63,6 \\
\hline 28 & 93-2699 & 23 & $0,93^{\text {ns }}$ & $73417^{\text {ns }}$ & 57 & 19,32 & $0,93^{\text {ns }}$ & $-0,019^{\text {ns }}$ & $84,6 i$ & 451 & $0,79^{\text {ns }}$ & $3106^{\mathrm{ns}}$ & 51,2 \\
\hline 29 & $93-2727$ & 22 & $0,88^{\text {ns }}$ & $-12959^{\mathrm{ns}}$ & 71 & 21,38 & $1,07^{\mathrm{ns}}$ & $-0,195^{\mathrm{ns}}$ & $93,9 i$ & 471 & $0,85^{\text {ns }}$ & $-928^{\text {ns }}$ & 73,3 \\
\hline 30 & $93-2756$ & 22 & $1,04^{\mathrm{ns}}$ & $122682 *$ & 56 & 20,97 & $1,20^{\mathrm{ns}}$ & $0,242^{\mathrm{ns}}$ & 83,71 & 477 & $1,15^{\mathrm{ns}}$ & $3334^{\text {ns }}$ & 68,7 \\
\hline 31 & & 21. & $0,57+$ & $-50935^{\text {ns }}$ & 67 & 19,68 & $0,93^{\text {ns }}$ & $0,250^{\mathrm{ns}}$ & 75,3 & 422 & $0,53+$ & $-2750^{\text {ns }}$ & 70,7 \\
\hline 32 & & 24 & $0,66^{\mathrm{ns}}$ & $57596^{\text {ns }}$ & 4 & 20,80 & $1,08^{\mathrm{ns}}$ & $-0,076^{\mathrm{ns}}$ & $90,0 !$ & 509 & $0,80^{\text {ns }}$ & $4822 *$ & 46,4 \\
\hline 33 & $93-2857$ & 23. & $0,98^{\text {ns }}$ & $19461^{\mathrm{ns}}$ & 68 & 20,59 & $0,87^{\mathrm{ns}}$ & $0,092^{\mathrm{ns}}$ & $78,3 !$ & 484 & $1,01^{\mathrm{ns}}$ & $1960^{\mathrm{ns}}$ & 67,3 \\
\hline 34 & $93-2858$ & $21{ }^{\prime}$ & $1,18^{\mathrm{ns}}$ & $454830 * *$ & 36 & 20,89 & $0,80^{\mathrm{ns}}$ & $-0,083^{\text {ns }}$ & 83,4 & 437 & $1,02^{\mathrm{ns}}$ & $17818^{\text {ns }}$ & 36,9 \\
\hline 35 & $93-2897$ & 26. & $1,00^{\text {ns }}$ & $76067^{\mathrm{ns}}$ & 60 & 20,38 & $0,83^{\text {ns }}$ & $-0,090^{\mathrm{ns}}$ & 85,0 & 539 & $1,07^{\text {ns }}$ & $3182^{\mathrm{ns}}$ & 65,6 \\
\hline 36 & 93-2909 & 24 & $0,86^{\text {ns }}$ & $-14629^{\mathrm{ns}}$ & 70 & 20,86 & $0,97^{\mathrm{ns}}$ & $-0,144^{\mathrm{ns}}$ & 90,7 & 517 & $0,80^{\text {ns }}$ & $-771^{\mathrm{ns}}$ & 69,8 \\
\hline 37 & 93-2916 & 23 & $0,94^{\text {ns }}$ & $82184 *$ & 56 & 21,26 & $0,92^{\mathrm{ns}}$ & $0,174^{\mathrm{ns}}$ & 77,3 & 508 & $1,00^{\text {ns }}$ & $5203 *$ & 56,8 \\
\hline 38 & 94-1017 & 22 & $1,43+$ & $122572 *$ & 71 & 21,30 & $0,82^{\mathrm{ns}}$ & $0,004^{\mathrm{ns}}$ & 80,0 & 478 & $1,44+$ & $7432 * *$ & $0,$, \\
\hline
\end{tabular}

,+++ : significativo ao nível de $5 \%$ e $1 \%$ de probabilidade, respectivamente, pelo teste t.

*,**: significativo ao nível de $5 \%$ e $1 \%$ de probabilidade, respectivamente, pelo teste $\mathrm{F}$.

ns: não significativo pelo teste t ou $\mathrm{F}$.

Tabela 24. Linhagens Semitardias: média, coeficiente de regressão $\left(b_{i}\right)$, variância dos desvios da regressão $\left(S^{2} d_{i}\right)$ e coeficiente de determinação $\left(\mathrm{R}^{2}\right)$ para os caracteres produtividade de grãos $(\mathrm{PG})$, porcentagem de óleo (\%OL) e produtividade de óleo (PO). Soja, semeaduras em 20/11/96, 16/11/97, 17/11/98, 23/11/99 (Anhembi), 12/11/96, 13/11/97, 05/11/98, 30/11/99 (Areão), 06/11/96, 12/11/97, 05/11/98, 08/11/99 (ESALQ). Piracicaba, SP.

\begin{tabular}{|c|c|c|c|c|c|c|c|c|c|c|c|c|c|}
\hline \multirow[b]{2}{*}{$\mathrm{N}$} & \multirow[b]{2}{*}{$\mathrm{N}^{0}$ USP } & \multicolumn{4}{|c|}{$\mathrm{PG}(\mathrm{Kg} / \mathrm{ha})$} & \multicolumn{4}{|c|}{$\% \mathrm{OL}$} & \multicolumn{4}{|c|}{$\mathrm{PO}(\mathrm{Kg} / \mathrm{ha})$} \\
\hline & & Média & $\mathrm{b}_{\mathrm{i}}$ & $\mathrm{s}^{2} \mathrm{~d}_{\mathrm{i}}$ & $\mathrm{R}^{2}$ & Média & $b_{i}$ & $\mathrm{~s}^{2} \mathrm{~d}_{\mathrm{i}}$ & $\mathrm{R}^{2}$ & Média & $\mathrm{b}_{\mathrm{i}}$ & $\mathrm{s}^{2} \mathrm{~d}_{\mathrm{i}}$ & $\mathrm{R}^{2}$ \\
\hline 1 & $93-2521$ & 2047 & $0,94^{\mathrm{ns}}$ & $-59828^{\mathrm{ns}}$ & $\overline{84,2}$ & 19,71 & $1,17^{\mathrm{ns}}$ & $0,032^{\mathrm{ns}}$ & 83,6 & 409 & $0,95^{\mathrm{ns}}$ & $-2961^{\mathrm{ns}}$ & $\overline{87,0}$ \\
\hline 2 & $93-5263$ & 2088 & $1,24^{\mathrm{ns}}$ & $72734^{\mathrm{ns}}$ & 79,7 & 19,47 & $1,36+$ & $-0,086^{\mathrm{ns}}$ & 90,9 & 411 & $1,17^{\mathrm{ns}}$ & $2364^{\mathrm{ns}}$ & 80,5 \\
\hline 3 & $93-5391$ & 2166 & $0,78^{\text {ns }}$ & $215941 *$ & 48,7 & 21,15 & $0,65+$ & $0,228^{\mathrm{ns}}$ & 51,3 & 463 & $0,85^{\mathrm{ns}}$ & $11546^{* *}$ & 52,0 \\
\hline 4 & $93-5419$ & 2268 & $1,07^{\mathrm{ns}}$ & $134394^{\mathrm{ns}}$ & 69,8 & 20,75 & $1,14^{\mathrm{ns}}$ & $-0,008^{\mathrm{ns}}$ & 84,5 & 472 & $1,12^{\mathrm{ns}}$ & $5546^{\mathrm{ns}}$ & 73 \\
\hline 5 & $93-5513$ & 2380 & $1,07^{\mathrm{ns}}$ & $190027 *$ & 65,9 & 19,80 & $0,94^{\mathrm{ns}}$ & $0,138^{\mathrm{ns}}$ & 72,2 & 474 & $1,02^{\mathrm{ns}}$ & $7248 *$ & 67,3 \\
\hline 6 & $93-5684$ & 2204 & $1,09^{\mathrm{ns}}$ & $-92333^{\mathrm{ns}}$ & 91,4 & 20,59 & $0,94^{\mathrm{ns}}$ & $-0,042^{\mathrm{ns}}$ & 80,4 & 459 & $1,12^{\mathrm{ns}}$ & $-2817^{\mathrm{ns}}$ & 90,0 \\
\hline 7 & $93-5802$ & 1951 & $0,80^{\mathrm{ns}}$ & $95199^{\mathrm{ns}}$ & 60,3 & 20,82 & $0,79^{\mathrm{ns}}$ & $0,339^{\mathrm{ns}}$ & 56,7 & 407 & $0,77^{\mathrm{ns}}$ & $4352^{\mathrm{ns}}$ & 59,5 \\
\hline
\end{tabular}

,+++ : significativo ao nível de $5 \%$ e $1 \%$ de probabilidade, respectivamente, pelo teste $\mathrm{t}$.

$* * *$ : significativo ao nível de $5 \%$ e $1 \%$ de probabilidade, respectivamente, pelo teste $\mathrm{F}$.

ns: não significativo pelo teste $\mathrm{t}$ ou $\mathrm{F}$. 
Tabela 25. Linhagens Precoces: análise de variância com a decomposição da interação genótipos $\mathrm{x}$ ambientes nos quatro primeiros componentes principais da interação (CPI) para os caracteres produtividade de grãos $(\mathrm{PG})$, porcentagem de óleo $(\% \mathrm{OL})$ e produtividade de óleo (PO). Soja, semeaduras em 20/11/96, 16/11/97, 17/11/98, 23/11/99 (Anhembi), 12/11/96, 13/11/97, 05/11/98, 30/11/99 (Areão), 06/11/96, 12/11/97, 05/11/98, 08/11/99 (ESALQ). Piracicaba, SP.

\begin{tabular}{|c|c|c|c|c|c|c|c|}
\hline \multirow{3}{*}{$\begin{array}{c}\text { Fontes } \\
\text { De } \\
\text { Variação }\end{array}$} & \multirow[b]{3}{*}{ G.L. } & \multicolumn{6}{|c|}{ Quadrados Médios } \\
\hline & & \multicolumn{2}{|c|}{ PG (Kg/ha) } & \multicolumn{2}{|c|}{$\% \mathrm{OL}$} & \multicolumn{2}{|c|}{$\mathrm{PO}(\mathrm{Kg} / \mathrm{ha})$} \\
\hline & & Q.M. & $\mathrm{R}^{2}(\%)^{\mathrm{a}}$ & Q.M. & $\mathrm{R}^{2}(\%)^{\mathrm{a}}$ & Q.M. & $\mathrm{R}^{2}(\%)^{\mathrm{a}}$ \\
\hline Linhagens (G) & 27 & $514168^{* * *}$ & 8,00 & 7,7377 ** & 25,55 & $24787 * *$ & 8,03 \\
\hline Ambientes (E) & 11 & $9443717 * *$ & 59,99 & $38,2770^{* * *}$ & 51,49 & $464086 * *$ & 61,27 \\
\hline$G \times E$ & 297 & $187033^{* *}$ & 32,00 & $0,6322 * *$ & 22,96 & $8612 * *$ & 30,69 \\
\hline CPI1 & 37 & $353244 * *$ & 23,53 & $1,7751 * *$ & 35,00 & $16312 * *$ & 23,60 \\
\hline Resíduo & 260 & $163380 * *$ & - & $0,4696^{\mathrm{ns}}$ & - & $7516 * *$ & - \\
\hline $\mathrm{CPI} 2$ & 35 & $290281 * *$ & 18,29 & $0,9824 * *$ & 18,29 & $12460 * *$ & 17,05 \\
\hline Resíduo & 225 & $143639 * *$ & - & $0,3898^{\mathrm{ns}}$ & - & $6747 * *$ & - \\
\hline CPI3 & 33 & $213305^{* * *}$ & 12,67 & $0,7126^{\mathrm{ns}}$ & 12,52 & $10487 * *$ & 13,53 \\
\hline Resíduo $_{\text {AMMI3 }}$ & 192 & $131665 * *$ & - & $0,3343^{\mathrm{ns}}$ & - & $6105^{* *}$ & - \\
\hline CPI4 & 31 & $206896 * *$ & 11,55 & $0,5448^{\mathrm{ns}}$ & 9,00 & $9628 * *$ & 11,66 \\
\hline Resíduo $_{\text {AMMI4 }}$ & 161 & $117180^{\mathrm{ns}}$ & - & $0,2938^{\mathrm{ns}}$ & - & $5426^{\mathrm{ns}}$ & - \\
\hline Erro médio/r ${ }^{1}$ & 324 & 95384 & & 0,5275 & & 4372 & \\
\hline
\end{tabular}

a: \%SQ $\mathrm{ST}_{\text {Tramentos }} / \mathrm{G}, \mathrm{E}$ e GxE; \% $\mathrm{SQ}_{\mathrm{GxE}} / \mathrm{CPI}$.

**: significativo ao nível de $1 \%$ de probabilidade pelo teste $\mathrm{F}$.

ns: não significativo pelo teste $\mathrm{F}$.

1: número de repetições.

Tabela 26. Linhagens Semiprecoces: análise de variância com a decomposição da interação genótipos x ambientes nos quatro primeiros componentes principais da interação (CPI) para os caracteres produtividade de grãos (PG), porcentagem de óleo (\%OL) e produtividade de óleo (PO). Soja, semeaduras em 20/11/96, 16/11/97, 17/11/98, 23/11/99 (Anhembi), 12/11/96, 13/11/97, 05/11/98, 30/11/99 (Areão), 06/11/96, 12/11/97, 05/11/98, 08/11/99 (ESALQ). Piracicaba, SP.

\begin{tabular}{|c|c|c|c|c|c|c|c|}
\hline \multirow{3}{*}{$\begin{array}{c}\text { Fontes } \\
\text { De } \\
\text { Variação }\end{array}$} & \multirow[b]{3}{*}{ G.L. } & \multicolumn{6}{|c|}{ Quadrados Médios } \\
\hline & & \multicolumn{2}{|c|}{ PG (kg/ha) } & \multicolumn{2}{|c|}{$\% \mathrm{OL}$} & \multicolumn{2}{|c|}{$\mathrm{PO}(\mathrm{KG} / \mathrm{ha})$} \\
\hline & & Q.M. & $\mathrm{R}^{2}(\%)^{\mathrm{a}}$ & Q.M. & $\mathrm{R}^{2}(\%)^{\mathrm{a}}$ & Q.M. & $\mathrm{R}^{2}(\%)^{\mathrm{a}}$ \\
\hline Linhagens $(\mathrm{G})$ & 37 & $445499 * *$ & 8,57 & $5,9765 * *$ & 18,00 & $21776^{* *}$ & 8,89 \\
\hline Ambientes (E) & 11 & $8859089 * *$ & 50,65 & $73,2365^{* *}$ & 65,56 & $425332 * *$ & 51,64 \\
\hline $\mathrm{G} \times \mathrm{E}$ & 407 & $192822 * *$ & 40,79 & $0,4964 * *$ & 16,44 & $8786 * *$ & 39,47 \\
\hline CPI1 & 47 & $390367 * *$ & 23,38 & $1,0648 * *$ & 24,77 & $17645^{* *}$ & 23,19 \\
\hline ResíduoAMMIı & 360 & $167031 * *$ & - & $0,4222^{\mathrm{ns}}$ & - & $7629 * *$ & - \\
\hline $\mathrm{CPI} 2$ & 45 & $367533 * *$ & 21,07 & $0,7153 * *$ & 15,93 & $17237 * *$ & 21,69 \\
\hline Resíduo $_{\text {АMмI2 }}$ & 315 & $138388 * *$ & - & $0,3803^{\mathrm{ns}}$ & - & $6257 * *$ & - \\
\hline CPI3 & 43 & $240795 * *$ & 13,20 & $0,6714 * *$ & 14,29 & $10272 * *$ & 12,35 \\
\hline Resíduo $_{\mathrm{AMMI} 3}$ & 272 & $122199 * *$ & - & $0,3343^{\mathrm{ns}}$ & - & $5622 * *$ & - \\
\hline CPI4 & 41 & $203457 * *$ & 10,63 & $0,5333^{\mathrm{ns}}$ & 10,83 & $10189 * *$ & 11,69 \\
\hline Resíduo $_{\text {AMMI4 }}$ & 231 & $107776^{\mathrm{ns}}$ & - & $0,2990^{\mathrm{ns}}$ & - & $4811^{\mathrm{ns}}$ & - \\
\hline Erro médio/r ${ }^{1}$ & 444 & 91582 & & 0,3519 & & 4188 & \\
\hline
\end{tabular}

a: $\% \mathrm{SQ}_{\text {Tratamentos }} / \mathrm{G}, \mathrm{E}$ e $\mathrm{GxE} ; \% \mathrm{SQ}_{\mathrm{GxE}} / \mathrm{CPI}$

**: significativo ao nível de $1 \%$ de probabilidade pelo teste $\mathrm{F}$.

ns: não significativo pelo teste $\mathrm{F}$.

1: número de repetições. 
Tabela 27. Linhagens Intermediárias: análise de variância com a decomposição da interação genótipos $\mathrm{x}$ ambientes nos dois primeiros componentes principais da interação (CPI) para os caracteres produtividade de grãos (PG), porcentagem de óleo (\%OL) e produtividade de óleo (PO). Soja, semeaduras em 20/11/96, 16/11/97, 17/11/98, 23/11/99 (Anhembi), 12/11/96, 13/11/97, 05/11/98, 30/11/99 (Areão), 06/11/96, 12/11/97, 05/11/98, 08/11/99 (ESALQ). Piracicaba, SP.

\begin{tabular}{|c|c|c|c|c|c|c|c|}
\hline \multirow{3}{*}{$\begin{array}{c}\text { Fontes } \\
\text { De } \\
\text { Variação }\end{array}$} & \multirow[b]{3}{*}{ G.L. } & \multicolumn{6}{|c|}{ Quadrados Médios } \\
\hline & & \multicolumn{2}{|c|}{ PG (Kg/ha) } & \multicolumn{2}{|c|}{$\% \mathrm{OL}$} & \multicolumn{2}{|c|}{ PO (Kg/ha) } \\
\hline & & Q.M. & $\mathrm{R}^{2}(\%)^{\mathrm{a}}$ & Q.M. & $\mathrm{R}^{2}(\%)^{\mathrm{a}}$ & Q.M. & $\mathrm{R}^{2}(\%)^{\mathrm{a}}$ \\
\hline Linhagens $(\mathrm{G})$ & 26 & $721452 * *$ & 12,41 & $5,5733 * *$ & 17,51 & $32865 * *$ & 12,13 \\
\hline Ambientes (E) & 11 & $7073925 * *$ & 51,50 & $46,3884 * *$ & 61,68 & $341871 * *$ & 53,38 \\
\hline $\mathrm{G} \times \mathrm{E}$ & 286 & $190603 * *$ & 36,08 & $0,6018 * *$ & 20,80 & $8497 * *$ & 34,49 \\
\hline CPI1 & 36 & $391920 * *$ & 25,88 & $1,2501 * *$ & 26,14 & $17150 * *$ & 25,40 \\
\hline Resíduo & 250 & $161614^{\mathrm{ns}}$ & - & $0,5085 * *$ & - & $7251 * *$ & - \\
\hline $\mathrm{CPI} 2$ & 34 & $298298 * *$ & 18,61 & $1,0033 * *$ & 19,82 & $12887 * *$ & 18,03 \\
\hline Resíduo & 216 & $140099^{\mathrm{ns}}$ & - & $0,4306^{\mathrm{ns}}$ & - & $6364^{\text {ns }}$ & - \\
\hline Erro médio/r ${ }^{1}$ & 312 & 126928 & & 0,3767 & & 5332 & \\
\hline
\end{tabular}

a: $\% \mathrm{SQ}_{\text {Tratamentos }} / \mathrm{G}, \mathrm{E}$ e $\mathrm{GxE} ; \% \mathrm{SQ} \mathrm{GxE}_{\mathrm{CPI}} / \mathrm{CP}$

**: significativo ao nível de $1 \%$ de probabilidade pelo teste $\mathrm{F}$.

ns: não significativo pelo teste $\mathrm{F}$.

1: número de repetições.

Tabela 28. Linhagens Semitardias: análise de variância com a decomposição da interação genótipos $\mathrm{x}$ ambientes no primeiro componente principal da interação (CPI) para os caracteres produtividade de grãos (PG), porcentagem de óleo (\%OL) e produtividade de óleo (PO). Soja, semeaduras em 20/11/96, 16/11/97, 17/11/98, 23/11/99 (Anhembi), 12/11/96, 13/11/97, 05/11/98, 30/11/99 (Areão), 06/11/96, 12/11/97, 05/11/98, 08/11/99 (ESALQ). Piracicaba, SP.

\begin{tabular}{|c|c|c|c|c|c|c|c|}
\hline \multirow{3}{*}{$\begin{array}{c}\text { Fontes } \\
\text { De } \\
\text { Variação }\end{array}$} & \multirow[b]{3}{*}{ G.L. } & \multicolumn{6}{|c|}{ Quadrados Médios } \\
\hline & & \multicolumn{2}{|c|}{ PG (Kg/ha) } & \multicolumn{2}{|c|}{$\% \mathrm{OL}$} & \multicolumn{2}{|c|}{$\mathrm{PO}(\mathrm{Kg} / \mathrm{ha})$} \\
\hline & & Q.M. & $\mathrm{R}^{2}(\%)^{\mathrm{a}}$ & Q.M. & $\mathrm{R}^{2}(\%)^{\mathrm{a}}$ & Q.M. & $\mathrm{R}^{2}(\%)^{\mathrm{a}}$ \\
\hline Linhagens (G) & 6 & $246948^{\mathrm{ns}}$ & 2,45 & $5,1631 * *$ & 18,39 & $11958^{\mathrm{ns}}$ & 2,62 \\
\hline Ambientes (E) & 11 & $3761914 * *$ & 68,43 & $9,2327 * *$ & 60,28 & $173480 * *$ & 69,85 \\
\hline $\mathrm{G} \times \mathrm{E}$ & 66 & $266823^{*}$ & 29,12 & $0,5448 *$ & 21,34 & $11392 *$ & 27,52 \\
\hline CPI1 & 16 & $434147 * *$ & 39,44 & $0,8545^{* *}$ & 38,02 & $18375^{* *}$ & 39,10 \\
\hline Resíduo $_{\mathrm{AMMI}}$ & 50 & $213280^{\mathrm{ns}}$ & - & $0,4457^{\mathrm{ns}}$ & - & $9158^{\mathrm{ns}}$ & - \\
\hline Erro médio/r ${ }^{1}$ & 72 & 158032 & & 0,3564 & & 6599 & \\
\hline
\end{tabular}

a: $\% \mathrm{SQ}_{\text {Tratamentos }} / \mathrm{G}, \mathrm{E}$ e GxE; \% SQ $\mathrm{GxE}_{\mathrm{CPI}}$.

**: significativo ao nível de $1 \%$ de probabilidade pelo teste $\mathrm{F}$.

ns: não significativo pelo teste $\mathrm{F}$.

1: número de repetições. 
Tabela 29. Linhagens precoces: médias e interações preditas pelo modelo AMMI4 ( $\left.\mathrm{A}_{\mathrm{i}} \%\right)$ para linhagens, ambientes e locais, referentes ao caráter produtividade de grãos $(\mathrm{Kg} / \mathrm{ha})$. Soja, semeaduras em 20/11/96, 16/11/97, 17/11/98, 23/11/99 (Anhembi), 12/11/96, 13/11/97, 05/11/98, 30/11/99 (Areão), 06/11/96, 12/11/97, 05/11/98, 08/11/99 (ESALQ). Piracicaba, SP.

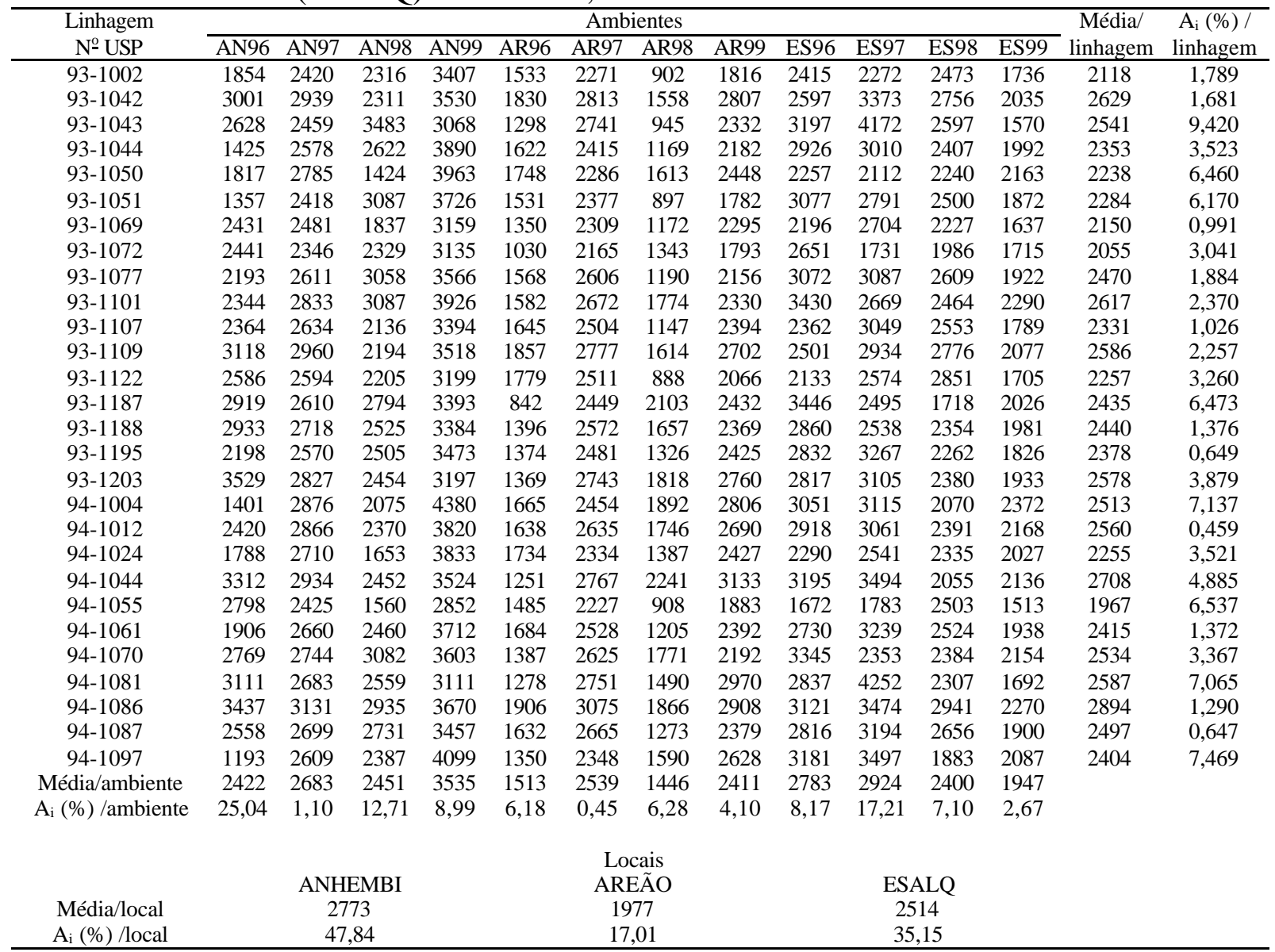


Tabela 30. Linhagens precoces: médias e interações preditas pelo modelo AMMI1 $\left(\mathrm{A}_{\mathrm{i}} \%\right)$ para linhagens, ambientes e locais, referentes ao caráter porcentagem de óleo (\%). Soja, semeaduras em 20/11/96, 16/11/97, 17/11/98, 23/11/99 (Anhembi), 12/11/96, 13/11/97, 05/11/98, 30/11/99 (Areão), 06/11/96, 12/11/97, 05/11/98, 08/11/99 (ESALQ). Piracicaba, SP.

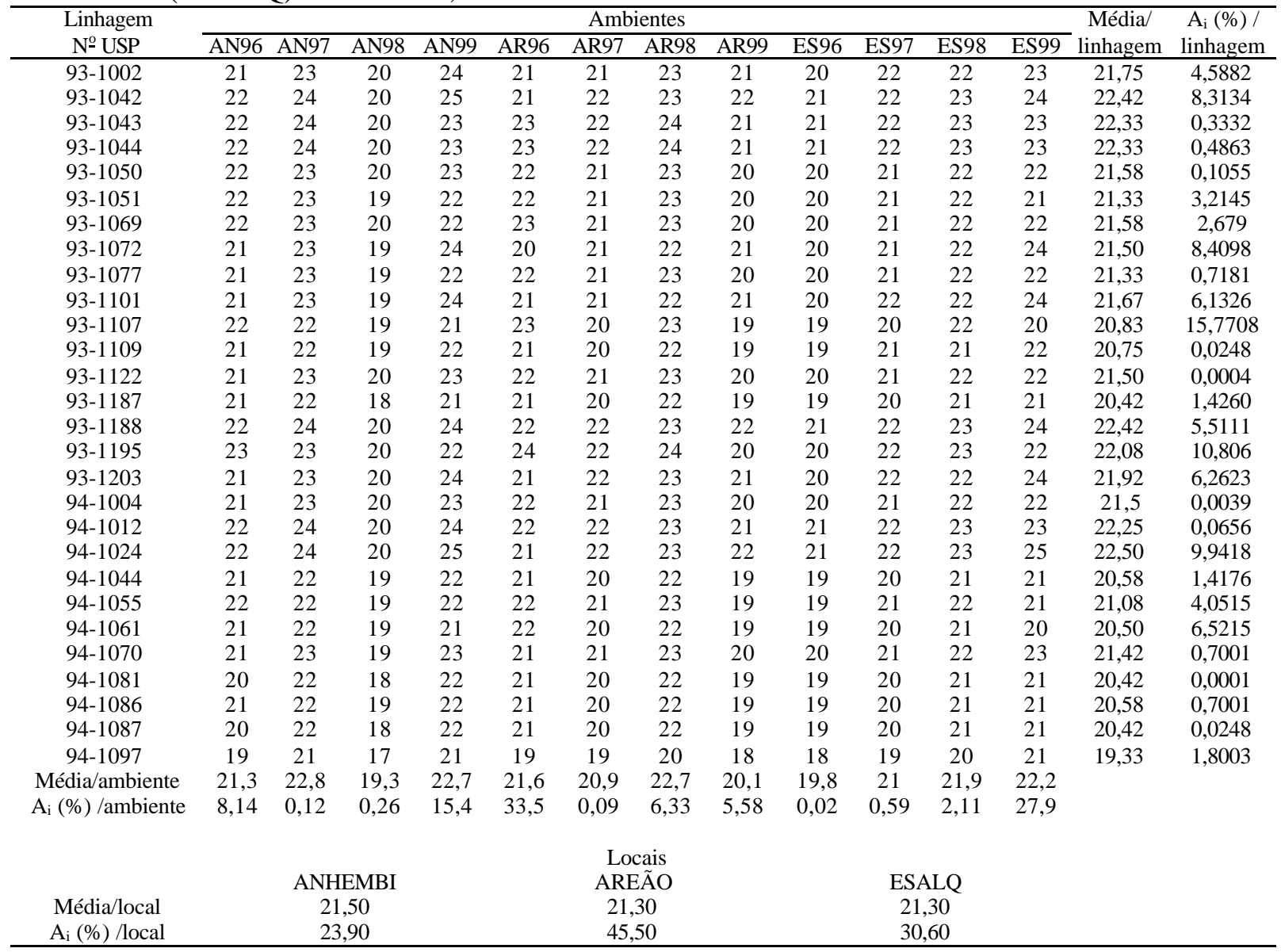


Tabela 31. Linhagens precoces: médias e interações preditas pelo modelo AMMI4 ( $\left.\mathrm{A}_{\mathrm{i}} \%\right)$ para linhagens, ambientes e locais, referentes ao caráter produtividade de óleo ( $\mathrm{Kg} / \mathrm{ha})$. Soja, semeaduras em 20/11/96, 16/11/97, 17/11/98, 23/11/99 (Anhembi), 12/11/96, 13/11/97, 05/11/98, 30/11/99 (Areão), 06/11/96, 12/11/97, 05/11/98, 08/11/99 (ESALQ). Piracicaba, SP.

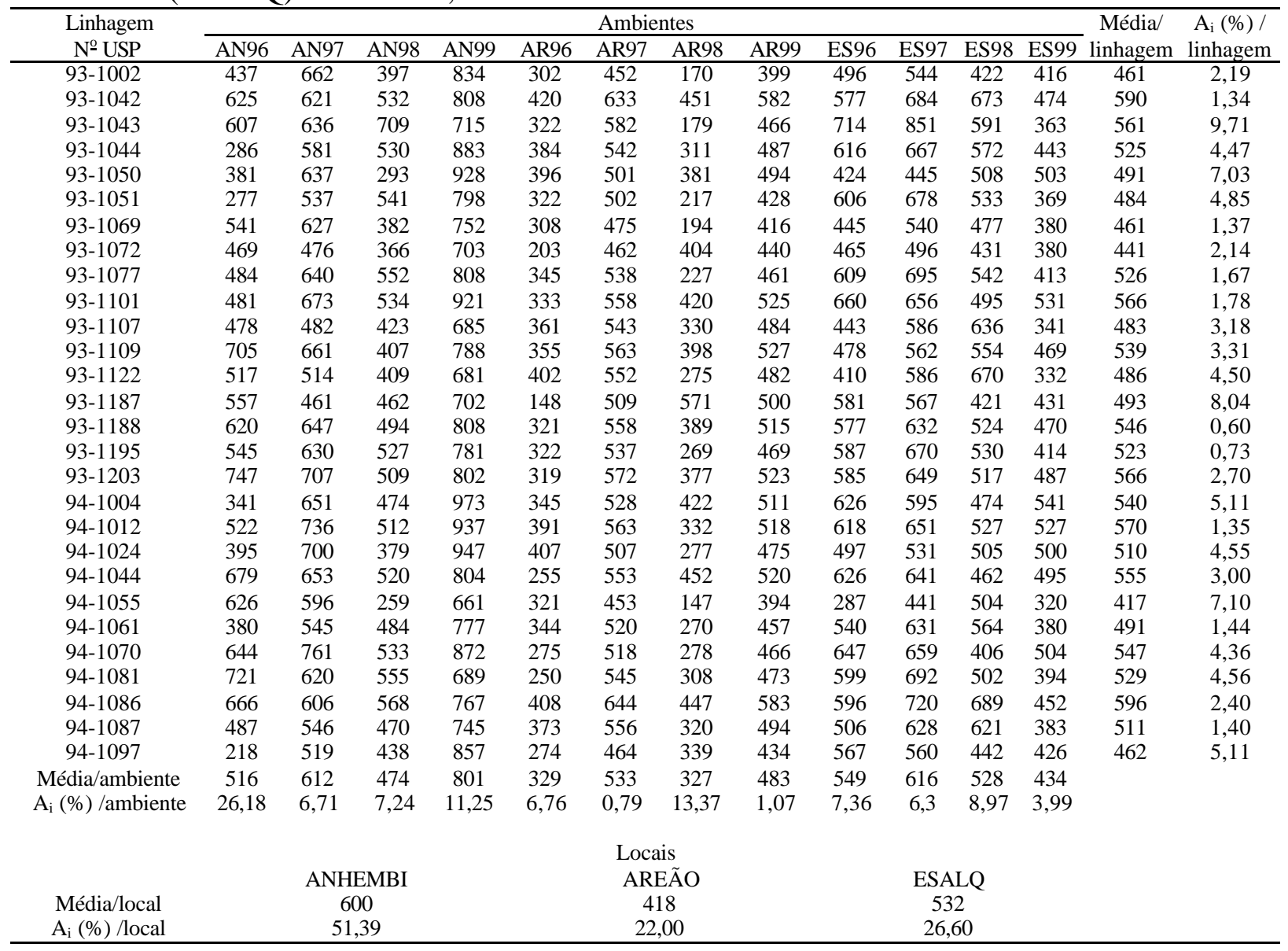


Tabela 32. Linhagens semiprecoces: médias e interações preditas pelo modelo AMMI4 ( $\mathrm{A}_{\mathrm{i}} \%$ ) para linhagens, ambientes e locais, referentes ao caráter produtividade de grãos (Kg/ha). Soja, semeaduras em 20/11/96, 16/11/97, 17/11/98, 23/11/99 (Anhembi), 12/11/96, 13/11/97, 05/11/98, 30/11/99 (Areão), 06/11/96, 12/11/97, 05/11/98, 08/11/99 (ESALQ). Piracicaba, SP.

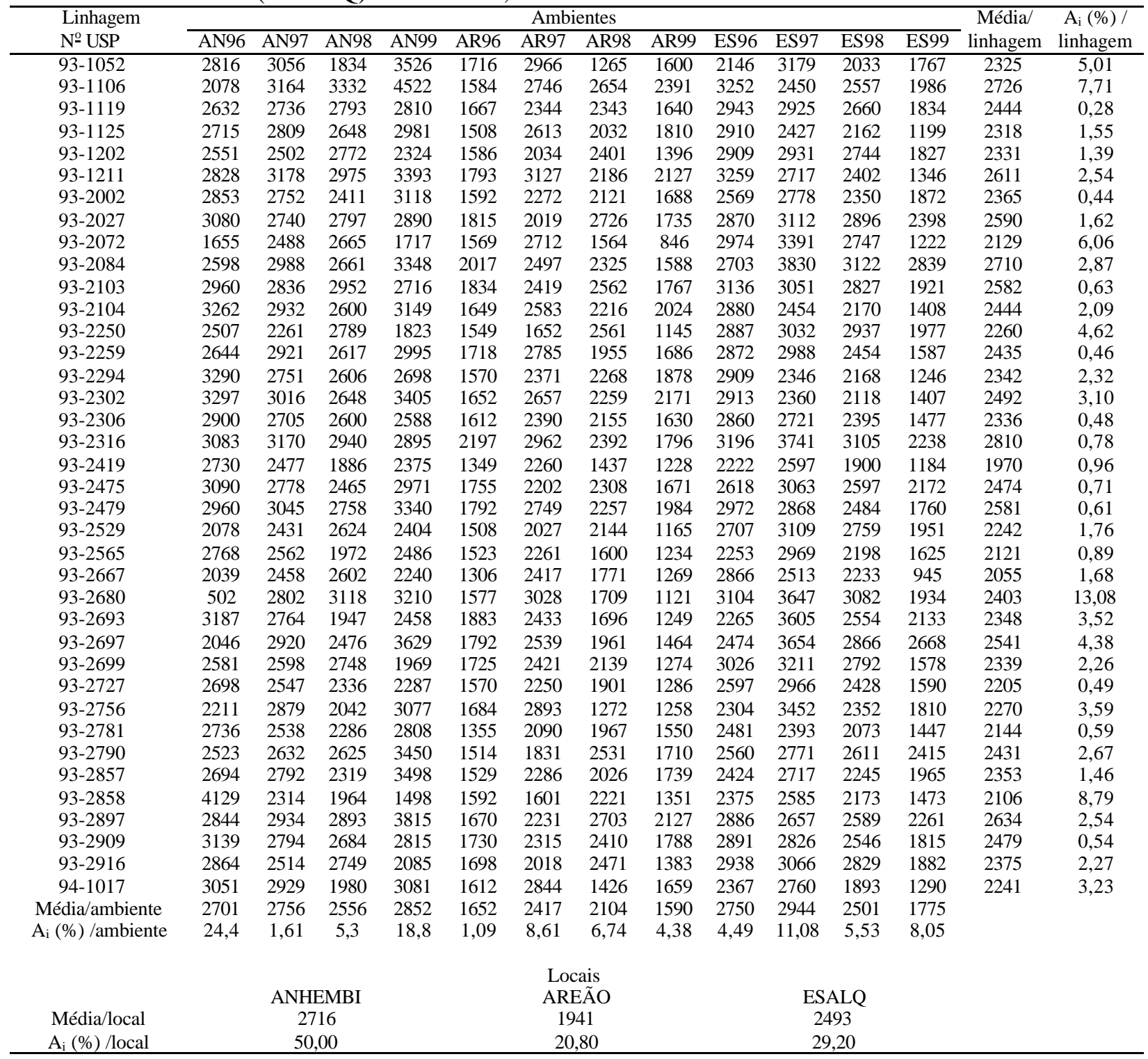


Tabela 33. Linhagens semiprecoces: médias e interações preditas pelo modelo AMMI1 ( $\left.\mathrm{A}_{\mathrm{i}} \%\right)$ para linhagens, ambientes e locais, referentes ao caráter porcentagem de óleo (\%). Soja, Piracicaba, SP. Soja, semeaduras em 20/11/96, 16/11/97, 17/11/98, 23/11/99 (Anhembi), 12/11/96, 13/11/97, 05/11/98, 30/11/99 (Areão), 06/11/96, 12/11/97, 05/11/98, 08/11/99 (ESALQ). Piracicaba, SP.

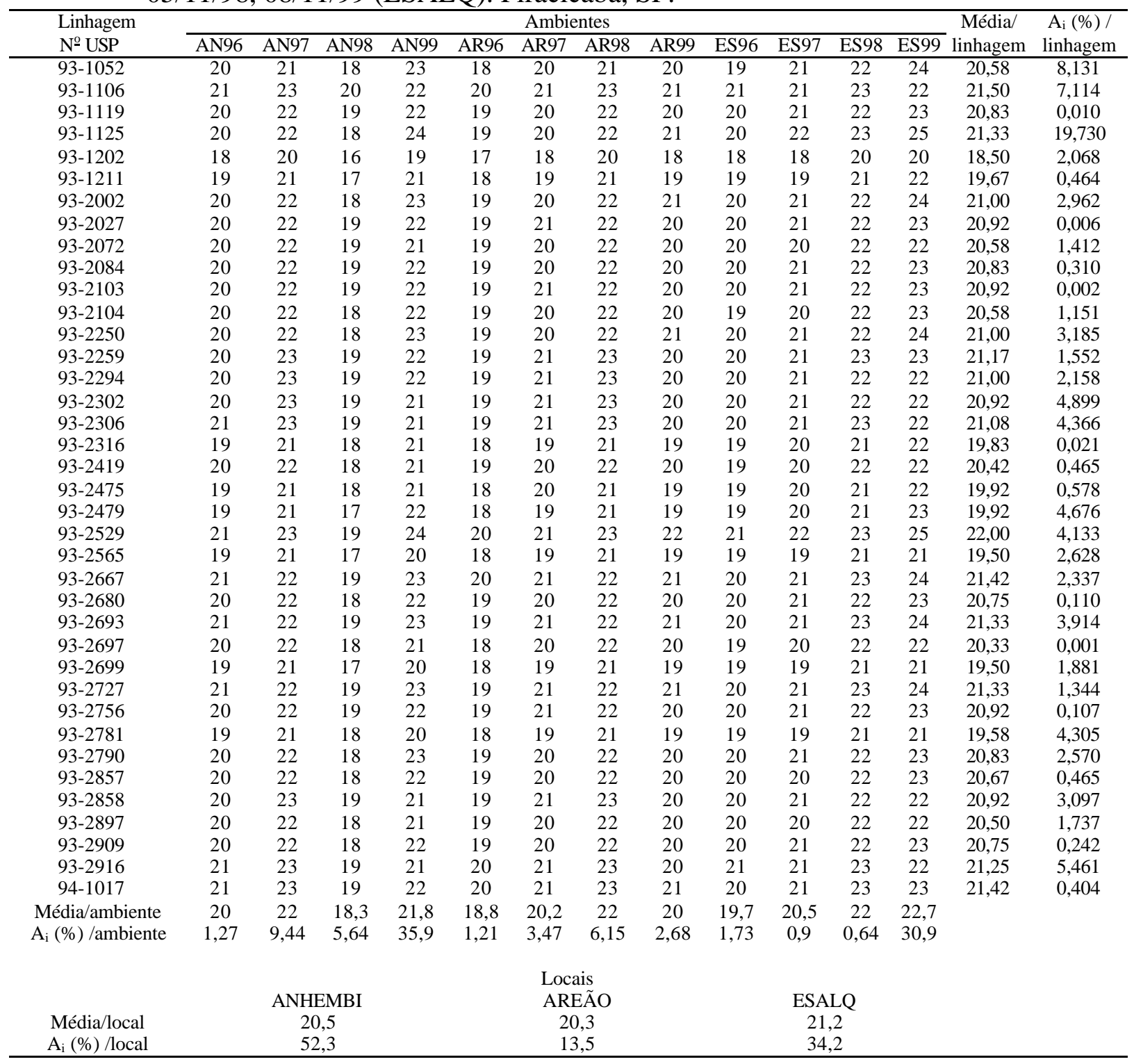


Tabela 34. Linhagens semiprecoces: médias e interações preditas pelo modelo AMMI4 $\left(\mathrm{A}_{\mathrm{i}} \%\right)$ para linhagens, ambientes e locais, referentes ao caráter produtividade de óleo (Kg/ha). Soja, semeaduras em 20/11/96, 16/11/97, 17/11/98, 23/11/99 (Anhembi), 12/11/96, 13/11/97, 05/11/98, 30/11/99 (Areão), 06/11/96, 12/11/97, 05/11/98, 08/11/99 (ESALQ). Piracicaba, SP.

\begin{tabular}{|c|c|c|c|c|c|c|c|c|c|c|c|c|c|c|}
\hline \multirow{2}{*}{$\begin{array}{c}\text { Linhagem } \\
\text { № USP }\end{array}$} & \multicolumn{12}{|c|}{ Ambientes } & \multirow{2}{*}{$\begin{array}{c}\text { Média/ } \\
\text { linhagem }\end{array}$} & \multirow{2}{*}{$\begin{array}{l}\mathrm{A}_{\mathrm{i}}(\%) / \\
\text { linhagem }\end{array}$} \\
\hline & AN96 & AN97 & AN98 & AN99 & AR96 & AR97 & AR98 & AR99 & ES96 & ES97 & ES98 & ES99 & & \\
\hline $93-1052$ & 576 & 631 & 327 & 841 & 298 & 541 & 285 & 334 & 435 & 633 & 431 & 407 & 478 & 5,206 \\
\hline $93-1106$ & 434 & 707 & 672 & 946 & 329 & 588 & 638 & 493 & 704 & 499 & 581 & 436 & 585 & 7,067 \\
\hline 93-1119 & 552 & 610 & 499 & 620 & 325 & 478 & 509 & 333 & 569 & 604 & 582 & 431 & 509 & 0,127 \\
\hline $93-1125$ & 561 & 636 & 466 & 722 & 299 & 536 & 451 & 382 & 557 & 527 & 473 & 320 & 494 & 1,480 \\
\hline $93-1202$ & 485 & 514 & 447 & 435 & 259 & 368 & 477 & 230 & 510 & 545 & 555 & 371 & 433 & 1,421 \\
\hline $93-1211$ & 543 & 667 & 506 & 737 & 313 & 601 & 454 & 403 & 592 & 544 & 483 & 287 & 511 & 2,347 \\
\hline $93-2002$ & 577 & 596 & 438 & 678 & 309 & 443 & 470 & 332 & 521 & 583 & 535 & 450 & 494 & 0,450 \\
\hline $93-2027$ & 630 & 619 & 525 & 642 & 361 & 426 & 601 & 367 & 596 & 618 & 638 & 541 & 547 & 1,415 \\
\hline $93-2072$ & 339 & 556 & 497 & 357 & 290 & 550 & 357 & 158 & 531 & 730 & 633 & 308 & 442 & 6,343 \\
\hline $93-2084$ & 519 & 649 & 494 & 793 & 387 & 511 & 467 & 315 & 539 & 809 & 698 & 675 & 571 & 4,158 \\
\hline $93-2103$ & 583 & 648 & 558 & 594 & 368 & 532 & 555 & 360 & 625 & 652 & 636 & 437 & 546 & 0,508 \\
\hline $93-2104$ & 651 & 636 & 446 & 693 & 314 & 509 & 476 & 399 & 556 & 516 & 465 & 329 & 499 & 1,864 \\
\hline $93-2250$ & 494 & 519 & 514 & 405 & 301 & 334 & 573 & 229 & 555 & 611 & 670 & 497 & 475 & 4,996 \\
\hline $93-2259$ & 538 & 650 & 501 & 668 & 330 & 578 & 449 & 356 & 579 & 618 & 543 & 350 & 513 & 0,584 \\
\hline $93-2294$ & 654 & 626 & 486 & 586 & 311 & 503 & 525 & 397 & 594 & 478 & 476 & 266 & 492 & 2,770 \\
\hline $93-2302$ & 694 & 671 & 494 & 713 & 334 & 548 & 531 & 457 & 610 & 485 & 463 & 293 & 524 & 3,705 \\
\hline $93-2306$ & 575 & 617 & 493 & 573 & 315 & 514 & 490 & 345 & 578 & 563 & 533 & 323 & 493 & 0,659 \\
\hline $93-2316$ & 628 & 659 & 518 & 610 & 401 & 543 & 512 & 342 & 593 & 749 & 668 & 514 & 561 & 0,876 \\
\hline $93-2419$ & 513 & 529 & 338 & 511 & 235 & 437 & 321 & 232 & 436 & 538 & 431 & 266 & 399 & 0,593 \\
\hline $93-2475$ & 620 & 589 & 417 & 625 & 321 & 428 & 464 & 316 & 508 & 611 & 547 & 464 & 492 & 0,747 \\
\hline $93-2479$ & 546 & 636 & 480 & 740 & 315 & 522 & 469 & 371 & 559 & 576 & 523 & 400 & 511 & 0,659 \\
\hline $93-2529$ & 433 & 570 & 517 & 571 & 306 & 441 & 501 & 262 & 554 & 647 & 641 & 485 & 494 & 1,687 \\
\hline $93-2565$ & 528 & 530 & 359 & 448 & 262 & 432 & 347 & 213 & 451 & 596 & 491 & 311 & 414 & 0,988 \\
\hline $93-2667$ & 409 & 583 & 489 & 525 & 256 & 546 & 401 & 276 & 551 & 541 & 496 & 214 & 440 & 1,978 \\
\hline $93-2680$ & 110 & 613 & 614 & 695 & 281 & 632 & 385 & 216 & 585 & 746 & 682 & 427 & 499 & 11,667 \\
\hline $93-2693$ & 630 & 617 & 393 & 564 & 367 & 521 & 370 & 268 & 488 & 775 & 599 & 476 & 506 & 2,891 \\
\hline $93-2697$ & 419 & 611 & 450 & 813 & 322 & 496 & 391 & 279 & 490 & 739 & 620 & 596 & 519 & 4,592 \\
\hline $93-2699$ & 479 & 549 & 485 & 393 & 289 & 454 & 463 & 232 & 546 & 607 & 587 & 329 & 451 & 2,237 \\
\hline $93-2727$ & 557 & 577 & 436 & 536 & 304 & 458 & 441 & 281 & 518 & 611 & 549 & 385 & 471 & 0,324 \\
\hline $93-2756$ & 450 & 616 & 409 & 672 & 309 & 581 & 296 & 257 & 478 & 724 & 541 & 392 & 477 & 2,846 \\
\hline $93-2781$ & 523 & 530 & 406 & 542 & 236 & 383 & 446 & 282 & 492 & 461 & 456 & 306 & 422 & 0,624 \\
\hline $93-2790$ & 510 & 574 & 474 & 779 & 292 & 358 & 547 & 340 & 528 & 548 & 576 & 577 & 508 & 3,338 \\
\hline $93-2857$ & 532 & 600 & 408 & 796 & 283 & 456 & 419 & 343 & 490 & 557 & 483 & 446 & 484 & 1,962 \\
\hline $93-2858$ & 794 & 534 & 348 & 324 & 310 & 349 & 479 & 282 & 489 & 531 & 488 & 313 & 437 & 7,236 \\
\hline $93-2897$ & 548 & 633 & 530 & 816 & 319 & 452 & 611 & 618 & 497 & 624 & 335 & 467 & 537 & 2,305 \\
\hline $93-2909$ & 578 & 411 & 593 & 529 & 562 & 501 & 537 & 361 & 579 & 581 & 570 & 428 & 519 & 0,423 \\
\hline $93-2916$ & 604 & 585 & 525 & 437 & 345 & 432 & 573 & 302 & 596 & 622 & 642 & 431 & 508 & 2,810 \\
\hline $94-1017$ & 628 & 652 & 360 & 714 & 316 & 603 & 302 & 350 & 484 & 620 & 424 & 283 & 478 & 4,110 \\
\hline Média/ambiente & 538 & 599 & 471 & 622 & 318 & 489 & 463 & 324 & 541 & 606 & 546 & 401 & & \\
\hline $\mathrm{A}_{\mathrm{i}}(\%)$ /ambiente & 20,10 & 1,16 & 4,60 & 23,00 & 0,82 & 7,71 & 7,76 & 4,27 & 2,45 & 11,20 & 6,85 & 10,40 & & \\
\hline & & $\mathrm{ANH}$ & $\mathrm{EMBI}$ & & & $\mathrm{AR}$ & ais & & & & & & & \\
\hline Média/local & 558 & & & & 398 & & & & 523 & & & & & \\
\hline $\mathrm{A}_{\mathrm{i}}(\%) /$ local & 48,50 & & & & 20,60 & & & & 30,90 & & & & & \\
\hline
\end{tabular}


Tabela 35. Linhagens intermediárias: médias e interações preditas pelo modelo AMMI1 ( $\left.\mathrm{A}_{\mathrm{i}} \%\right)$ para linhagens, ambientes e locais, referentes aos caracteres produtividade de grãos (Kg/ha). Soja, semeaduras em 20/11/96, 16/11/97, 17/11/98, 23/11/99 (Anhembi), 12/11/96, 13/11/97, 05/11/98, 30/11/99 (Areão), 06/11/96, 12/11/97, 05/11/98, 08/11/99 (ESALQ). Piracicaba, SP.

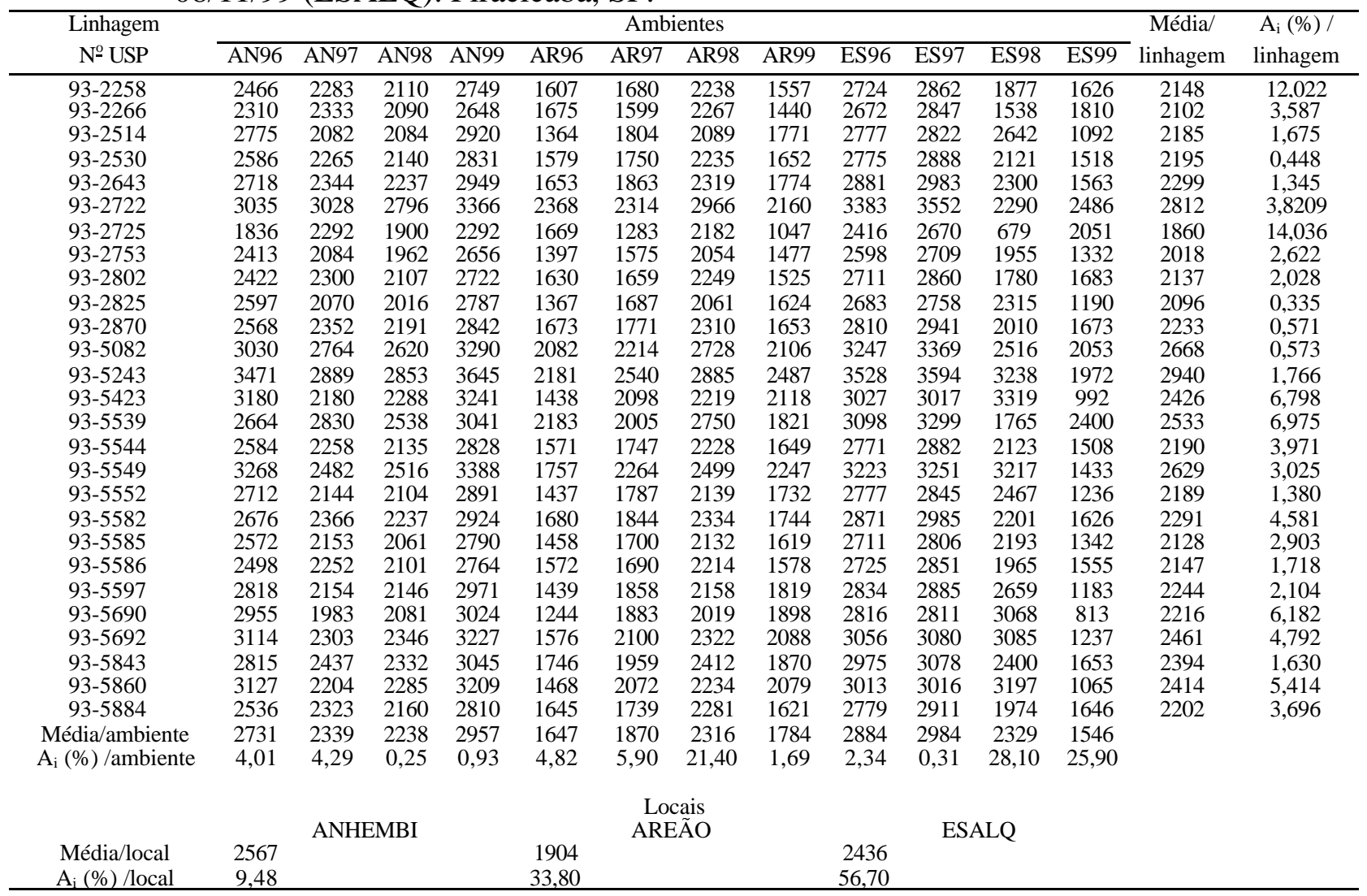


Tabela 36. Linhagens intermediárias: médias e interações preditas pelo modelo AMMI2 ( $\left.\mathrm{A}_{\mathrm{i}} \%\right)$ para linhagens, ambientes e locais, referentes ao caráter porcentagem de óleo (\%OL). Soja, semeaduras em 20/11/96, 16/11/97, 17/11/98, 23/11/99 (Anhembi), 12/11/96, 13/11/97, 05/11/98, 30/11/99 (Areão), 06/11/96, 12/11/97, 05/11/98, 08/11/99 (ESALQ). Piracicaba, SP.

\begin{tabular}{|c|c|c|c|c|c|c|c|c|c|c|c|c|c|c|}
\hline \multirow{2}{*}{$\begin{array}{c}\text { Linhagem } \\
\mathrm{N}^{\circ} \text { USP }\end{array}$} & \multicolumn{12}{|c|}{ Ambientes } & \multirow{2}{*}{$\begin{array}{l}\text { Média/ } \\
\text { linhagem }\end{array}$} & \multirow{2}{*}{$\begin{array}{c}\mathrm{A}_{\mathrm{i}}(\%) / \\
\text { linhagem }\end{array}$} \\
\hline & AN96 & AN97 & AN98 & AN99 & AR96 & AR97 & AR98 & AR99 & ES96 & ES97 & ES98 & ES99 & & \\
\hline $93-2258$ & 18 & 20 & 20 & 21 & 19 & 20 & 22 & 20 & 20 & 21 & 22 & 20 & 20,25 & 2,057 \\
\hline $93-2266$ & 18 & 20 & 20 & 23 & 19 & 20 & 22 & 21 & 19 & 21 & 22 & 20 & 20,42 & 0,568 \\
\hline $93-2514$ & 17 & 19 & 19 & 20 & 18 & 19 & 22 & 19 & 19 & 20 & 21 & 20 & 19,42 & 5,975 \\
\hline $93-2530$ & 17 & 20 & 19 & 22 & 18 & 19 & 21 & 20 & 19 & 20 & 21 & 20 & 19,67 & 1,303 \\
\hline $93-2643$ & 18 & 20 & 20 & 22 & 18 & 19 & 22 & 20 & 19 & 20 & 22 & 21 & 20,08 & 2,752 \\
\hline $93-2722$ & 17 & 20 & 19 & 22 & 18 & 18 & 21 & 20 & 18 & 20 & 21 & 21 & 19,58 & 4,221 \\
\hline $93-2725$ & 17 & 20 & 19 & 22 & 19 & 19 & 21 & 20 & 19 & 20 & 22 & 19 & 19,75 & 0,502 \\
\hline $93-2753$ & 17 & 19 & 19 & 21 & 18 & 19 & 21 & 20 & 19 & 20 & 21 & 19 & 19,42 & 0,092 \\
\hline $93-2802$ & 16 & 19 & 18 & 22 & 18 & 18 & 20 & 19 & 18 & 19 & 21 & 19 & 18,92 & 1,825 \\
\hline $93-2825$ & 17 & 20 & 19 & 23 & 19 & 20 & 21 & 21 & 20 & 21 & 22 & 19 & 20,12 & 8,283 \\
\hline $93-2870$ & 17 & 20 & 19 & 22 & 19 & 19 & 22 & 20 & 19 & 20 & 22 & 20 & 19,92 & 0,676 \\
\hline $93-5082$ & 18 & 20 & 20 & 22 & 19 & 20 & 22 & 20 & 20 & 21 & 22 & 21 & 20,42 & 0,881 \\
\hline $93-5243$ & 17 & 20 & 19 & 21 & 18 & 18 & 21 & 19 & 18 & 19 & 21 & 20 & 19,25 & 3,144 \\
\hline $93-5423$ & 18 & 19 & 20 & 21 & 19 & 20 & 22 & 20 & 20 & 21 & 22 & 20 & 20,17 & 4,178 \\
\hline $93-5539$ & 19 & 21 & 21 & 24 & 20 & 21 & 23 & 22 & 21 & 22 & 23 & 21 & 21,50 & 0,696 \\
\hline $93-5544$ & 18 & 21 & 20 & 22 & 19 & 19 & 22 & 20 & 19 & 20 & 22 & 22 & 20,33 & 4,564 \\
\hline $93-5549$ & 18 & 21 & 20 & 23 & 19 & 19 & 22 & 21 & 19 & 20 & 22 & 21 & 20,42 & 5,031 \\
\hline $93-5552$ & 19 & 21 & 21 & 22 & 20 & 21 & 23 & 21 & 20 & 22 & 23 & 21 & 21,17 & 1,102 \\
\hline $93-5582$ & 18 & 21 & 20 & 23 & 20 & 20 & 22 & 21 & 20 & 21 & 22 & 20 & 20,67 & 1,116 \\
\hline $93-5585$ & 17 & 20 & 19 & 24 & 20 & 20 & 21 & 21 & 20 & 21 & 22 & 19 & 20,33 & 5,866 \\
\hline $93-5586$ & 18 & 20 & 20 & 23 & 20 & 21 & 22 & 21 & 21 & 21 & 23 & 20 & 20,83 & 1,378 \\
\hline $93-5597$ & 18 & 21 & 20 & 23 & 20 & 20 & 23 & 21 & 20 & 21 & 23 & 21 & 20,92 & 0,439 \\
\hline $93-5690$ & 19 & 20 & 21 & 20 & 20 & 22 & 24 & 20 & 21 & 22 & 23 & 21 & 21,08 & 22,837 \\
\hline $93-5692$ & 18 & 20 & 20 & 23 & 19 & 19 & 22 & 21 & 19 & 20 & 22 & 20 & 20,25 & 1,871 \\
\hline $93-5843$ & 18 & 20 & 19 & 24 & 21 & 21 & 22 & 22 & 22 & 22 & 23 & 19 & 21,08 & 14,292 \\
\hline $93-5860$ & 19 & 21 & 21 & 24 & 21 & 22 & 23 & 22 & 22 & 22 & 24 & 21 & 21,83 & 2,530 \\
\hline $93-5884$ & 17 & 20 & 19 & 23 & 19 & 19 & 22 & 21 & 19 & 21 & 22 & 20 & 20,17 & 1,813 \\
\hline Média/ambiente & 17,70 & 20,10 & 19,70 & 22,30 & 19,10 & 19,70 & 21,90 & 20,50 & 19,60 & 20,70 & 22 & 20,19 & & \\
\hline $\mathrm{A}_{\mathrm{i}}(\%) /$ ambiente & 2,40 & 7,35 & 7,23 & 32,40 & 4,88 & 7,88 & 3,52 & 5,37 & 9,83 & 2,43 & 0,20 & 16,49 & & \\
\hline \multicolumn{15}{|c|}{ Locais } \\
\hline & \multirow{2}{*}{\multicolumn{4}{|c|}{$\begin{array}{c}\text { ANHEMBI } \\
19,90\end{array}$}} & \multicolumn{4}{|c|}{ AREÃO } & \multicolumn{4}{|c|}{ ESALQ } & & \\
\hline Média/local & & & & & \multirow{2}{*}{\multicolumn{4}{|c|}{$\begin{array}{l}20,30 \\
21,60\end{array}$}} & \multirow{2}{*}{\multicolumn{4}{|c|}{$\begin{array}{l}20,60 \\
29,00\end{array}$}} & & \\
\hline $\mathrm{A}_{\mathrm{i}}(\%) /$ local & \multicolumn{4}{|c|}{49,30} & & & & & & & & & & \\
\hline
\end{tabular}


Tabela 37. Linhagens intermediárias: médias e interações preditas pelo modelo AMMI2 ( $\left.\mathrm{A}_{\mathrm{i}} \%\right)$ para linhagens, ambientes e locais, referentes ao caráter produtividade de óleo (Kg/ha). Soja, semeaduras em 20/11/96, 16/11/97, 17/11/98, 23/11/99 (Anhembi), 12/11/96, 13/11/97, 05/11/98, 30/11/99 (Areão), 06/11/96, 12/11/97, 05/11/98, 08/11/99 (ESALQ). Piracicaba, SP.

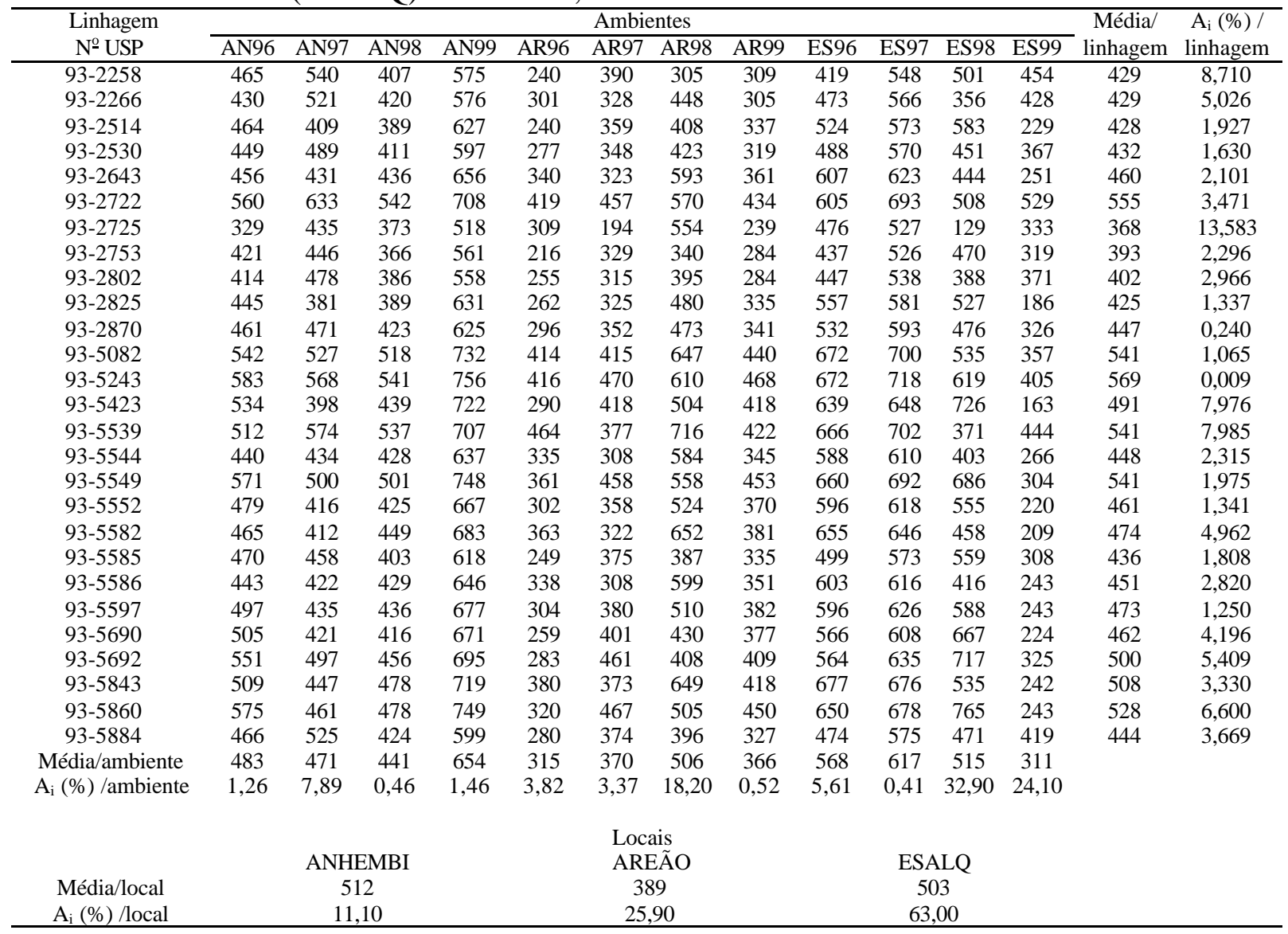


Tabela 38. Linhagens semitardias: médias e interações preditas pelo modelo AMMI1 $\left(\mathrm{A}_{\mathrm{i}} \%\right)$ para linhagens, ambientes e locais, referentes aos caracteres produtividade de grãos (PG), porcentagem de óleo (\%OL) e produtividade de óleo (PO). Soja, semeaduras em 20/11/96, 16/11/97, 17/11/98, 23/11/99 (Anhembi), 12/11/96, 13/11/97, 05/11/98, 30/11/99 (Areão), 06/11/96, 12/11/97, 05/11/98, 08/11/99 (ESALQ). Piracicaba, SP.

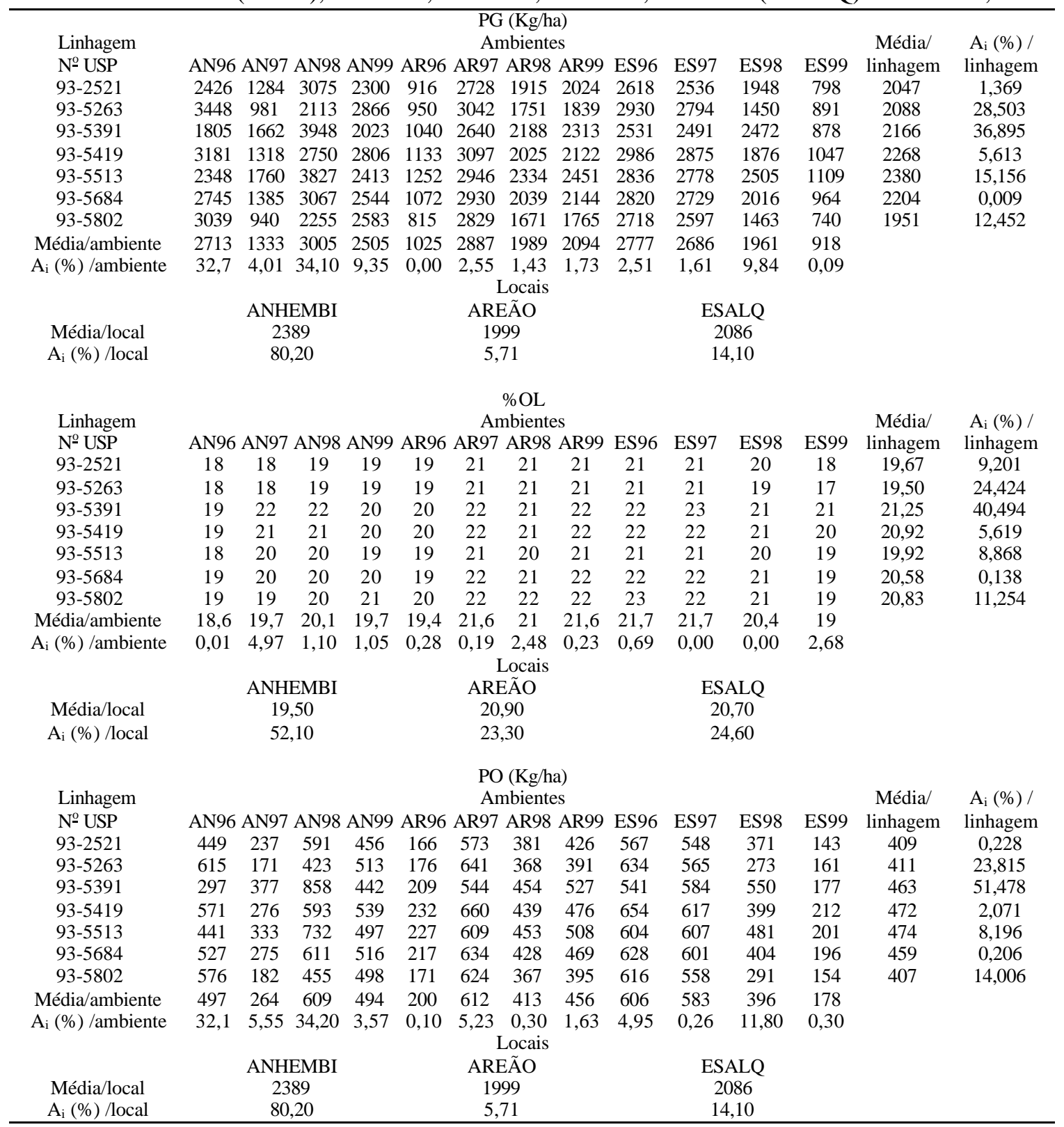


Tabela 39. Linhagens Precoces e Semiprecoces: coeficientes de correlação de Spearman entre parâmetros de adaptabilidade e estabilidade estimados pelos métodos da ecovalência $\left(\omega_{i}\right)$, Eberhart \& Russel (média: $\mathrm{m}_{i}$; coeficiente de regressão: $b_{i}$; variância dos desvios da regressão: $s^{2} d_{i}$; coeficiente de determinação: $\mathrm{R}^{2}$ ) e AMMI (interação predita pelo modelo AMMI selecionado: $\mathrm{A}$ ), referentes aos caracteres produtividade de grãos (PG), porcentagem de óleo (\%OL) e produtividade de óleo (PO). Soja, semeaduras em 20/11/96, 16/11/97, 17/11/98, 23/11/99 (Anhembi), 12/11/96, 13/11/97, 05/11/98, 30/11/99 (Areão), 06/11/96, 12/11/97, 05/11/98, 08/11/99 (ESALQ). Piracicaba, SP.

\begin{tabular}{|c|c|c|c|c|c|c|}
\hline \multirow[b]{2}{*}{ Parâmetro } & \multicolumn{6}{|c|}{ LINHAGENS PRECOCES } \\
\hline & $\mathrm{m}_{\mathrm{i}}$ & $\omega_{i}$ & $b_{i}$ & $\mathrm{~s}^{2} \mathrm{~d}_{\mathrm{i}}$ & $\mathrm{R}^{2}$ & $\mathrm{~A}_{\mathrm{i}}(\mathrm{AMMI} 4)$ \\
\hline $\mathrm{m}_{\mathrm{i}}$ & - & $0,01^{\mathrm{ns}}$ & $0,21^{\mathrm{ns}}$ & $-0,15^{\mathrm{ns}}$ & $0,08^{\mathrm{ns}}$ & $0,03^{\mathrm{ns}}$ \\
\hline$\omega_{\mathrm{i}}$ & & & $-0,18^{\mathrm{ns}}$ & $0,91 * *$ & $0,80 * *$ & $0,84 * *$ \\
\hline $\mathrm{b}_{\mathrm{i}}$ & & & - & $-0,31^{\mathrm{ns}}$ & $0,39 *$ & $-0,24^{\mathrm{ns}}$ \\
\hline $\mathrm{s}^{2} \mathrm{~d}_{\mathrm{i}}$ & & & & - & $0,63 * *$ & $0,79 * *$ \\
\hline $\mathrm{R}^{2}$ & & & & & - & $0,66^{* * *}$ \\
\hline Parâmetro & $\mathrm{m}_{\mathrm{i}}$ & $\omega_{\mathrm{i}}$ & $b_{i}$ & $\begin{array}{c}\% \mathrm{OL} \\
\mathrm{s}^{2} \mathrm{~d}_{\mathrm{i}}\end{array}$ & $\mathrm{R}^{2}$ & $\mathrm{~A}_{\mathrm{i}}(\mathrm{AMMI} 1)$ \\
\hline $\mathrm{m}_{\mathrm{i}}$ & - & $-0,28^{\mathrm{ns}}$ & $-0,12^{\text {ns }}$ & $-0,28^{\mathrm{ns}}$ & $0,38 *$ & $-0,24^{\text {ns }}$ \\
\hline$\omega_{\mathrm{i}}$ & & - & $-0,06^{\mathrm{ns}}$ & $0,99 * *$ & $0,82 * *$ & $0,71 * *$ \\
\hline$b_{i}$ & & & - & $-0,05^{\mathrm{ns}}$ & $-0,06^{\mathrm{ns}}$ & $0,15^{\mathrm{ns}}$ \\
\hline $\mathrm{s}^{2} \mathrm{~d}_{\mathrm{i}}$ & & & & - & $0,83^{* *}$ & $0,71 * *$ \\
\hline $\mathrm{R}^{2}$ & & & & & - & $0,54 * *$ \\
\hline & & & & $\mathrm{PO}(\mathrm{Kg} / \mathrm{ha}$ & & \\
\hline Parâmetro & $\mathrm{m}_{\mathrm{i}}$ & $\omega_{\mathrm{i}}$ & $b_{i}$ & $\mathrm{~s}^{2} \mathrm{~d}_{\mathrm{i}}$ & $\mathrm{R}^{2}$ & $\mathrm{~A}_{\mathrm{i}}$ (AMMI4) \\
\hline $\mathrm{m}_{\mathrm{i}}$ & - & $0,17^{\mathrm{ns}}$ & $0,22^{\mathrm{ns}}$ & $0,06^{\mathrm{ns}}$ & $0,23^{\mathrm{ns}}$ & $0,24^{\mathrm{ns}}$ \\
\hline$\omega_{\mathrm{i}}$ & & - & $-0,13^{\text {ns }}$ & $0,92 * *$ & $0,75^{* *}$ & $0,89 * *$ \\
\hline$b_{i}$ & & & - & $-0,19^{\mathrm{ns}}$ & $0,49 * *$ & $-0,11^{\mathrm{ns}}$ \\
\hline $\mathrm{s}^{2} \mathrm{~d}_{\mathrm{i}}$ & & & & - & $0,66^{* *}$ & $0,88^{* *}$ \\
\hline $\mathrm{R}^{2}$ & & & & & - & $0,69 * *$ \\
\hline & & & LIN & INS SEMIP & & \\
\hline & & & & PG (Kg/ha) & & \\
\hline Parâmetro & $\mathrm{m}_{\mathrm{i}}$ & $\omega_{\mathrm{i}}$ & $b_{i}$ & $\mathrm{~s}^{2} \mathrm{~d}_{\mathrm{i}}$ & $\mathrm{R}^{2}$ & $\mathrm{~A}_{\mathrm{i}}$ (AMMI4) \\
\hline $\mathrm{m}_{\mathrm{i}}$ & - & $0,09^{\mathrm{ns}}$ & $0,17^{\mathrm{ns}}$ & $0,08^{\mathrm{ns}}$ & $0,12^{\mathrm{ns}}$ & $0,05^{\mathrm{ns}}$ \\
\hline$\omega_{\mathrm{i}}$ & & & $-0,25^{\mathrm{ns}}$ & $0,97 * *$ & $0,81 * *$ & $0,89 * *$ \\
\hline$b_{i}$ & & & - & $-0,29^{\mathrm{ns}}$ & $0,28^{\mathrm{ns}}$ & $-0,28^{\mathrm{ns}}$ \\
\hline $\mathrm{s}^{2} \mathrm{~d}_{\mathrm{i}}$ & & & & - & $0,80 * *$ & $0,89 * *$ \\
\hline $\mathrm{R}^{2}$ & & & & & - & $0,72 * *$ \\
\hline Parâmetro & $\mathrm{m}_{\mathrm{i}}$ & $\omega_{i}$ & $b_{i}$ & $\begin{array}{c}\% \mathrm{OL} \\
\mathrm{s}^{2} \mathrm{~d}_{\mathrm{i}}\end{array}$ & $\mathrm{R}^{2}$ & $\mathrm{~A}_{\mathrm{i}}(\mathrm{AMMI} 1)$ \\
\hline $\mathrm{m}_{\mathrm{i}}$ & - & $-0,25^{\mathrm{ns}}$ & $0,07^{\mathrm{ns}}$ & $-0,20^{\mathrm{ns}}$ & $-0,14^{\mathrm{ns}}$ & $-0,19^{\mathrm{ns}}$ \\
\hline$\omega_{\mathrm{i}}$ & & - & $-0,03^{\mathrm{ns}}$ & $0,98^{* *}$ & $0,81 * *$ & $0,59 * *$ \\
\hline$b_{i}$ & & & - & $-0,02^{\mathrm{ns}}$ & $0,34^{\mathrm{ns}}$ & $0,11^{\mathrm{ns}}$ \\
\hline $\mathrm{s}^{2} \mathrm{~d}_{\mathrm{i}}$ & & & & - & $0,84 * *$ & $0,57 * *$ \\
\hline $\mathrm{R}^{2}$ & & & & & - & $0,54 * *$ \\
\hline & & & & $\mathrm{PO}(\mathrm{Kg} / \mathrm{ha})$ & & \\
\hline Parâmetro & $\mathrm{m}_{\mathrm{i}}$ & $\omega_{\mathrm{i}}$ & $b_{i}$ & $\mathrm{~s}^{2} \mathrm{~d}_{\mathrm{i}}$ & $\mathrm{R}^{2}$ & $\mathrm{~A}_{\mathrm{i}}(\mathrm{AMMI} 4)$ \\
\hline $\mathrm{m}_{\mathrm{i}}$ & - & $0,06^{\mathrm{ns}}$ & $0,31^{\mathrm{ns}}$ & $0,11^{\mathrm{ns}}$ & $0,19^{\mathrm{ns}}$ & $-0,01^{\mathrm{ns}}$ \\
\hline$\omega_{\mathrm{i}}$ & & - & $-0,31^{\mathrm{ns}}$ & $0,93^{* *}$ & $0,83 * *$ & $0,91 * *$ \\
\hline$b_{i}$ & & & - & $-0,25^{\mathrm{ns}}$ & $0,19^{\mathrm{ns}}$ & $-0,39^{\mathrm{ns}}$ \\
\hline $\mathrm{s}^{2} \mathrm{~d}_{\mathrm{i}}$ & & & & - & $0,75^{* *}$ & $0,86^{* *}$ \\
\hline $\mathrm{R}^{2}$ & & & & & - & $0,67 * *$ \\
\hline
\end{tabular}

***: significativo ao nível de $5 \%$ e $1 \%$ de probabilidade, respectivamente, pelo teste t. ns: não significativo pelo teste $\mathrm{t}$. 
Tabela 40. Linhagens Intermediárias e Semitardias: coeficientes de correlação de Spearman entre parâmetros de adaptabilidade e estabilidade estimados pelos métodos da ecovalência $\left(\omega_{i}\right)$, Eberhart \& Russel (média: n; coeficiente de regressão: $b_{1}$; variância dos desvios da regressão: $s^{2} d_{i}$; coeficiente de determinação: $\mathrm{R}^{2}$ ) e AMMI (interação predita pelo modelo AMMI selecionado: $\mathrm{A}_{\mathrm{i}}$ ), referentes aos caracteres produtividade de grãos (PG), porcentagem de óleo (\%OL) e produtividade de óleo (PO). Soja, semeaduras em 20/11/96, 16/11/97, 17/11/98, 23/11/99 (Anhembi), 12/11/96, 13/11/97, 05/11/98, 30/11/99 (Areão), 06/11/96, 12/11/97, 05/11/98, 08/11/99 (ESALQ). Piracicaba, SP.

\begin{tabular}{|c|c|c|c|c|c|c|}
\hline \multirow[b]{3}{*}{ Parâmetro } & \multicolumn{6}{|c|}{ LINHAGENS INTERMEDIÁRIAS } \\
\hline & \multicolumn{6}{|c|}{ PG (Kg/ha) } \\
\hline & $\mathrm{m}_{\mathrm{i}}$ & $\omega_{\mathrm{i}}$ & $b_{i}$ & $\mathrm{~s}^{2} \mathrm{~d}_{\mathrm{i}}$ & $\mathrm{R}^{2}$ & $\mathrm{~A}_{\mathrm{i}}(\mathrm{AMMI} 1)$ \\
\hline $\mathrm{m}_{\mathrm{i}}$ & - & $0,01^{\mathrm{ns}}$ & $0,62 * *$ & $0,02^{\text {ns }}$ & $0,47 *$ & $-0,17^{\mathrm{ns}}$ \\
\hline$\omega_{\mathrm{i}}$ & & - & $0,17^{\mathrm{ns}}$ & $0,97 * *$ & $0,66^{* *}$ & $0,61 * *$ \\
\hline $\mathrm{b}_{\mathrm{i}}$ & & & - & $0,17^{\mathrm{ns}}$ & $0,78^{* *}$ & $0,02^{\mathrm{ns}}$ \\
\hline $\mathrm{s}^{2} \mathrm{~d}_{\mathrm{i}}$ & & & & - & $0,69 * *$ & $0,59 * *$ \\
\hline \multirow[t]{2}{*}{$\mathrm{R}^{2}$} & & & & & - & $0,29^{\mathrm{ns}}$ \\
\hline & & & & $\% \mathrm{OL}$ & & \\
\hline Parâmetro & $\mathrm{m}_{\mathrm{i}}$ & $\omega_{\mathrm{i}}$ & $b_{i}$ & $\mathrm{~s}^{2} \mathrm{~d}_{\mathrm{i}}$ & $\mathrm{R}^{2}$ & $\mathrm{~A}_{\mathrm{i}}(\mathrm{AMMI})$ \\
\hline $\mathrm{m}_{\mathrm{i}}$ & - & $-0,20^{\mathrm{ns}}$ & $0,24^{\mathrm{ns}}$ & $-0,15^{\mathrm{ns}}$ & $-0,28^{\mathrm{ns}}$ & $-0,05^{\mathrm{ns}}$ \\
\hline$\omega_{\mathrm{i}}$ & & - & $-0,29^{\mathrm{ns}}$ & $0,96 * *$ & $0,84 * *$ & $0,83 * *$ \\
\hline$b_{i}$ & & & - & $-0,26^{\mathrm{ns}}$ & $-0,17^{\text {ns }}$ & $-0,22^{\mathrm{ns}}$ \\
\hline $\mathrm{s}^{2} \mathrm{~d}_{\mathrm{i}}$ & & & & - & $0,90 * *$ & $0,85 * *$ \\
\hline \multirow[t]{2}{*}{$\mathrm{R}^{2}$} & & & & & - & $0,63 * *$ \\
\hline & & & & $\mathrm{PO}(\mathrm{Kg} / \mathrm{ha}$ & & \\
\hline Parâmetro & $\mathrm{m}_{\mathrm{i}}$ & $\omega_{\mathrm{i}}$ & $b_{i}$ & $\mathrm{~s}^{2} \mathrm{~d}_{\mathrm{i}}$ & $\mathrm{R}^{2}$ & $\mathrm{~A}_{\mathrm{i}}(\mathrm{AMMI} 2)$ \\
\hline $\mathrm{m}_{\mathrm{i}}$ & - & $0,15^{\mathrm{ns}}$ & $0,66^{* *}$ & $0,15^{\mathrm{ns}}$ & $0,58 * *$ & $0,05^{\mathrm{ns}}$ \\
\hline$\omega_{\mathrm{i}}$ & & - & $0,16^{\mathrm{ns}}$ & $0,89 * *$ & $0,54 * *$ & $0,59 * *$ \\
\hline$b_{i}$ & & & - & $0,27^{\mathrm{ns}}$ & $0,89 * *$ & $0,36^{\mathrm{ns}}$ \\
\hline $\mathrm{s}^{2} \mathrm{~d}_{\mathrm{i}}$ & & & & - & $0,62 * *$ & $0,56^{* *}$ \\
\hline \multirow[t]{3}{*}{$\mathrm{R}^{2}$} & & & & & - & $0,53 * *$ \\
\hline & \multicolumn{6}{|c|}{ LINHAGENS SEMITARDIAS } \\
\hline & & & & PG $(\mathrm{Kg} / \mathrm{ha})$ & & \\
\hline Parâmetro & $\mathrm{m}_{\mathrm{i}}$ & $\omega_{\mathrm{i}}$ & $b_{i}$ & $\mathrm{~s}^{2} \mathrm{~d}_{\mathrm{i}}$ & $\mathrm{R}^{2}$ & $\mathrm{~A}_{\mathrm{i}}($ AMMI1) \\
\hline $\mathrm{m}_{\mathrm{i}}$ & - & $-0,36^{\mathrm{ns}}$ & $0,32^{\mathrm{ns}}$ & $-0,36^{\mathrm{ns}}$ & $0,03^{\mathrm{ns}}$ & $0,00^{\mathrm{ns}}$ \\
\hline$\omega_{\mathrm{i}}$ & & - & $0,53^{\mathrm{ns}}$ & $1,00^{* *}$ & $0,89 * *$ & $0,75^{*}$ \\
\hline $\mathrm{b}_{\mathrm{i}}$ & & & - & $0,53^{\mathrm{ns}}$ & $0,71^{\mathrm{ns}}$ & $0,28^{\mathrm{ns}}$ \\
\hline $\mathrm{s}^{2} \mathrm{~d}_{\mathrm{i}}$ & & & & - & $0,89 * *$ & $0,75^{*}$ \\
\hline \multirow[t]{2}{*}{$\mathrm{R}^{2}$} & & & & & - & $0,75^{*}$ \\
\hline & & & & $\% \mathrm{OL}$ & & \\
\hline Parâmetro & $\mathrm{m}_{\mathrm{i}}$ & $\omega_{\mathrm{i}}$ & $b_{i}$ & $s^{2} d_{i}$ & $\mathrm{R}^{2}$ & $\mathrm{~A}_{\mathrm{i}}(\mathrm{AMMI} 1)$ \\
\hline $\mathrm{m}_{\mathrm{i}}$ & - & $-0,07^{\mathrm{ns}}$ & $-0,89 * *$ & $-0,68^{\mathrm{ns}}$ & $-0,75^{\mathrm{ns}}$ & $-0,14^{\mathrm{ns}}$ \\
\hline$\omega_{\mathrm{i}}$ & & - & $0,18^{\mathrm{ns}}$ & $0,41^{\mathrm{ns}}$ & $0,41^{\mathrm{ns}}$ & $0,77^{*}$ \\
\hline $\mathrm{b}_{\mathrm{i}}$ & & & - & $0,71^{\mathrm{ns}}$ & $0,93 * *$ & $0,14^{\mathrm{ns}}$ \\
\hline $\mathrm{S}_{\mathrm{di}}^{2}$ & & & & - & $0,86^{* *}$ & $0,36^{\mathrm{ns}}$ \\
\hline \multirow[t]{2}{*}{$\mathrm{R}^{2}$} & & & & & - & $0,28^{\mathrm{ns}}$ \\
\hline & & & & $\mathrm{PO}(\mathrm{Kg} / \mathrm{ha})$ & & \\
\hline Parâmetro & $\mathrm{m}_{\mathrm{i}}$ & $\omega_{\mathrm{i}}$ & $b_{i}$ & $\mathrm{~s}^{2} \mathrm{~d}_{\mathrm{i}}$ & $\mathrm{R}^{2}$ & $\mathrm{~A}_{\mathrm{i}}(\mathrm{AMMI} 1)$ \\
\hline $\mathrm{m}_{\mathrm{i}}$ & - & $-0,64^{\mathrm{ns}}$ & $0,28^{\mathrm{ns}}$ & $-0,64^{\mathrm{ns}}$ & $-0,18^{\mathrm{ns}}$ & $0,00^{\mathrm{ns}}$ \\
\hline$\omega_{\mathrm{i}}$ & & - & $0,32^{\mathrm{ns}}$ & $1,00^{* *}$ & $0,85 * *$ & $0,64^{\mathrm{ns}}$ \\
\hline $\mathrm{b}_{\mathrm{i}}$ & & & - & $0,32^{\mathrm{ns}}$ & $-0,25^{\mathrm{ns}}$ & $0,28^{\text {ns }}$ \\
\hline $\mathrm{s}^{2} \mathrm{~d}_{\mathrm{i}}$ & & & & - & $0,85^{* *}$ & $0,64^{\mathrm{ns}}$ \\
\hline $\mathrm{R}^{2}$ & & & & & - & $0,78^{*}$ \\
\hline
\end{tabular}

***: significativo ao nível de $5 \%$ e $1 \%$ de probabilidade, respectivamente, pelo teste $\mathrm{t}$. ns: não significativo pelo teste $\mathrm{t}$. 

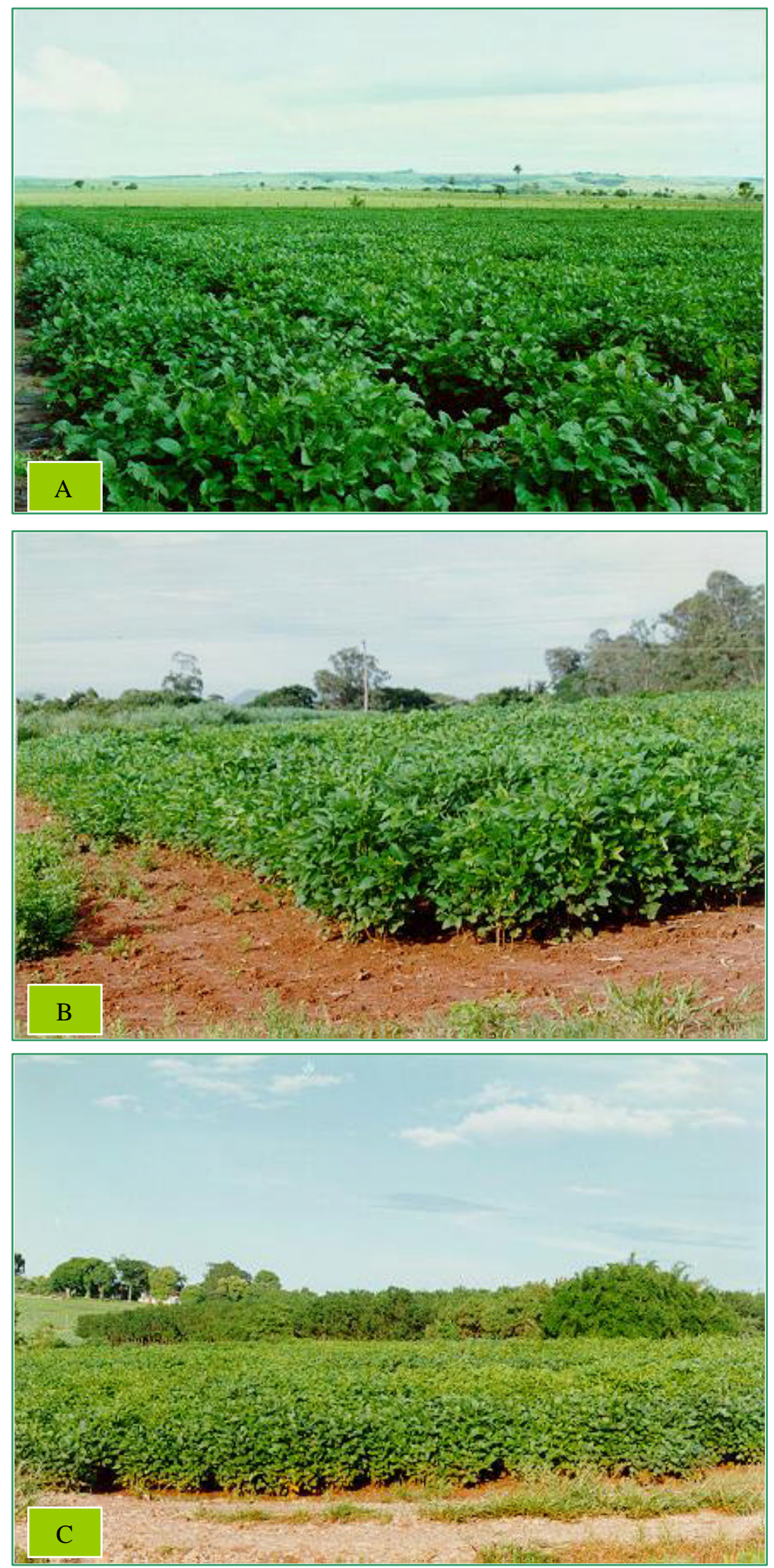

Figura 1 - Vista panorâmica dos locais de avaliação dos experimentos. A: local Anhembi; B: local Areão; C: local ESALQ. Soja, Piracicaba, SP. 

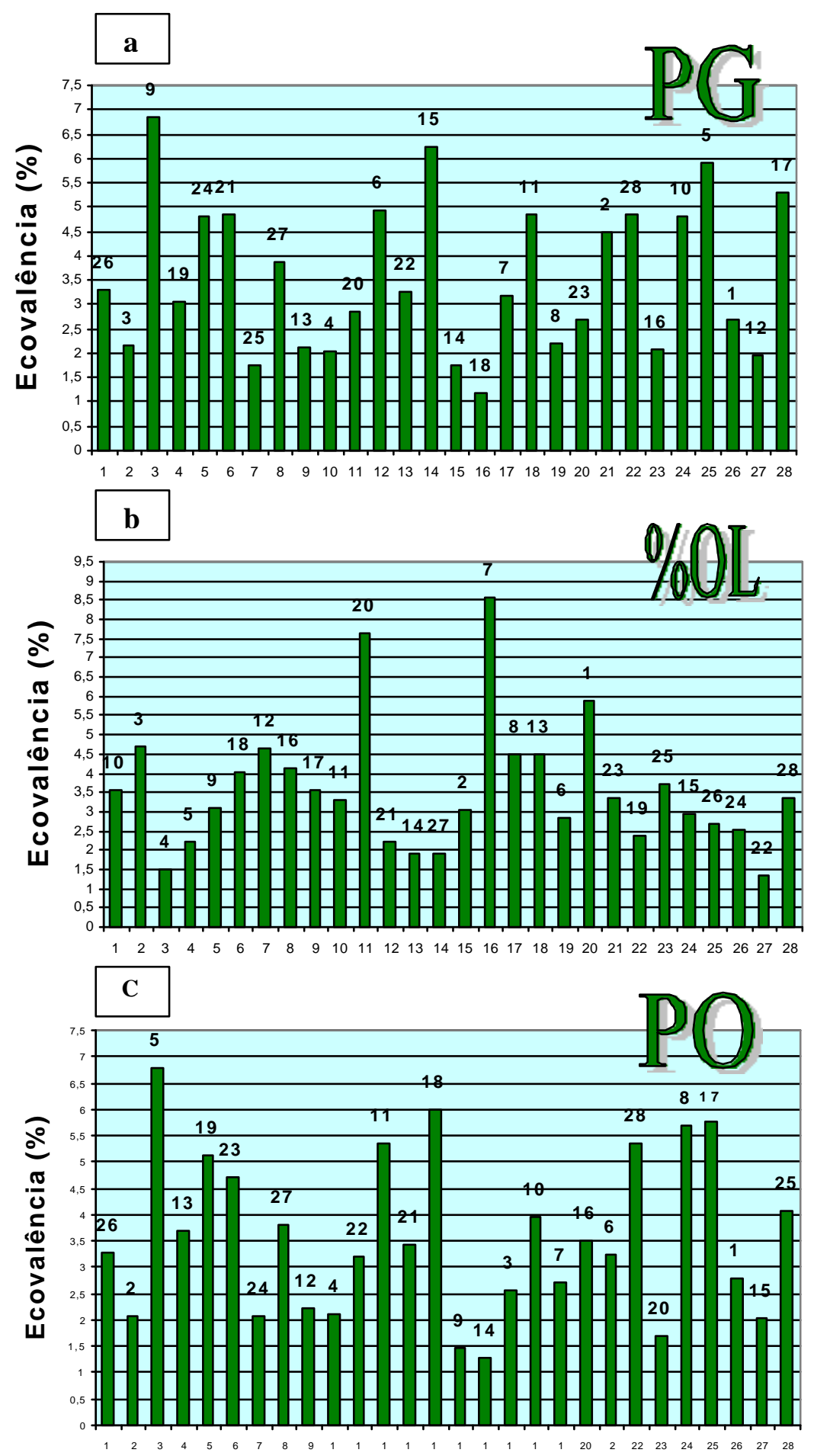

Linhagens precoces

Figura 2 - Linhagens Precoces: ecovalências estimadas pelo método de Wricke para médias de 28 linhagens obtidas em 12 ambientes, referentes aos seguintes caracteres: a) produtividade de grãos (PG); b) porcentagem de óleo (\%OL); e c) produtividade de óleo (PO). $\mathrm{N}^{\mathrm{o}}$ acima da coluna representa a classificação da linhagem com base na média. Soja, Piracicaba, SP. 

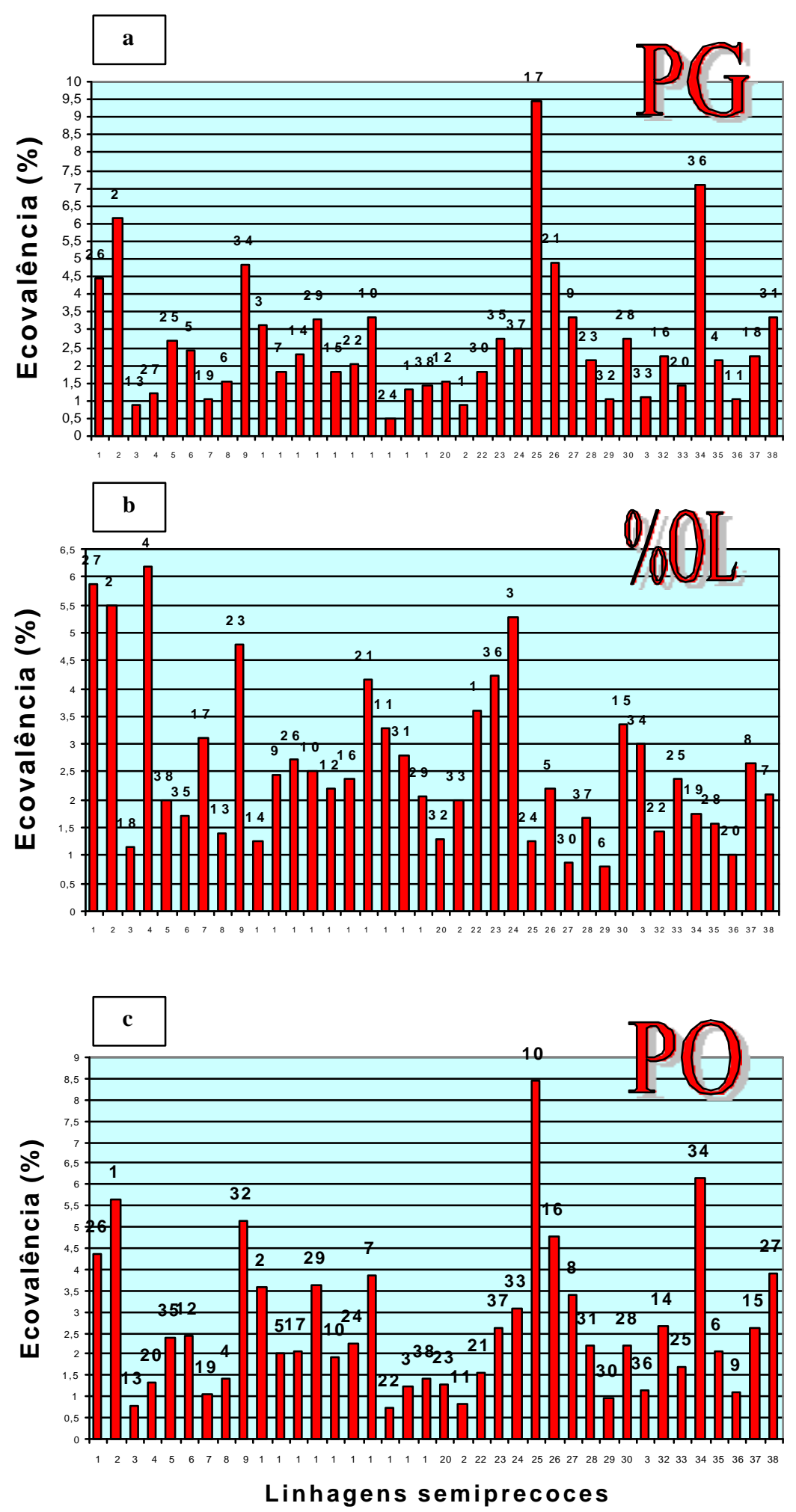

Figura 3 - Linhagens Semiprecoces: ecovalências estimadas pelo método de Wricke para médias de 38 linhagens obtidas em 12 ambientes, referentes aos seguintes caracteres: a) produtividade de grãos (PG); b) porcentagem de óleo (\%OL); e c) produtividade de óleo (PO). № acima da coluna representa a classificação da linhagem com base na média. Soja, Piracicaba, SP. 

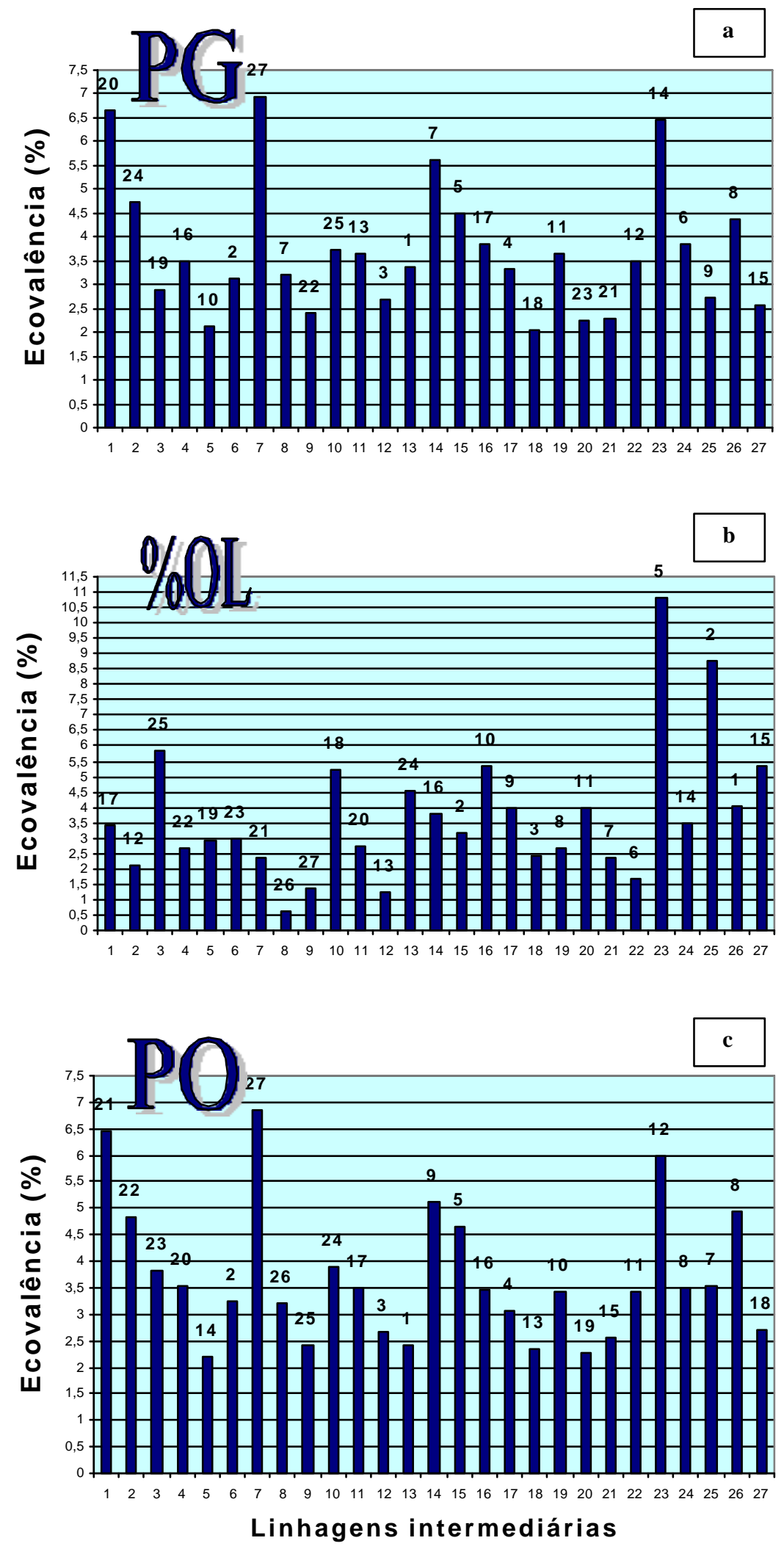

Figura 4 - Linhagens Intermediárias: ecovalências estimadas pelo método de Wricke para médias de 27 linhagens obtidas em 12 ambientes, referentes aos seguintes caracteres: a) produtividade de grãos (PG); b) porcentagem de óleo (\%OL); e c) produtividade de óleo (PO). № acima da coluna representa a classificação da linhagem com base na média. Soja, Piracicaba, SP. 

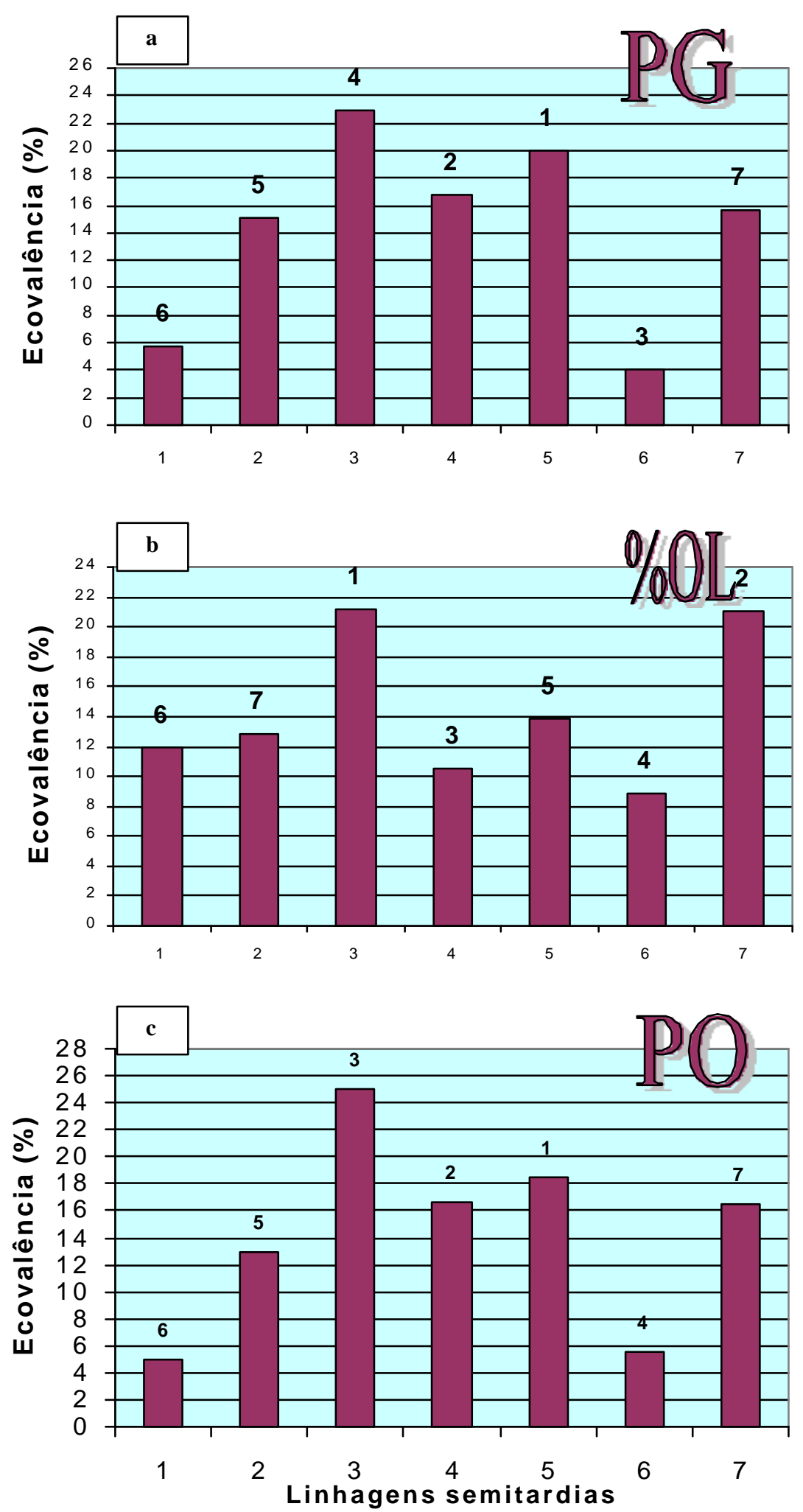

Figura 5 - Linhagens Semitardias: ecovalências estimadas pelo método de Wricke para médias de sete linhagens obtidas em 12 ambientes, referentes aos seguintes caracteres: a) produtividade de grãos (PG); b) porcentagem de óleo (\%OL); e c) produtividade de óleo $(\mathrm{PO})$. № acima da coluna representa a classificação da linhagem com base na média. Soja, Piracicaba, SP. 

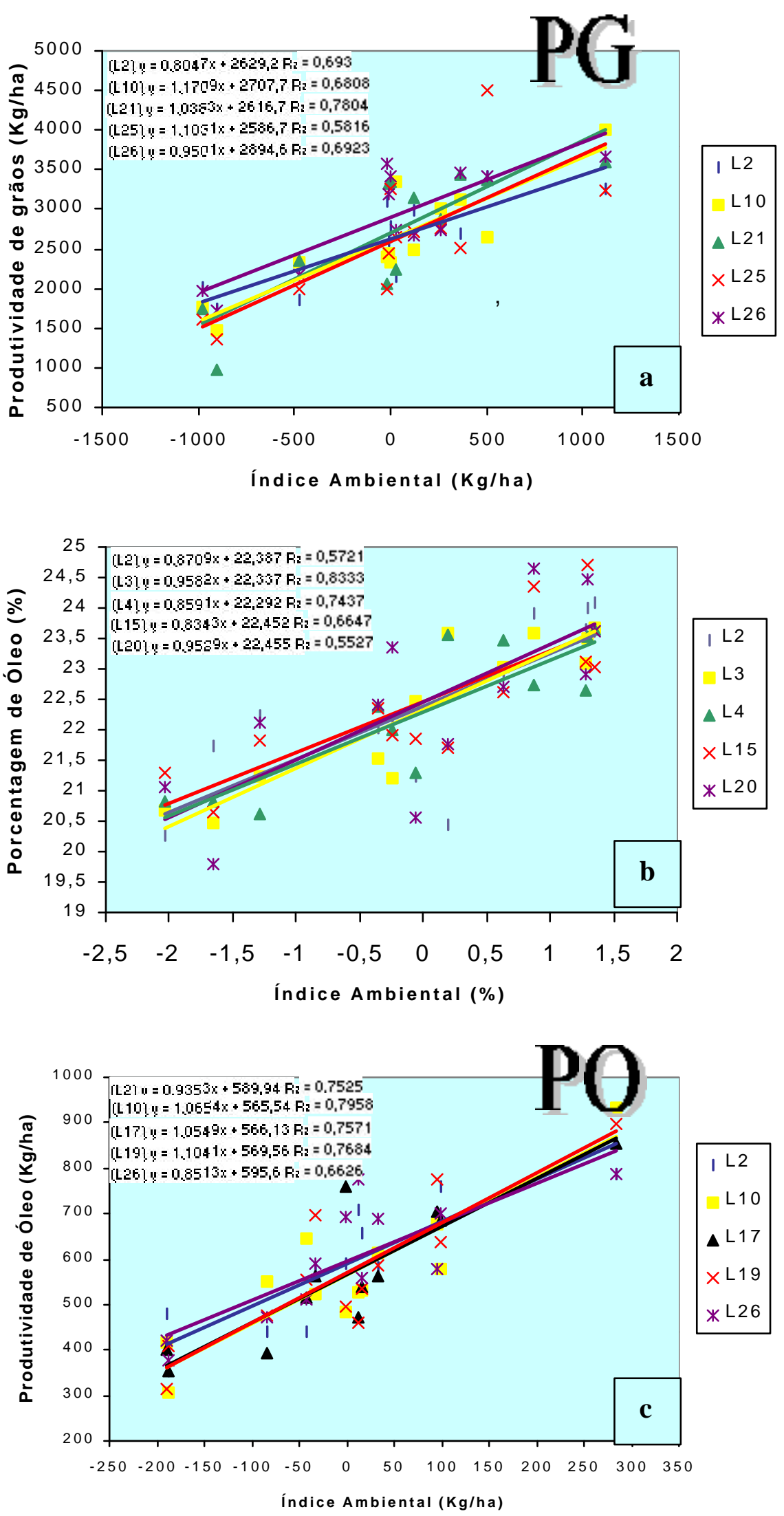

Figura 6 - Linhagens Precoces: linhas de regressão das cinco linhagens mais produtivas avaliadas em doze ambientes para: a) produtividade de grãos ( $\mathrm{PG})$; b) porcentagem de óleo (\%OL); e c) produtividade de óleo (PO), estimadas pelo método de Eberhart \& Russel (1966). 

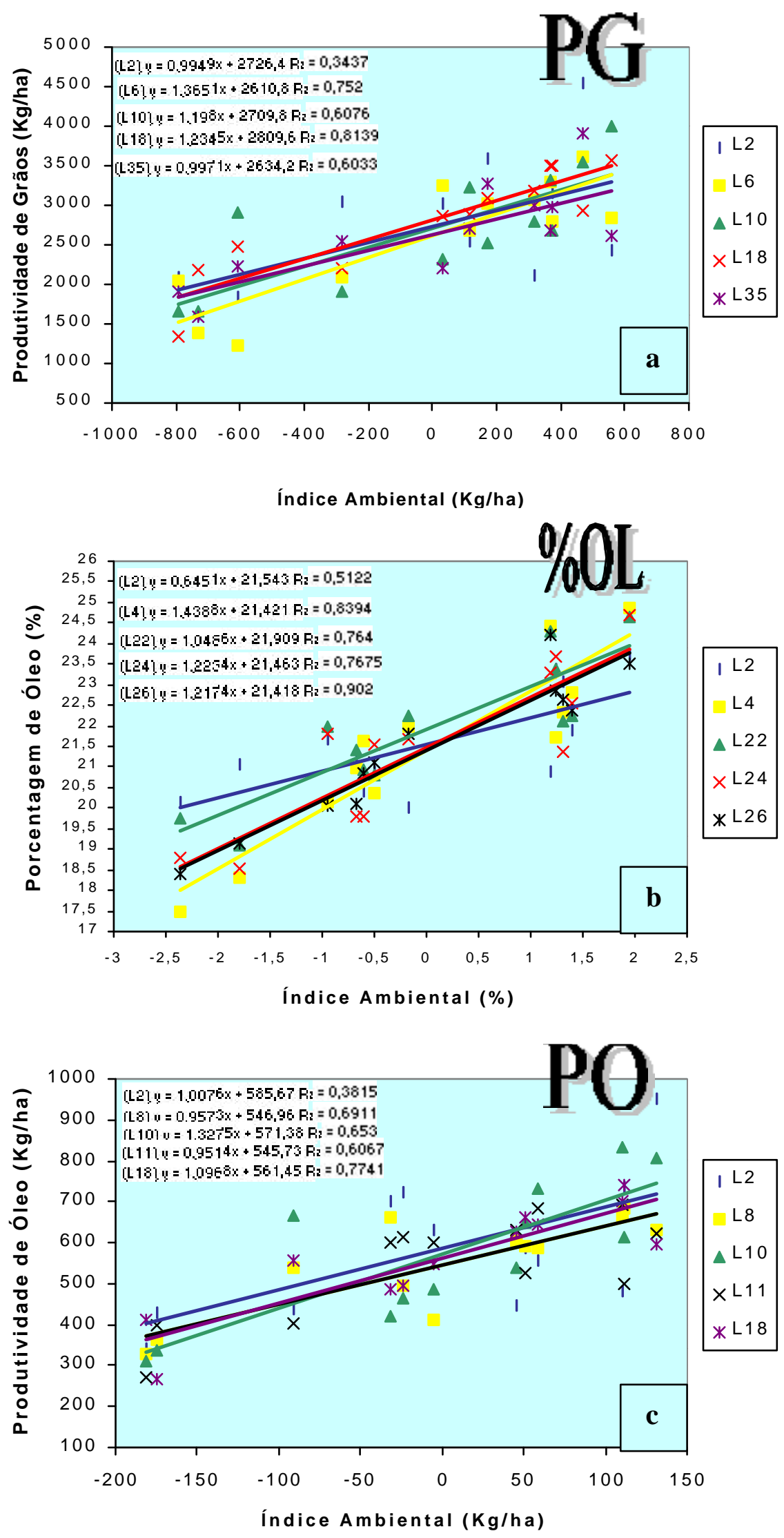

Figura 7 - Linhagens Semiprecoces: linhas de regressão das cinco melhores linhagens avaliadas em doze ambientes para: a) produtividade de grãos (PG); b) porcentagem de óleo (\%); e c) produtividade de óleo (PO), estimadas pelo método de Eberhart \& Russel (1966). 

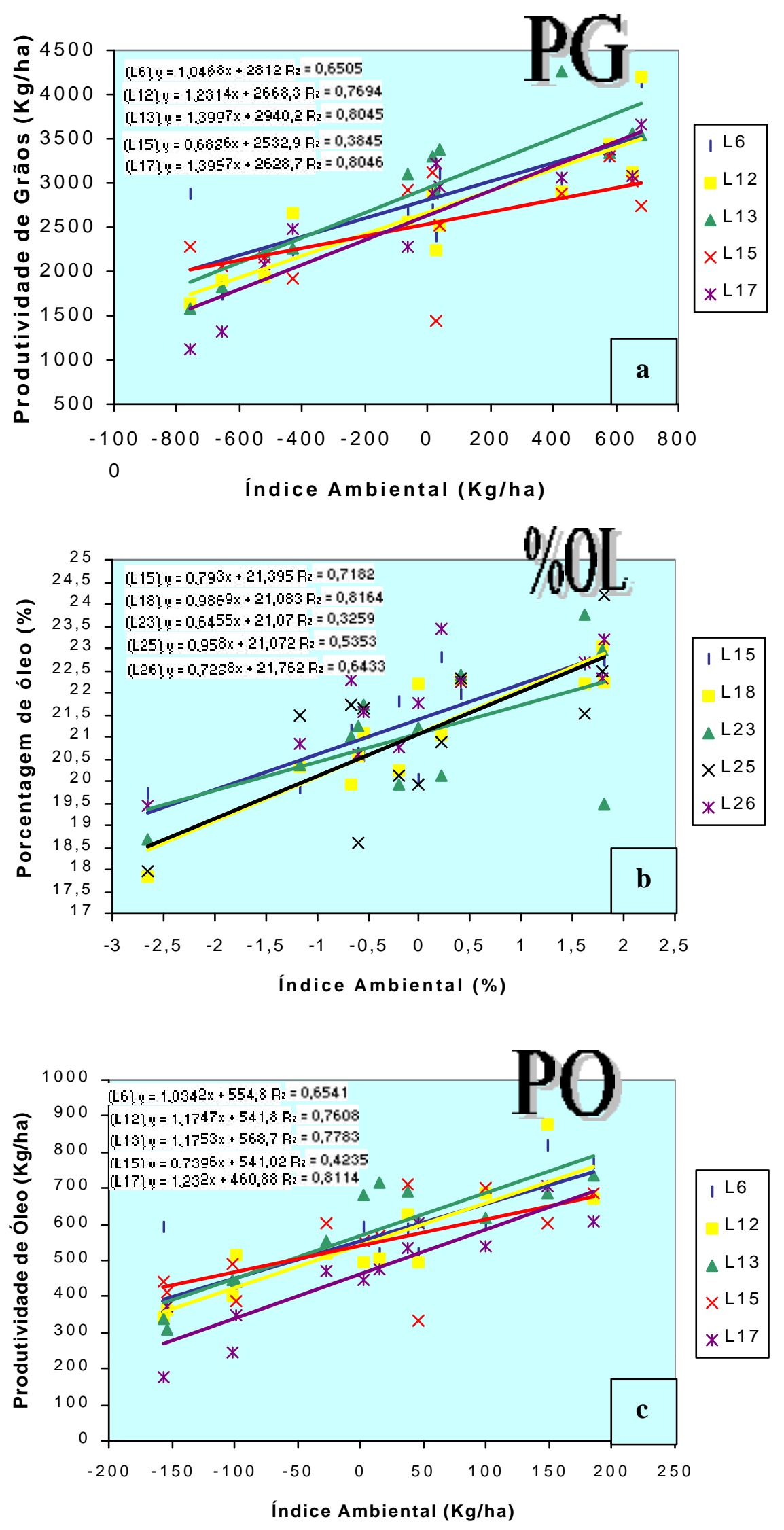

Figura 8 - Linhagens Intermediárias: linhas de regressão das cinco melhores linhagens avaliadas em doze ambientes para: a) produtividade de grãos (PG); b) porcentagem de óleo (\%); e c) produtividade de óleo (PO), estimadas pelo método de Eberhart \& Russel (1966). 

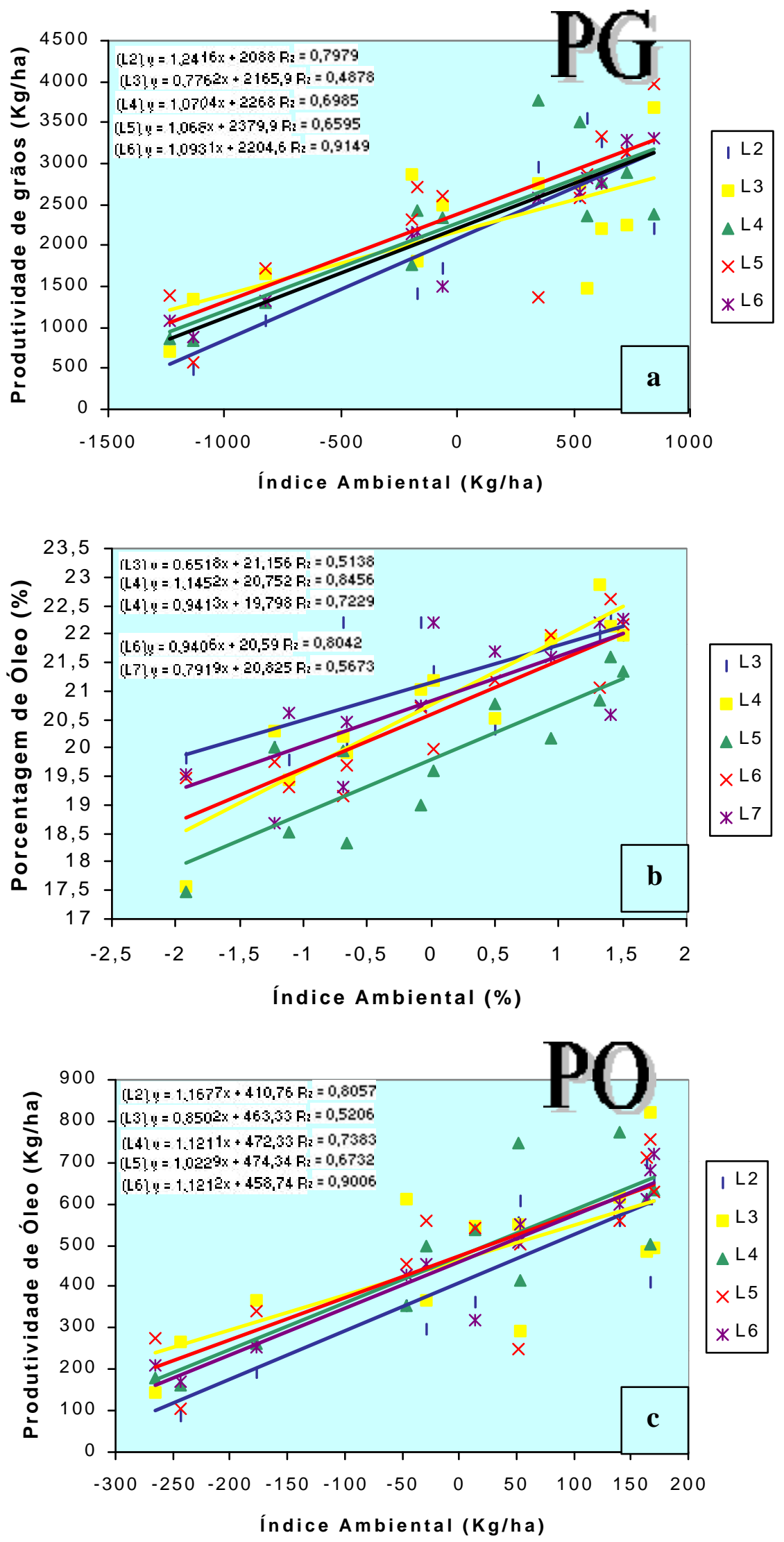

Figura 9 - Linhagens Semitardias: linhas de regressão das cinco melhores linhagens avaliadas em doze ambientes para: a) produtividade de grãos (PG); b) porcentagem de óleo (\%); e c) produtividade de óleo (PO), estimadas pelo método de Eberhart \& Russel (1966). 

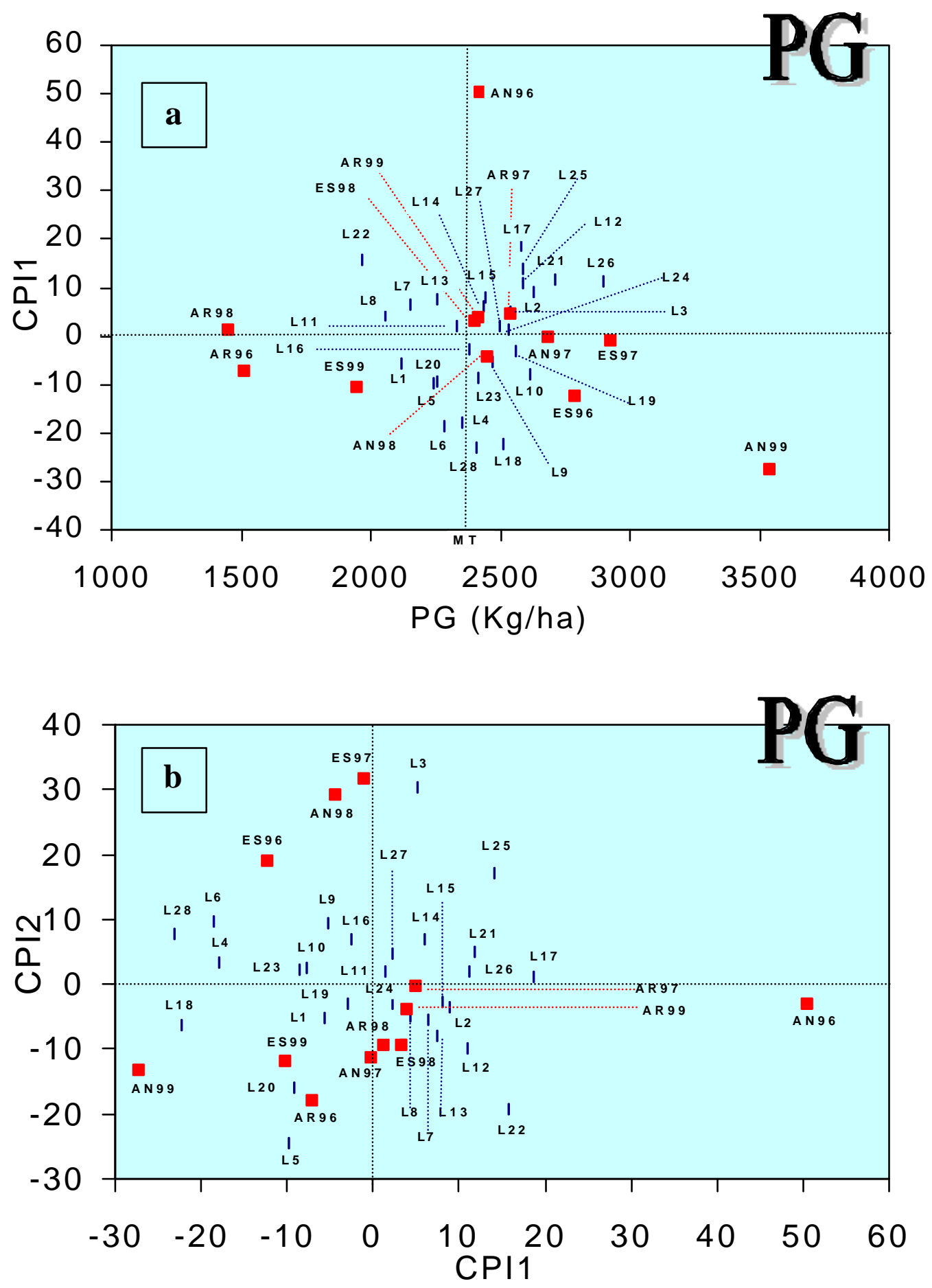

Figura 10 - Linhagens Precoces. a) Biplot AMMI1: produtividade de grãos (PG) x primeiro componente principal da interação (CPI1), MT: média das testemunhas; b) Biplot AMMI2: CPI1 x segundo componente principal da interação (CPI2). Análise de 28 linhagens (losangos em azul) em 12 ambientes (quadrados em vermelho). 

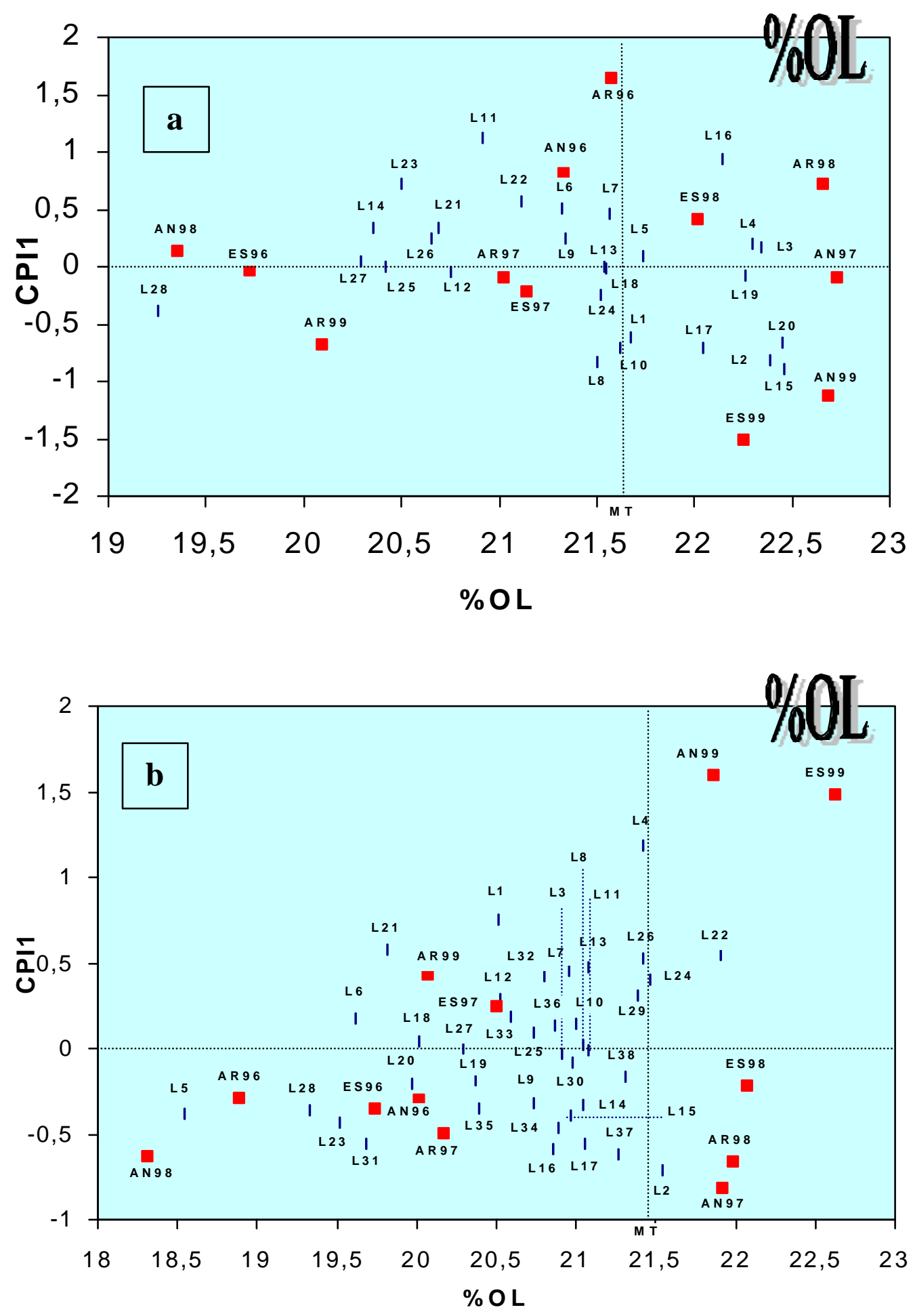

Figura 11 - a) Linhagens Precoces. Biplot AMMI1: porcentagem de óleo (\%OL) x primeiro componente principal da interação (CPI1); b) Linhagens Semiprecoces. Biplot AMMI1: \%OL x CPI1. MT: média das testemunhas. Análise de 28 linhagens precoces e 38 semiprecoces (losangos em azul) em 12 ambientes (quadrados em vermelho). 

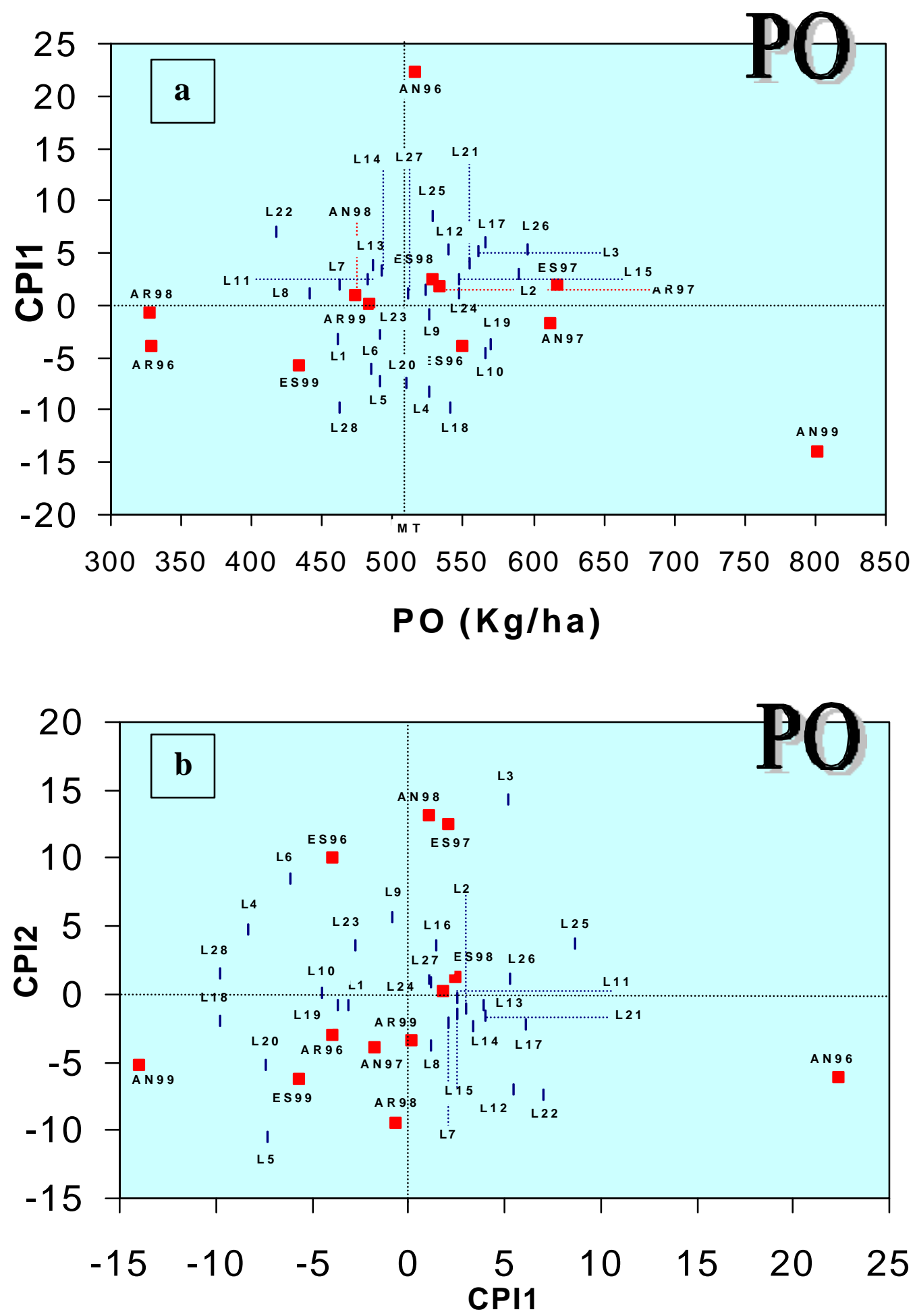

Figura 12 - Linhagens Precoces. a) Biplot AMMI1: produtividade de óleo (PO) x primeiro componente principal da interação (CPI1). MT: média das testemunhas; b) Biplot AMMI2: CPI1 x segundo componente principal da interação (CPI2). Análise de 28 linhagens (losangos em azul) em 12 ambientes (quadrados em vermelho). 

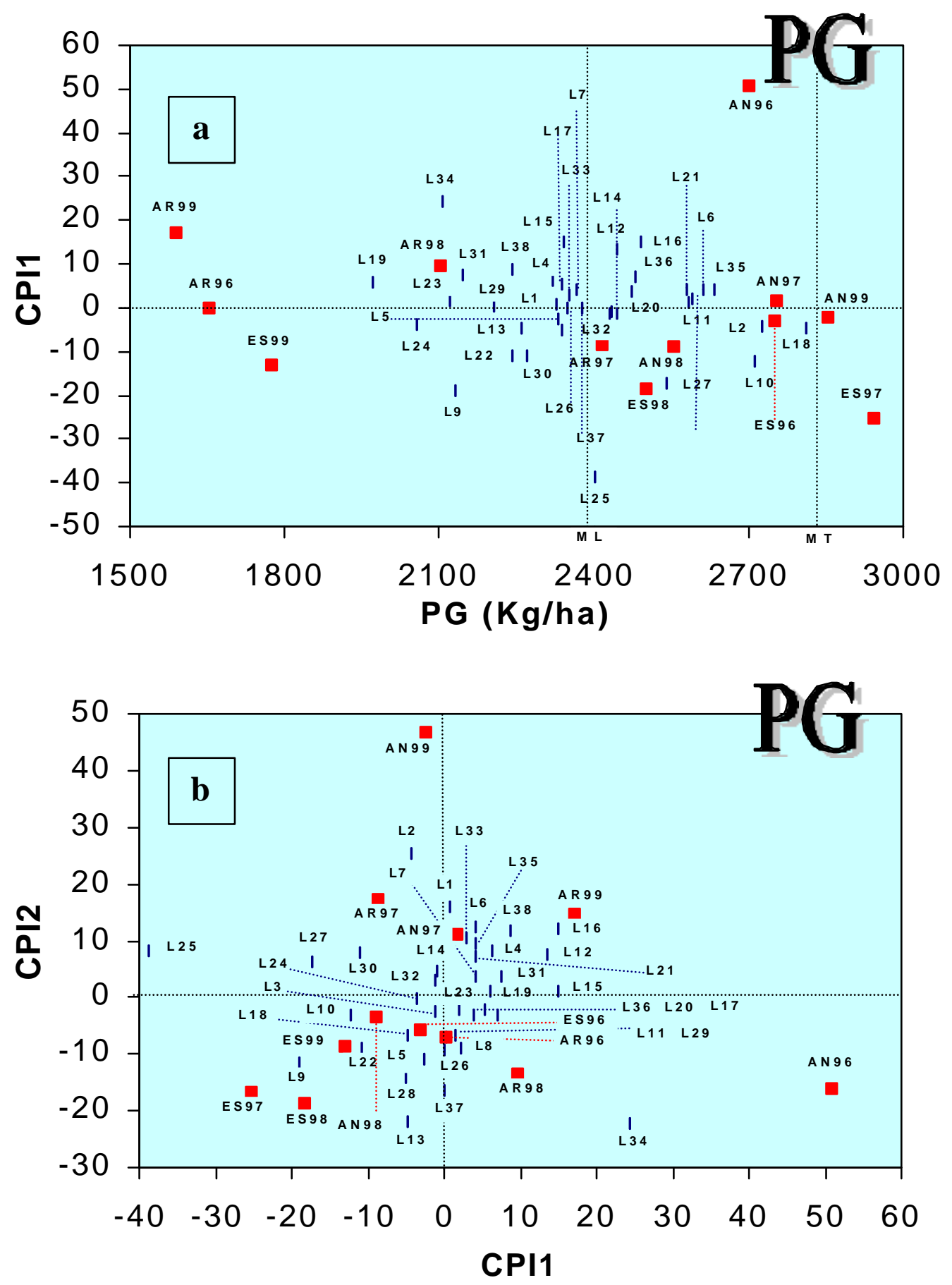

Figura 13 - Linhagens Semiprecoces. a) Biplot AMMI1: produtividade de grãos (PG) x primeiro componente principal da interação (CPI1). ML: média das linhagens, MT: média das testemunhas; b) Biplot AMMI2: CPI1 x segundo componente principal da interação (CPI2). Análise de 38 linhagens (losangos em azul) em 12 ambientes (quadrados em vermelho). 

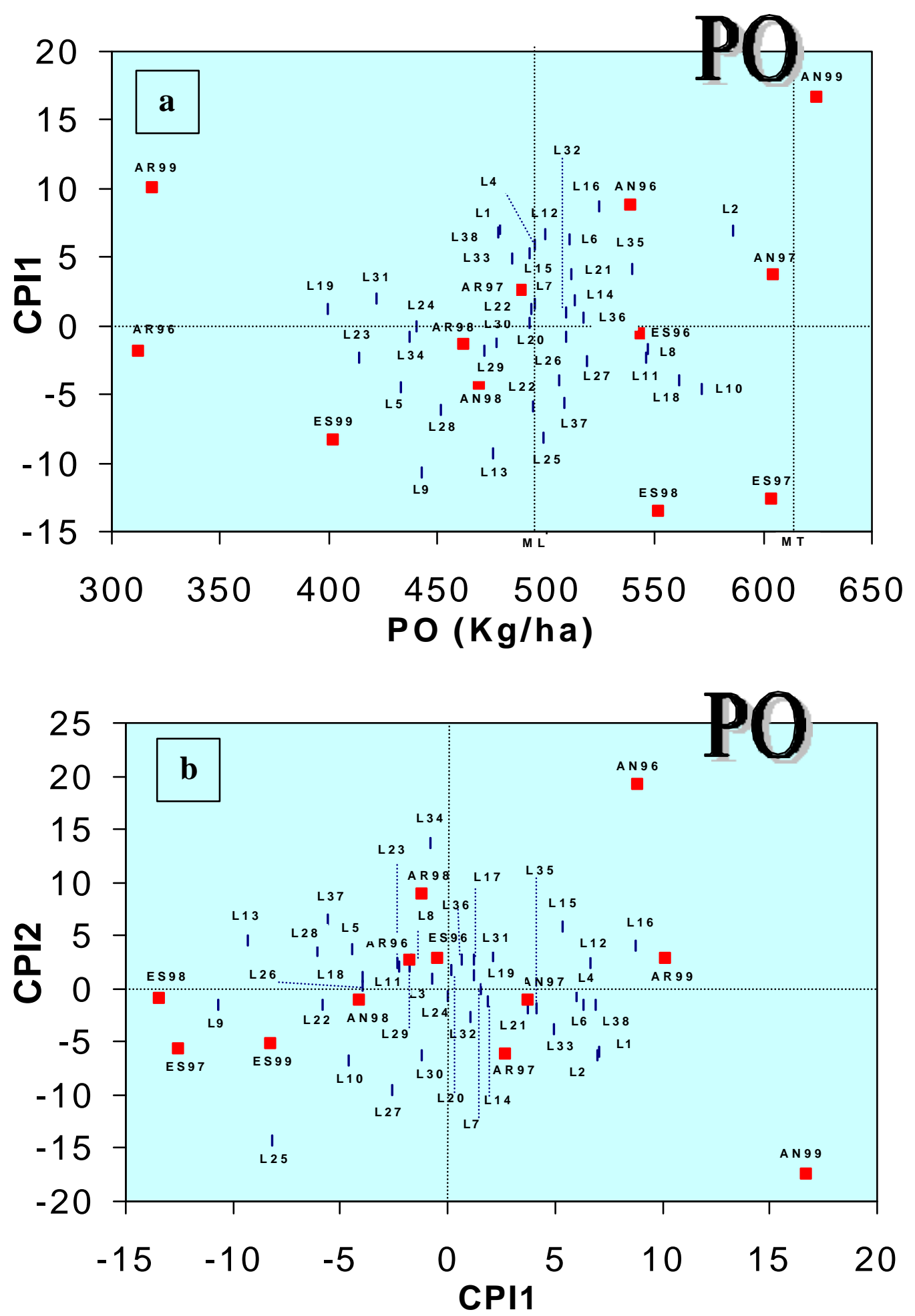

Figura 14 - Linhagens Semiprecoces. a) Biplot AMMI1: produtividade de óleo (PO) x primeiro componente principal da interação (CPI1). ML: média das linhagens, MT: média das testemunhas; b) Biplot AMMI2: CPI1 x segundo componente principal da interação (CPI2). Análise de 38 linhagens (losangos em azul) em 12 ambientes (quadrados em vermelho). 

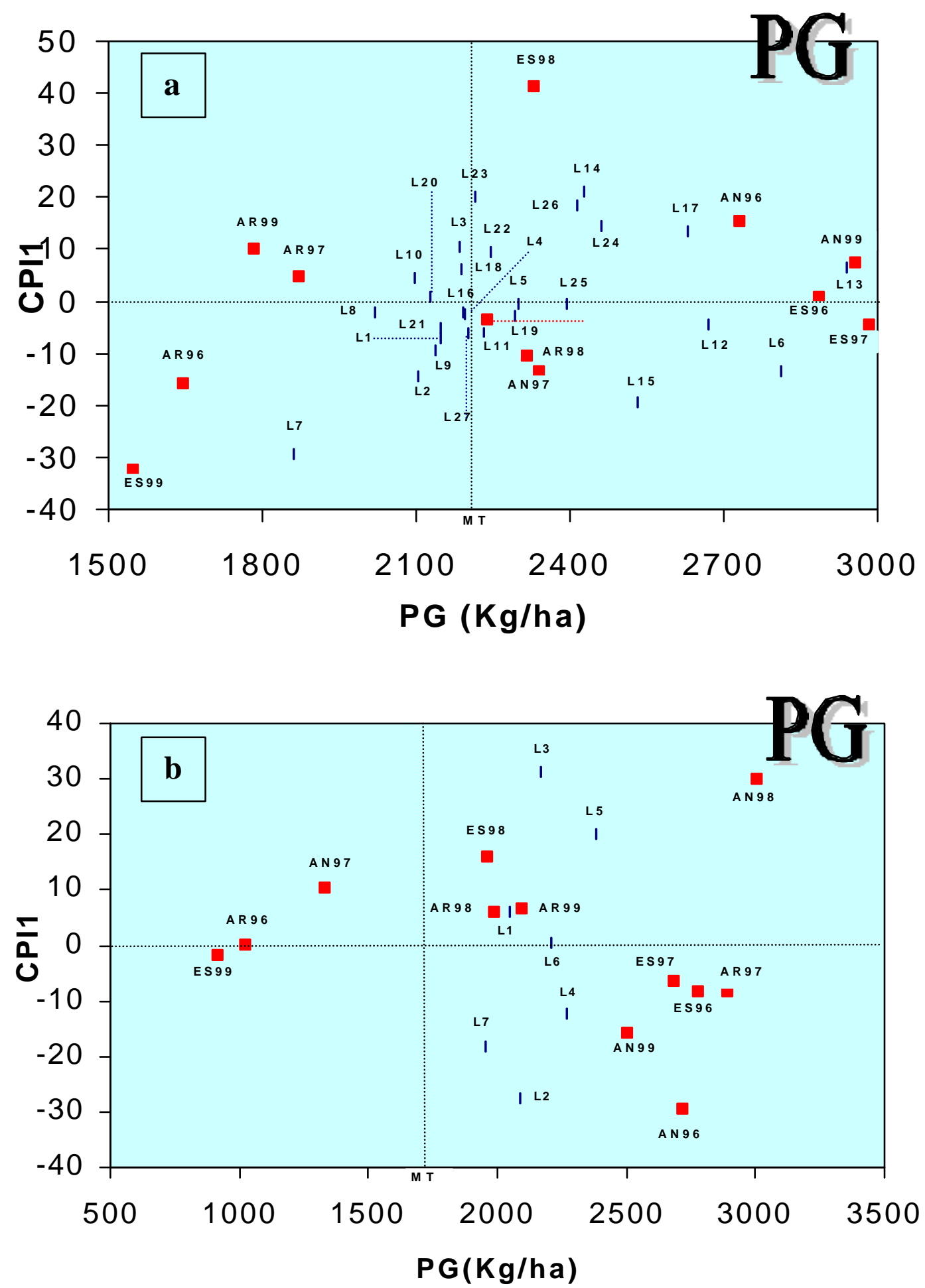

Figura 15 - a) Linhagens Intermediárias. Biplot AMMI1: produtividade de grãos (PG) x primeiro componente principal da interação (CPI1); b) Linhagens Semitardias. Biplot AMMI1: PG x CPI1; MT: média das testemunhas. Análise de 27 linhagens intermediárias e 7 semitardias (losangos em azul) em 12 ambientes (quadrados em vermelho). 

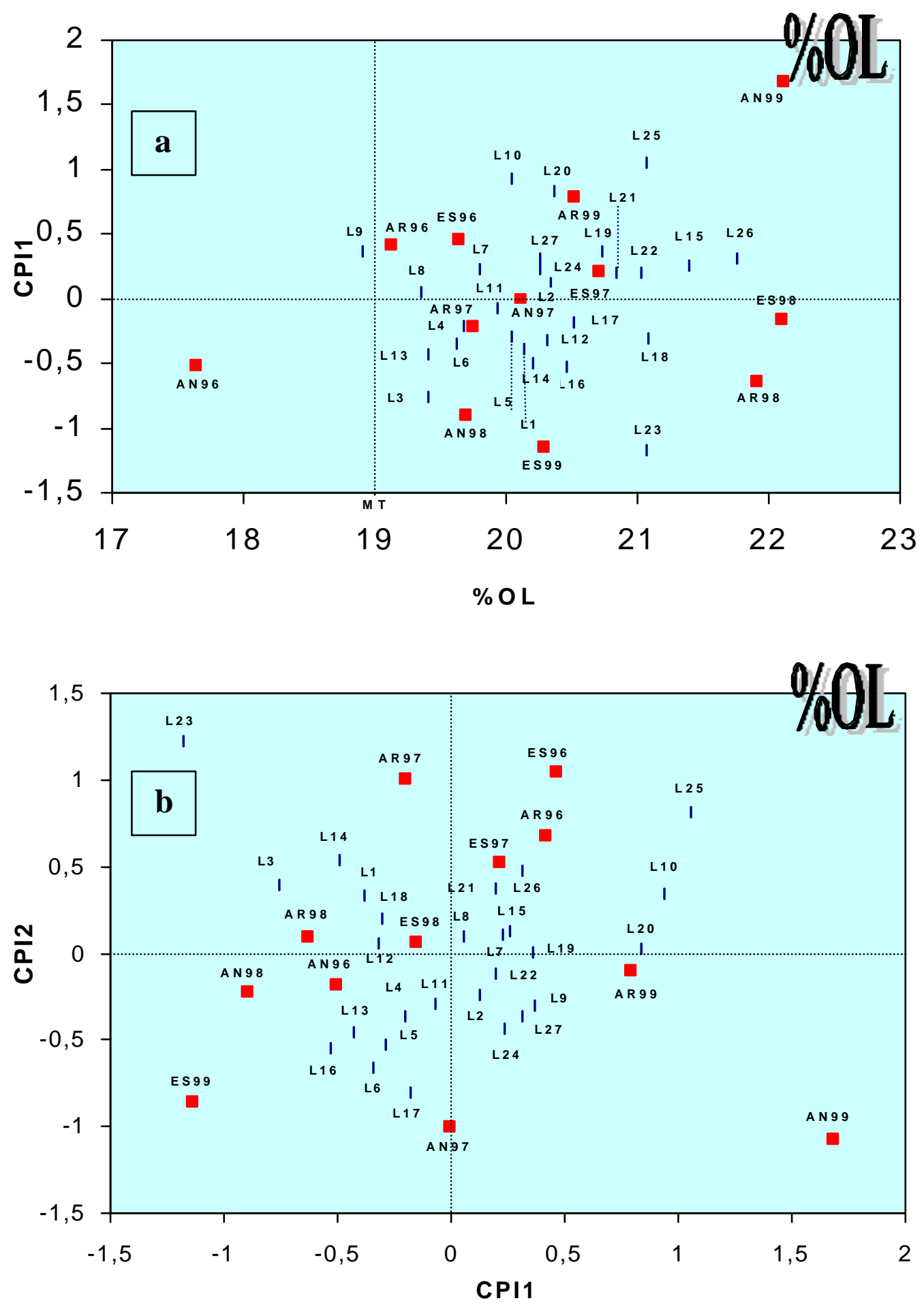

Figura 16 - Linhagens Intermediárias. a) Biplot AMMI1: porcentagem de óleo (\%OL) x primeiro componente principal da interação (CPI1). MT: média das testemunhas; b) Biplot AMMI2: CPI1 x segundo componente principal da interação (CPI2). Análise de 27 linhagens (losangos em azul) em 12 ambientes (quadrados em vermelho). 

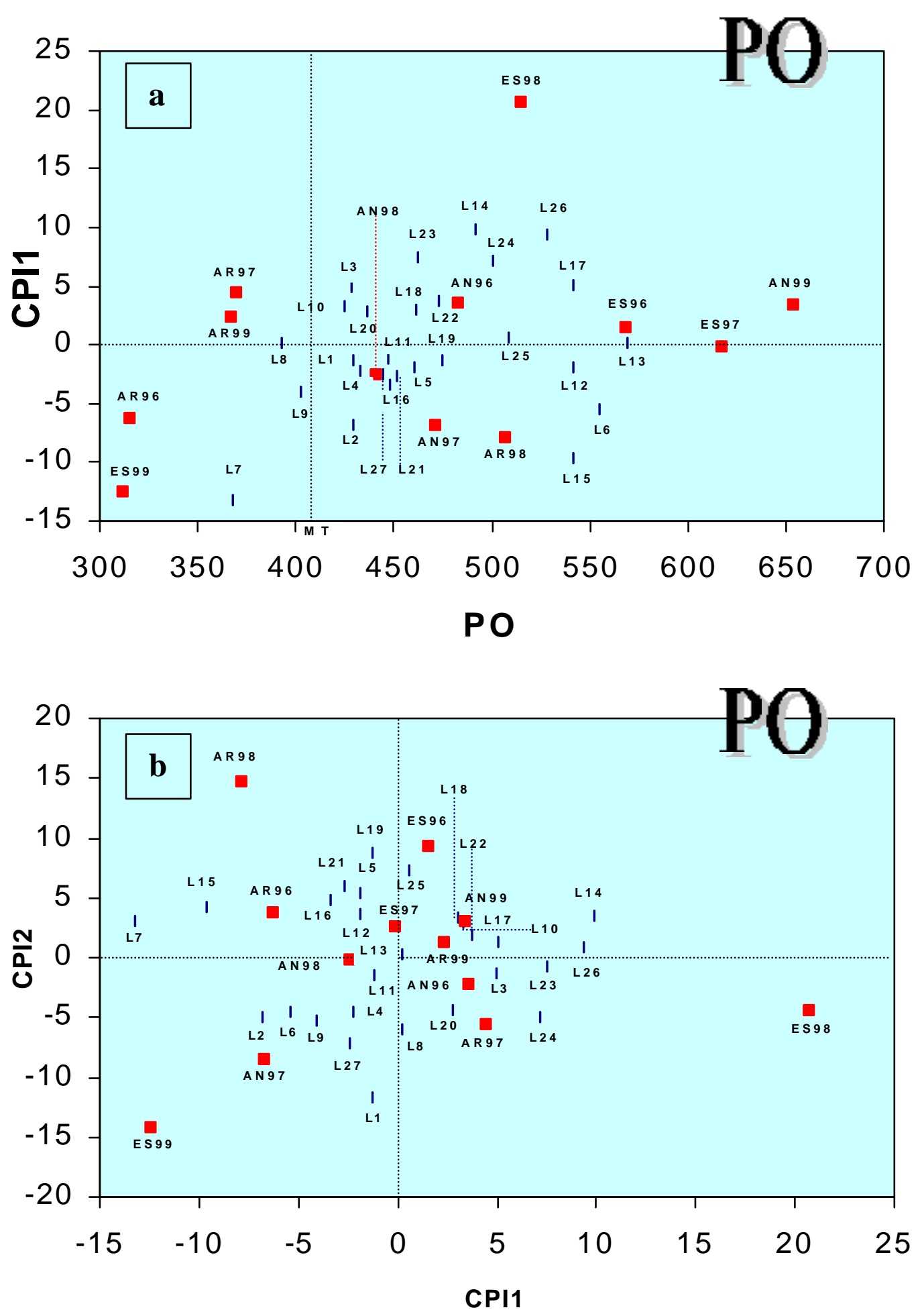

Figura 17 - Linhagens Intermediárias. a) Biplot AMMI1: produtividade de óleo (PO) x primeiro componente principal da interação (CPI1). MT: média das testemunhas; b) Biplot AMMI2: CPI1 x segundo componente principal da interação (CPI2). Análise de 27 linhagens (losangos em azul) em 12 ambientes (quadrados em vermelho). 

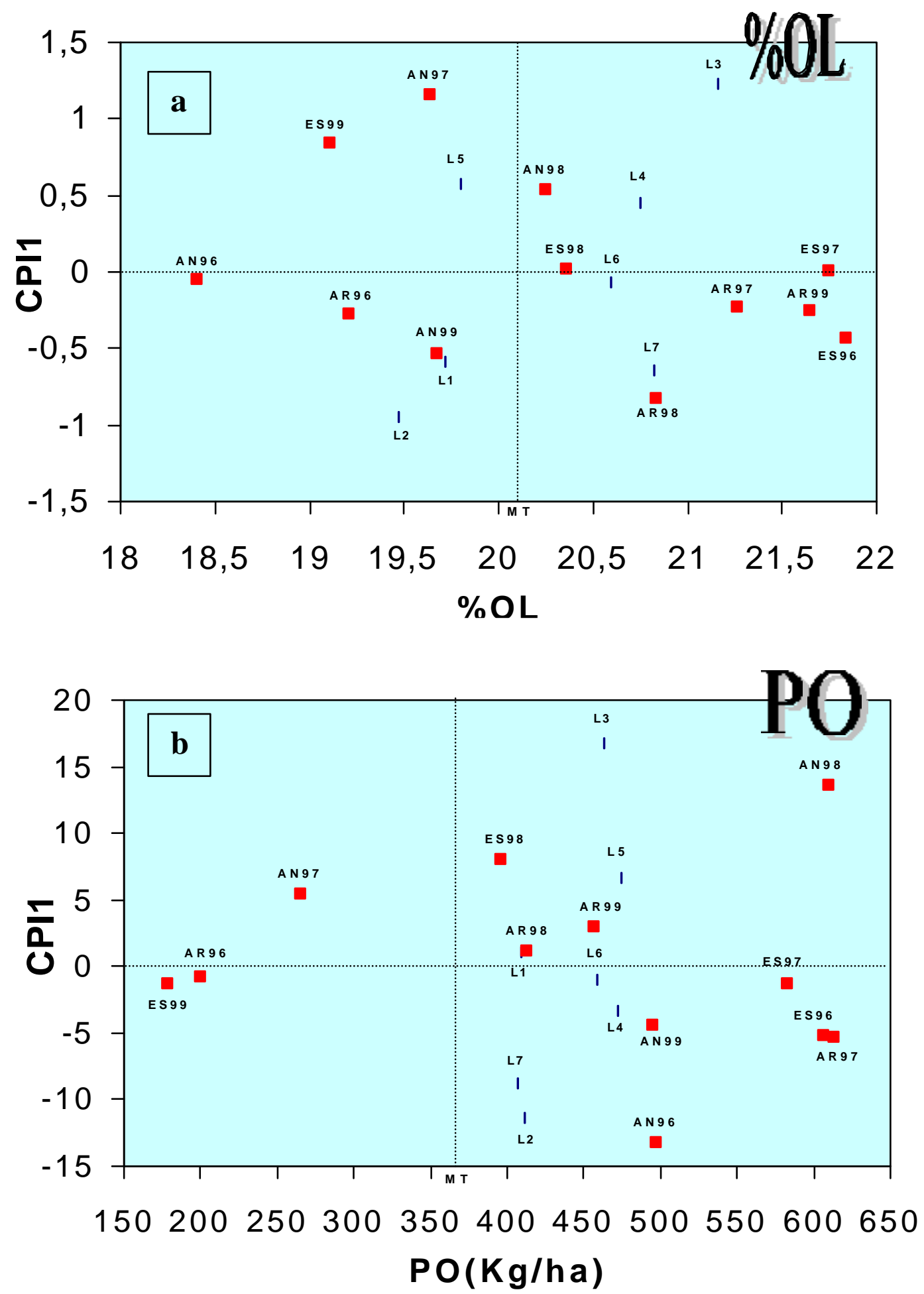

Figura 18 - Linhagens Semitardias. a) Biplot AMMI1: porcentagem de óleo (\%OL) x primeiro componente principal da interação (CPI1); b) Biplot AMMI1: produtividade de óleo (PO) x CPI1. MT: média das testemunhas. Análise de 7 linhagens (losangos em azul) em 12 ambientes (quadrados em vermelho). 


\section{REFERÊNCIAS BIBLIOGRÁFICAS}

ABLETT, G.R.; BEVERSDORF, W.D.; DIRKS, V.A. Performance and stability of indeterminate and determinate soybean in short-season environments. Crop Science, v.29, n.6, p.1428-1433, 1989.

ABLETT, G.R.; BUZZELL, R.I.; BEVERSDORF, W.D.; ALLEN, O.B. Comparative stability of 40 indeterminate and semideterminate soybean lines. Crop Science, v.34, n.2, p.347-351, 1994.

ABOU-EL-FITTOUH, H.A.; RAWLINGS, J.O.; MILLER, P.A. Classification of environments to control genotype by environment interactions with an application to cotton. Crop Science, v.9, n.2, p.135-140, 1969.

AKHTER, M.; SNELLER, C.H. Genotype x planting date interaction and selection of early maturing soybean genotypes. Crop Science, v.36, n.4, p.883-889, 1996a.

AKHTER, M.; SNELLER, C.H. Yield and yield components of early maturing soybean genotypes in the Mid-South. Crop Science, v.36, n.4, p.877-882, 1996b.

ALLARD, R.W. Princípios do melhoramento genético das plantas. Rio de Janeiro: USAID/Edgard Blucher, 1971. 381p.

ALLARD, R.W.; BRADSHAW, A.D. Implications of genotype-environmental interactions in applied plant breeding. Crop Science, v.4, n.5, p.503-508, 1964.

ALLIPRANDINI, L.F. Estudo dos efeitos ambientais, estabilidade, adaptabilidade e ganho genético em linhagens de soja (Glycine max (L.) Merrill) no Estado do Paraná. Londrina, 1992. 122p. Dissertação (Mestrado) - Universidade Estadual de Londrina.

ALLIPRANDINI, L.F.; TOLEDO, J.F.F. de.; FONSECA JUNIOR, N.F.; ALMEIDA, L.A. de.; KIIHL, R.A.S. Efeitos da interação genótipo $\mathrm{x}$ ambiente sobre a produtividade da soja no Estado do Paraná. Pesquisa Agropecuária Brasileira, v.29, n.9, p.1433-1444, 1994.

ALLIPRANDINI, L.F.; TOLEDO, J.F.F.; FONSECA JUNIOR, N.S.; KIIHL, R.A. S. Ganho genético em soja no Estado do Paraná, via melhoramento no período de 1985/86 a 1989/90. Pesquisa Agropecuária Brasileira, v.28, n.4, p.473-479, 1993. 
ALLIPRANDINI, L.F.; TOLEDO, J.F.F.; FONSECA Jr., N.; ALMEIDA, L.A.; KIIHL, R.A.S. Análise de adaptação e estabilidade de genótipos de soja no Estado do Paraná. Pesquisa Agropecuária Brasileira, v.33, n.9, p.1321-1328, 1998.

ANNICCHIARICO, P. Additive main effects and multiplicative interaction (AMMI) analysis of genotype-location interaction in variety trials repeated over years. Theoretical and Applied Genetics, v.94, n.8, p.1072-1077, 1997a.

ANNICCHIARICO, P. Joint regression vs AMMI analysis of genotype-environment interactions for cereals in Italy. Euphytica, v.94, n.1, p.53-62, 1997 b.

ARGILER, O.; HÉBERT, Y.; BARRIÈRE, Y. Statistical analysis and interpretation of line $\mathrm{x}$ environment interaction for biomass yield in maize. Agronomie, v.14, n.10, p.661-672, 1994.

ARIAS, E.R.A. Adaptabilidade e estabilidade das cultivares de milho avaliadas no Estado do Mato Grosso do Sul e avanço genético obtido no período de 1986/87 a 1993/94. Lavras, 1996. 118p. Tese (Doutorado) - Universidade Federal de Lavras.

ARIYO, O.J. Use of additive main effects and multiplicative interaction model to analyse multilocation soybean varietal trials. Journal of Genetics \& Breeding, v.53, n.2, p.129-134, 1998.

ATLIN, G.N.; BAKER, R.J.; McRAE, K.B.; LU, X. Selection response in subdividid target regions. Crop Science, v.40, n.1, p.7-13, 2000.

AZEVEDO FILHO, J.A. Potencialidade de linhagens experimentais de soja em solos contrastantes na saturação de alumínio. Piracicaba, 1997. 139p. Tese (Doutorado) Escola Superior de Agricultura "Luiz de Queiroz", Universidade de São Paulo.

BAKER, R.J. Tests for crossover genotype-environment interactions. Canadian Journal of Plant Science, v.68, n.2, p.405-410, 1988.

BASFORD, K.E.; COOPER, M. Genotype x environment interactions and some considerations of their implications for wheat breeding in Australia. Australian Journal of Agricultural Research, v.49, n.2, p.153-174, 1998.

BATITUCCI, G. Adaptabilidade e estabilidade de genótipos de soja (Glycine max (L.) Merrill) quanto à produção de grãos e à altura de planta, em Minas Gerais. Viçosa, 1990. 84p. Dissertação (Mestrado) - Universidade Federal de Viçosa.

BECKER, H.C. Correlation among some statistical, measures of phenotypic stability. Euphytica, v.30, n.3, p.835-840, 1981.

BECKER, H.C.; LÉON, J. Stability analysis in plant breeding. Plant Breeding, v.101, n.1, p.1-23, 1988. 
BHATIA, V.S.; TIWARI, S.P.; JOSHI, O.P. Yield and its attributes as effected by planting dates in soybean (Glycine max) varieties. Indian Journal of Agricultural Sciences, v.69, n.10, p.696-699, 1999.

BILLORE, S.D.; JOSHI, O.P. Genotypical variability for yield and quality in Glycine max L. Merrill. Soybean Genetics Newsletter, v.24, p.88-91, 1997.

BONATO, E.R.; BERTAGNOLLI, P.F.; IGNACZAK, J.C.; TRAGNAGO, J.L.; RUBIN, S.A.L. Desempenho de cultivares de soja em três épocas no Rio Grande do Sul. Pesquisa Agropecuária Brasileira, v.33, n.6, p.879-884, 1998.

BONATO, E.R.; BERTAGNOLLI, P.F.; LANGE.; C.E.; RUBIN, S.A.L. Teor de óleo e de proteína em genótipos de soja desenvolvidos após 1990. Pesquisa Agropecuária Brasileira, v.35, n.12, p.2391-2398, 2000.

BORGES, L.C.; FERREIRA, D.F.; ABREU, A.F.B.; RAMALHO, M.A.P. Emprego de metodologias de avaliação da estabilidade fenotípica na cultura do feijoeiro (Phaseolus vulgaris L.). Revista Ceres, v.47, n.269, p.89-102, 2000.

BRASIL, E. M.; CHAVES, L. J. Utilizacion de un modelo cuadratico para el estudio de la respuesta de cultivares a la variacion ambiental. In: CONGRESSO LATINOAMERICANO DE GENÉTICA, 11., Monterrey, 1994. Memorias. Monterrey: Asociacion Lationoamericana de Genetica, 1994. p.616.

BURTON, J.W. Soyabean (Glycine max (L.) Merrill). Field Crops Research, v.53, n.13, p.171-186, 1997.

CÂMARA, G.M. Ecofisiologia da soja e rendimento. In: CÂMARA, G.M.S. Soja: tecnologia da produção. Piracicaba: Publique, 1998. p.256-277.

CARBONELL, S.A.M. Análise genética da reação da semente de soja ao dano mecânico avaliada em um dialelo do ciclo precoce. Piracicaba, 1995. 144p. Tese (Doutorado) Escola Superior de Agricultura “Luiz de Queiroz”, Universidade de São Paulo.

CHAVES, L.J. Interação de genótipos com ambientes. In: NASS, L.L.; VALOIS, A.C. C.; MELO, I.S.; VALADARES-INGLIS, M.C. (ed.) Recursos genéticos \& melhoramento: plantas. Rondonópolis: Fundação MT, 2001. 1183p.

CHAVES, L.J.; VENCOVSKY, R.; GERALDI, I.O. Modelo não-linear aplicado ao estudo da interação genótipo $\mathrm{x}$ ambiente em milho. Pesquisa Agropecuária Brasileira, v.24, n.2, p.259-268, 1989.

CENTRO INTERNACIONAL DE MEJORAMIENTO DEL MAIZ Y TRIGO. Toward the $21^{\text {st }}$ century: CIMMYT's strategy. El Batan: CIMMYT, 1989. p.58.

COBER, E.R.; FRÉGEAU-REID, J.A.; PIETRZAK, L.N.; McELROY, A.R.; VOLDENG, H.D. Genotype and environmental effects on natto soybean quality traits. Crop Science, v.37, n.1, p.1151-1154, 1997. 
COCKERHAM, C.C. Estimation of genetics variance. In: HANSON, W.D.; ROBINSON, H.F. (Eds.) Statistical genetics and plant breeding. Madison: National Academy of Sciences, 1963. p.53-94.

COMSTOCK, R.E.; MOLL, R.H. Genotype-environment interactions. In: HANSON, W.D.; ROBINSON, H.F. (Eds.) Statistical genetics and plant breeding. Washington: National Academy Science Natural Research,1963. p.164-196. (Publication, 982)

CORNELIUS, P.L. Statistical tests and retention of terms in the additive main affects and multiplicative interaction model for cultivar trials. Crop Science, v.33, n.6, p.1186-1193, 1993.

CORNELIUS, P.L.; CROSSA, J.; SEYEDSADR, M.S. Statistical tests and estimators of multiplicative models for genotype-by-environment interaction. In: KANG, M.S.; GAUCH, H.G. (ed.) Genotype-by-environment interaction New York: CRC Press, 1996. 416p.

CORNELIUS, P.L.; SEYEDSADR, M.; CROSSA, J. Using the shifted multiplicative model to search for "separability" in crop cultivar trials. Theoretical and Applied Genetics, v.84, n.1-2, p.161-172, 1992.

CROSSA, J. Statistical analyses of multilocation trials. Advances in Agronomy, v.44, p.55-85, 1990.

CROSSA, J.; FOX, P.N.; PFEIFFER, W.H.; RAJARAM, S.; GAUCH, H.G. AMMI adjustment for statistical analysis of an international wheat yield trial. Theoretical and Applied Genetics, v.81, n.1, p.27-37, 1991.

CROSSA, J.; GAUCH, H, G.; ZOBEL, R.W. Additive main effects and multiplicative interaction analysis of two international maize cultivar trials. Crop Science, v.30, n.3, p.493-500, 1990.

CROSSA, J.A.; VARGAS, M.; VAN EEUWIJK, F.A; JIANG, C. Interpreting genotype $\mathrm{x}$ environment interaction in tropical maize using linked molecular markers and environmental covariables. Theoretical and Applied Genetics, v.99, n.3-4, p.611625, 1999.

CRUZ, C.D. Programa GENES: aplicativo computacional em genética e estatística (software). Viçosa: Imprensa Universitária, 1997. 442p. + 1 cd.

CRUZ, C.D.; CASTOLDI, F.L. Decomposição da interação genótipos x ambientes em partes simples e complexa. Revista Ceres, v.38, n.219, p.422-430, 1991.

CRUZ, C.D.; REGAZZI, A.J. Modelos biométricos aplicados ao melhoramento genético. Viçosa: UFV, Imprensa Universitária, 1994. 390p. 
CRUZ, C.D.; TORRES, R.A.A.; VENCOVSKY, R. An alternative approach to the stability analysis proposed by Silva and Barreto. Revista Brasileira de Genética, v.12, n.2, p.567-580, 1989.

DASHIEL, K.E.; ARIYO, O.J.; BELLO, L.; OJO, K. Genotype x environment interaction and simultaneous selection for high yield and stability in soybeans (Glycine max (L.) Merrill). Annals of Applied Biology, v.124, n.1, p.133-139, 1994.

DUARTE, J.B. Aspectos gerais da interação genótipos x ambientes com ênfase na formação de redes de avaliação (compact disc). In: CONGRESSO BRASILEIRO DE MELHORAMENTO DE PLANTAS, 1., Goiânia, 2001. Resumos. Goiânia: SBPM, 2001.

DUARTE, J.B. Estudo da adaptabilidade e estabilidade fenotípica em cultivares de feijão mulatinho (Phaseolus vulgaris L.). Goiania, 1988. 155p. Dissertação (Mestrado) - Escola de Agronomia, Universidade Federal de Goiás.

DUARTE, J.B.; ROLIM, R.B.; OLIVEIRA, P. M.F.; SOUZA, J.R. Adaptabilidade e estabilidade de rendimento de genótipos de soja (Glycine max (L.) Merrill), nas condições de Goiás e Distrito Federal. Anais da Escola de Agronomia e Veterinária, v.24, n.1, p.90-109, 1994.

DUARTE, J.B.; VENCOVSKY, R. Interação genótipos x ambientes: uma introdução à análise AMMI. Ribeirão Preto: Sociedade Brasileira de Genética, 1999. 60p. (Série Monografias, 9)

DUARTE, J.B.; ZIMMERMANN, M.J.O. Correlation among yield stability parameters in common bean. Crop Science, v.35, n.3, p.905-912, 1995.

EBERHART, S.A.; RUSSEL, W.A. Stability parameters for comparing varieties. Crop Science, v.6, n.1, p.36-40, 1966.

FALCONER, D.S. Introduction to quantitative genetics. 3.ed. Harlow: Longman, 1989. 438p.

FALCONER, D.S.; MACKAY, T.F.C. Introduction to quantitative genetics. 4.ed. Harlow: Longman, 1996. 464p.

FARIAS NETO, J.T. Comportamento e variabilidade de genótipos de soja (Glycine max (L.) Merrill) em cultivos de verão e inverno. Piracicaba, 1987. 87p. Dissertação (Mestrado) - Escola Superior de Agricultura "Luiz de Queiroz", Universidade de São Paulo.

FARIAS NETO, J.T. Potencialidade de progênies $\mathrm{F}_{4: 3}$ e $\mathrm{F}_{5: 3}$ derivadas de cruzamentos em cadeia para produtividade de óleo em soja. Piracicaba, 1995. 150p. Tese (Doutorado) - Escola Superior de Agricultura "Luiz de Queiroz", Universidade de São Paulo. 
FEHR, W.R. Principles of cultivar development. New York: Macmillan, 1987. cap.18, p.247-258.

FEHR, W.R.; CAVINESS, C.C. Stages of soybean development. Ames: Iowa State University, 1977. 12p. (Special Report, 80)

FINLAY, K.W.; WILKINSON, G.N. The analysis of adaptation in a plant-breeding programme. Australian Journal of Agricultural Research, v.14, n.5, p.742-754, 1963.

FNP CONSULTORIA \& COMÉRCIO. Agrianual 2001: anuário da agricultura brasileira. São Paulo, 2001. p.495-505.

FLORES, F.; MORENO, M.T.; CUBERO, J.I. A comparasion of univariate and multivariate methods to analyse G x E interaction. Field Crops Research, v.56, n.3, p.271-286, 1998.

FOX, P. N.; CROSSA, J.; ROMAGOSA, I. Multi-environmental testing and genotype x environment interaction. In: KENPTON, R.A; FOX, P.N. Statistical methods for plant variety evaluation. London: Chapman \& Hall, 1997. cap.8, p.117-138.

FOX, P. N.; SKOVMAND, B.K.; THOMPSON, H,J.; BRAUN, H.J.; CORMIER, R. Yield and adaptation of hexaploid spring triticale. Euphytica, v.47, n.1, p.57-64, 1990.

FRANCIS, T. R.; KANNENBERG, L. W. Yield stability studies in short-season maize. I. A descriptive method for grouping genotypes. Canadian Journal of Plant Science, v.58, n.4, p.1029-1034, 1978.

FREIRE FILHO, F.R. Análise genética de um dialelo entre genótipos precoces de soja (Glycine $\max$ (L.) Merrill). Piracicaba, 1988. 224p. Tese (Doutorado) - Escola Superior de Agricultura “Luiz de Queiroz”, Universidade de São Paulo.

GABRIEL, K.R. The biplot graphic display of matrices with application to principal component analysis. Biometrika, v.58, n.3, p.453-467, 1971.

GALVÃO, E.R.; SEDIYAMA, T.; SEDIYAMA, C.S.; ROCHA, V.S.; SCAPIM, C.A. Adaptabilidade e estabilidade fenotípica de nove cultivares e linhagens de soja (Glycine Max (L.) Merrill) em Ponta Porã, Mato Grosso do Sul. Revista Ceres, v.45, n.259, p.221-231, 1998.

GAUCH, H.G. Full and reduced models for yield trials. Theoretical and Applied Genetics, v.80, n.1, p.153-160, 1990.

GAUCH, H.G. Statistical analysis of regional yield trial: AMMI analysis of factorial designs. New York: Elsevier Science, 1992. 278p. 
GAUCH, H.G.; ZOBEL, R.W. AMMI analysis of yield trials. In: KANG, M.S.; GAUCH, H.G. (ed.) Genotype-by-environment interaction New York: CRC Press, 1996. 416p.

GAUCH, H.G.; ZOBEL, R.W. Identifying mega-environments and targeting genotypes. Crop Science, v.37, n.2, p.311-326, 1997.

GAUCH, H.G.; ZOBEL, R.W. Imputing missing yield trial data. Theoretical and Applied Genetics, v.79, n.6, p.753-761, 1990.

GAUCH, H.G.; ZOBEL, R.W. Predictive and postdictive success of statistical analysis of yield trials. Theoretical and Applied Genetics, v.76, n.1, p.1-10, 1988.

GIECO, J.O. Interação genótipos x ambientes e implicações para o melhoramento da soja. Piracicaba, 1997. 98p. Dissertação (Mestrado) - Escola Superior de Agricultura "Luiz de Queiroz", Universidade de São Paulo.

GOLLOB, H.F. A statistical model which combines features of factor analytic and analysis of variance techniques. Psychometrika, v.33, n.1, p.73-115, 1968.

GOMES, R.L.F. Análise genética de progênies $\mathrm{F}_{6}$ e $\mathrm{F}_{7: 6}$ de soja obtidas de cruzamentos dialélicos. Piracicaba, 1995. 140p.Tese (Doutorado) - Escola Superior de Agricultura "Luiz de Queiroz", Universidade de São Paulo.

GONÇALVES, F.M.A. Adaptabilidade e estabilidade de cultivares de milho avaliadas em "safrinha" no período de 1993 a 1995. Lavras, 1997. 86p. Dissertação (Mestrado) - Universidade Federal de Lavras.

HAMAWAKI, O.T. Potencial de progênies selecionadas em cruzamentos óctuplos de soja com ênfase na produtividade de óleo. Piracicaba, 1998. 128p. Tese (Doutorado) Escola Superior de Agricultura "Luiz de Queiroz", Universidade de São Paulo.

HAMAWAKI, O.T.; VELLO, N.A.; DIDONÉ, C.A. Improvement in genetic characteristics and oil yeld of selected soybean progenies from octuple crosses. Genetics and Molecular Biology, v.23, n.4, p.855-864, 2000.

HANSON, W.D. Distance statistics and interpretation of Southern states regional soybean tests. Crop Science, v.34, n.6, p.1498-1504, 1994.

HILL, M.O. Correspondence analysis: a neglected multivariate method. Apllied Statistics, v.23, n.2, p.340-354, 1974.

HORNER, T.W.; FREY, K.J. Methods of determining natural areas for oat varietal recommendations. Agronomy Journal, v.49, n.6, p.313-315, 1957.

HÜHN, M. Nonparametric analysis of genotype x environment interactions by ranks. In: KANG, M.S.; GAUCH, H.G. Genotype-by-environment interaction. Boca Raton: CRC Press, 1996. cap.9, p.235-270. 
HYMOWITZ, T.; SINGH, R.J.; KOLLIPARA, K.P. Biosystematics of the genus Glycine, 1996. Soybean Genetics Newsletter, v.24, p.119-120, 1997.

IVORY, D.A.; KAEWMEECHAI, S.; DELACY, I.H.; BASFORD, K.E. Analysis of the environmental component of genotype $\mathrm{x}$ environment interaction in crop adaptation evaluation. Field Crops Research, v.28, n.1-2, p.71-84, 1991.

JOHNSON, H.W.; ROBINSON, J.H.F.; COMSTOCK, R.E. Estimates of genetic and environmental variability in soybeans. Agronomy Journal, v.47, n.7, p.314-318, 1955.

KANG, M.S. A rank-sum method for selecting high-yielding stable corn genotypes. Cereal Research Communications, v.16, n.1-2, p.113-115, 1988.

KANG, M.S. Using genotype-by-environment interaction for crop cultivar development. Advances in Agronomy, v.62, p.199-252, 1998.

KANG, M.S.; HARVILLE, B.G.; GORMAN, D.P. Contribution of weather variables to genotype x environment interaction in soybean. Field Crops Research, v.21, n.3-4, p.297-300, 1989.

KANG, M.S.; MAGARI, R. New developments in selecting for phenotypic stability in crop breeding. In: KANG, M.S.; GAUCH, H.G. Genotype-by-environment interaction. Boca Raton: CRC Press, 1996. cap.1, p.1-14.

KEARSEY, M.J.; POONI, H.S. The Genetical analysis of quantitative traits. London: Stanley Thornes Publichers, 1998. cap.12, p.241-245: Genotype by environment interaction.

KIIHL, R.A.S. Melhoramento da soja para as médias e baixas latitudes (compact disc). In: CONGRESSO BRASILEIRO DE MELHORAMENTO DE PLANTAS, 1., Goiânia, 2001. Resumos. Goiânia: SBPM, 2001.

KRIEGER, M. Análise dialélica envolvendo dez parentais semiprecoces de soja (Glycine max (L.) Merrill). Piracicaba, 1992. 65p. Dissertação (Mestrado) - Escola Superior de Agricultura “Luiz de Queiroz”, Universidade de São Paulo.

LAÍNEZ-MEJÍA, J.R. Implicações da interação genótipos x ambientes na seleção de progênies de soja com ênfase nas produtividades de grãos e óleo. Piracicaba, 1996. 145p. Tese (Doutorado) - Escola Superior de Agricultura "Luiz de Queiroz", Universidade de São Paulo.

LAVORANTI, O. J. Estudo da adaptabilidade e estabilidade genética de progênies de Eucalyptus grandis, através da metodologia AMMI. In: REUNIÃO ANUAL DA RBRAS, 46.; SEAGRO, 9., Piracicaba, 2001. Anais. Piracicaba: ESALQ/ USP, 1998. p.118-121. 
LAZARINI, E. Avaliação das características agronômicas e análises nutricionais de genótipos de soja semeados em diferentes épocas em Jaboticabal - SP. Jaboticabal, 1995. 197p. Tese (Doutorado) - Faculdade de Ciências Agrárias e Veterinárias, Universidade Estadual Paulista.

LIMA, W.F.; TOLEDO, J.F.F.; ARIAS, C.A.A.; OLIVEIRA, M.F. Stability of soybean yield through different sowing periods. Pesquisa Agropecuária Brasileira, v.35, n.11, p.2181-2189, 2000.

LIN, S.M.; NELSON, R.L. Effect of plant height and flowering date on seed yield of determinate soybean. Crop Science, v.28, n.2, p.218-222, 1988.

LIN, C.S.; BINNS, M.R. A superiority measure of cultivar performance for cultivars $\mathrm{x}$ location data. Canadian Journal of Plant Science, v.68, n.1, p.193-198, 1988.

LIN, C.S.; BINNS, M.R.; LEFKOVICTH, L.P. Stability analysis: where do we stand? Crop Science, v.26, n.5, p.894-900, 1986.

LOPES, A.C.A. Análise dialélica envolvendo genótipos parentais de soja resistentes ao nematóide de cisto. Piracicaba, 2001. 122p. Tese (Doutorado) - Escola Superior de Agricultura "Luiz de Queiroz", Universidade de São Paulo.

MAGARI, R.; KANG, M.S. SAS STABLE: stability analysis of balanced and unbalanced data. Agronomy Journal, v.89, n.5, p.929-932, 1997.

MALAVOLTA, E.; VITTI, G.C.; OLIVEIRA, S.A. Avaliação do estado nutricional das plantas: princípios e aplicações. Piracicaba: Potafos, 1989. 201p.

MANDEL, J.A. A new analysis of variance model for non-adittive data. Technometrics, v.13, n.1, p.1-18, 1971.

MAREGA FILHO, M.; DESTRO, D.; MIRANDA, L.A.; SPINOSA, W.A.; CARRÃOPANIZZI, M.C.; MONTALVÁN, R. Relationships among oil content, protein content and seed size in soybeans. Brazilian Archives of Biology and Technology, v.44, n.1, p.23-32, 2001.

MARIOTTI, J.A.; OYARZABAL, E.S.; OSA, J.M.; BULACIO, A.N.R.; ALMADA, G.H. Analisis de estabilidad y adaptabilidad de genótipos de caña de azucar. I. Interacciones dentro de una localidad experimental. Revista Agronomica del Noroeste Argentino, v.13, n.1-4, p.105-127, 1976.

MAURO, A.O.; CURCIOLI, V.B.; NÓBREGA, J.C. M.; BANZATO, D.A.; SEDIYAMA, T. Correlação entre medidas paramétricas e não paramétricas de estabilidade em soja. Pesquisa Agropecuária Brasileira, v.35, n.4, p.687-696, 2000. 
MIRANDA, F.T.S. Interação genótipos x ambientes em linhagens de soja selecionadas para resistência ao nematóide de cisto. Piracicaba, 1999. 141p. Dissertação (Mestrado) - Escola Superior de Agricultura "Luiz de Queiroz", Universidade de São Paulo.

MIRANDA, Z.F.S.; ARIAS, C.A.A.; TOLEDO, J.F.F.; OLIVEIRA, M.F. Soybean seed oil content: genetic control under different photoperiods. Genetics and Molecular Biology, v.21, n.3, p.387-394, 1998.

MOHANTY, S.K.; BAISAKH, B.; BHOL, B.B. Phenotypic stability of seed yield and maturity in soybean (Glycine max). Indian Journal of Agricultural Sciences, v.69, n.12, p.820-822, 1999.

MONTAÑO-VELASCO, J.C. Análise genética de progênies $F_{3}$ de soja derivadas de cruzamentos em cadeia com ênfase na produtividade de óleo. Piracicaba, 1994. 115p. Tese (Doutorado) - Escola Superior de Agricultura "Luiz de Queiroz", Universidade de São Paulo.

MOREIRA, R.M.P. Predição do comportamento de cruzamentos dialélicos de soja avaliados na geração $F_{3}$ em cultivo de inverno. Piracicaba, 1992. 95p. Dissertação (Mestrado) - Escola Superior de Agricultura "Luiz de Queiroz", Universidade de São Paulo.

NACHIT, M. M.; NACHIT, G.; KETATA, H.; GAUCH, H.G. ZOBEL, R.W. Use of AMMI and linear regression models to analyze genotype-environment interaction in durum wheat. Theoretical and Applied Genetics, v.83, n.5, p.597-601, 1992.

NASS, L.L. Potencialidade de genótipos de soja (Glycine max (L.) Merrill) para cultivo de inverno avaliada por cruzamentos dialélicos. Piracicaba, 1989. 112p. Dissertação (Mestrado) - Escola Superior de Agricultura "Luiz de Queiroz", Universidade de São Paulo.

NJITI, V.N.; SHENAUT, R.J.; SUTTNER, R.J.; SCHMIDT, M.E.; GIBSON, P.T. Relationship between soybean sudden death syndrome disease measures and yield components in $\mathrm{F}_{6}$-derived lines. Crop Science, v.38, n.3, p.673-678, 1998.

OLIVEIRA, A.C. Comparação de alguns métodos de determinação da estabilidade em plantas cultivadas. Brasília, 1976. 64p. Dissertação (Mestrado) - Universidade de Brasília.

OLIVEIRA, L.O. Estabilidade fenotípica de cultivares de soja (Glycine max (L.) Merrill) em relação a elementos climáticos. Viçosa, 1990. 56p. Dissertação (Mestrado) - Universidade Federal de Viçosa. 
ORTIZ, R.; MADSEN, S.; WAGOIRE, W.W.; HILL, J.; CHANDRA, S.; STOLEN, O. Additive main effect and multiplicative interaction model for a diallel-cross analysis. Theoretical and Applied Genetics, v.102, n.6-7, p.1103-1106, 2001.

PANDINI, F.; VELLO, N.A.; LOPES, A.C.A. Heterose para caracteres agronômicos e componentes da produtividade em soja. Piracicaba: ESALQ, Departamento de Genética, 2001. 97p.

PEIXOTO, T.C.; SILVA, J.G.C.; BARRETO, J.N. Técnicas de análise de interação genótipo por ambiente e estabilidade de clones de cana-de-açúcar. In: SIMPÓSIO DE ESTATÍSTICA APLICADA À EXPERIMENTAÇÃO AGRONÔMICA, 1., Piracicaba, 1985. Anais. Campinas: Fundação Cargil, 1985. p.243-258.

PEREIRA, A.S.; COSTA, D.M. Análise de estabilidade de produção de genótipos de batata no Rio Grande do Sul. Pesquisa Agropecuária Brasileira, v.33, n.4, p.405409, 1998.

PERKINS, J.M.; JINKS, J.L. Environmental and genotype-environmental components of variability. III. Multiple lines and crosses. Heredity, v.23, n.3, p.339-356, 1968.

PFEIFFER, T.W.; GRABAU, L.J.; ORF, J.H. Early maturity soybean production system: genotype $\mathrm{x}$ environment interaction between regions of adaptation. Crop Science, v.35, n.1, p.108-112, 1995.

PIEPHO, H.P. Robustness of statistical test for multiplicative terms in the additive main effects and multiplicative interaction model for cultivar trial. Theoretical and Applied Genetics, v.90, n.3-4, p.438-443, 1995.

PINTHUS, M.J. Estimate of genotypic value: a proposed method. Euphytica, v.22, n.1, p.121-123, 1973.

PLAISTED, R.L.; PETERSON, L.C. A technique for evaluating the ability of selections to yield consistently in different locations or seasons. American Potato Journal, v.36, n.2, p.381-385, 1959.

PRADO, E.E.; HIROMOTO, D.M.; GODINHO, V.P.C.; UTUMI, M.M.; RAMALHO, A.R. Adaptabilidade e estabilidade de cultivares de soja em cinco épocas de plantio no cerrado de Rondônia. Pesquisa Agropecuária Brasileira, v.36, n.4, p.625-635, 2001.

RAMALHO, M.A.P.; SANTOS, J.B.; ZIMMERMANN, M.J.O. Genética quantitativa em plantas autógamas: aplicações ao melhoramento do feijoeiro. Goiânia: UFG, 1993. 271p.

RAUT, V.M.; TAWARE, S.P.; HALVANKAR, G.B.; PATIL, V.P. Stability analysis for oil and yield in soybean. Soybean Genetics Newsletter, v.24, p.92-95, 1997. 
ROCHA, M.M. Interação genótipos x locais em linhagens experimentais de soja com diferentes ciclos de maturação. Piracicaba, 1998. 98p. Dissertação (Mestrado) Escola Superior de Agricultura "Luiz de Queiroz", Universidade de São Paulo.

ROCHA, M.M.; VELLO, N.A. Interação genótipos e locais para rendimento de grãos de linhagens de soja com diferentes ciclos de maturação. Bragantia, v.58, n.1, p.69-81, 1999.

ROMAGOSA, I.; FOX, P.N. Genotype x environment interaction and adaptation. In: HAYWARD, M.D.; BOSEMARK, N.O.; ROMAGOSA, I. Plant breeding: principles and prospects. London: Chapman \& Hall, 1993. chap. 20, p. 375-390.

ROSSE, L.N.; VENCOVSKY, R. Modelo de regressão não-linear aplicado ao estudo da estabilidade fenotípica de genótipos de feijão no Estado do Paraná. Bragantia, v.59, n.1, p.99-107, 2000.

SCOTT, R.A.; CHAMPOUX, M.; SCHAPAUGH Jr., W.T. Influence of environmental productivity levels and yield stability on selection strategies in soybean. Euphytica, v.78, n.1-2, p.115-122, 1994.

SHAFII, B.; PRICE, W.J. Analysis of genotype-by-environment interaction using the additive main effects and multiplicative interaction model and stability estimates. Journal of Agricultural, Biological, and Environmental Statistics, v.3, n.3, p.335345, 1998.

SHARMA, P.K.; GUPTA, P.K.; GOVILA, O.P. AMMI analysis of a pearl millet yield trial. Indian Journal of Genetics and Plant Breeding, v.58, n.2, 183-192, 1998.

SHUKLA, G.K. Some statistical aspects of partitioning genotype-environmental components of variability. Heredity, v.29, n.2, p.237-245, 1972.

SILVA, J.G.C. Análise da adaptabilidade por regressão segmentada com estimação da junção dos segmentos. Pesquisa Agropecuária Brasileira, v.33, n.7, p.1013-1029, 1998.

SILVA, J.G.C.; BARRETO, J.N. An application of segmented linear regression to the study of genotypes environment interaction. Biometrics, v.41, n.4, p.1093, 1986.

SIVEIRO, A.; MENTEN, J.O.; VELLO, N.A. Herança da resistência da soja a Diaphorte phaseolorum f. sp. Meridionalis. Summa Phytopathologica, v.23, n.2, p.139-142, 1997.

SNELLER, C.H.; DOMBEK, D. Comparing soybean cultivar ranking and selection for yield with AMMI and full-data performance estimates. Crop Science, v.35, n.6, p.1536-1541, 1995.

SNELLER, C.H.; KILGORE-NORQUEST, L.; DOMBEK, D. Repeatability of yield stability statistics in soybean. Crop Science, v.37, n.2, p.383-390, 1997. 
SOLDINI, D.O. Interação genótipos x locais e correlações entre caracteres com ênfase na produtividade de óleo em soja. Piracicaba, 1993. 136p. Dissertação (Mestrado) Escola Superior de Agricultura "Luiz de Queiroz", Universidade de São Paulo.

SOLDINI, D.O. Potencial genético de cruzamentos dialélicos parciais de soja com ênfase nas produtividades de grãos e óleo. Piracicaba, 1998. 80p. Tese (Doutorado) Escola Superior de Agricultura "Luiz de Queiroz", Universidade de São Paulo.

SOOD, O.P.; SOOD, V.K.; ANAND, D.; KALIA, N.R. Phenotypic stability for yield and maturity in soybean (Glycine max) in mid-hills of Himachal Pradesh Indian Journal of Agricultural Sciences, v.69, n.7, p.536-537, 1999.

SPEHAR, C.R. Breeding soybeans to the latitudes of Brazilian cerrados (savannahs). Pesquisa Agropecuária Brasileira, v.29, n.8, p.1167-1180, 1994.

STATISTICAL ANALYSIS SYSTEM INSTITUTE. SAS/STAT software: changes and enhancements through release 6.12. (software). Cary: SAS INSTITUTE, 1997. $1116 \mathrm{p} .+1 \mathrm{~cd}$.

STORCK, L.; VENCOVSKY, R. Stability analysis on a bi-segmented discontinuous model with measurement errors in the variables. Revista Brasileira de Genética, v.17, n.1, p.75-81, 1994.

TAI, G.C.C. Genotypic stability analyses and its application to potato regional trials. Crop Science, v.2, n.2, p.184-194, 1971.

THILLAINATHAN, M.; FERNANDEZ, G.C.J. SAS application for Tai's stability analysis and AMMI model in genotype $\mathrm{x}$ environmental interaction (GEI) effects. Journal of Heredity, v.92, n.4, p.367-373, 2001.

TAYE, G.; GETACHEW, T.; BEJIGA, G. AMMI adjustment for yield estimate and classification of genotypes and environments in field pea (Pisum sativum L.). Journal of Genetics \& Breeding, v.54, n.3, p.183-191, 2000.

TOLEDO, J.F.F.; ALMEIDA, L.A.; KIIHL, R.F.S.; MENOSSO, O.G. Ganho genético em soja no Estado do Paraná, via melhoramento. Pesquisa Agropecuária Brasileira, v.25, n.1, p.89-94, 1990.

TOLEDO, J.F.F.; ARIAS, C.A.A.; OLIVEIRA, M.F.; TRILLER, C.; MIRANDA, Z.F.S. Genetical and environmental analyses of yield in six biparental soybean crosses. Pesquisa Agropecuária Brasileira, v.35, n.9, p.1783-1796, 2000.

TOLER, J.E.; BURROWS, P.M. Genotypic performance over environmental arrays: a non-linear grouping protocol. Journal of Applied Statistics, v.25, n.1, p.131-143, 1998.

TOMKINS, J.P.; SHIPE, E.R. Environmental adaptation of long-juvenile soybean cultivars and elite strains. Agronomy Journal, v.89, n.2, p.257-262, 1997. 
TRILLER, C.; TOLEDO, F.F. de. Using the $F_{3}$ generation for predicting potential of soybean crosses. Revista Brasileira de Genética, v.19, n.2, p.289-294, 1996.

TSUTSUMI, C.Y. Caracterização agronômica de cruzamentos de soja tipo alimento com tipo grão. Piracicaba, 2000. 158p. Tese (Doutorado) - Escola Superior de Agricultura "Luiz de Queiroz", Universidade de São Paulo.

UNÊDA-TREVISOLI, S.H. Estabilidade fenotípica e potencialidade de progênies obtidas por cruzamentos óctuplos em soja. Piracicaba, 1999. 228p. Tese (Doutorado) - Escola Superior de Agricultura “Luiz de Queiroz”, Universidade de São Paulo.

UNIVERSIDADE FEDERAL DE LAVRAS. Estabilidade (software). Versão 1.0, Lavras: UFV, DEXA. 2000.

VAN RAAMSDONK, L.W.D. The cytological and genetical mechanisms of plant domestication exemplified by four crop models. The Botanical Review, v.61, n.4, p.367-399, 1995.

VARGAS, M.; CROSSA, J.; VAN EEUWIJK, F.; SAYRE, K.D.; REYNOLDS, M.P. Interpreting treatment $\mathrm{x}$ environment in agronomy trials. Agronomy Journal, v.93, n.4, p.949-960, 2001.

VELLO, N.A. Ampliação da base genética do germoplasma e melhoramento de soja na ESALQ/USP. In: SIMPÓSIO SOBRE A CULTURA E PRODUTIVIDADE DA SOJA, 1., Piracicaba, 1991. Anais. Piracicaba: FEALQ, 1992. p. 60-81.

VELLO, N.A. Base genética, fontes de genes e métodos de melhoramento para resistência a doenças. In: ENCONTRO SOBRE TEMAS DE GENÉTICA E MELHORAMENTO, 12., Piracicaba, 1995. Anais. Piracicaba: ESALQ, Departamento de Genética, 1995. p.11-23.

VELLO, N.A. Efeitos da introdução de germoplasma exótico sobre a produtividade e relações com a base genética dos cultivares de soja (Glycine max (L.) Merrill). Piracicaba, 1985. 91p. Tese (Livre-Docência) - Escola Superior de Agricultura "Luiz de Queiroz", Universidade de São Paulo.

VELlO, N.A.; HIROMOTO, D.M.; AZEVEDO FILHO, A.J.BV. Coefficient of parentage and breeding of Brazilian soybean germplasm. Revista Brasileira de Genética, v.11, n.3, p.679-697, 1988.

VENCOVSKY, R.; BARRIGA, P. Genética biométrica no fitomelhoramento. Ribeirão Preto: Sociedade Brasileira de Genética, 1992. 486p.

VENCOVSKY, R.; TORRES, R.A.A. Estabilidade geográfica e temporal de algumas cultivares de milho. In: CONGRESSO NACIONAL DE MILHO E SORGO, 16., Belo Horizonte, 1988. Anais. Belo Horizonte: EMBRAPA, CNPMS, 1988. p.294300. 
VERMA, M.M.; CHAHAL, G.S.; MURTY, B.R. Limitations of conventional regression analysis, a proposed modification. Theoretical and Applied Genetics, v.53, n.2, p.89-91, 1978.

VERNETTI, F.J. Origem da espécie, introdução e disseminação no Brasil. In: FUNDAÇÃO CARGILL. Soja: planta, clima, pragas, moléstias e invasoras. Campinas, 1983. p.3-123.

WESTCOTT, B. A method of assessing the yield stability of crop genotypes. Journal of Agricultural Sciences, v.108, n.2, p.267-274, 1987.

WRICKE, G.; WEBER, E.W. Quantitative genetics and selection in plant breeding. Berlin: Walter de Gruyter, 1986. 406p.

WU, R.L.; MALLEY, D.M.O. Nonlinear genotypic response to macro- and microenvironments. Theoretical and Applied Genetics, v.96, n.5, p.669-675, 1998.

XU, B.; ZHEN, H.; LU, Q.; ZHAO, S. HU, Z. Three evidence of the original area of soybean. In: WORLD SOYBEAN RESEARCH CONFERENCE, 4., Buenos Aires, 1988. Proceedings. Buenos Aires: Asssociation Argentina de la Soja, 1989. p.124128.

YAN, W.; CORNELIUS, P.L.; CROSSA, J.; HUNT, L.A. Two types of GGE biplots for analyzing multi-environment trial data. Crop Science, v.41, n.3, p.656-663, 2001.

YATES, F.; COCHRAN, W. G. The analysis of groups of experiments. Journal of Agricultural Sciences, v.28, n.4, p.556-580, 1938.

YAU, S. K. Regression and AMMI analyses of genotype x environment interactions: an empirical comparison. Agronomy Journal, v.87, n.1, p.121-126, 1995.

YOKOMIZO, G.K. Interação genótipos x ambientes em topocruzamentos de soja tipo alimento com tipo grão. Piracicaba, 1999. 171p. Tese (Doutorado) - Escola Superior de Agricultura "Luiz de Queiroz", Universidade de São Paulo.

YUE, G.L.; ROOZEBOOM, K.L.; SCHAPAUGH Jr., W.T.; LIANG, G.H. Evaluation of soybean cultivars using parametric and nonparametric stability estimates. Plant Breeding, v.116, n.3, p.271-275, 1997.

ZIMBACK, L. Cruzamento em cadeia entre genótipos adaptados e exóticos de soja com ênfase na produção de óleo. Piracicaba, 1992. 163p. Tese (Doutorado) - Escola Superior de Agricultura "Luiz de Queiroz".

ZOBEL, R.W.; MADISON, J.W.; GAUCH, H.G. Statistical analysis of a yield trial. Agronomy Journal, v.80, n.3, p.388-393, 1988. 


\section{APÊNDICES}


Apêndice 1. Identificação, genealogia, geração de endogamia (GE), ciclo de maturação (CM) e programa de origem das linhagens experimentais avaliadas. Soja, Piracicaba, SP.

\begin{tabular}{|c|c|c|c|c|c|}
\hline $\mathrm{N}$ & No USP & Genealogia & GE & $\mathrm{CM}$ & Programa de origem \\
\hline 1 & $93-1002$ & Paraná x IAC-Foscarin-31 & $\mathrm{F}_{15: 6}$ & $\mathrm{P}^{1}$ & $\mathrm{PG}^{\mathrm{b}}$ \\
\hline 2 & $93-1042$ & IAC-Foscarin-31 x Primavera ${ }^{a}$ & $F_{15: 6}$ & $\mathrm{P}$ & PG \\
\hline 3 & $93-1043$ & IAC-Foscarin-31 x Primavera ${ }^{a}$ & $\mathrm{~F}_{15: 6}$ & $\mathrm{P}$ & PG \\
\hline 4 & $93-1044$ & IAC-Foscarin-31 x Primavera ${ }^{a}$ & $\mathrm{~F}_{15: 6}$ & $\mathrm{P}$ & PG \\
\hline 5 & $93-1050$ & IAC-Foscarin-31 x Forrest ${ }^{\mathrm{m}}$ & $\mathrm{F}_{15: 6}$ & $\mathrm{P}$ & PG \\
\hline 6 & $93-1051$ & IAC-Foscarin-31 x Forrest ${ }^{\mathrm{m}}$ & $\mathrm{F}_{15: 6}$ & $\mathrm{P}$ & PG \\
\hline 7 & $93-1069$ & Coker $136 \times$ Primavera $^{\mathrm{m}}$ & $\mathrm{F}_{15: 6}$ & $\mathrm{P}$ & PG \\
\hline 8 & $93-1072$ & Coker $136 \times$ Primavera $^{\mathrm{m}}$ & $F_{15: 6}$ & $\mathrm{P}$ & PG \\
\hline 9 & $93-1077$ & Coker 136 x Forrest $^{\mathrm{m}}$ & $\mathrm{F}_{15: 6}$ & $\mathrm{P}$ & PG \\
\hline 10 & $93-1101$ & Primavera $\mathrm{x}$ Forrest $\mathrm{t}^{\mathrm{m}}$ & $\mathrm{F}_{15: 6}$ & $\mathrm{P}$ & PG \\
\hline 11 & $93-1107$ & Primavera x FT $81-1835^{\mathrm{a}}$ & $\mathrm{F}_{15: 6}$ & $\mathrm{P}$ & PG \\
\hline 12 & $93-1109$ & Primavera x SOC $81-79^{a}$ & $\mathrm{~F}_{15: 6}$ & $\mathrm{P}$ & PG \\
\hline 13 & $93-1122$ & Década x Forrest ${ }^{\mathrm{m}}$ & $\mathrm{F}_{15: 6}$ & $\mathrm{P}$ & PG \\
\hline 14 & $93-1187$ & IAC-Foscarin-31 x Década ${ }^{a}$ & $\mathrm{~F}_{15: 6}$ & $\mathrm{P}$ & PG \\
\hline 15 & $93-1188$ & IAC-Foscarin-31 x Forrest ${ }^{\mathrm{m}}$ & $\mathrm{F}_{15: 6}$ & $\mathrm{P}$ & PG \\
\hline 16 & $93-1195$ & Coker $136 \times$ Primavera $^{\mathrm{m}}$ & $F_{15: 6}$ & $\mathrm{P}$ & PG \\
\hline 17 & $93-1203$ & Primavera x SOC $81-79^{\mathrm{a}}$ & $\mathrm{F}_{15: 6}$ & $\mathrm{P}$ & PG \\
\hline 18 & $94-1004$ & Paraná x Forrest ${ }^{\mathrm{m}}$ & $\mathrm{F}_{15: 6}$ & $\mathrm{P}$ & PG \\
\hline 19 & 94-1012 & IAC-Foscarin-31 x Primavera ${ }^{a}$ & $\mathrm{~F}_{15: 6}$ & $\mathrm{P}$ & PG \\
\hline 20 & $94-1024$ & IAC-Foscarin-31 x Forrest ${ }^{\mathrm{m}}$ & $\mathrm{F}_{15: 6}$ & $\mathrm{P}$ & PG \\
\hline 21 & $94-1044$ & Coker $136 \times$ Hale $321^{\mathrm{e}}$ & $\mathrm{F}_{15: 6}$ & $\mathrm{P}$ & PG \\
\hline 22 & $94-1055$ & Primavera $\mathrm{x}$ Forrest $\mathrm{t}^{\mathrm{m}}$ & $\mathrm{F}_{15: 6}$ & $\mathrm{P}$ & PG \\
\hline 23 & $94-1061$ & Primavera $x$ FT $81-1835^{\mathrm{a}}$ & $\mathrm{F}_{15: 6}$ & $\mathrm{P}$ & PG \\
\hline 24 & $94-1070$ & Primavera x FT 81-2134 & $F_{15: 6}$ & $\mathrm{P}$ & PG \\
\hline 25 & $94-1081$ & Década x FT 81-2134 & $\mathrm{F}_{15: 6}$ & $\mathrm{P}$ & PG \\
\hline 26 & $94-1086$ & Década x FT $81-1835^{\mathrm{a}}$ & $\mathrm{F}_{15: 6}$ & $\mathrm{P}$ & PG \\
\hline 27 & $94-1087$ & Forrest x FT $81-2134^{\mathrm{m}}$ & $\mathrm{F}_{15: 6}$ & $\mathrm{P}$ & PG \\
\hline 28 & 94-1097 & FT $81-1835 \times$ FT $81-2134^{a}$ & $\mathrm{~F}_{15: 6}$ & $\mathrm{P}$ & PG \\
\hline 29 & $93-1052$ & IAC-Foscarin-31 x Forrest ${ }^{\mathrm{m}}$ & $\mathrm{F}_{15: 6}$ & SP & PG \\
\hline 30 & $93-1106$ & Primavera x FT $81-1835^{\mathrm{a}}$ & $\mathrm{F}_{15: 6}$ & $\mathrm{SP}$ & PG \\
\hline 31 & $93-1119$ & Primavera x FT 81-2134 & $\mathrm{F}_{15: 6}$ & $\mathrm{SP}$ & PG \\
\hline 32 & $93-1125$ & Década x FT $81-1835^{\mathrm{a}}$ & $F_{15: 6}$ & $\mathrm{SP}$ & PG \\
\hline 33 & $93-1202$ & Primavera x FT $81-1835^{\mathrm{a}}$ & $\mathrm{F}_{15: 6}$ & $\mathrm{SP}$ & PG \\
\hline 34 & $93-1211$ & FT $81-1835 \times$ Hale $321^{\mathrm{m}}$ & $\mathrm{F}_{15: 6}$ & SP & PG \\
\hline 35 & $93-2002$ & Davis-1 x Bossier ${ }^{\mathrm{m}}$ & $\mathrm{F}_{11: 3}$ & $\mathrm{SP}$ & PG \\
\hline 36 & $93-2027$ & Davis-1 Viçoja $^{\mathrm{m}}$ & $F_{11: 3}$ & $\mathrm{SP}$ & PG \\
\hline 37 & 93-2072 & Bossier x Viçoja ${ }^{a}$ & $F_{11: 3}$ & $\mathrm{SP}$ & PG \\
\hline 38 & $93-2084$ & Bossier $x$ Viçoja $^{a}$ & $F_{11: 3}$ & $\mathrm{SP}$ & PG \\
\hline 39 & $93-2103$ & Bossier x BR-1-Fosca ${ }^{a}$ & $\mathrm{~F}_{11: 3}$ & $\mathrm{SP}$ & PG \\
\hline 40 & $93-2104$ & Bossier x BR-1-Fosca ${ }^{a}$ & $\mathrm{~F}_{11: 3}$ & $\mathrm{SP}$ & PG \\
\hline 41 & $93-2250$ & Bossier x IAC- $12^{\mathrm{a}}$ & $\mathrm{F}_{11: 3}$ & $\mathrm{SP}$ & PG \\
\hline 42 & $93-2259$ & Bossier x IAC- $12^{\mathrm{a}}$ & $\mathrm{F}_{11: 3}$ & $\mathrm{SP}$ & PG \\
\hline 43 & $93-2294$ & Davis-1 x BR-1-Fosca ${ }^{\mathrm{m}}$ & $\mathrm{F}_{11: 3}$ & $\mathrm{SP}$ & PG \\
\hline 44 & $93-2302$ & Davis-1 x BR-1-Fosca ${ }^{\mathrm{m}}$ & $F_{11: 3}$ & SP & PG \\
\hline 45 & $93-2306$ & Davis-1 $x$ BR-1-Fosca ${ }^{\mathrm{m}}$ & $F_{11: 3}$ & $\mathrm{SP}$ & PG \\
\hline 46 & $93-2316$ & Bossier x GO 81-11.646 & $\mathrm{F}_{11: 3}$ & $\mathrm{SP}$ & PG \\
\hline
\end{tabular}


Apêndice 1. Identificação, genealogia, geração de endogamia (GE), ciclo de maturação (CM) e programa de origem das linhagens experimentais avaliadas. Soja, Piracicaba, SP.

\begin{tabular}{|c|c|c|c|c|c|}
\hline $\mathrm{N}$ & N은 USP & Genealogia & GE & $\mathrm{CM}$ & Programa de origem \\
\hline 47 & $93-2419$ & Viçoja x IAC- $1^{\mathrm{a}}$ & $\mathrm{F}_{11: 3}$ & SP & PG \\
\hline 48 & 93-2475 & Viçoja x GO 81-11.646 & $\mathrm{F}_{11: 3}$ & $\mathrm{SP}$ & PG \\
\hline 49 & $93-2479$ & Viçoja x GO 81-11.646a & $\mathrm{F}_{11: 3}$ & SP & PG \\
\hline 50 & $93-2529$ & IAC- $10 \times$ IAC- $12^{a}$ & $\mathrm{~F}_{11: 3}$ & SP & PG \\
\hline 51 & $93-2565$ & IAC-10 $\times$ BR-1-Fosca ${ }^{a}$ & $\mathrm{~F}_{11: 3}$ & SP & PG \\
\hline 52 & 93-2667 & IAC- $12 \times$ IAC- $1^{\mathrm{a}}$ & $F_{11: 3}$ & SP & PG \\
\hline 53 & $93-2680$ & IAC- $12 \times$ IAC- $1^{\mathrm{a}}$ & $F_{11: 3}$ & SP & PG \\
\hline 54 & $93-2693$ & IAC-12 $\times$ BR-1-Fosca ${ }^{a}$ & $\mathrm{~F}_{11: 3}$ & SP & PG \\
\hline 55 & 93-2697 & IAC-12 $\times$ BR-1-Fosca ${ }^{a}$ & $\mathrm{~F}_{11: 3}$ & SP & PG \\
\hline 56 & 93-2699 & IAC-12 $\times$ BR-1-Fosca ${ }^{a}$ & $\mathrm{~F}_{11: 3}$ & SP & PG \\
\hline 57 & 93-2727 & IAC- $12 \times$ FT $81-2706^{\mathrm{a}}$ & $\mathrm{F}_{11: 3}$ & SP & PG \\
\hline 58 & $93-2756$ & IAC- $12 \times$ SOC $81-228^{\mathrm{a}}$ & $\mathrm{F}_{11: 3}$ & SP & PG \\
\hline 59 & $93-2781$ & IAC-1 x BR-1-Fosca ${ }^{a}$ & $\mathrm{~F}_{11: 3}$ & SP & PG \\
\hline 60 & $93-2790$ & IAC-1 x BR-1-Fosca ${ }^{a}$ & $\mathrm{~F}_{11: 3}$ & SP & PG \\
\hline 61 & 93-2857 & IAC-1 x SOC $81-228^{\mathrm{a}}$ & $\mathrm{F}_{11: 3}$ & SP & PG \\
\hline 62 & $93-2858$ & IAC- $1 \times$ SOC $81-228^{\mathrm{a}}$ & $\mathrm{F}_{11: 3}$ & SP & PG \\
\hline 63 & 93-2897 & GO $81-11.646 \times$ FT $81-2706^{a}$ & $\mathrm{~F}_{11: 3}$ & SP & PG \\
\hline 64 & 93-2909 & BR-1-Fosca x SOC 81-228 ${ }^{\mathrm{a}}$ & $\mathrm{F}_{11: 3}$ & SP & PG \\
\hline 65 & 93-2916 & BR-1-Fosca x SOC $81-228^{\mathrm{a}}$ & $\mathrm{F}_{11: 3}$ & SP & PG \\
\hline 66 & 94-1017 & IAC-Foscarin-31 x Primavera & $\mathrm{F}_{15: 3}$ & SP & PG \\
\hline 67 & $93-2258$ & Bossier x IAC- $12^{\mathrm{a}}$ & $\mathrm{F}_{11: 3}$ & $I^{3}$ & PG \\
\hline 68 & $93-2266$ & Bossier x IAC- $1^{\mathrm{a}}$ & $\mathrm{F}_{11: 3}$ & I & PG \\
\hline 69 & $93-2514$ & Viçoja x FT 81-2706 ${ }^{\mathrm{a}}$ & $\mathrm{F}_{11: 3}$ & I & PG \\
\hline 70 & $93-2530$ & IAC- $10 \times$ IAC- $12^{\mathrm{a}}$ & $\mathrm{F}_{11: 3}$ & I & PG \\
\hline 71 & $93-2643$ & IAC-10 x FT 81-2706 & $\mathrm{F}_{11: 3}$ & I & PG \\
\hline 72 & $93-2722$ & IAC-12 x GO $81-11.646^{\mathrm{a}}$ & $\mathrm{F}_{11: 3}$ & I & PG \\
\hline 73 & $93-2725$ & IAC-12 x GO $81-11.646^{\mathrm{a}}$ & $\mathrm{F}_{11: 3}$ & I & PG \\
\hline 74 & $93-2753$ & IAC-12 x SOC $81-228^{a}$ & $\mathrm{~F}_{11: 3}$ & I & PG \\
\hline 75 & 93-2802 & IAC-1 x GO 81-11.646 ${ }^{\mathrm{a}}$ & $\mathrm{F}_{11: 3}$ & I & PG \\
\hline 76 & $93-2825$ & IAC-1 x FT 81-2706 & $\mathrm{F}_{11: 3}$ & I & PG \\
\hline 77 & $93-2870$ & BR-1-Fosca x FT 81-2706a & $\mathrm{F}_{11: 3}$ & I & PG \\
\hline 78 & $93-5082$ & GO $81-11.646 \times$ SOC $81-228^{a}$ & $\mathrm{~F}_{13: 3}$ & I & PG \\
\hline 79 & $93-5243$ & FT $81-2706 \times$ PI $371610^{m}$ & $F_{13: 3}$ & I & $\mathrm{PO}^{\mathrm{c}}$ \\
\hline 80 & $93-5423$ & SOC $81-76 \times$ Foster $^{\mathrm{m}}$ & $F_{13: 3}$ & I & $\mathrm{PO}$ \\
\hline 81 & 93-5539 & Paranagoiana x Jackson-4028-s $\mathrm{m}$ & $\mathrm{F}_{13: 3}$ & I & $\mathrm{PO}$ \\
\hline 82 & 93-5544 & Paranagoiana x Jackson-4028-s $\mathrm{m}$ & $F_{13: 3}$ & I & $\mathrm{PO}$ \\
\hline 83 & 93-5549 & Jackson-4028-s x FT 81-2129 & $F_{13: 3}$ & I & $\mathrm{PO}$ \\
\hline 84 & 93-5552 & Jackson-4028-s x FT 81-2129 & $F_{13: 3}$ & I & $\mathrm{PO}$ \\
\hline 85 & 93-5582 & Cobb $\times$ BR $-8^{m}$ & $F_{13: 3}$ & I & $\mathrm{PO}$ \\
\hline 86 & 93-5585 & Cobb $\times$ BR $-8^{m}$ & $F_{13: 3}$ & I & $\mathrm{PO}$ \\
\hline 87 & 93-5586 & Cobb $\times$ BR $-8^{m}$ & $F_{13: 3}$ & I & $\mathrm{PO}$ \\
\hline 88 & 93-5597 & Cobb $\times$ BR $-8^{m}$ & $F_{13: 3}$ & I & $\mathrm{PO}$ \\
\hline 89 & $93-5690$ & 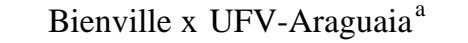 & $F_{13: 3}$ & I & $\mathrm{PO}$ \\
\hline
\end{tabular}


Apêndice 1. Identificação, genealogia, geração de endogamia, ciclo de maturação (CM) e programa de origem das linhagens experimentais avaliadas. Soja, Piracicaba, SP.

\begin{tabular}{|c|c|c|c|c|c|}
\hline $\mathrm{N}$ & $\mathrm{N} N \underline{\mathrm{O}}$ USP & Genealogia & GE & $\mathrm{CM}$ & Programa de origem \\
\hline 90 & $93-5692$ & Foster x FT 79-3408 ${ }^{\mathrm{m}}$ & $\mathrm{F}_{13: 3}$ & $\mathrm{I}$ & $\overline{\mathrm{PO}}$ \\
\hline 91 & $93-5843$ & BR 80-15725-B-s x Planalto-s ${ }^{a}$ & $\mathrm{~F}_{13: 3}$ & I & $\mathrm{PO}$ \\
\hline 92 & $93-5860$ & BR 80-15725-B-s x Planalto-s ${ }^{a}$ & $\mathrm{~F}_{13: 3}$ & I & $\mathrm{PO}$ \\
\hline 93 & $93-5884$ & Planalto-s x GO 81-11.094 & $\mathrm{F}_{13: 3}$ & I & $\mathrm{PO}$ \\
\hline 94 & $93-2521$ & Viçoja x FT 81-2706 ${ }^{\mathrm{a}}$ & $\mathrm{F}_{11: 3}$ & $\mathrm{ST}^{4}$ & PG \\
\hline 95 & $93-5263$ & PI 371610 x Paraná-s ${ }^{\mathrm{m}}$ & $\mathrm{F}_{13: 3}$ & ST & $\mathrm{PO}$ \\
\hline 96 & $93-5391$ & Wright $x$ SOC $81-76^{\mathrm{m}}$ & $\mathrm{F}_{13: 3}$ & ST & $\mathrm{PO}$ \\
\hline 97 & $93-5419$ & SOC $81-76 \times$ Foster $^{\mathrm{m}}$ & $\mathrm{F}_{13: 3}$ & ST & $\mathrm{PO}$ \\
\hline 98 & $93-5513$ & AX 53-55-s x Paranagoiana ${ }^{\mathrm{m}}$ & $\mathrm{F}_{13: 3}$ & ST & $\mathrm{PO}$ \\
\hline 99 & $93-5684$ & Bienville $x$ UFV-Araguaia $^{a}$ & $\mathrm{~F}_{13: 3}$ & ST & $\mathrm{PO}$ \\
\hline 100 & 93-5802 & UFV-2 $x$ GO $81-8491^{\mathrm{a}}$ & $\mathrm{F}_{13: 3}$ & ST & $\mathrm{PO}$ \\
\hline
\end{tabular}

${ }^{1}$ : Precoce ${ }^{2}$ : Semiprecoce; ${ }^{3}:$ Intermediário; ${ }^{4}$ : Semitardio.

a: Cruzamento adaptado (parental adaptado x parental adaptado).

m: Cruzamento misto (parental adaptado x parental exótico).

b : PG: Produtividade de grãos; ${ }^{\mathrm{c}}$ : PO: Produtividade de óleo.

Obs: o sufixo "s" observado em alguns genótipos refere-se à seleção de uma planta do genótipo que apresentou teor de óleo superior. 
Apêndice 2. Número de linhagens, testemunhas, repetições, conjuntos/repetição, locais e geração de endogamia nos anos agrícolas 1996/97, 1997/98, 1998/99 e 1999/00. Soja, Piracicaba, SP.

\begin{tabular}{|c|c|c|c|c|}
\hline & \multicolumn{4}{|c|}{ Ciclo de Maturação } \\
\hline & Precoce & Semiprecoce & Intermediário & Semitardio \\
\hline \multicolumn{5}{|c|}{ ANO AGRÍCOLA 1996/97 } \\
\hline $\mathrm{N}^{\mathrm{o}}$ de linhagens & 43 & 63 & 49 & 33 \\
\hline Geração de endogamia & $\mathrm{F}_{12: 6}$ & $\mathrm{~F}_{8: 3}$ e $\mathrm{F}_{12: 6}$ & $\mathrm{~F}_{8: 3}, \mathrm{~F}_{10: 3}$ e $\mathrm{F}_{12: 6}$ & $F_{10: 3}, F_{11: 6}$ e $F_{12: 6}$ \\
\hline № de repetições & 2 & 2 & 2 & 2 \\
\hline № de conjuntos/Rep. & 2 & 3 & 3 & 2 \\
\hline $\mathrm{N}^{\mathrm{o}}$ de locais & 3 & 3 & 3 & 3 \\
\hline \multirow[t]{4}{*}{ Testemunhas } & FT-Cometa & FT-10 & IAC-100 & IAC-4 \\
\hline & FT-Guaíra & FT-200 & IAC-12 & IAC-8 \\
\hline & IAC-Foscarin-31 & FT-Iramaia & IAC-4 & IAC-11 \\
\hline & Primavera & IAC-12 & Stwart & Stwart \\
\hline \multicolumn{5}{|c|}{ ANO AGRÍCOLA 1997/98 } \\
\hline $\mathrm{N}^{\mathrm{o}}$ de linhagens & 30 & 42 & 30 & 8 \\
\hline Geração de endogamia & $\mathrm{F}_{13: 6}$ & $\mathrm{~F}_{9: 3}$ e $\mathrm{F}_{13: 6}$ & $F_{9: 3}, F_{11: 3}$ e $F_{13: 6}$ & $\mathrm{~F}_{11: 3}, \mathrm{~F}_{12: 6}$ e $\mathrm{F}_{13: 6}$ \\
\hline $\mathrm{N}^{\mathrm{Q}}$ de repetições & 2 & 2 & 2 & 2 \\
\hline № de conjuntos/Rep. & 2 & 3 & 2 & 1 \\
\hline № de locais & 3 & 3 & 3 & 3 \\
\hline \multirow[t]{4}{*}{ Testemunhas } & FT-Cometa & FT-10 & IAC-100 & IAC-4 \\
\hline & FT-Guaíra & FT-200 & IAC-12 & IAC-8 \\
\hline & IAC-Foscarin-31 & FT-Iramaia & IAC-4 & IAC-11 \\
\hline & Primavera & IAC-12 & Stwart & Stwart \\
\hline \multicolumn{5}{|c|}{ ANO AGRÍCOLA 1998/99 } \\
\hline $\mathrm{N}^{\mathrm{o}}$ de linhagens & 28 & 38 & 27 & 7 \\
\hline Geração de endogamia & $\mathrm{F}_{14: 6}$ & $\mathrm{~F}_{10: 3}$ e $\mathrm{F}_{14: 6}$ & $\mathrm{~F}_{10: 3}, \mathrm{~F}_{12: 3}$ e $\mathrm{F}_{14: 6}$ & $\mathrm{~F}_{12: 3}, \mathrm{~F}_{13: 6}$ e $\mathrm{F}_{14: 6}$ \\
\hline $\mathrm{N}^{0}$ de repetições & 2 & 2 & 2 & 2 \\
\hline № de conjuntos/Rep. & 2 & 2 & 2 & 1 \\
\hline $\mathrm{N}^{0}$ de locais & 3 & 3 & 3 & 3 \\
\hline \multirow[t]{4}{*}{ Testemunhas } & FT-Cometa & FT-10 & IAC-100 & IAC-4 \\
\hline & FT-Guaíra & FT-200 & IAC-12 & IAC-8 \\
\hline & IAC-Foscarin-31 & FT-Iramaia & IAC-4 & IAC-11 \\
\hline & Primavera & IAC-12 & Stwart & Stwart \\
\hline \multicolumn{5}{|c|}{ ANO AGRÍCOLA 1999/00 } \\
\hline № de linhagens & 28 & 38 & 27 & 7 \\
\hline Geração de endogamia & $\mathrm{F}_{15: 6}$ & $\mathrm{~F}_{11: 3}$ e $\mathrm{F}_{15: 6}$ & $\mathrm{~F}_{11: 3}, \mathrm{~F}_{13: 3}$ e $\mathrm{F}_{15: 6}$ & $\mathrm{~F}_{13: 3}, \mathrm{~F}_{14: 6}$ e $\mathrm{F}_{15: 6}$ \\
\hline № de repetições & 2 & 2 & 2 & 2 \\
\hline № de conjuntos/Rep. & 2 & 2 & 2 & 1 \\
\hline № de locais & 3 & 3 & 3 & 3 \\
\hline \multirow[t]{4}{*}{ Testemunhas } & IAC-Foscarin-31 & BR-16 & IAC-100 & IAC-4 \\
\hline & IAS-5 & IAC-18 & IAC-12 & IAC-8-2 \\
\hline & Primavera & FT-200 & IAC-4 & IAC-11 \\
\hline & OCEPAR-4 & FT-Iramaia & Stwart & Stwart \\
\hline
\end{tabular}


Apêndice 3. Fotoperíodo, temperatura, umidade relativa e precipitação pluviométrica, no período de novembro a abril dos anos agrícolas de 1996/97, 1997/98, 1998/99 e 1999/00, relativos à avaliação de linhagens experimentais de soja em Piracicaba-SP.

\begin{tabular}{|c|c|c|c|c|c|c|c|}
\hline \multirow[t]{2}{*}{ Ano } & \multirow[t]{2}{*}{ Mês } & \multirow{2}{*}{$\begin{array}{c}\text { Fotoperíodo } \\
\text { (horas/dia) }\end{array}$} & \multicolumn{3}{|c|}{ Temperatura $\left({ }^{\circ} \mathrm{C}\right)$} & \multirow{2}{*}{$\begin{array}{c}\text { Umidade } \\
\text { Relativa (\%) }\end{array}$} & \multirow{2}{*}{$\begin{array}{l}\text { Precipitação } \\
\text { Pluvial }(\mathrm{mm})\end{array}$} \\
\hline & & & Máxima & Média & Mínima & & \\
\hline \multirow[t]{6}{*}{$1996 / 97$} & Novembro & 6,22 & 29,07 & 23,41 & 17,75 & 79,50 & 212,00 \\
\hline & Dezembro & 6,04 & 30,61 & 25,20 & 19,78 & 84,77 & 188,30 \\
\hline & Janeiro & 4,21 & 29,71 & 24,90 & 20,09 & 86,87 & 352,20 \\
\hline & Fevereiro & 7,55 & 31,73 & 24,73 & 19,50 & 79,50 & 87,10 \\
\hline & Março & 7,65 & 29,94 & 23,72 & 17,50 & 73,29 & 73,20 \\
\hline & Abril & 7,57 & 28,68 & 21,85 & 15,02 & 73,20 & 22,00 \\
\hline \multirow[t]{6}{*}{$1997 / 98$} & Novembro & 5,62 & 30,34 & 24,94 & 19,54 & 81,57 & 269,40 \\
\hline & Dezembro & 6,68 & 31,11 & 25,40 & 19,68 & 79,74 & 186,62 \\
\hline & Janeiro & 6,49 & 31,71 & 26,16 & 20,61 & 78,77 & 120,90 \\
\hline & Fevereiro & 4,84 & 30,03 & 25,25 & 20,46 & 90,07 & 362,04 \\
\hline & Março & 6,04 & 31,01 & 25,40 & 19,80 & 85,35 & 127,72 \\
\hline & Abril & 6,94 & 28,39 & 22,71 & 17,02 & 81,03 & 62,10 \\
\hline \multirow[t]{6}{*}{ 1998/99 } & Novembro & 7,04 & 29,47 & 22,59 & 15,70 & 71,90 & 52,10 \\
\hline & Dezembro & 7,23 & 30,56 & 24,78 & 18,99 & 77,97 & 269,90 \\
\hline & Janeiro & 4,91 & 30,59 & 25,50 & 20,41 & 87,97 & 382,80 \\
\hline & Fevereiro & 5,37 & 30,73 & 25,41 & 20,05 & 90,00 & 198,30 \\
\hline & Março & 7,70 & 31,42 & 25,20 & 18,98 & 80,74 & 210,80 \\
\hline & Abril & 8,09 & 28,52 & 21,86 & 15,20 & 80,70 & 89,00 \\
\hline \multirow[t]{6}{*}{ 1999/00 } & Novembro & 6,79 & 29,82 & 23,77 & 17,72 & 77,27 & 239,20 \\
\hline & Dezembro & 5,63 & 29,78 & 24,42 & 19,00 & 80,90 & 196,20 \\
\hline & Janeiro & 6,37 & 30,22 & 24,65 & 19,09 & 82,68 & 235,90 \\
\hline & Fevereiro & 5,49 & 29,92 & 24,58 & 19,24 & 86,59 & 124,00 \\
\hline & Março & 5,42 & 29,68 & 24,10 & 18,53 & 84,35 & 185,30 \\
\hline & Abril & 9,08 & 28,34 & 21,81 & 15,35 & 72,17 & 0,80 \\
\hline
\end{tabular}

Fonte: Setor de Física e Meteorologia, Departamento de Ciências Exatas, ESALQ/USP. 
Apêndice 4. Critérios utilizados para a interpretação de análises de solos para o Estado de São Paulo.

\begin{tabular}{|c|c|c|c|c|c|c|c|c|}
\hline \multirow[t]{2}{*}{ Acidez } & \multirow[t]{2}{*}{$\mathrm{pH}$} & \multirow[t]{2}{*}{ Níveis } & \multirow{2}{*}{$\begin{array}{l}\text { M.O } \\
(\%)\end{array}$} & \multirow{2}{*}{$\begin{array}{c}\mathrm{P} \\
\left(\mu \mathrm{g} / \mathrm{cm}^{3}\right)\end{array}$} & \multicolumn{3}{|c|}{ Meq/100g } & \multirow{2}{*}{$\begin{array}{c}\mathrm{V} \\
(\%) \\
\end{array}$} \\
\hline & & & & & $\mathrm{K}$ & $\mathrm{Ca}$ & $\mathrm{Mg}$ & \\
\hline Muito baixa & $>6,0$ & Muito baixo & - & 6,0 & 0,07 & - & - & $\leq 25$ \\
\hline Baixa & $5,6-6,0$ & Baixo & 1,5 & $7,08-15,0$ & $0,08-0,15$ & 0,4 & 0,4 & $26-50$ \\
\hline Média & $5,1-5,5$ & Médio & $1,5-2,5$ & $15,0-40,0$ & $0,16-30,0$ & $0,5-0,8$ & $0,5-0,8$ & $51-70$ \\
\hline Alta & $4,4-5,0$ & Alto & $>2,5$ & $>80,0$ & $>80,0$ & - & - & $71-90$ \\
\hline Muito alta & $<4,3$ & Muito alto & - & - & - & - & - & $>90$ \\
\hline
\end{tabular}

Fonte: Malavolta et al., 1989.

Apêndice 5. Análises químicas do solo nas áreas de pesquisa com soja, nos locais Anhembi, Areão e ESALQ, Piracicaba, SP.

\begin{tabular}{cccccccc}
\hline Local & $\mathrm{PH}$ & $\mathrm{M} . \mathrm{O}$ & $\mathrm{P}$ & \multicolumn{3}{c}{$\mathrm{Meq} / 100 \mathrm{~g}$} & $\mathrm{~V}$ \\
\cline { 5 - 6 } & $\mathrm{CaCl}_{2}$ & $(\%)$ & $\left(\mu \mathrm{g} / \mathrm{cm}^{3}\right)$ & $\mathrm{K}$ & $\mathrm{Ca}$ & $\mathrm{Mg}$ & \\
\hline Anhembi $^{1}$ & 6,0 & - & 55 & 0,23 & 2,9 & 2,3 & 90 \\
Areão $^{2}$ & 4,3 & 1,6 & 15 & 0,26 & 3,6 & 1,2 & 50 \\
ESALQ $^{1}$ & 5,4 & - & 45 & 0,40 & 3,3 & 1,1 & 61 \\
\hline
\end{tabular}

Fonte: ${ }^{1}$ : Departamento de Química - ESALQ/USP.

2: Departamento de Ciência do Solo - ESALQ/USP.

Apêndice 6. Esquema da análise de variância conjunta/local para as testemunhas em blocos ao acaso, com repetições subdivididas em conjuntos experimentais, ao nível de parcelas, e respectivas esperanças matemáticas dos quadrados médios.

\begin{tabular}{lcclc}
\hline \multicolumn{1}{c}{ F. V. } & G.L. & Q.M. & \multicolumn{1}{c}{ E(Q.M.) } & F \\
\hline Locais (L) & $1-1$ & $\mathrm{Q}_{1}$ & $\sigma_{\mathrm{e}}^{2}+\mathrm{T} \sigma_{\mathrm{c} / 1}^{2}+\mathrm{CTV}_{1}$ & $\mathrm{Q}_{1} / \mathrm{Q}_{2}$ \\
Conjuntos/L & $1(\mathrm{c}-1)$ & $\mathrm{Q}_{2}$ & $\sigma_{\mathrm{e}}^{2}+\mathrm{LT} \sigma_{\mathrm{c} / 1}^{2}$ & $\mathrm{Q}_{2} / \mathrm{Q}_{6}$ \\
Testemunhas (T) & $(\mathrm{t}-1)$ & $\mathrm{Q}_{3}$ & $\sigma_{\mathrm{e}}^{2}+\mathrm{L} \sigma_{\mathrm{ct}}^{2}+\mathrm{L} \sigma_{\mathrm{c} / 1}+\mathrm{CLV}_{\mathrm{t}}$ & $\left.\left(\mathrm{Q}_{3}+\mathrm{Q}_{6}\right) / \mathrm{Q}_{2}+\mathrm{Q}_{4}\right)$ \\
C x T & $(\mathrm{c}-1)(\mathrm{t}-1)$ & $\mathrm{Q}_{4}$ & $\sigma_{\mathrm{e}}^{2}+\mathrm{L} \sigma_{\mathrm{ct}}^{2}$ & $\mathrm{Q}_{4} / \mathrm{Q}_{6}$ \\
$\mathrm{~T}$ x L & $(\mathrm{t}-1)(1-1)$ & $\mathrm{Q}_{5}$ & $\sigma_{\mathrm{e}}^{2}+\mathrm{CV}_{\mathrm{lt}}$ & $\mathrm{Q}_{5} / \mathrm{Q}_{6}$ \\
Resíduo médio & $\mathrm{L}(\mathrm{c}-1)(\mathrm{t}-1)$ & $\mathrm{Q}_{6}$ & $\sigma_{\mathrm{e}}^{2}$ & \\
Total & $(\mathrm{clt})-1$ & & & \\
\hline
\end{tabular}

Apêndice 7. Esquema da análise de variância conjunta geral para as testemunhas em blocos ao acaso, com repetições subdivididas em conjuntos experimentais, ao nível de parcelas, e respectivas esperanças matemáticas dos quadrados médios.

\begin{tabular}{|c|c|c|c|c|}
\hline F. V. & G.L. & Q.M. & E(Q.M.) & $\mathrm{F}$ \\
\hline Anos (A) & $a-1$ & $\mathrm{Q}_{1}$ & $\sigma_{\mathrm{e}}^{2}+\mathrm{LT} \sigma_{\mathrm{c} / \mathrm{a} / 1}^{2}+\mathrm{CLT} \sigma_{\mathrm{a}}^{2}$ & $\mathrm{Q}_{1} / \mathrm{Q}_{3}$ \\
\hline Locais (L) & $1-1$ & $\mathrm{Q}_{2}$ & $\sigma_{\mathrm{e}}^{2}+\mathrm{CT} \sigma_{\mathrm{al}}^{2}+\mathrm{AT}_{\mathrm{c} / \mathrm{a} / 1}^{2}+\mathrm{ACTV}_{1}$ & $\left(\mathrm{Q}_{2}+\mathrm{Q}_{10}\right) /\left(\mathrm{Q}_{3}+\mathrm{Q}_{6}\right)$ \\
\hline Conjuntos/A/L & $\mathrm{al}(\mathrm{c}-1)$ & $\mathrm{Q}_{3}$ & $\sigma_{\mathrm{e}}^{2}+\mathrm{ALT} \sigma_{\mathrm{c} / \mathrm{a} / 1}^{2}$ & $\mathrm{Q}_{3} / \mathrm{Q}_{10}$ \\
\hline Testemunhas (T) & $(\mathrm{t}-1)$ & $\mathrm{Q}_{4}$ & $\sigma_{\mathrm{e}}^{2}+\mathrm{CL}_{\mathrm{at}}^{2}+\mathrm{AL}_{\mathrm{ct}}^{2}+\mathrm{ACLV}_{\mathrm{t}}$ & $\mathrm{Q}_{4} / \mathrm{Q}_{5}$ \\
\hline $\mathrm{C} \times \mathrm{T}$ & $(\mathrm{c}-1)(\mathrm{t}-1)$ & $\mathrm{Q}_{5}$ & $\sigma_{\mathrm{e}}^{2}+\mathrm{L} \sigma_{\mathrm{at}}^{2}+\mathrm{AL} \sigma_{\mathrm{ct}}^{2}$ & $\mathrm{Q}_{5} / \mathrm{Q}_{7}$ \\
\hline$A \times L$ & $(\mathrm{a}-1)(1-1)$ & $\mathrm{Q}_{6}$ & $\sigma_{\mathrm{e}}^{2}+\mathrm{CT} \sigma_{\mathrm{al}}^{2}$ & $\mathrm{Q}_{6} / \mathrm{Q}_{10}$ \\
\hline $\mathrm{T} \times \mathrm{A}$ & $(\mathrm{t}-1)(\mathrm{a}-1)$ & $\mathrm{Q}_{7}$ & $\sigma_{\mathrm{e}}^{2}+\mathrm{CL} \sigma_{\mathrm{at}}^{2}$ & $\mathrm{Q}_{7} / \mathrm{Q}_{10}$ \\
\hline $\mathrm{T} \times \mathrm{L}$ & $(\mathrm{t}-1)(1-1)$ & $\mathrm{Q}_{8}$ & $\sigma_{\mathrm{e}}^{2}+\mathrm{C \sigma}_{\mathrm{alt}}^{2}+\mathrm{ACV}_{\mathrm{lt}}$ & $\mathrm{Q}_{8} / \mathrm{Q}_{9}$ \\
\hline $\mathrm{T} \times \mathrm{A} \times \mathrm{L}$ & $(\mathrm{t}-1)(\mathrm{a}-1)(\mathrm{l}-1)$ & $\mathrm{Q}_{9}$ & $\sigma_{\mathrm{e}}^{2}+C \sigma_{\mathrm{alt}}^{2}$ & $\mathrm{Q}_{9} / \mathrm{Q}_{10}$ \\
\hline Resíduo médio & $\mathrm{al}(\mathrm{c}-1)(\mathrm{t}-1)$ & $Q_{10}$ & $\sigma_{\mathrm{e}}^{2}$ & \\
\hline Total & (aclt) -1 & & & \\
\hline
\end{tabular}


Apêndice 8. Esquema da análise de variância individual para as linhagens em blocos ao acaso, ao nível de parcelas, e respectivas esperanças matemáticas dos quadrados médios.

\begin{tabular}{lcccc}
\hline \multicolumn{1}{c}{ F. V. } & G.L. & Q.M. & E(Q.M.) & $\mathrm{F}$ \\
\hline Repetições (R) & $\mathrm{r}-1$ & $\mathrm{Q}_{1}$ & $\sigma_{\mathrm{e}}^{2}+\mathrm{G} \sigma_{\mathrm{r}}^{2}$ & $\mathrm{Q}_{1} / \mathrm{Q}_{3}$ \\
Linhagens (G) & $\mathrm{g}-1$ & $\mathrm{Q}_{2}$ & $\sigma_{\mathrm{e}}^{2}+\mathrm{RV}$ & $\mathrm{Q}_{2} / \mathrm{Q}_{3}$ \\
Resíduo & $(\mathrm{r}-1)(\mathrm{g}-1)$ & $\mathrm{Q}_{3}$ & $\sigma_{\mathrm{e}}^{2}$ & \\
Total & $(\mathrm{rg})-1$ & & & \\
\hline
\end{tabular}

Apêndice 9. Esquema da análise de variância conjunta/ano para as linhagens, em blocos ao acaso, ao nível

\begin{tabular}{lcccc}
\multicolumn{5}{c}{ de parcelas, e respectivas esperanças matemáticas dos quadrados médios. } \\
\hline F. V. & G.L. & Q.M. & E(Q.M.) & F \\
\hline Locais (L) & $1-1$ & $\mathrm{Q}_{1}$ & $\sigma_{\mathrm{e}}^{2}+\mathrm{G \sigma}_{\mathrm{r}(\mathrm{l})}^{2}+\mathrm{RGV}_{1}$ & $\mathrm{Q}_{1} / \mathrm{Q}_{2}$ \\
Repetições (R)/L & $1(\mathrm{r}-1)$ & $\mathrm{Q}_{2}$ & $\sigma_{\mathrm{e}}^{2}+\mathrm{G}_{\mathrm{r}(\mathrm{l})}^{2}$ & $\mathrm{Q}_{2} / \mathrm{Q}_{5}$ \\
Linhagens (G) & $\mathrm{g}-1$ & $\mathrm{Q}_{3}$ & $\sigma_{\mathrm{e}}^{2}+\mathrm{LRV}_{\mathrm{g}}$ & $\mathrm{Q}_{3} / \mathrm{Q}_{5}$ \\
G x L & $(\mathrm{g}-1)(1-1)$ & $\mathrm{Q}_{4}$ & $\sigma_{\mathrm{e}}^{2}+\mathrm{RV} \mathrm{V}_{1 \mathrm{~g}}$ & $\mathrm{Q}_{4} / \mathrm{Q}_{5}$ \\
Resíduo médio & $1(\mathrm{~g}-1)(\mathrm{r}-1)$ & $\mathrm{Q}_{5}$ & $\sigma_{\mathrm{e}}^{2}$ & \\
Total & $(\mathrm{rgl})-1$ & & & \\
\hline
\end{tabular}

Apêndice 10. Esquema da análise de variância conjunta geral para as linhagens, em blocos ao acaso, ao nível de parcelas, e respectivas esperanças matemáticas dos quadrados médios.

\begin{tabular}{|c|c|c|c|c|}
\hline F. V. & G.L. & Q.M. & E(Q.M.) & $\mathrm{F}$ \\
\hline $\mathrm{R} / \mathrm{L} / \mathrm{A}$ & $(\mathrm{r}-1) \mathrm{al}$ & $\mathrm{Q}_{1}$ & $\sigma_{\mathrm{e}}^{2}+\mathrm{G} \sigma_{(\mathrm{r} / \mathrm{a}) / 1}^{2}$ & $\mathrm{Q}_{1} / \mathrm{Q}_{9}$ \\
\hline $\operatorname{Anos}(\mathrm{A})$ & $a-1$ & $\mathrm{Q}_{2}$ & $\sigma_{\mathrm{e}}^{2}+\mathrm{G} \sigma_{(\mathrm{r} / \mathrm{a}) / 1}^{2}+\mathrm{RGL} \sigma_{\mathrm{a}}^{2}$ & $\mathrm{Q}_{2} / \mathrm{Q}_{1}$ \\
\hline Locais (L) & $1-1$ & $\mathrm{Q}_{3}$ & $\sigma_{\mathrm{e}}^{2}+\mathrm{G} \sigma_{(\mathrm{r} / \mathrm{a}) / 1}^{2}+\mathrm{RA} \sigma_{\mathrm{al}}^{2}+\mathrm{RGAV}_{1}$ & $\mathrm{Q}_{3} / \mathrm{Q}_{7}$ \\
\hline Linhagens $(\mathrm{G})$ & $g-1$ & $\mathrm{Q}_{4}$ & $\sigma_{\mathrm{e}}^{2}+\operatorname{RL} \lambda \sigma_{\mathrm{ga}}^{2}+\mathrm{RALV}_{\mathrm{g}}$ & $\mathrm{Q}_{4} / \mathrm{Q}_{5}$ \\
\hline $\mathrm{G} \times \mathrm{A}$ & $(g-1)(a-1)$ & $\mathrm{Q}_{5}$ & $\sigma_{\mathrm{e}}^{2}+\operatorname{RL} \lambda \sigma_{\mathrm{ga}}^{2}$ & $\mathrm{Q}_{5} / \mathrm{Q}_{9}$ \\
\hline$G \times L$ & $(g-1)(1-1)$ & $\mathrm{Q}_{6}$ & $\sigma_{\mathrm{e}}^{2}+\mathrm{R} \alpha \sigma_{\mathrm{gal}}^{2}+\mathrm{RAV}_{\mathrm{gl}}$ & $\mathrm{Q}_{6} / \mathrm{Q}_{8}$ \\
\hline$A \times L$ & $(a-1)(1-1)$ & $\mathrm{Q}_{7}$ & $\sigma_{\mathrm{e}}^{2}+\mathrm{G} \sigma_{(\mathrm{r} / \mathrm{a}) 1}^{2}+\mathrm{RA} \varphi \sigma_{\mathrm{al}}^{2}$ & $\mathrm{Q}_{7} / \mathrm{Q}_{1}$ \\
\hline $\mathrm{G} \times \mathrm{A} \times \mathrm{L}$ & $(g-1)(a-1)(1-1)$ & $\mathrm{Q}_{8}$ & $\sigma_{\mathrm{e}}^{2}+\mathrm{R} \alpha \sigma_{\text {gal }}^{2}$ & $\mathrm{Q}_{8} / \mathrm{Q}_{9}$ \\
\hline Resíduo médio & $\mathrm{al}(\mathrm{g}-1)(\mathrm{r}-1)$ & $\mathrm{Q}_{9}$ & $\sigma_{\mathrm{e}}^{2}$ & \\
\hline Total & $($ ragl $)-1$ & & & \\
\hline
\end{tabular}


Apêndice 11. Esquema da análise de variância com a decomposição da soma de quadrados de ambientes/genótipos, conforme a metodologia de Eberhart \& Russel (1966).

\begin{tabular}{|c|c|c|c|c|}
\hline F.V. & G & & & \\
\hline Genótipos (G) & g-1 & & & \\
\hline Ambientes (E) & e-1 & & & \\
\hline$G \times E$ & $(g-1)(e-1)$ & & & \\
\hline $\mathrm{E} / \mathrm{G}$ & $\mathrm{g}(\mathrm{e}-1)$ & & $\mathrm{SQ}_{\mathrm{E}}+\mathrm{SQ}_{\mathrm{GxE}}$ & \\
\hline E linear & & 1 & & $\mathrm{SQ}_{\mathrm{E} \text { linear }}$ \\
\hline $\mathrm{G} \times \mathrm{E}$ linear & & $g-1$ & & $\mathrm{SQ}_{\mathrm{GxE} \text { linear }}$ \\
\hline Desvio combinado (E/G) & & $g(e-1)$ & & $\mathrm{SQ}_{\mathrm{D}}$ \\
\hline Erro médio & & $\mathrm{ge}(\mathrm{r}-1)$ & & $\mathrm{SQ}_{\mathrm{EM}}$ \\
\hline
\end{tabular}

Apêndice 12. Esquema da análise de variância AMMI ao nível de médias de ambientes, adotando o critério de Gollob para atribuição de graus de liberdade aos componentes principais da interação (CPI).

\begin{tabular}{lcccc}
\hline \multicolumn{1}{c}{ F.V. } & $\mathrm{G} . \mathrm{L}$. & $\mathrm{S} . \mathrm{Q}$. & $\mathrm{Q} . \mathrm{M}$ & $\mathrm{F}$ \\
\hline Genótipos (G) & $\mathrm{g}-1$ & $\mathrm{SQ}_{\mathrm{G}}$ & $\mathrm{QM}_{\mathrm{G}}$ & \\
Ambientes (E) & $\mathrm{e}-1$ & $\mathrm{SQ}_{\mathrm{E}}$ & $\mathrm{QM}_{\mathrm{E}}$ & \\
G x E & $(\mathrm{g}-1)(\mathrm{e}-1)$ & $\mathrm{SQ}_{\mathrm{GxE}}$ & $\mathrm{QM}_{\mathrm{GxE}}$ & \\
CPI1 & $\mathrm{g}+\mathrm{e}-1-(2.1)$ & $\lambda_{1}{ }^{2}$ & $\mathrm{QM}_{\mathrm{CPI} 1}$ & $\mathrm{QM}_{\mathrm{CPI} 1} / \mathrm{QM}_{\mathrm{EM}}$ \\
CPI2 & $\mathrm{g}+\mathrm{e}-1-(2.2)$ & $\lambda_{2}{ }^{2}$ & $\mathrm{QM}_{\mathrm{CPI} 2}$ & $\mathrm{QM}_{\mathrm{CPI} 2} / \mathrm{QM}_{\mathrm{EM}}$ \\
CPI3 & $\mathrm{g}+\mathrm{e}-1-(2.3)$ & $\lambda_{3}{ }^{2}$ & $\mathrm{QM}_{\mathrm{CPI} 3}$ & $\mathrm{QM}_{\mathrm{CPI} 3} / \mathrm{QM}_{\mathrm{EM}}$ \\
$\ldots$ & $\ldots$ & $\ldots$ & $\ldots$ & $\ldots$ \\
CPIp & $\mathrm{g}+\mathrm{e}-1-(2 . \mathrm{p})$ & $\lambda_{\mathrm{p}}{ }^{2}$ & $\mathrm{QM}_{\mathrm{CPIp}}$ & $\mathrm{QM}_{\mathrm{CPIp}} / \mathrm{QM}_{\mathrm{EM}}$ \\
Erro médio & $\mathrm{ge}(\mathrm{r}-1)$ & $\mathrm{SQ}_{\mathrm{EM}}$ & $\mathrm{QM}_{\mathrm{EM}}$ & \\
\hline
\end{tabular}

